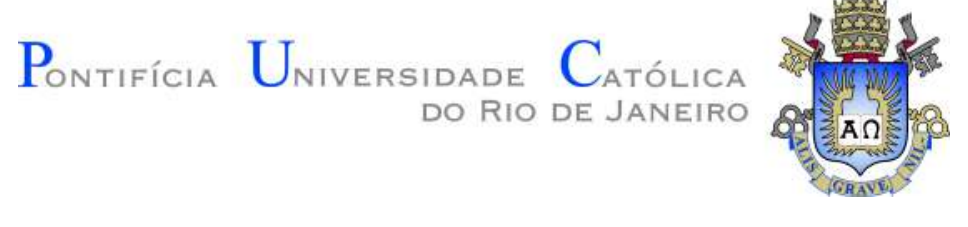

Marcel Passos Zylberberg

\title{
Desenvolvimento e Caracterização de Compósitos Balísticos Laminados
}

Tese de Doutorado

Tese apresentada como requisito parcial para a obtenção do grau de Doutor pelo Programa de Pós-graduação em Engenharia de Materiais e de Processos Químicos e Metalúrgicos do Departamento de Engenharia Química e de Materiais da PUCRio.

Orientador: Prof. José Roberto Moraes d'Almeida

Rio de Janeiro

Dezembro de 2019 


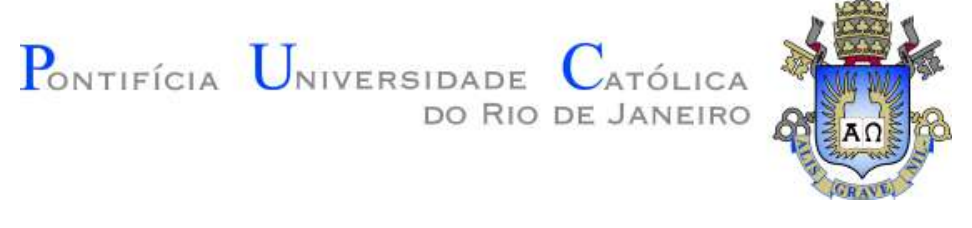

Marcel Passos Zylberberg

\section{Desenvolvimento e Caracterização de Compósitos Balísticos Laminados}

Tese apresentada como requisito parcial para a obtenção do grau de Doutor pelo Programa de Pós-graduação em Engenharia de Materiais e de Processos Químicos e Metalúrgicos da PUCRio. Aprovada pela Comissão Examinadora abaixo.

Prof. José Roberto Moraes d'Almeida

Orientador

Departamento de Engenharia Química e de Materiais - PUC-Rio

Prof. Francisco José da Cunha Pires Soeiro Departamento de Engenharia Mecânica - UERJ

Profa. Marília Garcia Diniz

Departamento de Engenharia Mecânica - UERJ

Prof. Carlos Frederico de Matos Chagas Instituto Militar de Engenharia - IME

Prof. Marcos Henrique de Pinho Maurício

Departamento de Engenharia Química e de Materiais - PUC-Rio

Rio de Janeiro, 26 de dezembro de 2019 
Todos os direitos reservados. É proibida a reprodução total ou parcial do trabalho sem autorização da universidade, do autor e do orientador.

\section{Marcel Passos Zylberberg}

Graduou-se em Ciências Militares na AMAN (Academia Militar das Agulhas Negras) em 2000, na especialidade Material Bélico. Em 2006, se formou em Engenharia de Materiais no IME (Instituto Militar de Engenharia). Trabalhou durante três anos no Arsenal de Guerra do Rio, quando cursou uma Pós-graduação em Conhecimentos Militares e em seguida passou a cursar a Pós-graduação em Engenharia de Produção no Departamento de Engenharia Industrial da PUC-Rio. Estava no IPCFEx (Instituto de Pesquisa da Capacitação Física do Exército), na função de pesquisador do Laboratório de Biomecânica quando obteve seu Título de Mestre em Engenharia de Produção. Transferido para trabalhar no CTEx (Centro Tecnológico do Exército) no Laboratório de Materiais, trabalhou como pesquisador ao longo de mais três anos na área de polímeros, compósitos e metais, até ingressar no Doutorado em Engenharia de Materiais na PUC-Rio.

Ficha Catalográfica

Zylberberg, Marcel Passos

Desenvolvimento e Caracterização de Compósitos Balísticos Laminados / Marcel Passos Zylberberg; orientador: José Roberto Moraes d'Almeida. - Rio de Janeiro: PUC-Rio, Departamento de Engenharia Química e de Materiais, 2019.

v., 159 f: il. color. ; $30 \mathrm{~cm}$

Tese (doutorado)- Pontifícia Universidade Católica do Rio de Janeiro, Departamento de Engenharia Química e de Materiais.

\section{Inclui bibliografia}

1. Engenharia Química e de Materiais - Teses. 2. UHMWPE. 3. compósitos. 4. blindagem. 5. colete balístico. 6. caracterização. I. d'Ameida, José Roberto Moraes. II. Pontifícia Universidade Católica do Rio de Janeiro. Departamento de Engenharia Química e de Materiais. III. Título. 
Aos meus pais, irmãos e à Vivian, pela força, paciência e motivação. 


\section{Agradecimentos}

Agradeço primeiramente a Força Maior que faz passar os segundos e dita o ritmo dos acontecimentos na vida. Obrigado por ter proporcionado as oportunidades de estudo e aperfeiçoamento que tive até hoje.

À minha família, que me inseriu e deu apoio neste mundo, e mesmo à distância se fez sempre presente, me sustentando em todos os momentos.

Ao meu Orientador Prof. d'Almeida, por ter acreditado nessa proposta de pesquisa, ter aceitado me orientar, e pela compreensão e suporte ao longo do desenvolvimento e conclusão dessa etapa.

Gostaria de agradecer destacadamente à Dra. Khrissy, pois sua orientação precisa foi decisiva para o delineamento e conclusão desta pesquisa e publicação. Sua paixão pela ciência é nobre, admirável e merece os muitos louros que virão.

É necessário ainda destacar a contribuição das Organizações CTEx, CAEx, PUC/Rio, IME e CBPF.

Aos grandes amigos e colaboradores mais diretos para a realização deste trabalho, Mayara, Camila, Flávia, Thalita, Freddy, Carlos Chagas, Édio, Lúcio e D’Mengeon por todo apoio e paciência.

À equipe do LTMC do CTEx, Franceschi, Helena, Priscilla Sieira, Jovine e Amanda, pela ajuda com a aquisição das imagens nos microscópios, com o máquina DiaStron, e demais ensaios.

Aos ilustres amigos e integrantes da CP\&D, da SMM e do LM, por toda compreensão e suporte.

Ao grande Chico pela contribuição na preparação do material e trabalhos de metalografia. Ao jovem Francisco, pelo pronto apoio com os ensaios de FTIR.

À DSM Company, na pessoa de Renato Santacroce, à Glágio do Brasil, à Rogers Corporation/EUA, à Pontacol AG/Suíça, à Sarkar Tactical e à ACNIS do Brasil, pela vital colaboração, parceria e fornecimento de material para essa pesquisa experimental.

Aos professores que participaram da Comissão examinadora.

A todos os professores e funcionários do Departamento pela colaboração e amizade. Aos meus colegas da PUC-Rio. 
Não fossem os conhecimentos adquiridos pelas disciplinas estudadas, o apoio e o ensinamento de amigos da PUC e de companheiros do trabalho, as críticas construtivas sobre elaboração da tese, este trabalho não seria concluído. Guardarei com muita estima as lembranças desse período de 2017 a 2019. Agradeço a todos que contribuíram nestes três anos para esta pesquisa.

O presente trabalho foi realizado com apoio da Coordenação de Aperfeiçoamento de Pessoal de Nível Superior - Brasil (CAPES) - Código de Financiamento 001. 


\section{Resumo}

Zylberberg, Marcel Passos; d'Ameida, José Roberto Moraes. Desenvolvimento e Caracterização de Compósitos Balísticos Laminados. Rio de Janeiro, 2019. 159p. Tese de Doutorado - Departamento de Engenharia Química e de Materiais, Pontifícia Universidade Católica do Rio de Janeiro.

Ameaças contra a vida, principalmente por disparos de armas de fogo, impulsionam a pesquisa de novos materiais para fabricação de soluções para proteção balística individual. Os compósitos poliméricos reforçados por fibras de polietileno de ultra alto peso molecular revolucionaram esse campo nos últimos 15 anos e têm sido extensivamente estudados, principalmente por suas excepcionais propriedades mecânicas e baixa densidade, visando desenvolver materiais com alta capacidade específica de absorção de energia. Em desacordo, a produção desses compósitos é dominada por poucas empresas no mundo, e sua disponibilidade relativamente limitada, além do fato das placas balísticas serem materiais controlados e de domínio de fabricação restrito, o que dificultou a obtenção de informações. Neste sentido, a presente pesquisa buscou projetar, fabricar e caracterizar seis modelos de placas balísticas para proteção contra disparo de munição de fuzil, utilizando diferentes tipos de compósitos (préimpregnados) com a adição de camada da liga de titânio. A caracterização contou com ensaios de FTIR do CBPF, TGA e DSC da PUC-Rio, ensaio de tração (EMT) das fibras, de dureza, MEV e metalografia no CTEx. A análise do desempenho das placas foi realizada no CAEx e contou com câmera de ultra alta velocidade, equipamentos para ensaios balísticos e equipamento de varredura 3D a laser. Os resultados dos ensaios foram mensurados pela velocidade dos disparos e pela profundidade da deformação da face posterior de 16 placas. Foi possível concluir que a fabricação de protótipos mantendo os valores de espessura ou densidade de área da solução semelhante a de placas controle somente em pré-impregnado foi eficiente. O emprego da chapa da liga de Ti-6Al-4V com espessura de apenas $1 \mathrm{~mm}$ se deu em substituição de até $30 \%$ do material pré-impregnado. Na situação limite, foi possível obter placas que resistiram aos impactos de munição de fuzil com cerca de $95 \%$ da velocidade especificada na norma, dentro da tolerância de deformação posterior.

\section{Palavras-chave}

UHMWPE; compósitos; blindagem; colete balístico; caracterização 


\section{Abstract}

Zylberberg, Marcel Passos; d'Ameida, José Roberto Moraes (Advisor). Development and Caracterization of Ballistic Laminated Composites. Rio de Janeiro, 2019. 159p. Tese de Doutorado Departamento de Engenharia Química e de Materiais, Pontifícia Universidade Católica do Rio de Janeiro.

Life threats, mainly from firearms, incentive research into new materials for manufacturing personal ballistic protection. Polymer composites reinforced with ultra high molecular weight polyethylene fiber have revolutionized this field over the last 15 years and have been extensively studied, especially for their exceptional mechanical properties and low density, to develop materials with high specific energy absorption capacity. In disagreement, the production of these composites is dominated by few companies in the world, and their availability is relatively limited, besides the fact that ballistic plates are controlled materials and restricted manufacturing domain, which made it difficult to obtain information. In this sense, the present research aims to design, manufacture and characterize six models of ballistic plates for protection against firing of rifle ammunition, using different types of composites (prepregs) with the addition of a titanium alloy layer. The characterization included FTIR at CBPF, TGA and DSC tests at PUC-Rio, fiber tensile strength, SEM, and metallography at CTEx. The plate performance analysis was performed at CAEx and included an ultra high speed camera, ballistic testing equipment and 3D laser scanning equipment. Test results were measured by firing speed and depth of the back face deformation of 16 plates. It was possible to conclude that the prototyping keeping the thickness or areal density values of the solution similar to control plates only in prepreg was efficient. The use of Ti-6Al-4V alloy plate with thickness of only $1 \mathrm{~mm}$ by replacing up to $30 \%$ of prepreg material. In the border situation, it was possible to obtain plates that withstood the impact of rifle ammunition at about $95 \%$ of the speed specified in the standard, within the back face deformation tolerance.

\section{Keywords}

UHMWPE; composites; armor; bulletproof vest; characterization 


\section{Sumário}

1 Introdução $\quad 19$

1.1 Objetivo Principal 21

1.2 Objetivos Específicos 21

2 Revisão Bibliográfica $\quad 23$

2.1 Materiais Poliméricos 23

2.1.1 Fibras de polietileno de ultra alto peso molecular (UHMWPE) 24

$\begin{array}{ll}2.1 .2 & \text { Compósitos com fibras de UHMWPE (prepreg) } \\ 2.1 .3\end{array}$

2.1.3 Espumas 32

2.2 Materiais metálicos $\quad 36$

2.2.1 Liga de Ti-6Al-4V 37

2.3 Comportamento dinâmico e balístico de polímeros 39

2.3.1 Energia do impacto 41

2.4 Blindagens Balísticas $\quad 44$

2.5 Ensaios Balísticos $\quad 47$

2.5.1 Ensaio de Resistência Balística 53

2.5.2 Ensaio de Limite Balístico (V50) 54

2.6 Análise de imagens em ultra alta velocidade 54

2.7 Espectroscopia $\quad 55$

2.7.1 Espectroscopia no Infravermelho com Transformada de Fourier (FTIR) 55

2.8 Análises térmicas $\quad 57$

2.8.1 Calorimetria exploratória diferencial (DSC) 58

2.8.2 Análise termogravimétrica (TGA) 58

2.9 Ensaios mecânicos $\quad 59$

2.9.1 Ensaio Mecânico de Tração (EMT) de fibra 59

2.9.2 Ensaio de Dureza 60

2.10 Microscopia Ótica (MO) 61

2.11 Microscopia Eletrônica de Varredura (MEV) 62

2.12 Metalografia 63

2.13 Bases para Análise Estatística 65

2.13.1 Análise de Regressão 65

$\begin{array}{ll}\text { 2.13.2 Distribuição de Weibull } & 67\end{array}$

3 Materiais e Métodos Experimentais $\quad 68$

$\begin{array}{lll}3.1 & \text { Aspectos gerais } & 68\end{array}$

$\begin{array}{ll}\text { 3.2 Materiais Utilizados } & 69\end{array}$

$\begin{array}{ll}\text { 3.3 Fabricação das placas balísticas } & 72\end{array}$

3.3.1 Técnica de fabricação $\quad 73$

$\begin{array}{ll}\text { 3.3.2 Preparação dos corpos de prova } & 76\end{array}$

$\begin{array}{ll}\text { 3.3.3 Metrologia das placas } & 77\end{array}$

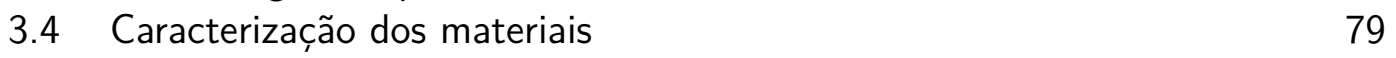

3.4.1 Caracterizações Espectroscópicas 80

3.4.2 Caracterizações Térmicas 81

3.4.3 Análise Termodinâmica 83 
3.5 Ensaios Mecânicos 85

3.5.1 Ensaio de Dureza do Titânio 85

3.5.2 Ensaio Mecânico de Tração (EMT) de fibras de UHMWPE 86

3.6 Microscopias 88

3.6.1 Microscopia Ótica 88

3.6.2 Microscopia eletrônica de varredura (MEV) 90

$\begin{array}{lll}3.7 & \text { Ensaio Balístico } & 92\end{array}$

3.7.1 Teste de Limite Balístico (V50) 95

3.7.2 Teste de Resistência Balística 96

3.8 Câmera de vídeo de ultra alta velocidade 96

3.9 Análise Estatística 98

4 Resultados e Discussões $\quad 100$

$\begin{array}{lll}4.1 & \text { Fabricação de placas balísticas } & 100\end{array}$

4.2 Caracterização de placas balísticas 101

4.2.1 Determinação da densidade de área 101

4.2.2 Caracterização das placas de Ti-6Al-4V 102

$\begin{array}{ll}\text { 4.2.3 Caracterização dos prepregs e das espumas } & 105\end{array}$

4.2.4 Resultado do ensaio mecânico de tração de fibras 115

$\begin{array}{lll}4.3 & \text { Resultado dos Ensaios Balísticos } & 117\end{array}$

$\begin{array}{lll}\text { 4.3.1 Ensaio de V50 } & 117\end{array}$

$\begin{array}{ll}\text { 4.3.2 Ensaio de resistência balística } & 119\end{array}$

$\begin{array}{lll}4.4 & \text { Resultados da Análise Estatística } & 123\end{array}$

5 Conclusões e Sugestões para Trabalhos Futuros $\quad 127$

$\begin{array}{llr}6 & \text { Referências bibliográficas } & 129\end{array}$

A Caracterização dos materiais das placas balísticas $\quad 142$

A.1 Especificação detalhada dos materiais empregados na pesquisa 142

$\begin{array}{ll}\text { A.2 Metrologia das placas balísticas } & 143\end{array}$

A.3 Análises de TGA e DSC das fibras e dos pré-impregnados 144

A.4 Ensaio Mecânico de Tração de fibra 148

$\begin{array}{ll}\text { B Procedimento de fabricação por prensagem a quente } & \mathbf{1 5 0}\end{array}$

C Resultados detalhados dos Ensaios Balísticos $\quad 153$

D Análise de Regressão Linear Múltipla $\quad \mathbf{1 5 6}$

D.1 Análise de Regressão Linear Múltipla com o emprego do programa R 156 


\section{Lista de figuras}

Figura 1.1 Exemplo de placa e colete balístico Nível III. 20

Figura 2.1 Representação do etileno e do polietileno. 24

Figura 2.2 Estrutura do UHMWPE (sendo $n$ maior que 100.000). 24

Figura 2.3 Diagrama esquemático para produção de rolo de prepreg. 28

Figura 2.4 Esquema de fibras formando o prepreg bidirecional. 29

Figura 2.5 Estrutura de espumas de célula aberta (a) e fechada (b). 33

Figura 2.6 Mecanismos de falha em compósitos reforçados com fibras. $\quad 40$

Figura 2.7 Tipos de blindagem por finalidade de emprego. 44

Figura 2.8 Desenho esquemático do projetil da munição 7,62×51 FMJ. 48

Figura 2.9 Esquema da linha de tiro do ensaio balístico. 51

Figura 2.10 Microestruturas presentes nas ligas Ti-6Al-4V (a) e (b) lamelar, (c) e (d) bimodal. $\quad 64$

(a) lamelas grosseiras 64

(b) lamelas finas $\quad 64$

(c) grãos $\alpha$ equiaxiais com $\beta$ intergranular 64

(d) grãos $\alpha$ alongados com $\beta$ intergranular 64

$\begin{array}{lll}\text { Figura 3.1 } & \text { Fluxograma para fabricação das placas balísticas. } & 68\end{array}$

Figura 3.2 Esquema de constituição e ensaio das placas de HB212. 69

Figura 3.3 Esquema de constituição e ensaio das placas de ST-HB13. 70

$\begin{array}{lll}\text { Figura 3.4 Prepregs balisticos (a) e (b) como recebidos. } & 71\end{array}$

$\begin{array}{ll}\text { (a) ST-HB13 } & 71\end{array}$

$\begin{array}{ll}\text { (b) HB212 } & 71\end{array}$

$\begin{array}{lll}\text { Figura 3.5 } & \text { Espuma Poron XRD }{ }^{\circledR} \text { para corte. } & 72\end{array}$

Figura 3.6 Prensa hidráulica utilizada (empresa Glágio do Brasil-BH). $\quad 73$

$\begin{array}{lll}\text { Figura 3.7 Ciclo de prensagem de placas balísticas Nível III. } & 74\end{array}$

Figura 3.8 Variação de temperatura na matriz e interna das placas durante a prensagem (a) dos CPs de HB212; e (b) dos CPs de ST-HB13. 76

(a) Temperaturas na matriz e interna nas placas 1, 4 e $5 \quad 76$

(b) Temperaturas na matriz e interna nas placas 9, 12 e $13 \quad 76$

Figura 3.9 Máquina de Corte com Jato de água Flow Mach 2 (IMBEL). 77

$\begin{array}{lll}\text { Figura 3.10 Metrologia das lâminas pré e pós prensagem. } & 78\end{array}$

(a) massa de HB212 pré-prensagem 78

(b) massa de STHB13 pré-prensagem 78

(c) placa prensada e paquímetro vertical $\quad 78$

Figura 3.11 Esquema utilizado para medição da espessura das placas. 78

Figura 3.12 Equipamento de FTIR (a) e Microscópio (b) do CBPF. 80

(a) Equipamento IRPrestige-21 FTI Spectrophotometer 80

(b) Equipamento AIM-8800 Automatic Infrared 80

Figura 3.13 Equipamento de análises térmicas da PUC-Rio. 82

Figura 3.14 Medição do diâmetro da perfuração na chapa de titânio. 84

Figura 3.15 Máquina para ensaio de dureza. 85

Figura 3.16 Equipamento LEX-820 Dia-Stron para EMT de fibra. 86

Figura 3.17 Preparação para EMT nas etapas (a), (b) e (c). 87 
(a) disposição de fibras nos suportes $\quad 87$

(b) cura do adesivo com luz UV $\quad 87$

(c) fibras prontas para o EMT 87

Figura 3.18 Equipamento de Microscopia Ótica do Laboratório de Materiais de Carbono do CTEx.

Figura 3.19 Equipamento (a) e configurações (b) da microscopia ótica do CTEx empregada para metalografia.

(a) Equipamento de Microscopia Zeiss 89

(b) Tela de configuração do microscópio 89

Figura 3.20 Equipamento de Microscopia Eletrônica de Varredura do CTEx. 90

Figura 3.21 Equipamento (a) e configurações para recobrimento (b). 91

(a) deposição de camada de ouro $\quad 91$

(b) configuração para a deposição 91

Figura 3.22 Amostras preparadas para estudo no MEV do CTEx. 91

Figura 3.23 Placas fabricadas para teste. 92

Figura 3.24 Munição 7,62 x 51 mm FMJ. $\quad 92$

Figura 3.25 Linha de Tiro IV do CAEx. 93

Figura 3.26 Provete 7,62×51 mm e Receptor universal AVL. 93

Figura 3.27 Equipamento para medição da velocidade (a) e o suporte de alvo (b) para o ensaio balístico.

(a) Barreira Ótica B471 da HPI 94

(b) Suporte para caixa de plastilina 94

Figura 3.28 Balança (a) e projetis (b) empregados para os ensaios. $\quad 94$

(a) Balança Analítica 94

(b) Projetis de calibre 7,62mm 94

Figura 3.29 Equipamento de varredura (a) e programa de suporte (b). $\quad 95$

(a) Escâner FARO FreeStyle ${ }^{3 D} \quad 95$

(b) Programa PolyWorks Viewer ${ }^{T M} \quad 95$

Figura 3.30 Disposição do local dos impactos nas placas. $\quad 97$

Figura 3.31 Equipamento para gravação de vídeo em ultra alta velocidade composto por: (a) programa de processamento de imagens; (b) conjunto de iluminação adequado; (c) câmera de ultra alta velocidade. 98

(a) programa Photron FastCam Viewer 98

(b) conjunto de refletores de led 98

(c) Câmera Photron Limited modelo FastCam SA-Z 98

Figura 4.1 Indentações do ensaio de dureza HRC na placa de Ti-6Al-4V. 103

Figura 4.2 Tela de resposta do programa Thermo-Calc ${ }^{\circledR}$. 104

Figura 4.3 Imagens câmera alta velocidade. 104

Figura 4.4 Imagem por MO da microestrutura da liga de Ti-6Al-4V (500x).105

$\begin{array}{lll}\text { Figura 4.5 Imagens de MEV do prepreg HB212 e fibras. } & 107\end{array}$

(a) Diâmetro de fibras de HB212 (500x) 107

(b) Espessura do prepreg HB212 (500x) 107

(c) Fibras dispostas a $0^{\circ} / 90^{\circ}$ no HB212 (300x) 107

(d) Matriz dispersa sobre as fibras do HB212 107

Figura 4.6 Imagens de MEV da disposição de fibras do ST-HB13. 107

(a) Diâmetro de fibras de ST-HB13 (500x) 107

(b) Matriz aderida e alterações superficiais das fibras do STHB13 (250x) 
$\begin{array}{lll}\text { Figura 4.7 Imagens de MEV do prepreg ST-HB13. } & 108\end{array}$

(a) Camadas do prepreg ST-HB13 (200x) 108

(b) Filme que compõe a matriz do ST-HB13 (125x) 108

Figura 4.8 Imagem de MEV da estrutura interna da espuma Poron XRD. 108

(a) Medição do diâmetro de células abertas (100x) 108

(b) Dimensão de poros das células abertas (250x) 108

Figura 4.9 Imagem de MEV da estrutura interna da espuma Poron XRD (500x).

Figura 4.10 Imagem de MEV da estrutura interna da espuma PEBD/EVA. 110

(a) Microestrutura de célula fechada seccionada (100x) 110

(b) Dimensão de células fechadas seccionadas (250x) 110

Figura 4.11 Imagem de MEV da estrutura interna do PEBD/EVA (500x). 110

Figura 4.12 Espectro FTIR de amostras de HB212 (a) prepreg e (b) placa. 111

(a) Amostra obtida do HB212 prepreg 111

(b) Amostra obtida do HB212 placa 111

Figura 4.13 Espectro FTIR de amostras de ST-HB13 (a) prepreg e (b) placa.112

(a) Amostra obtida do ST-HB13 prepreg 112

(b) Amostra obtida do ST-HB13 placa 112

Figura 4.14 Espectro FTIR de amostra de espuma Poron XRD. 113

$\begin{array}{lll}\text { Figura 4.15 Espectro FTIR de amostra de adesivo BP21.2008. } & 114\end{array}$

Figura 4.16 Distribuição de Weibull para EMT de fibra de ST-HB13. 116

Figura 4.17 Distribuição de Weibull para EMT de fibra de HB212. 116

Figura 4.18 Resultado do Ensaio $V_{50}$ para CP6, CP7, CP14 e CP15. 119

Figura 4.19 Resultados da média de BFS para o ensaio de P-BFS. 121

Figura 4.20 Placas pós-teste de resistência balística, mostrando as faces anterior e posterior após ensaios.

(a) Frontal CP1 121

(b) Posterior CP1 121

(c) Frontal CP2 121

(d) Posterior CP2 121

Figura 4.21 Resultado de energia média e específica absorvidas no Ensaio de P-BFS.

Figura 4.22 Resultado dos somatórios de energia absorvida e BFS no Ensaio de P-BFS. 122

Figura 4.23 Gráficos de Análise Residual de Mod1 (a) e de Mod2 (b). 125

(a) Modelo com 7 variáveis $\quad 125$

(b) Modelo com 28 variáveis 125

Figura 4.24 Gráficos Q-Q de Mod1 (a) e de Mod2 (b). 126

(a) Modelo com 7 variáveis $\quad 126$

(b) Modelo com 28 variáveis 126

Figura 4.25 Histograma de Resíduos de Mod1 (a) e de Mod2 (b). 126

(a) Modelo com 7 variáveis $\quad 126$

(b) Modelo com 28 variáveis 126

Figura A.1 Ensaio de TGA com amostras de HB212 pré-impregnado e placa.

Figura A.2 Ensaio de TGA - ST-HB13 pré-impregnado e placa. 144

Figura A.3 Ensaio de TGA - HB212 pré-impregnado e fibra do HB212. 145

Figura A.4 Ensaio de TGA - ST-HB13 pré-impregnado e fibra do ST-HB13.145 
Figura A.5 Ensaio de TGA - fibra de HB212 e fibra do ST-HB13.

Figura A.6 Ensaio de TGA e curva DTG - HB212 pré-impregnado e de placa.

Figura A.7 Ensaio de TGA e curva DTG - pré-impregnados HB212 e STHB13.

Figura A.8 Ensaio de TGA e curva DTG - ST-HB13 pré-impregnado e de placa.

Figura A.9 Ensaio de DSC - HB212 pré-impregnado e placa. 147

Figura A.10 Ensaio de DSC - ST-HB13 pré-impregnado e placa. 147

Figura A.11 Ensaio de DSC - HB212 pré-impregnado e fibra do HB212. 147

Figura A.12 Ensaio de DSC - ST-HB13 pré-impregnado e fibra do ST-HB13.148

Figura A.13 Ensaio de DSC - pré-impregnados de HB212 e de ST-HB13. 148

Figura A.14 Gráficos de EMT de fibra de HB212. 149

$\begin{array}{lll}\text { Figura A.15 Gráficos de EMT de fibra de ST-HB13. } & 149\end{array}$

Figura D.1 Área de trabalho do Programa R - 28 fatores, primeira análise 158

Figura D.2 Área de trabalho do Programa R - 18 fatores, segunda análise 159 


\section{Lista de tabelas}

Tabela 2.1 Propriedades mecânicas das fibras de UHMWPE. 26

Tabela 2.2 Propriedades de fibras comerciais obtidas por ensaios balísticos e a altas taxas de deformação. $\quad 26$

Tabela 2.3 Propriedades mecânicas da fibra Dyneema SK99. 27

Tabela 2.4 Propriedades físicas de prepregs de UHMWPE. 29

Tabela 2.5 Propriedades de prepregs DSM e materiais constituintes. 31

Tabela 2.6 Composição química da Liga Ti-6Al-4V Gr 23 ELI. 38

Tabela 2.7 Nível de proteção do sistema de blindagem quanto ao impacto

balístico. 45

Tabela 3.1 Especificações do compósito ST-HB13.

Tabela 3.2 Especificações do compósito HB212, DSM Company. 70

Tabela 3.3 Especificações das espumas Poron XRD e PEBD/EVA. 71

Tabela 3.4 Constituição e finalidade dos Corpos de prova fabricados. $\quad 75$

Tabela 3.5 Amostras utilizadas para ensaio de STA (DSC/TGA). 83

Tabela 3.6 Parâmetros para Ensaio Mecânico de Tração de fibras. 88

Tabela 4.1 Principais valores dos ciclos de fabricação das placas. $\quad 100$

Tabela 4.2 Densidade de área das placas fabricadas. 102

$\begin{array}{lll}\text { Tabela 4.3 Dados do EMT de fibras retiradas dos referidos prepregs. } & 116\end{array}$

Tabela 4.4 Resultado do Ensaio de Limite Balístico V50. 118

$\begin{array}{lll}\text { Tabela 4.5 Parâmetros da resistência balística das placas. } & 120\end{array}$

Tabela 4.6 Energia absorvida e deformação da face posterior. 123

Tabela 4.7 Variáveis principais empregadas na Regressão Linear Múltipla. 124

Tabela 4.8 Descrição das variáveis de interação da Análise de Regressão. 124

Tabela A.1 Especificações da chapa de Ti-6Al-4V ELI. 142

Tabela A.2 Especificações do Adesivo Spray 3M ${ }^{\mathrm{TM}} 76$.

Tabela A.3 Especificações do Filme Adesivo BP21.2008, Pontacol. 143

Tabela A.4 Metrologia da espessura das placas. 143

Tabela B.1 Controle dos parâmetros de fabricação dos CPs de HB212. 151

Tabela B.2 Controle dos parâmetros de fabricação dos CPs de ST-HB13. 152

Tabela C.1 Resultado detalhado do Ensaio de Limite Balístico $V_{50}$. 153

Tabela C.2 Resultado detalhado do Ensaio de Resistência Balística (HB212).154

Tabela C.3 Resultado detalhado do Ensaio de Resistência Balística

(STHB13). 155

Tabela D.1 Valor das variáveis $x_{1}$ a $x_{7}$ do modelo de Regressão. 157 


\section{Siglas e Abreviaturas}

$\mathrm{AP}$ - armor piercing (munição para penetração de blindagens)

ASTM - American Society for Testing and Materials

BFD/BFS - Back-face deformation/Back-face signature

(deformação da face posterior, trauma)

$\mathrm{CP}$ - Corpo de prova

CAEx - Centro de Avaliações do Exército

CBPF - Centro Brasileiro de Pesquisas Físicas

CTEx - Centro Tecnológico do Exército

D/A - Densidade de área (Areal Density)

DIC - Digital Image Correlation

DSC - Calorimetria exploratória diferencial

EB - Exército Brasileiro

EMT - Ensaio mecânico de tração

EUA - Estados Unidos da América

EVA - Etileno acetato de vinila

FA - Forças Armadas

FTIR - Fourier transform infrared spectroscopy

(Espectroscopia por transformada de Fourier na região do infravermelho)

HDPE - High density polyethylene (polietileno de alta densidade)

HRC - Hardness Rockwell C (Escala de Dureza Rockwell C)

HV - Hardness Vickers (Escala de Dureza Vickers)

ICW - in conjunction with

IMBEL - Indústria de Material Bélico do Brasil

IME - Instituto Militar de Engenharia

LDPE - Low density polyethylene (polietileno de baixa densidade)

LRT - Limite de resistência à tração

MEV - Microscópio Eletrônico de Varredura 
MO - Microscópio Ótico

NIJ - National Institute of Justice - Washington, EUA)

P-BFS - Ensaio de Resistência Balística

PCE - Produto Controlado pelo Exército

PEBD - Polietileno de baixa densidade

Prepreg - Pré-impregnado

$\mathrm{SA}$ - stand alone

SHPB - Split Hokinson pressure bar (barra Hopkinson)

STA - Simultaneous Thermal Analysis (Análise Térmica Simultânea)

TGA - Thermogravimetric analysis (Análise termogravimétrica)

Ti-6Al-4V - Liga de Titânio, com 6\% de Alumínio e 4\% de Vanádio

UD - unidirecional

UHMWPE - Ultra-high molecular weight polyethylene

(Polietileno de ultra-alto peso molecular)

WD - Work Distance 
The dynamic behaviour of materials is an area of study at the confluence of many scientific disciplines. The processes that occur when bodies are subjected to rapidly changing loads can differ significantly from those that occur under static or quasi-static situations.

Marc André Meyers, Dynamic Behaviour of Materials. 


\section{1 \\ Introdução}

As Forças Armadas (FA) Brasileiras, compostas pela Marinha, Exército e Força Aérea, são o instrumento militar responsável pela defesa do Brasil. São funções destas instituições militares: assegurar a integridade do território nacional; defender os interesses e os recursos naturais, industriais e tecnológicos brasileiros; proteger os cidadãos e os bens do país; assim como garantir a soberania da nação.

Também é missão das Forças Armadas a garantia dos poderes constitucionais constituídos e, por iniciativa destes, atuar na garantia da lei e da ordem para, em espaço e tempo delimitados, preservar o exercício da soberania do Estado e a indissolubilidade da Federação.

Para reduzir o risco no cumprimento de determinadas atividades, a proteção balística individual é fundamental para membros de forças de segurança, sendo item principal de proteção o colete balístico - "colete à prova de balas". Este equipamento é um Produto Controlado pelo Exército (PCE), logo, existe a limitação da venda (dependendo do nível de proteção), para que a posse do mesmo seja restrito a pessoas legalmente habilitadas.

Normalmente militares das FA e policiais portam equipamento de peso considerável para o cumprimento de suas tarefas, deve-se então buscar sempre o aumento da eficiência e redução da carga transportada por meio de otimização constante dos materiais e processos para fabricação de coletes.

A pesquisa e desenvolvimento de tecnologia nesta área aumentam de importância ao se considerar que o Exército Brasileiro (EB) é responsável por toda a avaliação de PCE no Brasil, e que as forças de segurança do país normalmente adotam os requisitos técnicos que descrevem o colete adotado pelo EB, quando da aquisição para suas instituições.

Nesse ínterim, o colete - exemplo na Figura 1.1 (1), geralmente composto por capa, painel flexível e placa balística rígida, tem incorporado à sua constituição materiais poliméricos como a aramida, desde a década de 1970, e mais recentemente, o polietileno de ultra-alto peso molecular (Ultra High Molecular Weight Polyethylene - UHMWPE), em substituição a placas de materiais metálicos e de cerâmicos, reduzindo o peso e aumentando a mobilidade.

Recentemente tropas federais tem atuado em intervenções na área de segurança pública, juntos às Polícias, aumentando a exposição ao poder de fogo e à violência de criminosos, elevando o risco a integridade, motivando ainda mais os estudos de novos materiais para aumentar a proteção pessoal. 

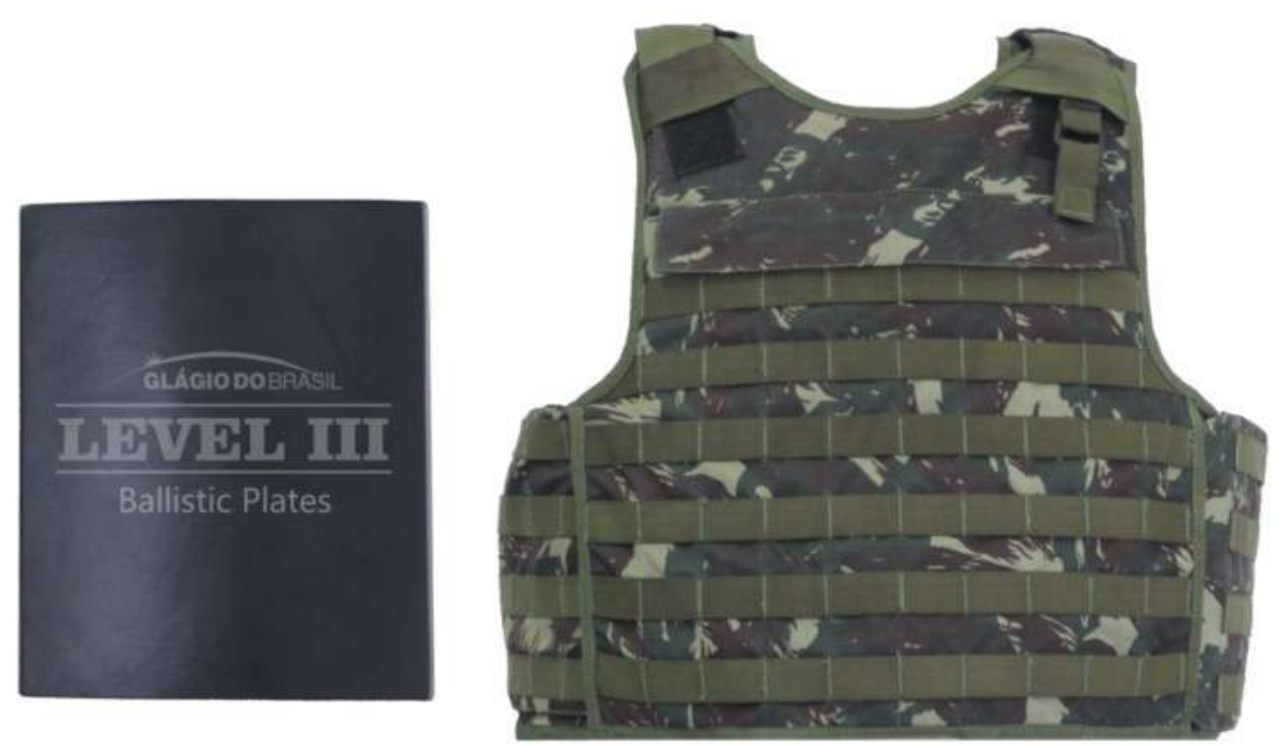

Figura 1.1: Exemplo de placa e colete balístico Nível III.

Visando a otimização constante do padrão das placas balísticas no país, faz-se necessário o emprego de novos materiais compósitos e melhoria nos processos fabris de prensagem. Buscou-se então a interação com fabricantes mundiais de pré-impregnados (prepregs) de UHMWPE e com empresas estratégicas de defesa para confecção de placas com novos materiais balísticos.

Os coletes em uso atualmente no país são dotados de placas balísticas tipo in conjunction with - ICW, e atingem a proteção Nível III (proteção contra tiro de fuzil 7,62 $\mathrm{mm}$ ) ao utilizar de forma sobreposta a placa e o painel balístico. Decorrente da prospecção em dois fabricantes internacionais fornecedores de matéria prima para coletes balísticos no Brasil, constatou-se que o material utilizado até então trata-se de prepregs Dyneema ${ }^{\circledR}$ HB2 ou Spectra Shield ${ }^{\circledR}$ SR-1226.

Porém, para pesquisar sobre este modelo de placa, seria necessário considerar mais uma variável, o painel balístico (tecidos flexíveis de proteção), e utilizar o mesmo nos ensaios. Visando manter o foco da pesquisa sobre a placa, optou-se pelo modelo denominado stand alone ( $S A$ ), no qual a placa isolada já é capaz de promover o nível de proteção desejado.

Os modelos de placas SA em uso no Brasil atualmente tem espessura entre 20 e $25 \mathrm{~mm}$, e a massa com valor próximo de $1,7 \mathrm{~kg}$.

Visando sensível melhoria, acredita-se que as placas de dotação dos próximos lotes de coletes balísticos para o EB deveriam ser fabricadas com prepregs recentemente introduzidos no mercado internacional, como o Dyneema ${ }^{\circledR}$ HB212 e o Spectra Shield ${ }^{\circledR} 5143$.

Buscou-se ainda a inovação de incorporar uma chapa metálica fina 
(de liga de titânio) aos protótipos de placa SA, com objetivo de otimizar as propriedades mecânicas da solução, avaliando o comportamento de dois modelos diferentes de pré-impregnados, com dois tipos de espumas diferentes de espumas para a função de redução de trauma. Dessa forma, envidou-se esforços para obter placas SA com espessura aproximada de $12 \mathrm{~mm}$ e a massa em torno de $1 \mathrm{~kg}$.

Este estudo na área de placas balísticas agregando chapa da liga de Ti$6 \mathrm{Al}-4 \mathrm{~V}$ com o novo compósito de fibras de UHMWPE como o Dyneema ${ }^{\circledR}$ HB212 é inédito. Não foi localizado na literatura estudos que tenham utilizado essa liga de titânio para reforço de placas para coletes balísticos.

Deste modo, através de estudo com novos materiais compósitos para solução balística, buscou-se otimizar: dimensões, massa, comportamento mecânico, poder de parada da placas, e ainda a deformação posterior após impacto, e pela melhoria destes parâmetros, justificar o desenvolvimento da presente pesquisa.

\section{1}

\section{Objetivo Principal}

O objetivo deste trabalho foi projetar, fabricar, caracterizar e testar placas balísticas passíveis de serem empregadas em blindagem pessoal.

\section{2 \\ Objetivos Específicos}

Em termos específicos, a tese buscou:

- caracterizar fibras e matrizes de diferentes fabricantes de préimpregnados de UHMWPE;

- planejar o processamento e realizar a fabricação de placas balísticas, contando com as particularidades para a união a quente da chapa de Ti-6Al-4V em parte das amostras;

- comparar o desempenho de dois tipos de espumas empregadas na função de redução da deformação da face posterior (BFS - Backface signature);

- caracterizar as placas após a fabricação por meio de ensaios mecânicos, de espectrometria, análises térmicas e técnicas de microscopia;

- ensaiar as placas quanto ao limite balístico $V_{50}$ e à resistência balística para o Nível III de ameaça;

- analisar o desempenho, em termos de limite balístico e de valor de BFS das diferentes matérias primas e composições;

- analisar estatisticamente por regressão linear múltipla o processo e resultados obtidos para propor um modelo do estudo desenvolvido. 
Após o desenvolvimento dos protótipos, que implicou em um extenso trabalho de caracterização e análise dos resultados, a pesquisa será apresentada de acordo com a estrutura descrita a seguir:

Este trabalho está dividido em cinco capítulos, sendo esta Introdução e Objetivos o Capítulo 1. O Capítulo 2 versa sobre a Revisão Bibliográfica, onde é abordado sobre blindagem e ensaios balísticos, define-se os fundamentos sobre materiais empregados para tal finalidade, e as análises necessárias. No Capítulo 3 são relatados Materiais e Métodos Experimentais. Em seguida, no Capítulo 4, aborda-se os Resultados e Discussões. As Conclusões e Sugestões para Trabalhos Futuros integram o Capítulo 5. Por fim as Referências Bibliográficas e Apêndices. 


\section{2 \\ Revisão Bibliográfica}

Este capítulo pretende apresentar de forma resumida a bibliografia revisada sobre o assunto desta tese. Esse estudo foi baseado em livros e artigos científicos encontrados em literatura específica, para servir de embasamento para o desenvolvimento da parte experimental e da redação da tese. Serão mencionados os principais trabalhos correlatos e a tendência atual das pesquisas na área de materiais balísticos para proteção individual, ressaltando observações e conclusões de interesse, com destaque para estudos sobre prepregs reforçados com fibras de UHMWPE e compósitos balísticos laminados.

\section{1}

\section{Materiais Poliméricos}

Polímeros são moléculas de cadeia longa (macromoléculas) formadas por uma repetição de pequenas unidades (meros). Os polímeros mais comuns tem estrutura básica formada por carbono (material orgânico), embora seja possível encontrar polímeros com elementos inorgânicos em sua cadeia, como silicatos. Materiais poliméricos exibem fortes ligações covalentes dentro de suas cadeias, entretanto, a ligação entre as cadeias frequentemente ocorre através de ligações secundárias, como Van der Waals e pontes de hidrogênio (2).

Existem três categorias de polímeros: termoplásticos, termofixos e elastômeros. Os termoplásticos tem configurações de cadeias lineares, sendo estas unidas por ligações secundárias fracas, como descrito acima. Esses materiais podem ser conformados mecanicamente (ao serem aquecidos) diversas vezes e retornar à forma rígida, desde que respeitadas as faixas de temperaturas características dos mesmos. Podem ser trabalhados por moldagem ou extrusão. Os termofixos quando curados usando calor, produtos químicos ou outros meios, transformam-se em um material substancialmente infusível e insolúvel (3). Os elastômeros diferem dos tipos anteriores por serem capazes de se comportar como borracha, apresentando alto grau de deformação recuperável, geralmente acima de $200 \%$ (2).

Por sua enorme diversidade, os polímeros possibilitam vasta aplicação, tendo participação em muitos campos, desde a engenharia até a medicina. $\mathrm{O}$ polímero polietileno é um destes materiais, e se forma quando a ligação dupla entre átomos de carbono na molécula de etileno $\left(\mathrm{C}_{2} \mathrm{H}_{4}\right)$ é substituída por uma ligação simples a cada um dos átomos de carbono adjacentes, dando origem a uma molécula de cadeia longa, conforme exposto na Figura 2.1. 


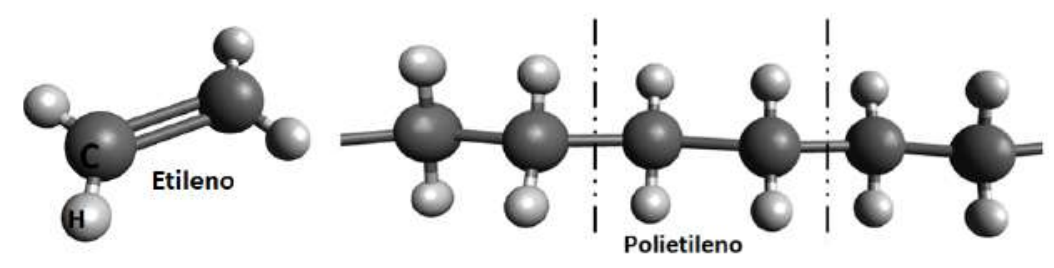

Figura 2.1: Representação do etileno e do polietileno.

Dependendo das condições empregadas na polimerização, diferentes tipos de polietileno podem ser produzidos, sendo de interesse para esta pesquisa o de ultra alto peso molecular, citado neste trabalho com a especificação mais comum na língua inglesa - ultra-high molecular weight polyethylene (UHMWPE). Este polímero apresenta cadeias lineares muito longas e elevada cristalinidade, o que tem como consequência elevadas propriedades mecânicas. O UHMWPE é um termoplástico linear de alta densidade, branco e opaco, com temperatura de transição vítrea $\left(\mathrm{T}_{g}\right)$ entre $-100{ }^{\circ} \mathrm{C}$ e $-125^{\circ} \mathrm{C}$ e temperatura de fusão $\left(\mathrm{T}_{m}\right)$ de $135{ }^{\circ} \mathrm{C}$. Atinge valores de peso molecular viscosimétrico médio superior a $3 \times 10^{6} \mathrm{~g} / \mathrm{mol}$ (4). Pode ser vista na Figura 2.2 uma estrutura de repetição do UHMWPE.

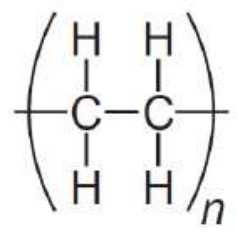

Figura 2.2: Estrutura do UHMWPE (sendo $n$ maior que 100.000).

Diversas linhas de ação tem sido propostas para otimizar o desempenho de blindagens, como desenvolver novos compósitos combinando diferentes fibras (como fibra de carbono, fibra de vidro, fibra de aramida - Kevlar ${ }^{\circledR}$ ), e mais recentemente a fibra de UHMWPE, que tem se mostrado um dos materiais mais promissores para a blindagem individual devido às suas propriedades mecânicas superiores e baixo peso (5).

\subsection{1}

\section{Fibras de polietileno de ultra alto peso molecular (UHMWPE)}

Segundo Callister (2001), uma característica importante de grande parte dos materiais é que quando se apresentam em forma de fibra, podem ser muito mais fortes e resistentes do que o material bruto. Isso ocorre devido à redução da probabilidade da existência de defeitos críticos na superfície do material, que 
poderiam levar à fratura, quando se tem a diminuição do volume de amostra. Esse recurso é usado com vantagem nos compósitos reforçados com fibras.

Um exemplo de fibra de alta resistência e alto módulo é a fibra de UHMWPE, que foi desenvolvida em meados dos anos 1980 como um polímero de alto desempenho usado para proteção balística (6). As fibras são produzidas por meio do processo de gel centrifugação (gel-spinning) a quente. O UHMWPE é dissolvido em solvente à temperatura de $150^{\circ} \mathrm{C}$. A solução é injetada através de uma fieira com centenas de capilares para formar filamentos líquidos que são, em seguida, temperados em água para formar uma fibra de gel. Esta é então estirada a uma taxa de deformação na ordem de $1 \mathrm{~s}^{-1} \mathrm{em}$ ar quente $\left(\right.$ a $\left.120^{\circ} \mathrm{C}\right)$, resultando numa fibra com alta orientação e cristalinidade, com $17 \mu m$ de diâmetro (7), translúcida (8).

Segundo Miao \& Xin (2017), esse tipo de fibra, além do emprego para material balístico, é usado ainda para cabos de proteção e utensílios de proteção contra materiais cortantes, sendo produzidos principalmente em países como Holanda, EUA, Japão e China (9).

Ao contrário das fibras de aramida, cuja resistência provém da forte ligação entre curtas moléculas adjacentes, a resistência da fibra de UHMWPE tem origem na força de ligação interna das moléculas extremamente longas de polietileno, com mais de 100.000 repetições de moléculas, e que podem atingir um grau de cristalinidade superior a 85\% (6), que faz com que as fibras possam resistir a grandes cargas de tração. As fibras de UHMWPE são 15 vezes mais fortes que o aço e são mais leves que a água, e esses fatores ressaltam sua importância para o uso militar.

Já segundo outra referência (10), a definição do "ultra-alto peso molecular"corresponderia ao peso deste polímero ser superior a $3 \times 10^{6} \mathrm{~g} / \mathrm{mol}$, geralmente variando até $6 \times 10^{6} \mathrm{~g} / \mathrm{mol}$. A fibra do UHMWPE apresenta elevada orientação axial e as cadeias formam uma estrutura altamente cristalina (entre 95-99\%).

O custo do UHMWPE em relação a outras fibras de alto desempenho é competitivo, variando de US\$35/ $\mathrm{kg}$ para modelos de menor desempenho como Spectra ${ }^{\circledR} 900$, chegando a cerca de US\$175/ $\mathrm{kg}$ para fibras de alto desempenho, como o Spectra ${ }^{\circledR} 1000(10)$.

Horrocks \& Anand (2016) destacam que o polímero UHMWPE apresenta baixa resistência ao calor devido às fracas ligações de Van der Waals presentes entre as moléculas, de forma que as fibras se fundem a aproximadamente $150^{\circ} \mathrm{C}$. Entretanto, a fibra de UHMWPE é extremamente resistente a ataques químicos e biológicos, e possui maior resistência à abrasão e à fadiga que as fibras de aramida (6). 
Miao \& Xin (2017) destacam as principais propriedades das fibras de UHMWPE (9) com nomes comerciais Dyneema ${ }^{\circledR}$ (DSM) e Spectra ${ }^{\circledR}$ (Honeywell), cujos valores são mostradas na Tabela 2.1.

Tabela 2.1: Propriedades mecânicas das fibras de UHMWPE.

\begin{tabular}{lccc}
\hline \multicolumn{1}{c}{ Fibra } & $\begin{array}{c}\text { Resistência à } \\
\text { Tração (GPa) }\end{array}$ & $\begin{array}{c}\text { Módulo de } \\
\text { Elasticidade (GPa) }\end{array}$ & $\begin{array}{c}\text { Elongamento } \\
\mathbf{( \% )}\end{array}$ \\
\hline Dyneema $^{\circledR}$ SK-66 & 3,0 & 95 & 3,7 \\
Dyneema $^{\circledR}$ SK-77 & 3,7 & 132 & 3,8 \\
Spectra $^{\circledR} 1000^{b}$ & 3,0 & 116 & 2,9 \\
Spectra $^{\circledR} 2000$ & 3,2 & 119 & 2,9 \\
\hline
\end{tabular}

${ }^{a}$ DSM Co., Holanda

${ }^{b}$ Honeywell Co., EUA

Uma metodologia para quantificar o desempenho balístico dos compósitos reforçados por fibras foi proveniente da observação experimental de que a velocidade crítica de penetração nas soluções de blindagem por um projetil teria relação linear com um termo denominado Velocidade de Cunniff $(7,11)$, $c^{*}$, sendo este parâmetro baseado nos valores de tensão de resistência à fratura $\sigma_{f}$, deformação máxima $\varepsilon_{f}$ e densidade $\rho$ da fibra, conforme Equação 2-1:

$$
c^{*} \equiv\left(\frac{\sigma_{f}}{\rho}\right)^{\frac{1}{2}}\left(\frac{\varepsilon_{f}}{4}\right)^{\frac{1}{6}}
$$

Esta correlação linear foi corroborada por estudos teóricos $(12,13)$, que revelaram que $c^{*}$ é sensível à resistência específica $\left(\sigma_{f} / \rho\right)^{1 / 2}$, porém fracamente dependente do fator deformação máxima. Os efeitos inerciais e a tensão de membrana foram citados como parâmetros dominantes para a deformação e falha das placas balísticas (7).

Algumas propriedades mecânicas das fibras comercias de UHMWPE, obtidas por meio de testes balísticos e ensaios a altas taxas de deformação são mostradas na Tabela 2.2 .

Tabela 2.2: Propriedades de fibras comerciais obtidas por ensaios balísticos e a altas taxas de deformação.

\begin{tabular}{cccccc}
\hline Fibra & $\rho\left(\mathrm{kg} \mathrm{m}^{-3}\right)$ & $\varepsilon\left(\mathbf{s}^{-1}\right)$ & $\sigma_{f}(\mathbf{G P a})$ & $\varepsilon_{f}(\%)$ & $c^{*}\left(\mathbf{m ~ s}^{-1}\right)$ \\
\hline Dyneema $^{\circledR}(14)$ & 970 & 700 & 2,55 & 6,26 & 698 \\
Spectra $^{\circledR} 900(15)$ & 970 & 433 & 2,5 & 3,0 & 689 \\
\hline
\end{tabular}

O mercado mundial de fibras de alta performance teve, em 2016, um potencial total de mercado maior que 1,2 bilhão de euros. Deste montante, as vendas de UHMWPE da marca Dyneema ${ }^{\circledR}$ (DSM) representaram $27 \%$ das vendas, ou o equivalente a 297 milhões de euros. Outras empresas que 
negociaram fibras de UHMWPE, dentre elas a Honeywell, detiveram $19 \%$ das vendas (16).

Devido à grande demanda por este tipo de fibra e seu significativo valor de mercado, diversas publicações exploram as propriedades e os métodos de ensaios desse material. Tais publicações serão apresentadas nas próximas seções.

Park \& Rutledge (2018), em publicação atual sobre fibras de UHMWPE, demonstram a tendência de redução do diâmetro das fibras chegando até a trabalhar com valores nanométricos. Segundo os autores, foi possível obter em escala laboratorial fibras de diâmetro de $490 \pm 50 \mathrm{~nm}$ com resistência à tração de 6,3 3 0,9GPa. Disponível comercialmente, tem-se a fibra SK99 da Dyneema ${ }^{\circledR}$ como a fibra mais recente da DSM, cujas propriedades estão relatadas na Tabela $2.3(17)$.

Tabela 2.3: Propriedades mecânicas da fibra Dyneema SK99.

\begin{tabular}{|l|c|}
\hline Diâmetro da fibra $(\mu \mathrm{m})$ & $12,2 \pm 0,5$ \\
\hline Módulo de Young $(\mathrm{GPa})$ & $131 \pm 8$ \\
\hline${ }^{a}$ LRT $(\mathrm{GPa})$ & $4,18 \pm 0,24$ \\
\hline Deformação de ruptura & 0,05 \\
\hline \multicolumn{2}{|c|}{${ }^{a}$ Limite de resistência à tração (LRT) }
\end{tabular}

\subsection{2}

\section{Compósitos com fibras de UHMWPE (prepreg)}

Os compósitos são considerados combinações de materiais que diferem em composição ou forma em uma macroescala. Os constituintes mantêm suas identidades mesmo quando combinados, isto é, eles não se dissolvem ou se fundem completamente um no outro, funcionando como um conjunto. Normalmente, os componentes podem ser diferenciados fisicamente e exibem uma interface entre si (10).

De acordo com Callister (2000), do ponto de vista tecnológico, os compósitos mais importantes são aqueles em que a fase dispersa está na forma de fibra. Ao se desenvolver projetos de compósitos reforçados por fibras geralmente tem-se como foco resistência e / ou rigidez elevadas, considerando o peso do material. Os parâmetros que denotam essas características são a resistência específica e o módulo específico, que correspondem, respectivamente, às razões entre o limite de resistência à tração e a densidade relativa, e entre o módulo de elasticidade e a densidade relativa.

É viável produzir compósitos reforçados por fibras com resistências e módulos específicos extremamente elevados, utilizando materiais de baixa 
densidade tanto para a matriz quanto para a fibra. Os compósitos reforçados com fibras são subclassificados de acordo com o comprimento das fibras. A presença de fibras contínuas, assim como o alinhamento das mesmas em relação à direção de carregamento, influenciam de forma determinante no desempenho dessa solução (18).

Callister (2000) menciona ainda que para a fabricação de compósitos reforçados por fibras contínuas atenderem a determinadas especificações, essas fibras devem estar distribuídas de maneira uniforme no interior da matriz, e na maioria dos casos que estejam ainda orientadas em uma mesma direção. O prepreg é um caso particular dessa formatação, pois trata-se de termo empregado pela indústria de compósitos para designar materiais com reforço de fibras contínuas pré-impregnadas com matriz polimérica em estado parcialmente curado. A Figura 2.3, adaptada de (18), demonstra um esquema para produção de prepregs.

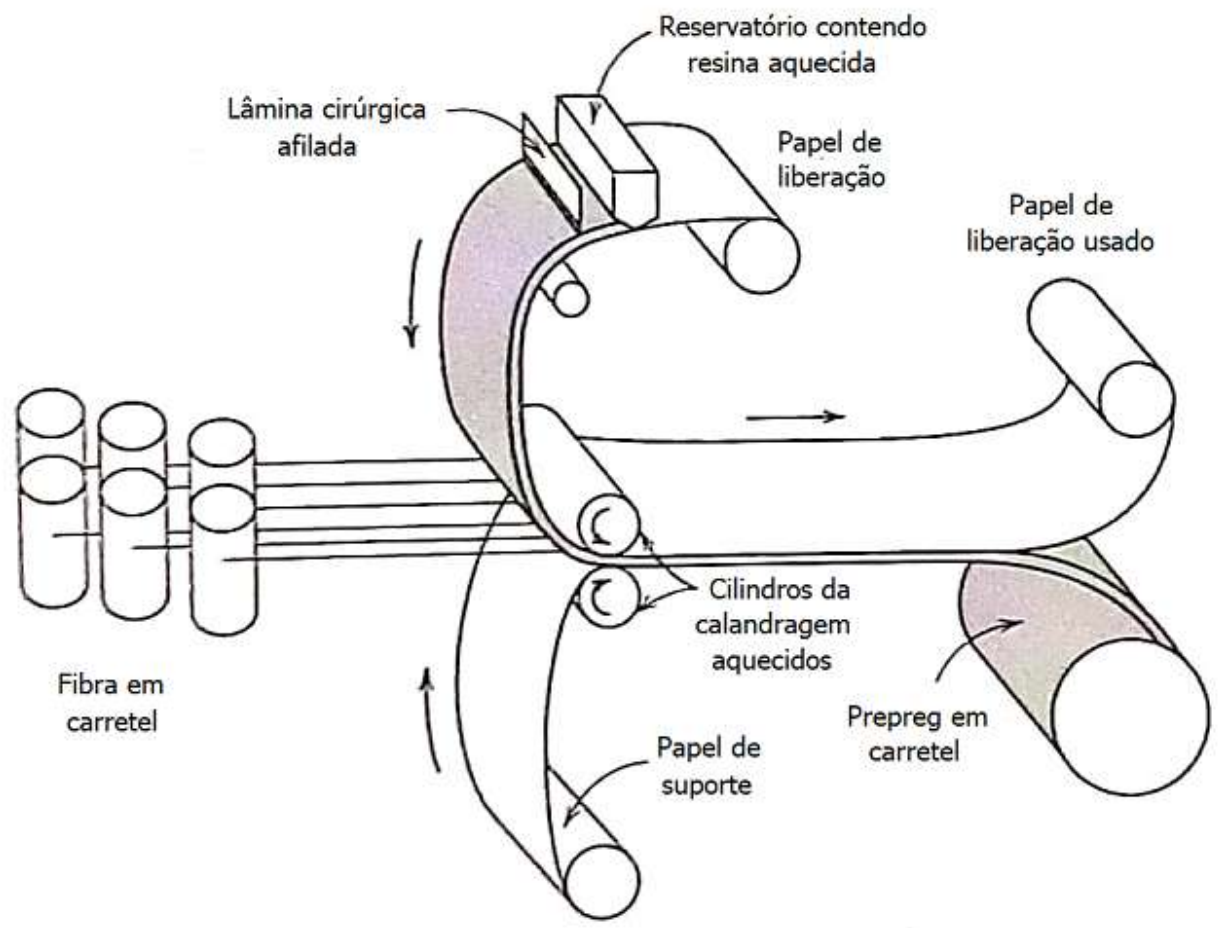

Figura 2.3: Diagrama esquemático para produção de rolo de prepreg.

Segundo Bhatanagar (2006), prepregs balísticos se tornaram uma forma de fabricação essencial para obter o máximo aproveitamento das fibras de alto desempenho. Esses compósitos maximizam a interação entre fibras e projetis de alta velocidade que penetram no material balístico, reduzindo assim a quantidade de material necessário para resistir à penetração dos disparos (19).

O material principal para esta pesquisa foi o pré-impregnado. Esse compósito é utilizado no desenvolvimento das proteções balísticas, sendo 
as camadas de fibras de UHMWPE dispostas de forma unidirecional, préimpregnadas por diferentes matrizes. Esses prepregs devem ser submetidos a prensagem a quente para que ocorra a cura das matrizes termoplásticas e consolidação de placas rígidas. A Tabela 2.4 reúne propriedades de prepregs de diversos fabricantes disponíveis no mercado internacional atualmente.

Tabela 2.4: Propriedades físicas de prepregs de UHMWPE.

\begin{tabular}{lccc}
\hline \multicolumn{1}{c}{ Prepreg } & $\begin{array}{c}\text { Densidade } \\
\left(\mathrm{g} / \mathrm{cm}^{3}\right)\end{array}$ & $\begin{array}{c}\text { Densidade } \\
\text { Superficial } \\
\left(\mathrm{g} / \mathrm{m}^{2}\right)\end{array}$ & $\begin{array}{c}{ }^{a} T_{m} \\
\left({ }^{\circ} \mathrm{C}\right)\end{array}$ \\
\hline${ }^{b}$ Tensylon & \\
${ }^{c}$ Dy & $>0,80$ & $111 \pm 7$ & $>140$ \\
${ }^{d}$ Spectra Shield ${ }^{\circledR}$ HB212 & 0,95 & $136 \pm 5$ & $\approx 145$ \\
${ }^{e}$ Spectra Shield ${ }^{\circledR} 5143$ & 0,97 & $253 \pm 7$ & $148 \pm 4$ \\
\hline${ }^{a}\left(T_{m}\right)$ Temperatura de fusão & 0,97 & $163 \pm 8$ & $148 \pm 4$ \\
${ }^{b}(20)^{c}(21)^{d}(22)^{e}(23)$ & & & \\
\hline
\end{tabular}

Os principais compósitos para proteção balística a base de fibras de UHMWPE seguem o padrão de camadas sobrepostas unidirecionais (UD), como Spectra Shield ${ }^{\circledR}$ e Dyneema ${ }^{\circledR}$ UD. Este tipo de sistema apresenta superioridade balística em relação aos tecidos convencionais com mesma densidade superficial (6). Apesar da denominação das camadas do material ser de UD a unidade básica para fabricação das placas pode ser considerada como material bidirecional, conforme exposto na Figura 2.4 (24).

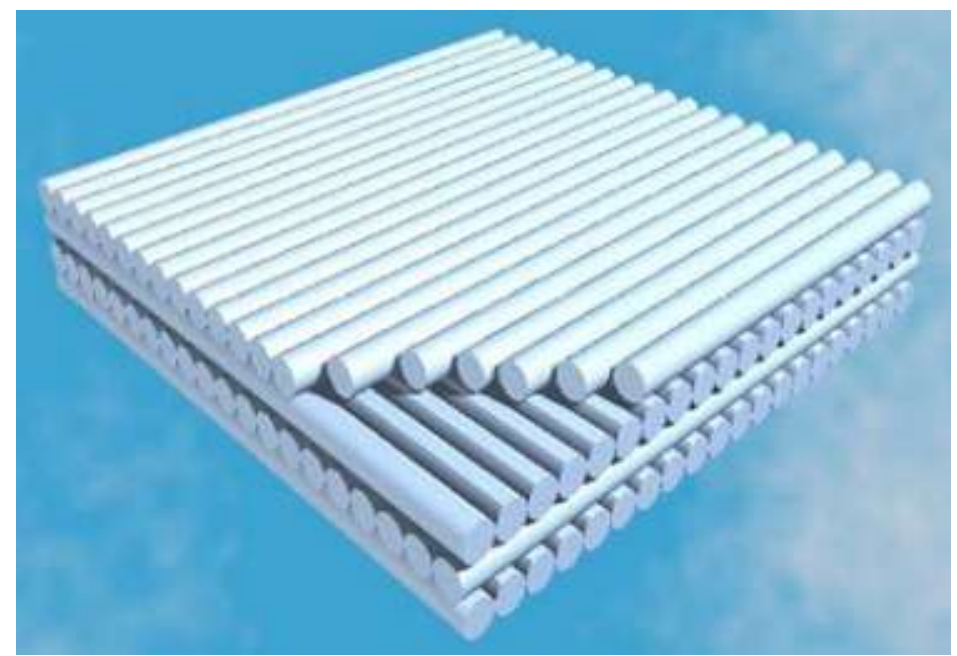

Figura 2.4: Esquema de fibras formando o prepreg bidirecional.

Exemplo de prepreg similar aos que serão estudados é o Dyneema ${ }^{\circledR}$ HB26. Este compósito é fabricado por prensagem a quente de prepregs de UHMWPE, nos quais as fibras tem diâmetro aproximado de $17 \mu \mathrm{m}$, dispostas de forma 
unidirecional em matriz de poliuretano (PU). Esse prepreg é formado por camadas superpostas alternadas de $0^{\circ} / 90^{\circ}$, sendo que a espessura de cada camada tem em torno de $60 \mu m(7)$.

\subsubsection{1}

\section{Estado da arte em compósitos com fibras de UHMWPE}

As fibras de alto desempenho, como as de UHMWPE, revolucionaram os projetos de coletes balísticos e o campo da proteção pessoal. As pesquisas abordando materiais compósitos para fins balísticos a base de fibras de UHMWPE começaram a ganhar vulto próximo do ano 2000, período no qual pode-se destacar um trabalho sobre este material, com referência às fibras Dyneema ${ }^{\circledR} \mathrm{e}$ Spectra ${ }^{\circledR}$ em formato de lâminas unidirecionais (25).

Examinando as publicações ao longo dos últimos anos, constata-se que as pesquisas e o lançamento de novas fibras e compósitos são interdependentes. Os trabalhos acompanham a evolução da tecnologia de novos materiais, assim como a indústria só estabelece novos produtos, após extenso trabalho dos pesquisadores. Tomando por base os produtos a base de fibras de UHMWPE mais presentes no mercado mundial, comprova-se este procedimento.

A pesquisa mais antiga que pode-se constatar sobre compósitos contendo fibras de UHMWPE da empresa DSM Co., usa o Dyneema ${ }^{\circledR}$ HB2 (25), explorando as propriedades e comportamento desse material para proteção balística. A evolução para as novas gerações de fibras e compósitos Dyneema ${ }^{\circledR}$ passa pelos tipos HB25 e HB26 (26, 27), HB50 (28), HB26 e HB50 (29, 30), e $\operatorname{HB} 80$ (31).

Os compósitos mais recentes desta empresa são o HB210 e HB212, e somente três publicações foram identificadas explorando as propriedades destes prepregs $(32,33,34)$, todas elas dentro dos últimos cinco anos.

O'Masta et al. (2016) compara o desempenho e propriedades de cinco prepregs, e destaca a utilização da fibra Dyneema ${ }^{\circledR}$ SK99 como sendo a fibra de reforço no compósito HB212. Essa foi a publicação mais recente encontrada sobre este pré-impregnado balístico, e a Tabela 2.5 (33) apresenta informações sobre três dos materiais da pesquisa. Park \& Rutledge (2018) apresentam publicação que aborda as propriedades mecânicas da fibra Dyneema ${ }^{\circledR}$ SK99, sendo este estudo direcionado para análise de fibras e redução do diâmetro das mesmas (17).

As publicações mencionadas acima exploram propriedades como: efeito da orientação das fibras dos compósitos laminados, mecanismos de deformação dinâmica, estudo de interfaces, compósitos híbridos com cerâmicos e efeito da resistência ao cisalhamento dos laminados. Observa-se que para estudar o 
Tabela 2.5: Propriedades de prepregs DSM e materiais constituintes.

\begin{tabular}{lccc}
\hline Prepregs Dyneema & HB26 & HB50 & HB212 \\
\hline Tipo de fibra (Dyneema) & SK76 & SK76 & SK99 \\
Matriz & PADP $^{a}$ & SISTC $^{b}$ & SISTC $^{b}$ \\
Diâmetro da fibra & 17 & 17 & 10 \\
Espessura do prepreg $(\mu m)$ & 67 & 60 & 35 \\
LRT $^{c}$ do prepreg $(\mathrm{GPa})$ & 1,7 & 1,7 & 2,6 \\
\hline${ }^{a}$ (PADP) Poliuretano diisocianato de polieterdiol-alifático \\
${ }^{b}$ (SISTC) Copolímero em tribloco de estireno-isopreno-estireno \\
${ }^{c}$ LRT - Limite de Resistência à Tração \\
\hline
\end{tabular}

comportamento durante o ensaio balístico, são necessários ensaios capazes de impor altas taxas de deformação, assim como instrumentação com velocidade e definição suficientes para captar os mecanismos presentes.

Câmeras de alta velocidade, sensores piezo elétricos, sistemas de medição com reconstrução de imagens de três dimensões, strain gauges, são alguns dos recursos utilizados para avaliar as deformações e os processos de absorção de energia durante os impactos. A simulação e modelagem computacional dos fenômenos também é uma ferramenta essencial para viabilizar o desenvolvimento de novas tecnologias na área.

As publicações abordando os compósitos Spectra ${ }^{\circledR}$ e Spectra Shield ${ }^{\circledR}$, da Honeywell Co., seguem padrão similar de evolução, e pode-se mencionar a progressão dos compósitos com publicações a partir de 2004, passando pelos produtos SR-1211, SR-1226, SR-3124, até a publicação mais recente, tratando do SR-3136, no ano de 2017 (35, 36, 37, 38, 39, 40). No decorrer da elaboração desta pesquisa houve a alteração das informações no sítio eletrônico dessa empresa, e foram apresentados novos materiais, dentre eles o compósito Spectra Shield ${ }^{\circledR} 5143$, sobre o qual não foi localizado até então artigo científico em periódicos internacionais.

Conforme destacado por Singh et al. (2017), as últimas duas décadas apresentaram uma significativa escalada do emprego de UHMWPE para aplicações balísticas, devido à alta resistência específica e alta capacidade de absorção de energia sob esforços dinâmicos deste polímero (41).

Uma vez apresentado o estado da arte sobre os materiais de UHMWPE, ao longo da duração deste estudo foi possível obter e trabalhar com o novo compósito Dyneema ${ }^{\circledR}$ HB212, porém não houve autorização para importação para outra marca, o Spectra Shield ${ }^{\circledR}$ 5143. Para confrontar o desempenho desse material com gerações anteriores, outro material empregado foi o prepreg da empresa Barrday, o ST-HB13. 


\subsection{3}

\section{Espumas}

São materiais poliméricos sólidos tridimensionais que contêm porcentagem relativamente alta de bolhas em sua estrutura física. Tanto os materiais termoplásticos quanto os termofixos podem dar origem a espumas. Essas são extensamente utilizadas na indústria automobilística, em móveis, bem como em embalagens e isolamento acústico ou térmico (42).

O processo de fabricação da espumas é realizado por incorporação de material específico para agir como o agente expansor, após reações químicas ou aquecimento, esse decompõe-se com a consequente liberação de gases. As bolhas de gás preenchem toda a massa polimérica, e permanecem como células após o resfriamento, gerando estrutura semelhante a de uma esponja. Efeito semelhante pode ser obtido ao borbulhar um gás inerte através do material enquanto o mesmo estiver no estado fundido (18).

As espumas tem como características: peso reduzido, alta capacidade de absorção de energia e ampla gama de propriedades mecânicas, que as torna adequadas para diversas aplicações industriais e de pesquisa. O comportamento mecânico das espumas depende dos materiais dos quais são constituídas, bem como da morfologia das células, isto é, a quantidade, o tamanho das mesmas e sua distribuição espacial (43).

Ramirez (2017) menciona que a interação entre as propriedades mecânicas do material polimérico sólido e a estrutura celular das espumas proporciona a capacidade única de dissipar uma ampla gama de impactos. Outro fator que se mostra importante é o tipo de célula presente nas espumas. Se as células são interconectadas, o material é chamado de espuma de célula aberta. Nesse tipo de polímero o ar pode fluir por dentro da espuma. Por outro lado, se as células não tem ligação, abertura entre elas, o material é designado como espuma de célula fechada. Para esse caso, o gás ou o ar ficam presos dentro de cada célula (44).

A Figura 2.5 (44) mostra o aspecto da microestrutura desses dois tipos de células.

A microestrutura de uma espuma pode ser analisada geometricamente empregando-se a Lei de Euler (45) para três dimensões, expressa na Equação $2-2$ :

$$
-C+F-E+V=1
$$

Onde $C$ é o número de células, $F$ é o número de faces, $E$ é o número de arestas e $V$ é o número de vértices. Para uma única célula $(C=1)$, o número médio de arestas $E$ por face $\bar{n}$ está relacionado com o número de faces $f$ (para 


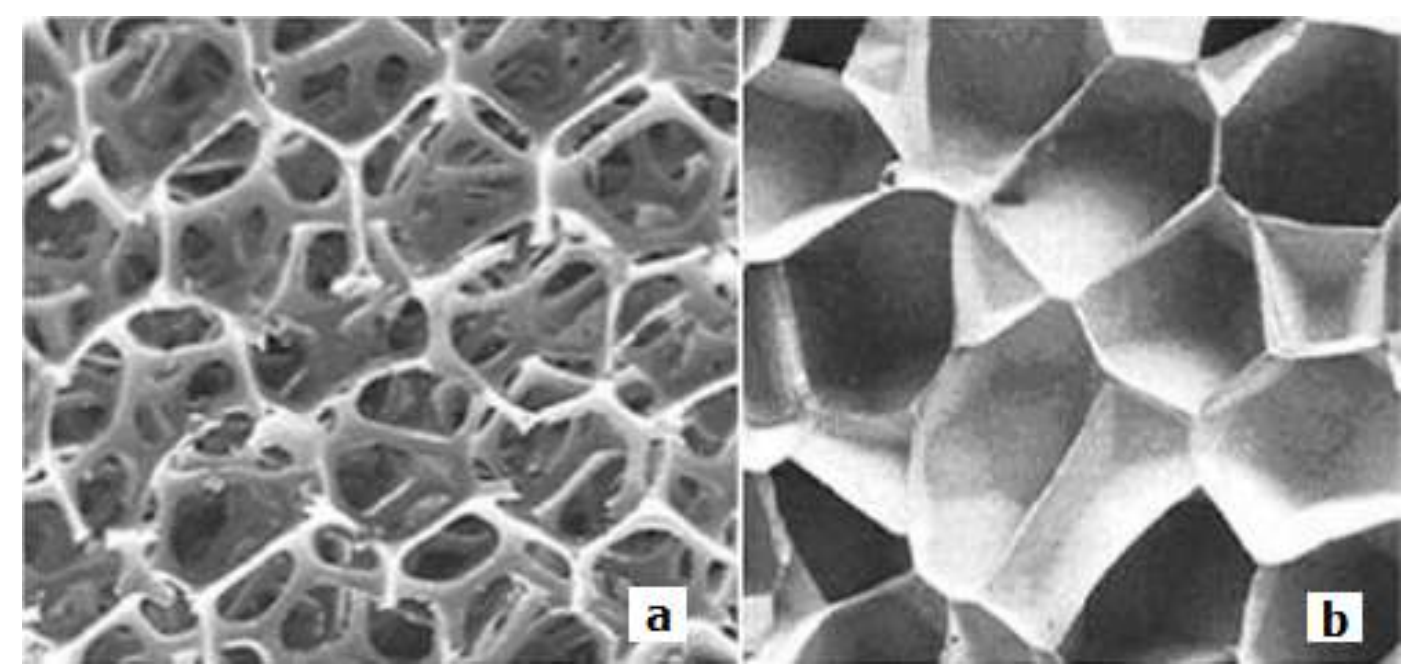

Figura 2.5: Estrutura de espumas de célula aberta (a) e fechada (b).

uma conexão tripla de arestas na superfície da célula) pela Equação 2-3:

$$
\bar{n}=6\left(1-\frac{2}{f}\right)
$$

De forma mais geral pode ser representado ainda pela Equação 2-4:

$$
\bar{n}=\frac{Z_{e} Z_{f}}{Z_{e}-2}\left(1-\frac{2}{f}\right)
$$

Onde $Z_{e}=\mathrm{n}^{o}$ de arestas que se encontram em um vértice, e $Z_{f}=\mathrm{n}^{o}$ de faces que se encontram em uma aresta (44).

Em Koohbor et al. (2016), estuda-se espumas poliméricas como sistema ideal de material absorvedor de energia, e as condicionantes necessárias para dissipar a energia cinética de um impacto, de forma a reduzir o nível de transferência da força de impacto para um dado objeto que se deseja proteger. Para tanto, foi caracterizado com precisão a dissipação de energia em condições de altas taxas de deformação, por meio de método não paramétrico, que permitiu avaliação a resposta compressiva constitutiva de espumas poliméricas rígidas submetidas a cargas de impacto (46).

Tal método baseia-se em estereovisão com fotografias de alta velocidade, em conjunto com a Correlação Digital de Imagem 3D (DIC), permitindo avaliação precisa das tensões inerciais desenvolvidas dentro da amostra durante o tempo de deformação. Distribuições do campo de tensão, deformação e taxa de deformação são usadas para extrair a resposta constitutiva do material em qualquer local ao longo do eixo da amostra. Além disso, a energia efetiva absorvida pelo material pode ser calculada. Esses resultados a partir da análise não-paramétrica proposta foram comparados com dados obtidos em procedimentos de teste convencionais, mostrando a capacidade de absorção de 
energia das espumas e a complexidade de modelagem do fenômeno (46).

Ramirez (2017) apresentou estudo sobre o desenvolvimento de espumas de poliureia de alto desempenho para ser empregada em equipamentos que demandam proteção à múltiplos impactos. Esse material se mostrou bastante versátil, podendo trabalhar em ampla faixa de valores de energia de impacto, temperatura e taxa de deformação, por meio da adequação da microestrutura durante a fabricação, maximizando a absorção da energia do impacto (44).

$\mathrm{Na}$ pesquisa em questão houve o emprego de dois tipos de espumas: a de poliuretano de célula aberta $\left(\right.$ Poron $\mathrm{XRD}^{\circledR}$ ) e a de célula fechada (PEBD/EVA). Foram verificados uma série de pesquisas que abordaram o comportamento de espumas submetidas a diferentes velocidades de impacto.

\subsubsection{1}

\section{Espuma de poliuretano Poron XRD}

Esse tipo de polímero é composto por células abertas, interconectadas por orifícios ou poros, que permitem que o ar flua pelo material. Isso significa que as propriedades do Poron $\mathrm{XRD}^{\circledR}$ não dependem da ação mecânica interna de bolhas de ar, mas das propriedades do material, de suas paredes celulares e do fluxo de ar por elas. Por isso, eles reagem à pressão de maneira semelhante a uma mola, retornando à posição original após cada compressão, devido ao ar se mover livremente por entre as células. Uma estrutura de célula aberta também permite a transmissão de vapor de umidade, ajudando na respirabilidade (47).

O Poron $\mathrm{XRD}^{\circledR}$, quando não solicitado mecanicamente, se apresenta como macio e flexível, acima da temperatura de transição vítrea $\left(T_{g}\right)$. Porém, quando o material sofre rápida deformação por força externa, a $T_{g}$ do material se altera, mudando a rigidez da estrutura momentaneamente. Esse fenômeno torna possível reduzir a transmissão do impacto, com maior absorção de energia de impacto em velocidades mais altas (48).

Yang \& Shim (2004) apresentaram estudo sobre dois modelos de espuma elastomérica de poliuretano e a resposta desses materiais à variação de altas taxas de compressão. Foi comprovado o comportamento hiperviscoelástico e capacidade de emprego para a absorção de impacto e a dissipação de energia cinética desses tipos de espumas (49).

Lothe (2013) avaliou o desempenho de um conjunto de 16 modelos de espumas Poron $\mathrm{XRD}^{\circledR}$, com variadas espessuras e densidades, com a finalidade de reduzir o impacto e o risco de fraturas ósseas decorrente de quedas. O material que demonstrou maior eficiência de desempenho para distribuição de força foi o modelo de $6 \mathrm{~mm}$ de espessura, com densidade de $320 \mathrm{~kg} / \mathrm{m}^{3}$, Poron $\mathrm{XRD}^{\circledR}$ 20236-35 (50). 
Tang et al. (2017) apresentou o estudo abordando três tipos de espumas empregados contra impacto, onde o $D 3 O^{\circledR}$ e o Poron $X R D^{\circledR}$ exibiram simultaneamente elevada resistência e grande absorção de energia em impacto de alta frequência, tornando-os adequados para emprego bem ajustado ao corpo. O material Deflexion ${ }^{\mathrm{TM}}$, por sua vez, dissipa muita energia sendo submetido à alta taxa de deformação ou não, podendo ser empregado para uso como material de proteção contra impactos de alto risco (47).

Um novo conceito de espuma composta à base de poliureia foi apresentado por Ramirez et al. (2018), que relataram as características de tensãodeformação e a eficiência da absorção de impacto a taxas de deformação quase-estáticas e dinâmicas. Os resultados são comparados com outras espumas, dentre as quais Poron 320, que demonstrou alto desempenho na absorção de impacto por conta do mecanismo de alteração da temperatura de transição vítrea induzido pela taxa de deformação. Ambas as espumas são viscoelásticas, e se recuperam completamente em aproximadamente 30 segundos após cada impacto, sem perda de qualquer capacidade de absorção de energia, proporcionando aos materiais ampla gama de aplicações militares e civis, especialmente em coletes balísticos e capacetes (51).

\subsubsection{2}

\section{Espuma de PEBD/EVA}

Em espuma de célula fechada cada célula está envolvida por uma parede de polímero, sendo compostas por células como bolhas de ar ou outro tipo de gás. Essas bolhas fazem parte da estrutura da espuma, de forma que as paredes celulares impedem que o gás escape. Agrupadas, essas células são cruciais para o funcionamento da espuma. Quando a mesma sofre compressão, o mesmo ocorre com o ar dentro de cada uma das células, o que permite que a espuma retorne quando a pressão é removida, caso o material não ultrapasse seu limite de comportamento elástico.

Nesse tipo de espuma, a contribuição do fluido (ar) depende da tensão, porque a redução de volume das células fechadas aumenta a pressão interna. Enquanto isso, a contribuição do fluido (ar) pode ser negligenciada se a rigidez da espuma for suficientemente alta.(47)

Grujicic et al. (2012), por meio de modelagem computacional, estudaram a transmissão do impacto para a parte interna de capacetes balísticos, dependendo da espuma e do modelo de capacete empregado. A espuma de etileno acetato de vinila (EVA) é um material tradicional empregado para absorção de impacto, e a utilização de espuma de poliureia em substituição a de EVA apresentou efeito adverso em algumas configurações de simulação, podendo 
transmitir um pico de tensão cisalhante para o cérebro cerca de $70 \%$ maior (52).

\section{2 \\ Materiais metálicos}

Diversos materiais metálicos vem sendo empregados em soluções de blindagens ao longo das décadas. As ligas de aço, devido ao custo, acabam sendo as mais utilizadas, sendo que existe grande variação nas composições, e no tipo de tratamento mecânico ou térmico para aumentar a eficiência dessas soluções.

Singh et al. (2017) apontam o aço RHA (Rolled Homogeneous Armour) como tradicional aço para blindagem, empregado como padrão principalmente para carros de combate, por seu baixo custo, confiabilidade, utilidade simultânea como material estrutural e facilidade de fabricação. Tratamentos térmicos para alterar a microestrutura desse metal são eficientes para prover aumento da dureza e ao mesmo tempo manter uma tenacidade adequada, levando ao alto desempenho para proteção balística (41).

Deniz (2010) apresentou estudo sobre modelagem numérica dos fenômenos de impacto balístico, em relação à penetração balística de chapas de aço temperado por projetil de 7,62 mm AP (Armor Piercing - perfurante de blindagem). Foram realizados testes com diferentes tipos de aços para verificar a eficiência no emprego balístico (53).

Segundo Deniz (2010), as ligas de alumínio são uma opção versátil para projetos de blindagem. A principal vantagem desse material é possuir densidade relativamente baixa, enquanto a resistência à tração varia de 60 a $600 \mathrm{MPa}$. Pode-se deduzir que para duas soluções de blindagem com massas iguais, sendo uma de alumínio outra de aço, a primeira terá maior volume, o que leva a uma melhoria na rigidez no caso de blindagem estrutural.

A versatilidade de processamento e conformação, também a significativa resistência à temperatura e ao impacto, fazem com que os metais mantenham considerável resistência específica, e sejam largamente empregados em composições balísticas. Metais tem módulo de elasticidade elevado e resistência mecânica alta. Porém, devido à densidade, tem sido substituídos por materiais compósitos nas últimas décadas (2).

Para aplicações balísticas que demandam resistência ao impacto extremamente elevada, como em proteções contra munição 7,62 mm, cuja velocidade do disparo chega próxima de $3250 \mathrm{~km} / \mathrm{h}$ (cerca de $900 \mathrm{~m} / \mathrm{s}$ ), por vezes se faz necessário reforçar a proteção exercida por placas constituídas somente de material polimérico empregando metais ou até mesmo cerâmicos. 


\subsection{1}

\section{Liga de Ti-6Al-4V}

Segundo Cortez et al. (2007), o titânio demonstra características importantes que o tornam diferente de outros metais de baixa densidade. Este material passa, a $882^{\circ} \mathrm{C}$, por uma transformação alotrópica, mudando da fase hexagonal compacta $(\alpha)$ para fase cúbica de corpo centrado $(\beta)$. Essa transformação torna viável obter ligas com microestruturas $\alpha, \beta$ ou mista $\alpha / \beta$, por meio de diferentes composições e tratamentos térmicos (54).

Logo, as ligas de titânio podem ser classificadas em quatro tipos: alfa $(\alpha)$, alfa-beta $(\alpha / \beta)$, ligas beta $(\beta)$ e os intermetálicos $\left(\mathrm{Ti}_{x} \mathrm{Al}\right.$, onde $\mathrm{x}=1$ ou 3). As ligas com finalidade de aplicação aeroespacial contêm elementos estabilizadores de $\alpha$ e $\beta$ para obter as propriedades mecânicas necessárias, como resistência à tração, fluência, fadiga, resistência à propagação de trinca por fadiga, tenacidade à fratura, trincas por corrosão sob tensão e resistência à oxidação (55).

De acordo com Wessel (2004), as ligas $\alpha / \beta$ contêm um ou mais estabilizadores $\alpha$ e $\beta$. Essas ligas podem ser reforçadas pelo tratamento de solubilização e envelhecimento, embora sejam geralmente empregadas na condição de recozidas. O tratamento por solubilização é seguido do envelhecimento a baixas temperaturas para precipitar $\alpha$, produzindo uma mistura de pequenas partículas de $\alpha$ retidas em matriz $\alpha / \beta$. Este tipo de tratamento pode aumentar a resistência dessas ligas em até $80 \%$.

A liga de titânio $\alpha / \beta$ mais comumente utilizada é justamente a que contem $6 \% \mathrm{Al}$ e $4 \% \mathrm{~V}$. Essa liga, chamada de Ti-6Al-4V, apresenta uma excelente combinação de resistência à corrosão, resistência mecânica e tenacidade (55).

Cerca de $75 \%$ da produção mundial de titânio se destina para a indústria aeroespacial, na forma da liga Ti-6Al-4V. O alto ponto de fusão, de $1660^{\circ} \mathrm{C}$ (56) é uma das características que mais tem contribuído para o crescimento do emprego dessa liga para fins estruturais. Sua utilização está centrada em componentes onde a resistência à fluência, fadiga e degradação são consideradas essenciais. A liga Ti-6Al-4V tem grande importância comercial, sendo alvo de mais da metade das aplicações das ligas de titânio nos EUA e na Europa (54).

Kissell et al. (2004) apontam o tipo de Ti-6Al-4V no qual se busca otimizar a tenacidade limitando rigorosamente a presença de elementos como ferro e oxigênio, por ELI (intersticiais extra baixos - extra low interstitials), sendo a nomenclatura da liga dada por Ti-6Al-4V ELI (57).

Segundo Nesterenko et al. (2003), o fato das ligas de titânio proporcionarem melhor resistência balística do que o aço ou o alumínio, fizeram com que fossem estudadas extensivamente como materiais de blindagem. Especifi- 
camente a liga Ti-6Al-4V ELI tornou-se a principal opção dentre as ligas de titânio para aplicações de blindagem devido à sua elevada dutilidade decorrente da presença controlada de elementos intersticiais como carbono, oxigênio, nitrogênio e hidrogênio (58).

A Tabela 2.6 apresenta a composição química de uma liga de Ti-6Al-4V ELI, de acordo com o Norma ASTM B265-15.

Tabela 2.6: Composição química da Liga Ti-6Al-4V Gr 23 ELI.

\begin{tabular}{lc}
\hline \multicolumn{2}{l}{ Composição - Porcentagem de peso (\% wt) } \\
\hline Alumínio & 6,00 \\
Vanádio & 4,00 \\
Oxigênio & 0,10 \\
Ferro & 0,18 \\
Titânio & 89,70 \\
\hline Dados da Norma ASTM B265-15 \\
\hline
\end{tabular}

De acordo com Deniz (2010), a liga de Ti-6Al-4V pode ser empregada para fins balísticos, se mostrando uma boa alternativa ao aço. Essa liga possui densidade relativamente baixa $\left(4,45 \mathrm{~g} / \mathrm{cm}^{3}\right)$, e altas resistência e dureza, com limite de escoamento de 900 a $1300 \mathrm{MPa}$, e dureza Vickers de 300 a 350 (33 HRC a 38 HRC). No entanto, o fator custo relacionado às ligas de titânio é uma questão importante que pode limitar seu emprego (53).

Segundo Kissell et al. (2004), uma alternativa a ser considerada para aplicações em blindagem, de relativo baixo custo quando comparada ao Ti6Al-4V, é a liga Timetal 62S (Ti-6Al-2Fe-0,1Si) cuja base para produção é uma liga de Al-Fe, com vantagens econômicas sobre a liga base de Al-V (57).

Meyer et al. (2008) demonstram a consequência de diferentes tipos de tratamentos térmicos aplicados à liga Ti-6Al-4V para o aumento da dureza e melhoria do desempenho na absorção de energia. O recozimento a $1065^{\circ} \mathrm{C}$ seguido de têmpera em água e envelhecimento a $600^{\circ} \mathrm{C}$ gerou o maior valor de dureza, $399 H V$, cerca de $41 H R C$, com a correspondente microestrutura de fase $\beta$ envelhecida com $\alpha$ dispersa em pequenos precipitados. A pesquisa aponta a fabricação de blindagem como potencial emprego para essa liga (59).

Thomas et al. (2012) reforça a possibilidade de emprego da liga de Ti-6Al$4 \mathrm{~V}$ em soluções de blindagem, pois o material pode conquistar ótima dureza e resistência se tratado termicamente. Logo, essa liga de titânio pode substituir o aço com significativa economia de peso, oferecendo boa proteção balística (60).

Nesterenko et al. (2003) estudou a diferença de resistência à deformação de dois corpos de prova de Ti-6Al-4V, quando submetidos à impacto balístico por projetil cônico, sendo que parte dos CPs foi fabricado pela técnica de 
metalurgia do pó e outra parte foi usinada a partir de barras comerciais da liga. Os materiais fabricados por prensagem isostática a quente demonstraram melhor desempenho balístico do que o material fabricado de forma tradicional, apontando novas possibilidades para fabricação de materiais de blindagem empregando o titânio (58).

\section{3}

\section{Comportamento dinâmico e balístico de polímeros}

Para que seja possível o desenvolvimento de novos compósitos mais eficientes para proteção balística pessoal, é necessário explorar não só fibras ou matrizes de forma isolada, buscando parâmetros como redução de massa ou aumento de resistência. A questão crítica que vai guiar o desempenho do material é a forma como este compósito se comporta durante o impacto, como absorve e dissipa a energia do projetil.

Sabe-se que as fibras de UHMWPE são as principais responsáveis pela resistência do compósito, entretanto, a matriz também contribui para o desempenho global. O elemento que forma a matriz comanda as funções de cisalhamento interlaminar, delaminação e manutenção da integridade do compósito retendo as fibras em suas posições. A fração volumétrica de matriz é normalmente inferior a 20\% em lâminas de UHMWPE, sendo que mesmo com a reduzida quantidade, essas matrizes são frequentemente muito resistentes. Para o Dyneema ${ }^{\circledR}$ HB26 a matriz trata-se de poliuretano (27), e segundo O'Masta (2014), mais especificamente PADP, poliuretano diisocianato de poliéterdiolalifático (37).

A resposta de um compósito com fibras de UHMWPE durante o impacto de um projetil é processo complexo que envolve muitos mecanismos de falha e de absorção de energia, como tensão trativa, compressão ao longo da espessura e delaminação. Embora haja um nível de compreensão destes mecanismos quando analisados individualmente, para determinar o comportamento global do compósito é difícil se basear em um modelo analítico preciso que possa ser usado para prever o desempenho balístico e auxiliar no projeto de novas proteções (27).

Fatores externos como a geometria do projetil e a velocidade de impacto também influenciam o comportamento dos laminados durante os processos de deformação e fratura ao serem impactados (61).

Alguns mecanismos envolvidos na deformação dos laminados e responsáveis por dissipar a energia do impacto podem ser destacados: fratura da fibra (pode ser estudada em testes quase estáticos e dinâmicos), o atrito (em várias interfaces durante a deformação), e o cisalhamento da matriz (ocorre exten- 
sivamente em toda a placa e pode fornecer diversas informações). Acontece ainda uma dissipação de energia nas extremidades da placa através de perdas vibracionais (28).

De acordo com a norma National Institute of Justice (Instituto Nacional de Justiça - NIJ) 100-01 - Selection and Application Guide to Personal Body Armor (62), resta evidenciado que: a deformação do projetil e a dispersão de energia ao longo do material são atribuições dos mecanismos do sistema de proteção, sendo este destinado à completa parada do projetil em iteração com o alvo.

Compreender os mecanismos de falha aos quais os compósitos poliméricos são susceptíveis é de fundamental importância para melhorar esses materiais. Essa questão cresce de importância para o caso de aplicações de responsabilidade, como para o emprego em blindagem balística. Geralmente a fratura não ocorre de modo catastrófico, sendo influenciada pelo percentual de fibras que reforçam o compósito. Em torno de 80 a $85 \%$ de volume de fibras de UHMWPE em prepregs balísticos são adequados para que a falha tenda a ser progressiva (7), sendo que o compósito absorve energia ao falhar em decorrência da combinação de mecanismos de fratura.

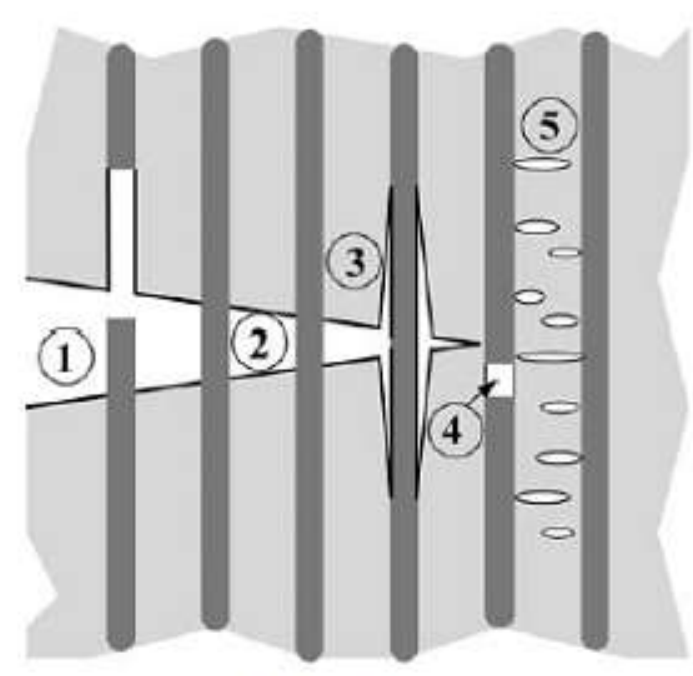

Falha no plano
1. Arrancamento de fibras

2. Estiramento de fibras

3. Descolamento fibra/matriz

4. Ruptura de fibras

5. Trincamento da matriz

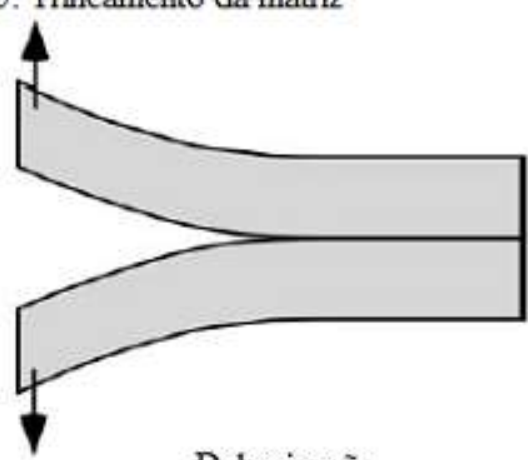

Delaminação

Figura 2.6: Mecanismos de falha em compósitos reforçados com fibras.

A Figura 2.6, adaptada de (63), expõe alguns mecanismos de falhas passíveis de ocorrer em compósitos reforçados por fibras. Dentre esses mecanismos destaca-se os seguintes: arrancamento de fibras ( pull-out), estiramento de fibras (fiber bridging), descolamento fibra/matriz, ruptura das fibras, trincamento da matriz e a delaminação (63). 
Greenhalgh et al. (2013) expõe as mudanças ocorridas nos modos de falha de placas de HB26 fabricadas em duas condições de pressão diferentes. O aumento da pressão de processamento reduziu principalmente a espessura da matriz entre as camadas de fibras, o que aumentou a delaminação, particularmente próximo à face posterior do painel. Essa menor espessura teria aumentado a tenacidade de falha no modo I (em tração), porém reduzido essa tenacidade para o modo II (cisalhamento) (64).

\subsection{1}

\section{Energia do impacto}

Conforme Karthikeyan \& Russell (2014), a ampla utilização de prepregs com fibras de UHMWPE em placas balísticas deve-se à resistência específica extremamente alta, proporcionando intensa oposição à perfuração. Entretanto, os mecanismos que controlam a perfuração e a deformação não são completamente compreendidos. Sob impacto balístico há tipicamente dois regimes de dano e deformação que ocorrem separados por uma grande delaminação: penetração da face frontal (face de impacto) com deformação local, até que o projetil seja desacelerado, e alongamento (em forma de membrana) na região posterior da placa (oposta ao lado do impacto). É relatado que deformação da parte posterior pode absorver até 6,5 vezes mais energia do que os mecanismos que ocorrem mais próximos à face de impacto (28).

Segundo Bhatnagar (2006), quando a placa balística é alvejada, a tensão gerada no material fica limitada a uma pequena área, próxima à posição de penetração do projetil. Consequentemente, somente um número limitado de fibras balísticas atua para reter o disparo. Quanto mais a tensão ficar restrita a uma área, maior será a deformação da face posterior daquela placa. Essa situação pode ser equilibrada pelo emprego de quantidade adequada de resina que une as fibras balísticas, reduzindo essa deficiência (19).

Durante um impacto balístico do projetil, diversas são as funções do material empregado como blindagem:

- desaceleração do projetil;

- deformação do projetil à medida que passa através das camadas;

- parada do projetil; e

- redução da deformação da face posterior.

Nos materiais fabricados com prepregs reforçados por fibra de UHMWPE ocorre interação do projetil com maior número de fibras no impacto inicial do que em um tecido balístico, devido à grande densidade dessas fibras. A matriz, 
por sua vez, impede que a onda de choque do projetil desloque as fibras para fora da trajetória deste projetil.

Se faz mister que uma estrutura dissipe a energia de impacto, ao invés de somente absorver a mesma. A dissipação ocorre em função da velocidade de propagação das ondas pela estrutura do compósito. Em se tratando de absorção de energia, um mecanismo que pode auxiliar durante a propagação da onda de deformação de um sistema balístico compósito reforçado por fibras é o atrito entre as fibras. Essa atuação cresce de importância quando se analisa uma solução fabricada com prepregs, pois a densidade de fibras costuma ser extremamente elevada nesse formato de solução (19).

De acordo com Bhatnagar (2006), a velocidade da onda de deformação é a velocidade na qual uma fibra ou estrutura pode absorver e dispersar a energia de deformação. Pode ser expresso pela Equação 2-5 (19)

$$
\nu=\sqrt{F / \mu}
$$

Onde

$\nu=$ velocidade da onda de tensão

$F=$ força aplicada à fibra (pelo projetil)

$\mu=$ densidade linear expressa em $\mathrm{kg} / \mathrm{m}$

É possível ainda expressar o termo $\nu$ por outra expressão, conforme Equação 2-6

$$
\nu=\sqrt{E / \rho}
$$

Onde

$E=$ módulo de Young do material

$\rho=$ densidade específica do material

Por meio da combinação das duas equações, chega-se à expressão para a dissipação ótima da energia de impacto, em Equação 2-7

$$
F=E \mu / \rho
$$

Segundo Werff \& Heisserer (2016), quanto mais energia de impacto uma estrutura é capaz de dissipar, mais eficiente é o mecanismo de absorção de energia pelo sistema como um todo. Quando se inicia a perfuração decorrente do impacto de um projetil, as fibras do mesmo passam a cooperar com a absorção dessa energia por três mecanismos:

- alongamento;

- deslizamento; e

- fratura. 
Maior será a absorção e dissipação de energia de um sistema balístico, se a interação da matriz for capaz de maximizar estes processos entre as fibras de alto módulo e alta resistência, otimizando a eficiência desse sistema (34).

Meyers (1994) destaca a importância da equação que relaciona a massa de um objeto e sua velocidade ao quadrado com a energia do mesmo, de forma que essa energia pode ser transferida por um projetil de massa $m$ para um alvo, sendo este fenômeno regulado pela Equação 2-8:

$$
d E=F d l
$$

onde $d l$ consiste na extensão sobre a qual a força $F$ vai agir. Essa energia cinética se transforma em deformação para o projetil e para o alvo. Quando essa deformação ocorre em velocidades muito elevadas, no regime dinâmico, uma região de um corpo fica sobre tensão enquanto outra parte ainda não sofreu influência dessa tensão (65).

Segundo Meyers (1994), existe a propagação da tensão dentro de um corpo (e da deformação associada), sendo que a velocidade dessa propagação pode ser calculada com boa precisão para grande parte dos materiais. Essa transmissão dinâmica de energia dentro do material, quando ocorre uma explosão próxima a uma chapa metálica, é denominada por onda de choque. A técnica de soldagem de dois metais por explosão se baseia nesse princípio (65).

Meyers (1994) associa ainda o Princípio de Conservação de Energia, agregando a energia potencial do volume infinitesimal de um corpo, à energia cinética recebida pelo mesmo, por meio da Equação 2-9

$$
\text { Taxa de acumulação }=\frac{\partial}{\partial t}\left(E+0,5 u^{2}\right) \rho \delta x \delta y \delta z
$$

onde $E$ representa a energia interna por unidade de massa. Essa energia acumulada é igual à energia que entra no cubo infinitesimal (cinética, potencial e química), menos a energia que deixa este cubo. Meyers (1994) demonstra o prosseguimento da análise diferencial, agregando a energia devido ao trabalho, a energia química e aplicando transformação de coordenadas pelo operador Lagrangeano, para por fim associar os conceitos da Primeira Lei da Termodinâmica, e assumir que o processo é adiabático, chegando dessa forma à Equação $2-10$

$$
\frac{d E}{d t}+P \frac{d V}{d t}=0
$$

Segundo Avillez (2015) durante um processo reversível que ocorre à pressão constante, a absorção de calor $\delta Q$ geralmente acarreta um aumento do volume $d V$ do sistema. Dessa forma, a variação da energia interna é dada pela Equação 2-11 


$$
d U=\delta Q-P d V \quad \log o, \quad \delta Q=d U+P d V
$$

Como os processos a pressão constante são extremamente comuns no processamento de materiais, se fez conveniente definir uma variável simplificadora $(H)$, descrita na Equação 2-12

$$
H=U+P V
$$

que se trata da Entalpia (66).

\section{4}

\section{Blindagens Balísticas}

Pode-se se considerar como blindagem balística um anteparo de proteção desenvolvido para oferecer resistência à penetração de projetis provenientes de arma de fogo. As blindagens podem ser divididas em tipos, dependendo da aplicação pretendida, sendo essa classificação em três grandes grupos (65), conforme a Figura 2.7.

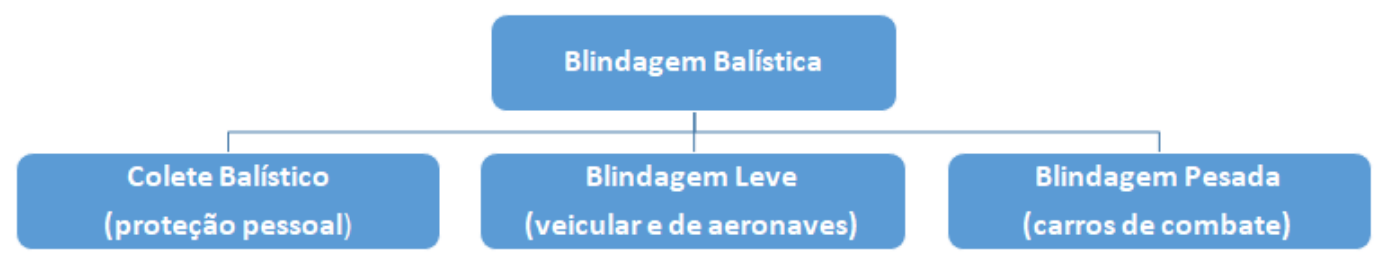

Figura 2.7: Tipos de blindagem por finalidade de emprego.

Segundo Yadav et al. (2016), a necessidade de proteção contra objetos lançados remonta a antiguidade. Dependendo das ameaças características de cada período histórico, vários dispositivos já foram empregados para defesa, porém, com a invenção da pólvora a dinâmica dos campos de batalha mudou completamente.

Desde as guerras francesas do século XIX, até a atual guerra contra o terrorismo, a humanidade passou a ser cada vez mais exposta a projetis de alta velocidade, com munições disparadas de pistolas ou fuzis, fragmentos de aço advindos de granadas de mão, explosões de granadas de artilharia ou de bombas artesanais (67).

Com potencial de dano cada vez maior, devido à alta energia cinética dos projetis e fragmentos, houve alteração das taxas de deformação às quais os alvos são submetidos, alterando dessa forma o mecanismo de interação entre alvo e projetil (68).

De acordo com Hamouda \& Risby (2006), durante as duas grandes Guerras Mundiais, o conhecimento sobre equipamentos de proteção pessoal 
esteve limitado ao emprego de materiais metálicos, como o aço. No entanto, devido ao grande peso dessas proteções e à falta de flexibilidade, esse material foi usado apenas em veículos de baixa velocidade e fortemente blindados, deixando a proteção individual completamente inócua.

Segundo Meyers (1994), grande diversidade de materiais vem sendo empregados para proteção balística ao longo da história. Há centenas de anos os samurais japoneses chegaram a utilizar escudos feitos até de cascos de tartaruga. Atualmente, os veículos modernos usam metais, cerâmica, compósitos e até materiais reativos para barrar a trajetória dos projetis.

As blindagens balísticas são classificadas por níveis de proteção, que estão relacionados diretamente à fatores como: forma, material, velocidade, energia do projetil e área de impacto. A norma para coletes balísticos NIJ 0101.06 - Ballistic Resistance of Body Armor (69), é referenciada na maioria das pesquisas científicas internacionais.

Parâmetros similares são determinados pela Norma ABNT NBR 15000:2005, da Associação Brasileira de Normas Técnicas, Blindagens para impactos balísticos - Classificação e critérios de avaliação (70), da qual podese reproduzir as informações da Tabela 2.7.

Tabela 2.7: Nível de proteção do sistema de blindagem quanto ao impacto balístico.

\begin{tabular}{|c|c|c|c|c|}
\hline Nível & Munição & $\begin{array}{l}\text { Massa do } \\
\text { projetil }(\mathrm{g})\end{array}$ & $\mathrm{V}_{0}(\mathrm{~m} / \mathrm{s})$ & $\begin{array}{l}\text { Número de } \\
\text { impactos }\end{array}$ \\
\hline \multirow{2}{*}{ I } & $.22 \mathrm{LRHV}$ & $2,6 \pm 0,1$ & $320 \pm 10$ & 5 \\
\hline & .38 Special RN Chumbo & $10,2 \pm 0,1$ & $254 \pm 15$ & 5 \\
\hline \multirow{2}{*}{ II-A } & 9 FMJ & $8,0 \pm 0,1$ & $332 \pm 12$ & 5 \\
\hline & 357 Magnum JSP & $10,2 \pm 0,1$ & $381 \pm 12$ & 5 \\
\hline \multirow{2}{*}{ II } & 9 FMJ & $8,0 \pm 0,1$ & $358 \pm 15$ & 5 \\
\hline & 357 Magnum JSP & $10,2 \pm 0,1$ & $425 \pm 15$ & 5 \\
\hline \multirow{2}{*}{ III-A } & 9 FMJ & $8,0 \pm 0,1$ & $426 \pm 15$ & 5 \\
\hline & .44 Magnum SWC GC & $15,6 \pm 0,1$ & $426 \pm 15$ & 5 \\
\hline III & $\begin{array}{c}\text { 7,62 x } 51 \text { FMJ } \\
\text { (.308 - Winchester) }\end{array}$ & $9,7 \pm 0,1$ & $838 \pm 15$ & 5 \\
\hline IV & $.30-06 \mathrm{AP}$ & $10,8 \pm 0,1$ & $868 \pm 15$ & 1 \\
\hline $\begin{array}{l}\text { Legen } \\
L R H \\
R N- \\
F M J \\
J S P- \\
S W G \\
A P-\end{array}$ & $\begin{array}{l}\text { la: } \\
\text { - Long Rifle High Velocit } \\
\text { Round Nose } \\
\text { Full Metal Jacketed } \\
\text { Joint Soft Point } \\
\text { C - Semi WadCutter Gas } \\
\text { Armor Piercing }\end{array}$ & Check & & \\
\hline
\end{tabular}

Nas últimas três décadas, cientistas e engenheiros de diversas indústrias, universidades e laboratórios vem realizando pesquisas sobre vários tipos de 
materiais balísticos e sobre a interação dos mesmos com projetis de alta velocidade. Porém, a maioria desses estudos detalhados acaba tendo distribuição restrita (67).

A partir da década de 1970, o surgimento recorrente de novos materiais poliméricos de alto desempenho para emprego balístico fizeram com que a utilização de aço e cerâmica fosse, dia-a-dia, sendo substituída no emprego em placas rígidas de coletes balísticos até o Nível III de ameaça.

Os principais compósitos em uso atualmente são feitos de fibras de aramida com matriz fenólica ou fibras de polietileno de ultra-alto peso molecular (UHMWPE) - $\left(\right.$ Spectra ${ }^{\circledR}$, Dyneema $^{\circledR}$ ou Tensylon $\left.{ }^{\mathrm{TM}}\right)$ com matriz polimérica termoplástica.

O colete balístico moderno pode conter duas estruturas de proteção utilizadas em sobreposição: painel flexível e placa rígida (existem coletes somente com a placa rígida, quando a mesma é chamada de placa stand alone). A fibra balística mais utilizada atualmente para placas rígidas é a de UHMWPE. Este material está ganhando terreno no campo balístico devido a sua excelente relação desempenho-peso. No Brasil, até 2004, as placas compradas eram de metal ou cerâmica, porém o uso de placas de UHMWPE substituiu completamente estes materiais há praticamente 10 anos.

Para a fabricação das placas de prepregs, o processamento mais eficiente é a prensagem a quente, em níveis consideráveis de pressão. No trabalho de Werff \& Heisserer (2016) a prensagem de placas de material da empresa DSM, modelo HB26, com diferentes espessuras, ocorreu à 165 bar de pressão (34).

Corroborando esse entendimento, Lässig et al. (2017) realizaram a compressão a quente também de prepreg HB26 à pressão de 165 bar (61).

O estudo de Greenhalgh et al. (2013) apresentou a análise do desempenho e mecanismos de absorção de energia de placas (feitas de HB26) submetidas ao ensaio balístico, após serem consolidadas em dois valores de pressão diferentes (165 bar e 300 bar). Nesse estudo, para condições de impacto semelhantes (mesmo projetil e cerca de $1000 \mathrm{~m} / \mathrm{s}$ ), o resultado foi discutível, pois houve placas que resistiram e que foram perfuradas, para as duas condições de fabricação (64).

Bogetti et al. (2017) descreveram os procedimentos para a fabricação de blindagens feitas de compósitos de UHMWPE, o Spectra Shield II SR3136, da empresa Honeywell. Esse prepreg é composto de quatro camadas $\mathrm{UD}$, alternadas $\left(0^{\circ} / 90^{\circ} / 0^{\circ} / 90^{\circ}\right)$, com aproximadamente $260 \mu \mathrm{m}$ de espessura. Foram empilhadas 40 camadas (espessura de 10,4 mm, com formato quadrado de $20,32 \mathrm{~cm}$ de lado) e submetidas à prensagem a quente, com pressão aproximada de 138 bar, e temperatura de $132{ }^{\circ} \mathrm{C}$. Embora o objetivo tenha 
sido estudar os mecanismos de cisalhamento, os autores apontam a necessidade de pesquisas futuras buscando avanços no desenvolvimento de compósitos de UHMWPE, novos métodos para caracterização, principalmente a taxas mais elevadas, para otimizar a modelagem de fenômenos de impacto balístico, fomentando projetos de blindagem mais eficientes e avançados (40).

Os principais requisitos que balizam o desenvolvimento de novos produtos são a manutenção do desempenho reduzindo o peso da solução, ou obter um nível significativamente mais alto de desempenho balístico sem alterar o peso. Tipicamente, a combinação redução de peso / manutenção do desempenho é a linha de ação mais adotada.

Buscar menor peso reduzindo a espessura da solução pode ter como consequência maior deflexão da face posterior quando alvejados pelo projetil. Assim, futuras placas balísticas devem equilibrar os três fatores: peso, limite balístico, e deformação da face posterior. Fica então destacada a importância do equilíbrio entre as propriedades físicas e dinâmicas do conjunto fibra / matriz.

O Exército Brasileiro demanda atualmente cerca de 35 toneladas de material balístico por ano para proteção individual, sendo esta quantidade apenas referente aos prepregs com fibras UHMWPE para fabricação de placas rígidas. A estrutura de blindagem do colete composta pelo painel flexível pode ser constituída por tecidos de aramida ou também por lâminas com fibras de UHMWPE, o que ressalta ainda mais a importância e a necessidade de pesquisas abordando o emprego deste polímero de alto desempenho.

Para este trabalho de pesquisa, o alvo do desenvolvimento será a placa balística stand alone Nível III, a ser testada contra a munição 7,62 x 51 FMJ (Full Metal Jacket). O projetil desse cartucho é composto por um núcleo de chumbo revestido da ponta até a base por uma lâmina de liga de latão (aproximadamente $90 \%$ de cobre e 10\% de zinco), formando o que se denomina camisa ou jaqueta de latão $(69,71)$, que normalmente deixa a parte do núcleo exposta na base, conforme detalhado na Figura 2.8 (72).

\section{5}

\section{Ensaios Balísticos}

Realizar ensaio balístico em blindagem consiste basicamente em disparar um projetil de arma de fogo em alta velocidade, em situação controlada, de forma a impactar um alvo, para que se registre as variáveis do evento e consequências do mesmo.

Os mecanismos envolvidos no fenômeno físico do impacto são de grande complexidade e por conta das rápidas e não tão previsíveis falhas e deforma- 


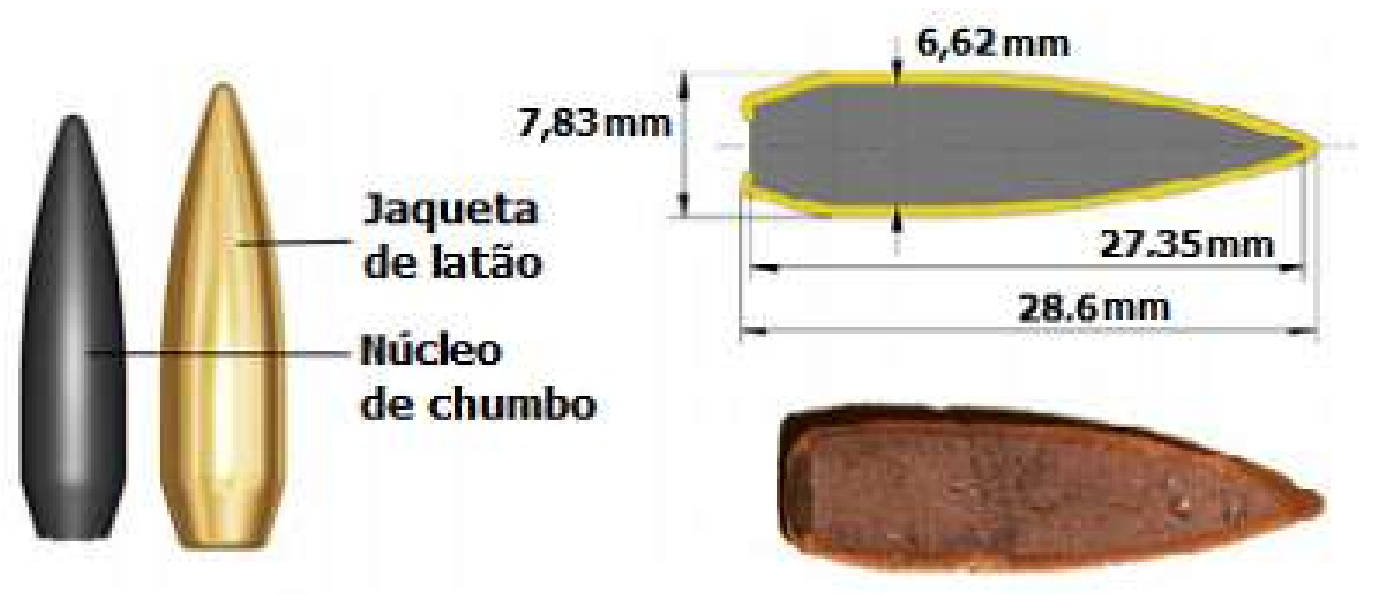

Figura 2.8: Desenho esquemático do projetil da munição 7,62x51 FMJ.

ções, torna-se um evento de difícil simulação computacional. Dessa forma, são necessários os ensaios práticos (testes balísticos) para desenvolver e qualificar novas soluções.

Entretanto, a gama de variáveis envolvidas nesses testes obrigam que os ensaios em blindagens ocorram dentro de parâmetros muito bem definidos, sob a pena da obtenção de resultados discutíveis caso não se adote os procedimentos de forma meticulosa.

Visando obter confiabilidade e reprodutibilidade, é necessário seguir as normas que regulam ensaios balísticos, pois estas abordam claramente os fatores que influenciam nos resultados do ensaio. Como exemplo de normas internacionais que regulam testes balísticos em blindagens, pode-se citar:

- Norma OTAN STANAG 2920 - Ballistic Test Method for Personal Armour Materials and Combat Clothing;

- Norma OTAN STANAG 4164 - Test Procedures for Armour Perforation Tests of Anti-armour Ammunition;

- Norma militar dos EUA, MIL-STD-662F - $V_{50}$ - Ballistic Test for Armor (73). Esta norma serve de base para testes balísticos empregando tratamento estatístico dos dados coletados nos ensaios. As normas a seguir utilizam a MIL-STD-662F como base, e todas são utilizadas pelas Forças Armadas Norte-Americanas:

- MIL-DTL-32378 - Laminate: Unidirectional, Reinforced, CrossPlied, Aramid Fiber, Plastic Armor Material;

- MIL-DTL-44050B - Cloth, Ballistic, Aramid; e

- MIL-PRF-46108C - Armor: Transparent. 
- Norma do Instituto de Justiça Americano, NIJ 0108.01 - Ballistic Resistance of Protective Materials;

- Norma do Instituto de Justiça Americano, NIJ 0106.01 - Ballistic Helmets;

- Normas do Instituto de Justiça Americano, NIJ 0101.04 e 0101.06 Ballistic Resistance of Personal Body Armor (74, 69). Essas normas são utilizadas pelas agências de segurança dos EUA para testar coletes balísticos, assim como o Brasil também segue essas orientações para teste e homologação de equipamentos de proteção balística.

Existe ainda a Norma Brasileira ABNT 15000 (70), que classifica as blindagens para impactos balísticos e fixa critérios de avaliação. Essa norma é baseada na NIJ 0101.04, apresentando pequenas variações na tolerância das velocidades de teste, especificando munições mais comuns presentes no território brasileiro, e destina-se às placas balísticas em geral (opacas e transparentes), não sendo específica para coletes.

O quesito mais importante para uma proteção balística pessoal é conseguir parar completamente o projetil. Porém, somente esse fator não implica que essa placa seria capaz de salvar vidas. Back-face signature (BFS) ou ainda back-face deformation (BFD), trata-se da deformação máxima imposta à face posterior, sendo este um parâmetro adicional para a certificação de blindagens. Atualmente, a deformação tolerável da face posterior de um sistema balístico é de $44 \mathrm{~mm}(60)$.

De acordo com Chagas (2014), existem diferentes critérios para se considerar se um anteparo sofreu perfuração. A designação de Critério do Exército, menciona que essa perfuração se dá quando é possível a passagem de luz visível através de um orifício produzido pelo impacto do projétil ou ainda quando a ponta do mesmo se torna visível aflorando na face posterior da blindagem (75).

A deformação da face posterior corresponde à profundidade da depressão causada na massa de apoio, geralmente a plastilina, decorrente de um impacto de projetil que não perfurou a blindagem (ocorreu apenas a penetração parcial). A medição da deformação deve ser realizada a partir do plano definido pela borda frontal da massa de plastilina (74).

As propriedades desse material tem extrema relevância, pois influenciam diretamente no valor de deformação a ser medido, sendo necessário que a plastilina passe por uma validação de consistência através do procedimento de Teste de Queda antes do ensaio balístico. O emprego desse material visa padronizar o procedimento para medição do trauma causado pelo impacto, porém a medida gerada não reflete o que seria a deformação física no torso humano (74). 
Segundo a Norma NIJ 0101.04, a validação para o emprego da plastilina deve ocorrer utilizando-se do material e especificações técnicas abaixo:

- esfera de aço com $63,5 \mathrm{~mm} \pm 0,05 \mathrm{~mm}$ de diâmetro e $1043 \mathrm{~g} \pm 5 \mathrm{~g}$;

- altura de queda de $2,0 \mathrm{~m}$;

- distância mínima de $76 \mathrm{~mm}$ entre os pontos de impacto e as extremidades da caixa, e de $152 \mathrm{~mm}$ entre os centro de cada um dos cinco pontos de impacto;

- média aritmética das cinco medições da profundidade deve ser de $19 \mathrm{~mm}$ $\pm 2 \mathrm{~mm}$, além de nenhuma das deformações poder superar $22 \mathrm{~mm}$ e ser inferior a $16 \mathrm{~mm}$.

Rodríguez-Millán et al. (2016) relatam o emprego de plastilina para levantar informações de ensaios balísticos em placas compósitas. O trabalho experimental dos testes de impacto forneceu dados reais para comparação com modelos numéricos desenvolvidos por meio de elementos finitos, possibilitando a comprovação e precisão desses modelos. O estudo visava otimizar conjuntamente a resistência balística e a redução de peso das soluções (76).

Segundo Medvedovski (2010), a plastilina disposta na parte posterior de uma placa balística é capaz de registrar a deformação transitória dessa placa após o impacto, permitindo que se avalie o desempenho e eficiência de protótipos de novas soluções em estudo (77).

Com o papel de assegurar o controle de qualidade das blindagens atuais, são empregados testes balísticos para certificar novas proteções apenas se essas soluções atenderem a uma série de requisitos. Um desses testes tem como pontos primordiais a necessidade de evitar a perfuração e de manter o valor BFS dentro do limite previsto. Essa dupla função é verificada no Teste de Resistência Balística, que pode ser referenciado como teste de PenetrationBack-face signature (P-BFS), ou seja, de resistência à penetração e deformação da face posterior.

O ensaio de P-BFS serve para aprovar ou reprovar as blindagens avaliadas, para um nível de ameaça específico. Porém, com o objetivo de classificar as mesmas por desempenho e ordená-las de acordo com sua resistência, existe o ensaio conhecido por Teste de Limite Balístico $V_{50}$.

Esse teste foi projetado para estimar estatisticamente a resistência de uma blindagem à perfuração. Visa apresentar um valor quantitativo de eficiência para a proteção balística, valor esse que referencia uma velocidade $\left(V_{50}\right)$ na qual a probabilidade de ocorrer a perfuração do alvo é de $50 \%$.

Dentre os demais procedimentos para os ensaios balísticos, as condições ambientais para a realização dos testes também são pré-determinadas (74): 
- Temperatura de $21^{\circ} \mathrm{C} \pm 2,9^{\circ} \mathrm{C}$

- Umidade relativa de $50 \% \pm 20 \%$.

Tanto os ensaios de resistência balística, quanto o de limite balístico $V_{50}$ foram realizados empregando o esquema da linha de tiro exposta na Figura $2.9(78)$.

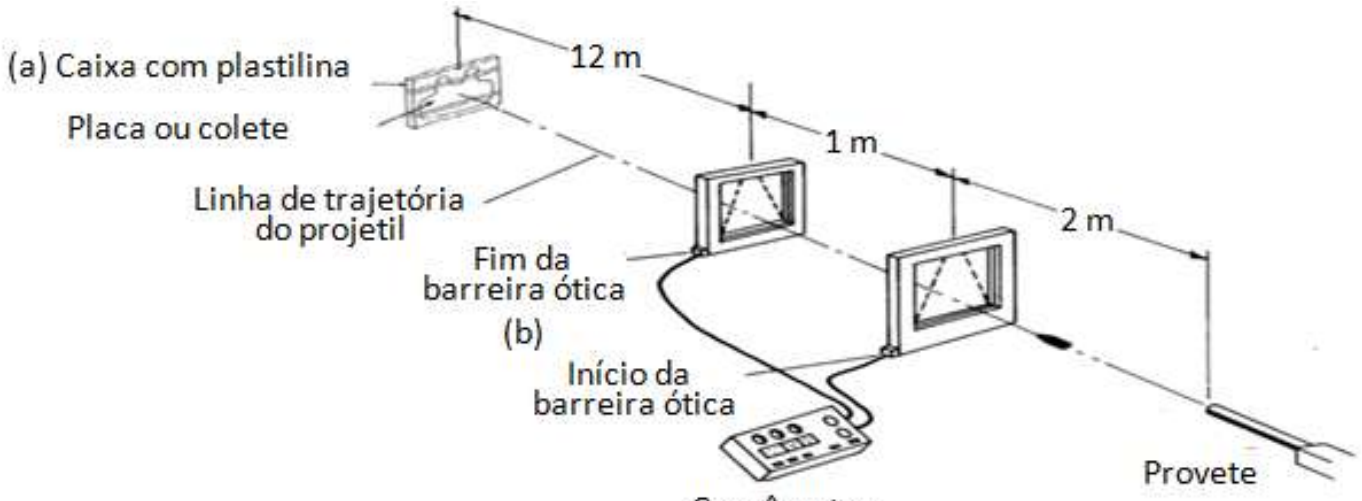

Figura 2.9: Esquema da linha de tiro do ensaio balístico.

Pode-se ressaltar ainda um parâmetro que permite comparar a efetividade balística de uma proteção com outras soluções (somente adotando uma ameaça pré-definida), a Densidade de Área (67), ou Densidade Superficial (Areal Density), chamada neste trabalho de $D / A$.

Esse fator é determinado pela massa do material empregado na blindagem por unidade de área, expresso em $\mathrm{kg} / \mathrm{m}^{2}$ ou $\mathrm{g} / \mathrm{cm}^{2}$, sendo capaz de quantificar comparativamente duas soluções sob o mesmo nível de ameaça.

Segundo Breeze et al. (2017), o disparo de uma arma de fogo seguido pelo impulso do projetil, e consequente voo do mesmo, pode ser estudado por uma disciplina científica chamada de Balística. Esta pode ser dividida em quatro áreas: a balística interna aborda o comportamento do projetil dentro da arma, a balística intermediária que cobre a área em que o projetil deixa o cano antes de entrar no voo livre coberto pela área seguinte, a balística externa, e por fim a balística terminal, que descreve o comportamento dos projetis quando atingem um alvo.

A parte final da balística externa e sua transição para a balística terminal, são de maior interesse, pois abordam fatores que contribuem para a interação entre os projetis e os anteparos balísticos reforçados com fibras. O alvo deve ser capaz de absorver e dissipar a energia cinética do projetil, sem projetar excesso de deformação para a face posterior (79), 
Devido à alta velocidade de um disparo de fuzil, mais de $800 \mathrm{~m} / \mathrm{s}$, o nível de energia cinética que um projetil com cerca de $9 \mathrm{~g}$ transporta (considerando a translação do mesmo), pode ser dado pela Equação 2-13.

$$
E_{c}=m V^{2} / 2
$$

onde $m$ seria a massa do projetil, $V$ a velocidade do mesmo na fase final da balística externa, início da balística terminal. De acordo com os valores aproximados mencionados acima, a $E_{c}$ seria de quase $3000 \mathrm{~J}$ (joules $=\mathrm{kg} \cdot \mathrm{m} / \mathrm{s}^{2}$ ).

Para fins de comparação, este valor seria equivalente à energia cinética de uma pessoa de $60 \mathrm{~kg}$ se deslocando a $10 \mathrm{~m} / \mathrm{s}(36 \mathrm{~km} / \mathrm{h})$, ou à energia dessa mesma pessoa ao tocar o solo, caindo de uma altura de 5 metros. Destacando que esse valor de energia cinética, no caso do projetil 7,62 $\mathrm{mm}$, normalmente é transferido ao alvo em uma área muito reduzida, na qual a seção reta projetada tem menos de $0,5 \mathrm{~cm}^{2}$.

Um projetil FMJ tem maior possibilidade de perfuração, porém normalmente gera menor trauma posterior. De forma contrária, um projetil de chumbo, com pouca ou nenhuma cobertura metálica, terá menos possibilidades de perfurar uma placa, entretanto irá gerar maior trauma posterior (67).

Carr \& Mabbott (2017) mencionam que as munições FMJ tendem a não se deformar muito durante o impacto ao perfurar tecidos não-resistentes (pele, músculo e outros tipos de tecido orgânico), geralmente resultando na perfuração completa do alvo. Já os projetis parcialmente encamisados são tipicamente revestidos a partir da base, deixando parte do núcleo exposta na ponta, o que facilita a expansão do projetil durante o impacto, resultando em maior transferência de energia cinética no início do evento de perfuração daqueles tipos de tecido, bem como profundidades menores de penetração do que as típicas dos projetis FMJ (71).

De acordo com Hamouda \& Risby (2006), o fenômeno da deformação de projetis durante a penetração em colete balístico reforçado com fibra de alto desempenho é complexo. A compreensão desse fenômeno é importante durante a pesquisa e desenvolvimento de um sistema de proteção balística, de forma a obter melhor eficiência na contenção do projetil.

Segundo Bhatnagar \& Risby (2006), as munições de fuzil começam a se deformar assim que penetram na primeira camada do colete reforçado com fibra, sendo esta deformação influenciada por vários fatores, que são interdependentes e complicado distinguir o reflexo de cada um deles no processo.

Entretanto, alguns efeitos importantes são consequência dos principais parâmetros: tipo de fibras de alto desempenho, orientação das fibras em relação 
às fibras adjacentes e em relação à direção do disparo, a força de ligação mecânica ou química entre as fibras, o número de camadas na blindagem e processo de consolidação das camadas desses materiais (67).

Para verificar o comportamento de novos materiais sob impacto balístico, é necessário realizar ensaios reais. Tanto os testes de Resistência Balística quanto o de Velocidade Limite $V_{50}$ demandam as seguintes condições em comum:

- Quando a blindagem for especificada para o Nível III de proteção, os impactos balísticos vão utilizar a munição 7,62 x $51 \mathrm{~mm}$;

- A munição será disparada por um dispositivo de ensaio balístico que replica as condições de disparo de um arma real, com mesmo raiamento, perfil e comprimento de cano, chamado de provete (70);

- A face frontal da placa deve ser marcada por seis pontos para receber os impactos, que devem ser espaçados uniformemente. Os pontos devem seguir o critério de espaçamento mínimo de $76 \mathrm{~mm}$ de qualquer borda ao centro e de $51 \mathrm{~mm}$ de qualquer impacto anterior;

- Duas placas para o ensaio de P-BFS e ao menos uma para a determinação do Limite Balístico $V_{50}$, com dimensões de no mínimo 254 mm x $305 \mathrm{~mm}$;

- Sequência de tiros de seis disparos, em direção ortogonal à face das placas;

- O impacto para ser aceitável / válido deve ter provete, munição, bem como a massa e a velocidade do projetil, de acordo com o especificado na TABELA 2.7, para o Nível de proteção III. O CP deve ser atingido em um ponto conforme a tolerância mencionada anteriormente.

\subsection{1}

\section{Ensaio de Resistência Balística}

Baseado na norma NIJ 0101.04 (74), o ensaio de Resistência Balística é um procedimento de teste formal que deve verificar a penetração e o trauma posterior (P-BFS), conforme procedimentos descritos na seção anterior.

O teste mede a BFS de forma indireta, com o auxílio da deformação transferida para uma caixa de plastilina. Essa caixa fica em contato direto com a superfície posterior da placa que recebe os disparos. 


\subsection{2}

\section{Ensaio de Limite Balístico (V50)}

Para o ensaio de Limite Balístico deve-se buscar um total de 6 disparos. A $V_{50}$ pode ser definida como a média aritmética de uma mesma quantidade de impactos entre penetrações e disparos retidos, sendo calculada com as mais altas velocidades dos disparos retidos na placa, e com as menores velocidades que causaram penetração. Na condição ideal seriam 3 perfurações e 3 projetis retidos.

Pode-se considerar um resultado válido se for possível calcular com pelo menos duas velocidades de perfuração e duas de projetis parados pela placa. O intervalo de velocidade máximo permitido depende do material da blindagem e das condições de teste.

Para iniciar a sequência do ensaio a velocidade inferior do projetil deverá estar próxima do valor superior da tolerância da velocidade de referência, cerca de $853 \mathrm{~m} / \mathrm{s}$. A técnica a ser empregada é denominada up and down, que consiste em variações de velocidades normalmente com os valores de 18, 27, 30 e $38 \mathrm{~m} / \mathrm{s}$, aumentando a mesma para se obter uma perfuração, e em seguida reduzi-la para que não haja a penetração (73).

\section{6}

\section{Análise de imagens em ultra alta velocidade}

De acordo com Meyers (1994), o estudo de eventos que envolvem fenômenos de curta duração e alta velocidade, como impactos balísticos, demandam técnicas de medição que permitam registrar os dados de forma compatível, pois para a maioria desses eventos dinâmicos, a pura observação sem equipamentos não agrega informações, pois só se verifica um brilho ou um estrondo.

A sequência de eventos em processos dinâmicos pode ter as imagens registradas por vários métodos cinematográficos como fotografias ou câmeras de video de alta velocidade ou ainda radiografias em flash. Os seres humanos conseguem distinguir, sem o auxílio de lentes ou de instrumentos óticos, eventos rápidos com duração de cerca de $5 \cdot 10^{-2} s$, as câmeras mais rápidas tem tempos de resolução de até $10^{-13} s(65)$.

A pesquisa de Wang et al. (2014) revela o emprego da análise de imagens de câmera de alta velocidade para identificar os fenômenos decorrentes do impacto em variadas velocidades em espumas de células fechadas de alumínio. Essa ferramenta possibilitou identificar os eventos mecânicos e o modo de falha presente nas variadas condições (80).

De acordo com Liu et al. (2014), o estudo com câmeras de alta velocidade permitiu identificar a sequência de deslocamentos da gelatina balística que 
suportava uma blindagem flexível durante o impacto de um projetil, assim como verificar a distribuição das ondas de pressão na amostra (81).

O estudo de Li et al. (2018) apresentou imagens de alta velocidade de uma amostra laminada de titânio e compósito polimérico reforçado por fibra de carbono impactada a $203 \mathrm{~m} / \mathrm{s}$. Essa ferramenta de análise permitiu identificar a sequência de eventos ao longo da penetração do projetil esférico no painel, como o surgimento de trincas, revelando o comportamento do titânio, e a ignição da camada de compósito, demonstrando o inflamabilidade do material, observações essas que validam a importância do emprego da câmera de alta velocidade (82).

Cada vez é mais frequente o emprego de câmeras de alta velocidade nas pesquisas sobre impactos balísticos e eventos de cura duração, que se mostram eficientes para visualização e entendimento e mensuração dos fenômenos decorrentes $(30,83,84,85,86,87)$.

\section{7}

\section{Espectroscopia}

\subsection{1}

\section{Espectroscopia no Infravermelho com Transformada de Fourier (FTIR)}

Trata-se de uma técnica analítica de espectroscopia vibracional de absorção para obter informações moleculares sobre a composição da superfície dos materiais, e capaz de fornecer informações qualitativas e quantitativas relacionadas à composição química.

Os espectrômetros de infravermelho são capazes de analisar o sinal dentro da faixa de comprimento de onda de 30 a $3.10^{4} \mathrm{~cm}^{-1}$, correspondentes a períodos de vibração molecular entre $10^{-12} s$ e $10^{-15} s$. Dessa forma, a espectroscopia de infravermelho permite o estudo de estrutura molecular em uma escala de tempo muito reduzida em comparação com outras técnicas de análise (88).

O ensaio por Espectroscopia no Infravermelho com Transformada de Fourier (FTIR) consegue captar mudanças nos momentos dipolares dos grupos vibracionais das moléculas e, consequentemente, produz informações úteis para a identificação dos componentes dos compósitos e polímeros. Essas informações são únicas para cada material, e este ensaio pode avaliar gases, líquidos e sólidos.

Avanços da tecnologia possibilitaram o desenvolvimento do FTIR, pois essa técnica é realizada com apoio de computador para rápida varredura e armazenamento de espectros de infravermelho (IR). As múltiplas varreduras 
e a aplicação da transformada de Fourier aos espectros de IR aprimoram a relação sinal-ruído e fornecem espectros otimizados para interpretação (3).

A qualidade da análise é dependente da composição dos materiais e diretamente relacionada aos cuidados tomados durante a preparação da amostra.

Empregando ainda a técnica de Refletância Total Atenuada (ATR), podese obter as frequências vibracionais presentes nas amostras, possibilitando o estudo da constituição de compósitos, bem como alterações nas ligações químicas e estruturas do material decorrentes de processamento ou variação de temperatura (89).

O trabalho de Fejdyś et al. (2016) demonstra a aplicação da técnica de FTIR por ATR para estudar compósitos balísticos. Esta pesquisa comparou, dentre outros materiais, três tipos de prepregs de UHMWPE do fabricante DSM Company: Dyneema ${ }^{\circledR}$ SB21, Dyneema ${ }^{\circledR}$ SB51, e o Dyneema ${ }^{\circledR}$ HB26.

O Dyneema ${ }^{\circledR}$ HB26 apresenta espectros de FTIR por ATR com bandas de absorção correspondentes à vibração das seguintes composições moleculares: $C-H_{2}\left(2911 \mathrm{~cm}^{-1}, 2845 \mathrm{~cm}^{-1}, 1470 \mathrm{~cm}^{-1}, 730 \mathrm{~cm}^{-1}\right), C-H_{3}\left(1370 \mathrm{~cm}^{-1}\right.$, $\left.1340 \mathrm{~cm}^{-1}\right), C-O-C\left(1100 \mathrm{~cm}^{-1}\right)$. No decorrer de análises, o HB26 indicou a presença de polietileno, sendo que o espectro aponta uma banda característica intensa em $1100 \mathrm{~cm}^{-1}$, provavelmente associada à vibração de alongamento da ligação $C=O$. O átomo de oxigênio gera mudança na frequência de absorção dos grupos $\mathrm{C}-\mathrm{H}_{2}$ vizinhos em relação às suas posições nos hidrocarbonetos, conforme evidenciado pela banda em $1520 \mathrm{~cm}^{-1}$, correspondendo à vibração de deformação no plano do grupo metileno (90).

Segundo Zheng et al. (2004), foi possível destacar por FTIR-ATR os seguintes picos de absorção ao analisar de fibras de UHMWPE (SK66 - DSM), no intervalo de 400 a $4000 \mathrm{~cm}^{-1}: 2910 \mathrm{~cm}^{-1}, 2840 \mathrm{~cm}^{-1}, 1464 \mathrm{~cm}^{-1}$ e $720 \mathrm{~cm}^{-1}$, todos atribuídos à forte reflexão do grupo $C-H$, e à pequenas alterações geradas pelo tratamento superficial realizado nas fibras (91).

A técnica de FTIR também pode ser empregada para verificar as modificações decorrentes de tratamentos específicos na superfície de fibras de UHMWPE, de acordo com Silverstein et al. (1994), visando o aumento da adesividade dessa fibra às matrizes (92).

Esse tipo de análise pode contribuir ainda para a caracterização de espumas, no que tange à composição química e grau de reticulação dos polímeros constituintes. De acordo com Tang et al. (2017), que estudou os espectros de FTIR de tipos diferentes de espumas para amortecimento de impacto, é possível observar similaridades ou diferenças nos espectros desses materiais, de forma a identificar constituintes presentes e tipos de ligações dos polímeros. 
Segundo Tang et al. (2017), em pesquisa envolvendo as espumas comerciais D3O ${ }^{\circledR}$ (D3O, Reino Unido) e Poron $\mathrm{XRD}^{\circledR}$ (similar ao modelo utilizado nesta tese), revelou que a banda de absorção localizada $3325 \mathrm{~cm}^{-1}$ é atribuída à vibração de alongamento das ligações $N-H$. A banda de absorção $1725 \mathrm{~cm}^{-1}$ é atribuída à vibração de alongamento das ligações $C=O$. A banda de absorção $1530 \mathrm{~cm}^{-1}$ corresponde à deformação das ligações $N-H$. A banda de absorção $1217 \mathrm{~cm}^{-1}$ é atribuída à vibração assimétrica de alongamento das ligações $C-O-C$. Estes resultados indicam que D3O ${ }^{\circledR}$ e Poron $\mathrm{XRD}^{\circledR}$ são espumas de poliuretano (47).

Outra opção para o emprego do FTIR é para avaliar a eficiência do reforço de compósitos de polietileno de alta densidade. Esse reforço é possível com a adição de fibras, visando melhorar as propriedades mecânicas do compósito final, como resistência à tração, flexão e impacto. A espectroscopia é eficaz para analisar as modificações na superfície das fibras que acarretam a melhoria da compatibilidade interfacial com a matriz (93).

Segundo Sethi \& Ray (2015), os efeitos ambientais em compósitos poliméricos reforçados com fibra podem ser analisados por meio de FTIR. Essa técnica permite verificar alterações causadas na resistência interfacial dos compósitos, decorrente de absorção de água, sendo que essa interdifusão entre fibra e matriz compreende fenômenos físicos, químicos, mecânicos e físico-químicos (94).

Sabe-se que a absorção de moléculas de água nos compósitos poliméricos têm efeitos significativos no desempenho final das estruturas compósitas, especialmente em sua utilização a longo prazo. As forças higrotérmicas resultantes, combinadas com as possíveis tensões residuais, podem ser suficientes para influenciar a falha do compósito laminado e, portanto, não devem ser negligenciadas no projeto do compósito e na estimativa de sua vida útil. Os espectros de FTIR permitem comparar estes materiais antes e após ciclos que causem alterações da presença de água nas camadas do compósito (94).

\section{8}

\section{Análises térmicas}

Os ensaios de análises térmicas compreendem técnicas como: análise termogravimétrica (TGA), análise térmica diferencial (DTA), calorimetria diferencial por varredura ou exploratória (DSC), análise termomecânica (TMA) e análise dinâmico-mecânica (DMA). Estes experimentos são úteis informações relacionadas à composição e processabilidade de resinas (3).

Vivas (2013) caracteriza em seu estudo dois tipos de prepregs balísticos reforçados por fibras de UHMWPE. A respeito das análises térmicas apresen- 
tadas, destaca-se os seguintes valores para o prepreg Dyneema ${ }^{\circledR}$ HB2: temperatura de início de perda de massa $\left(T_{\text {onset }}\right)$ de cerca de $420^{\circ} \mathrm{C}$, temperatura de máxima taxa de perda de massa $\left(T_{d}\right)$ de cerca de $470{ }^{\circ} \mathrm{C}$, temperatura de decomposição entre $480^{\circ} \mathrm{C}$ e $490^{\circ} \mathrm{C}$. O calor de fusão para o polietileno $100 \%$ cristalino foi de $290 \mathrm{~J} / \mathrm{g}(8)$.

Marissen (2011) aponta que a temperatura de fusão típica do UHMWPE não orientado é de cerca de $135{ }^{\circ} \mathrm{C}$. No entanto, quando o material apresenta extrema orientação longitudinal das cadeias moleculares, como no caso das fibras Dyneema ${ }^{\circledR}$ de seu estudo, ocorre o aumento do ponto de fusão, até cerca de $150^{\circ} \mathrm{C}$, dependendo da morfologia da estrutura cristalina.

\subsection{1}

\section{Calorimetria exploratória diferencial (DSC)}

DSC é uma técnica de análise térmica na qual as diferenças de energia no fluxo de calor da substância é medido em função da temperatura da amostra, enquanto a mesma está submetida a um ciclo de temperatura programado

Por meio dessa técnica pode-se determinar: a temperatura de transição vítrea $\left(T_{g}\right)$, a quantidade de energia $(\mathrm{J} / \mathrm{g})$ que uma amostra absorve durante a fusão $\left(\Delta H_{m}\right)$, a temperatura ou ponto de fusão $\left(T_{m}\right)$, a temperatura de início de transição $\left(\mathrm{T}_{\text {onset }}\right)$, bem como o percentual de cristalinidade $\left(X_{c}\right)$ do material. É necessário que a amostra tenha massa de cerca de 10 a 15 mg. Os procedimentos gerais para o ensaio com fibras orgânicas estão descritos na norma ASTM D $3418(95,3)$.

O cálculo do grau de cristalinidade $\left(X_{c}\right)$ das diferentes amostras por meio da equação 2-14:

$$
X_{c}(\%)=\frac{\Delta H_{m}}{\Delta H_{100 \% \text { crist }}^{*}} .100
$$

$\Delta H_{100 \% \text { crist }}^{*}=$ calor de fusão para o material $100 \%$ cristalino

Considerado $\Delta H_{100 \% \text { crist }}^{*}$ igual a: $291 \mathrm{~J} / \mathrm{g}$ para o UHMWPE (96).

Segundo Deng \& Uhrich (1997), as propriedades térmicas dos materiais podem ser analisadas por DSC devido à simplicidade e devido à pequena amostra necessária para tal. No entanto, dados de DSC publicados sobre o UHMWPE demonstram uma grande variação, como para $X_{c}$, que tem resultados de $30 \%$ a $88 \%$, e $T_{m}$ com diferença superior a $10{ }^{\circ} \mathrm{C}(97)$.

\subsection{2}

\section{Análise termogravimétrica (TGA)}

A análise termogravimétrica monitora a variação de massa de uma amostra em função de mudança controlada de temperatura. Esse ensaio, embora seja 
empregado de forma mais frequente para estudar os processos de degradação, também pode ser aplicado como uma técnica de controle de qualidade e identificação, fornecendo informações sobre o teor de voláteis, resina, fibra e resíduos inorgânicos de materiais pré-impregnados. A composição desses materiais pode ser determinada porque seus constituintes geralmente se degradam e volatilizam em diferentes temperaturas e taxas, refletindo nos termogramas ou curvas de decomposição térmica, que são gráficos da massa ou do percentual da massa em função do tempo. (3).

Um recurso possível de ser explorado na análise de dados de TGA é o cálculo da Derivada da Curva de Termogravimetria (DTG). Por meio da DTG, pode-se obter curvas que correspondem à primeira derivada da curva de TG e nas quais as mudanças de coeficiente angular são substituídos por picos que delimitam áreas proporcionais às variações de massa sofridas pela amostra.

A análise da curva de DTG aponta com exatidão as temperaturas correspondentes ao início e ao patamar no qual a velocidade de reação é máxima. Picos definidos permitem distinguir uma sequência de reações que frequentemente não se fazem distinguíveis nas curvas TGA. Pode-se ainda obter a perda ou ganho de massa da amostra por meio do cálculo das áreas sob as curvas, gerando dados quantitativos.

\section{9 \\ Ensaios mecânicos}

\subsection{1}

\section{Ensaio Mecânico de Tração (EMT) de fibra}

Este é um método de ensaio destrutivo que permite levantar informações sobre o comportamento mecânico das fibras. O EMT permite consiste em se impor uma carga axial trativa ao material, e verificar a reação do mesmo em relação ao alongamento sofrido. Conhecido o diâmetro do material ensaiado se torna possível traçar a curva de tensão-deformação ao longo do tempo do ensaio. Esse método é extremamente útil para avaliar as propriedades das fibras, tais como Limite de Resistência à Tração ( $L R T)$ e Módulo de Elasticidade ou Módulo de Young (E). A norma ASTM C1557 trata do procedimento para realizar a tração em fibras.

Huang et al. (2004) estudou as propriedades dinâmicas de tração de fibras isoladas e de feixe de fibras de UHMWPE, e aplicou os resultados em modelos estatísticos existentes para se comprovar os procedimentos adotados. Houve diversificação de taxas de deformação e de temperaturas durante os ensaios. As curvas de tensão-deformação das amostras foram obtidas com sucesso, assim 
como houve boa consistência entre a modelagem estatística dada por meio da Distribuição de Weibull e os resultados experimentais (14).

A pesquisa de Zheng et al. (2004) analisou fibras de UHMWPE SK66 da Dyneema ${ }^{\circledR}$ após provocar alterações na superfície dessas fibras, visando melhoria das propriedades de adesão a uma resina epóxi vinil éster. Foi verificada a resistência à tração das fibras UHMWPE tratadas, comparando ao material como recebido, e as resistência se manteve próxima à 3, $5 G P a$ (91).

O estudo de Sanborn et al. (2015), comparou a eficiência da realização de ensaio de tração, por preensão direta de fibras de UHMWPE Dyneema ${ }^{\circledR}$ SK76, para diversas velocidades de ensaios, em função do diâmetro e do comprimento das fibras. Foi relatado da dificuldade de fixação por métodos adesivos, devido às propriedades superficiais desse material, comparado a métodos empregados normalmente para outras fibras. Esta pesquisa tinha por objetivo adquirir informações sobre as fibras para emprego em simulações de eventos balísticos (98).

Segundo van der Werff \& Heisserer (2016), as fibras de UHMPWE agregam três fatores: diâmetro extremamente reduzido, altíssima resistência e coeficiente de atrito muito baixo. Essas propriedades combinadas acarretam problemas de fixação (derrapagem, falha da fixação) durante o ensaio de tração da fibra. Para reduzir a ocorrência de falhas, a DSM Dyneema ${ }^{\circledR}$ desenvolveu, juntamente com a Textechno $G m b H$ na Alemanha, garras especiais para serem usadas no ensaio de tração de fibras com a máquina Textechno Favimat (34).

\subsection{2}

\section{Ensaio de Dureza}

Segundo Herrmann (2011) dureza pode ser entendida como a resistência com a qual um corpo contraria a penetração de outro corpo, sendo essa resistência característica do material em decorrência das forças de ligação entre seus átomos e da configuração de sua rede cristalina (99).

O ensaio de dureza quantifica a resistência de um material à deformação plástica localizada. Geralmente essa caracterização é feita com um equipamento chamado durômetro, por meio da indentação na superfície do corpo de prova $(\mathrm{CP})$.

Técnicas de dureza foram desenvolvidas ao longo anos, estabelecendo escalas e formas de se quantificar essa propriedade dos materiais, sendo exemplo de escalas comumente empregadas nos dias atuais: Brinell, Rockwell, Knoop e Vickers.

Dentre as técnicas existentes diferem basicamente: o indentador, a carga, e a taxa de aplicação carga que é aplicada ao corpo de prova. A profundidade ou 
as dimensões laterais da penetração resultante são medidos, sendo relacionado a um valor específico de dureza.

Segundo Hamouda \& Risby (2006), a dureza de uma munição AP (para penetração de blindagem), além da velocidade desse projetil, são fatores importantes para o desempenho contra a blindagem (67).

Deniz (2010) observou em seu estudo sobre simulação de blindagens metálicas que a eficiência da proteção balística das placas modeladas aumentava conjuntamente com o aumento da dureza das mesmas (53).

Siebert (2017) relata ter obtido para a liga de Ti-6Al-4V, fabricada por dois processos diferentes, durezas de $352,5 \mathrm{HV}$ e $326,9 \mathrm{HV}$, o que equivale respectivamente a $36 H R C$ e $33 H R C$ (100).

Lee \& Lin (1998) relatam que submeteram amostras da liga de Ti-6Al$4 \mathrm{~V}$ à encruamento, provocando o endurecimento das mesmas, e obtiveram amostras com $450 H V(46 H R C)$ e $395 H V$ (cerca de $40 H R C$ ), dependendo das temperaturas dos procedimentos. Os melhores resultados de dureza foram obtidos com a deformação plástica em temperaturas abaixo da temperatura de recristalização (101).

Segundo Meyer et al. (2008), a dureza da liga Ti-6Al-4V pode experimentar grande amplitude de valor dependendo do tratamento térmico ao qual o material for submetido, desde aproximados $320 \mathrm{HV}$ para o recozimento e resfriamento ao forno, até cerca de $400 \mathrm{HV}$ para diferentes temperaturas de recozimento, têmpera em água, com posterior envelhecimento (59).

Fedrigo \& Wolfart (2017) realizaram variados tratamentos térmicos com amostras da liga de Ti-6Al-4V visando aumentar a dureza do material. Os autores relatam que após tratamento de solubilização, têmpera em água e envelhecimento, foi possível aumentar a dureza em relação à amostra inicial em $23 \%$, chegando ao valor de $447 H V$, o que corresponde a $45 H R C$ (102).

\subsection{0 \\ Microscopia Ótica (MO)}

O emprego de um microscópio ótico (MO) é bastante útil no estudo e caracterização de materiais. Ressalta-se a importância da aplicação nos exames microestruturais que tornam possível relacionar as propriedades macroscópicas dos materiais com sua estrutura ou ainda a presença de defeitos internos. Podese ainda verificar se um material passou por tratamento térmico, destacar fases ou componentes presentes (42).

Outra capacidade do emprego da microscopia ótica é a de fornecer informações sobre o diâmetro de fibras e a variação no diâmetro ao longo do comprimento das mesmas. O limite de resolução do microscópio ótico 
é de aproximadamente um décimo de um mícron, portanto, estruturas de dimensões inferiores à $0,1 \mu \mathrm{m}$ não podem ser bem caracterizados por este tipo de equipamento (3).

\subsection{1}

\section{Microscopia Eletrônica de Varredura (MEV)}

O microscópio eletrônico de varredura (MEV), é capaz de fornecer características estruturais e de superfície dos materiais. Essa técnica se mostra útil para determinar o diâmetro de fibras e para identificar características morfológicas da estrutura das mesmas ao longo da superfície (3).

Este tipo de microscópio fornece uma resolução muito superior a do microscópio ótico. É viável verificar desde a seção transversal de fibras com diâmetro da ordem de mícrons, até características nanométricas das superfícies desses materiais. Além disso, a grande profundidade de campo fornecida pelo MEV favorece o estudo das características das superfícies e topografia das fibras e compósitos balísticos (3).

Hamouda \& Risby (2006) sugerem a análise por MEV para préimpregnados balísticos para verificar a distribuição de fibras, as características estruturais, possíveis danos decorrentes do processo de fabricação e informações sobre a disposição da matriz nesses materiais. A análise também pode ser utilizada para verificar a presença de impurezas nos prepregs. A técnica de MEV é uma ferramenta importante para fins de projetos de prepregs balísticos visando aplicações específicas (67).

Zheng et al. (2004) estudaram a melhoria das propriedades mecânicas de fibras de UHMWPE por meio de técnicas de tratamento da superfície dessas fibras. Foi analisada a mudança na adesão com a matriz e consequente resistência do compósito, destacando o emprego o MEV (tensão de aceleração de 20 kV e WD = 10) para obter informações sobre alterações físicas e químicas dos materiais (91).

O estudo de Dangsheng (2005) demonstrou por meio do emprego de MEV (tensão de aceleração de 19 kV e ampliação de 3000 vezes) a análise de UHMWPE reforçado por fibras e carbono. Foi estudada a morfologia das superfícies do material reforçado e o desgaste ocorrido em diferentes condições de ensaio (103).

Sui et al. (2009) analisaram a microestrutura na superfície de fratura de amostras de nanocompósitos UHMWPE/HDPE, empregando o MEV (tensão de aceleração de $20 \mathrm{kV}$ ) para entender o comportamento do coeficiente de atrito entre os componentes do material (104).

A técnica de MEV foi utilizada por Ren et al. (2017) para analisar 
fibras UHMWPE, a fim de verificar alterações das propriedades que dependem diretamente de aspectos superficiais, como molhabilidade e adesão. As imagens foram obtidas com uma tensão de feixe de $10 \mathrm{kV}$ e WD de 11 a $13 \mathrm{~mm}$, possibilitando a caracterização do material (105).

Echlin (2009) ressalta a necessidade de realizar o recobrimento com camada metálica de amostras de materiais não condutores de energia antes do emprego da técnica de MEV. Essa atividade visa eliminar o carregamento de elétrons da superfície a ser analisada, sendo que quatro principais fatores que influenciam a taxa de recobrimento, tensão, corrente do plasma, material alvo e natureza do gás inerte (106).

\subsection{2}

\section{Metalografia}

Segundo Yogi et al. (2008), a metalografia pode ser empregada para estudar a constituição, a estrutura e a textura de metais. Esse ensaio analisa o metal sob o enfoque de sua microestrutura, procurando relacioná-la à composição, às propriedades físicas, ao processo de conformação que deu origem à peça em questão, dentre a outros fatores.

Dessa forma, busca-se esclarecer, ou prever o comportamento do metal em uma dada aplicação. O exame metalográfico é feito por meio da análise de seções do material (preparadas com metodologia específica) em um microscópio, após o polimento e ataque químico com reagentes apropriados (107).

De acordo com Nesterenko et al. (2003), para a liga de Ti-6Al-4V, características da microestrutura como tamanho de grão, a distribuição das fases presentes ( $\alpha$ ou $\beta$ ), forma dos grãos primários, textura e fração volumétrica, exercem forte influência sobre propriedades como resistência, ductilidade e tenacidade. A presença de microestrutura lamelar (Figuras 2.10a e 2.10b) ou de grãos da fase $\alpha \operatorname{com} \beta$ intergranular (Figuras 2.10c e 2.10d) tem estreita ligação com os mecanismos de deformação que ocorrem nos materiais (58). 


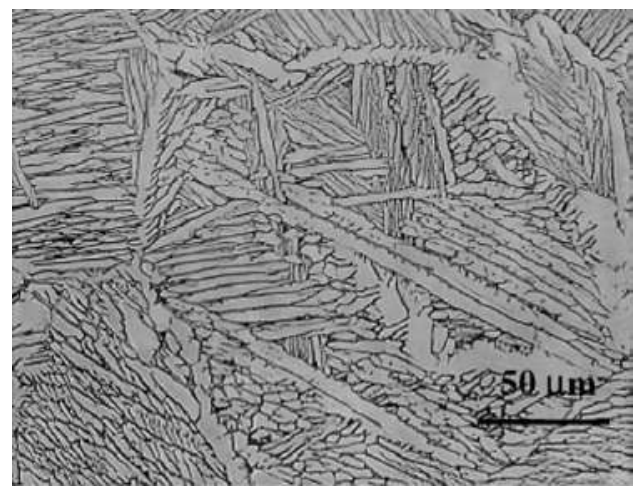

(a) lamelas grosseiras

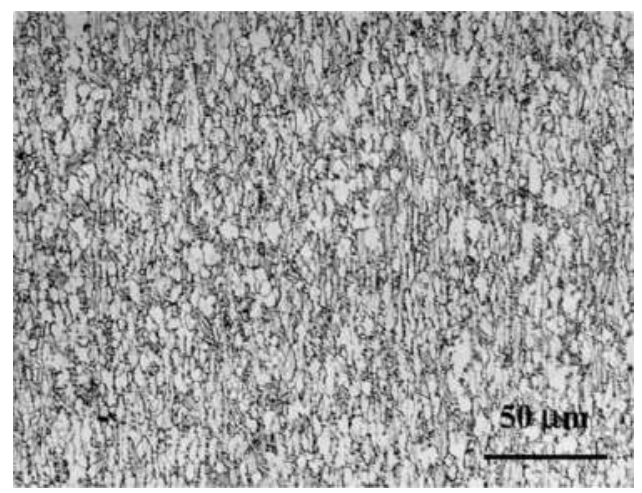

(c) grãos $\alpha$ equiaxiais com $\beta$ intergranular

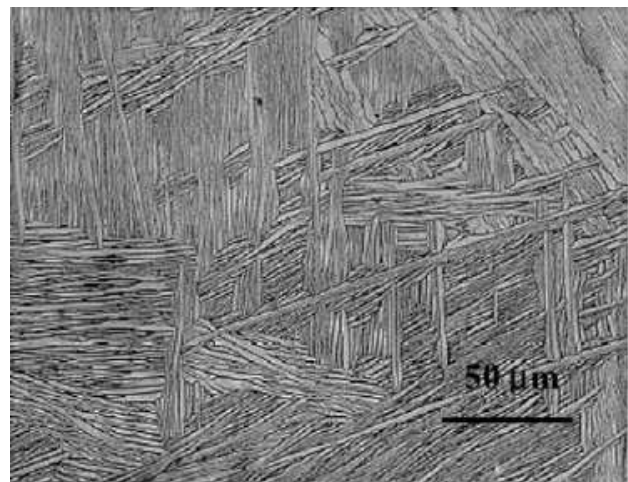

(b) lamelas finas

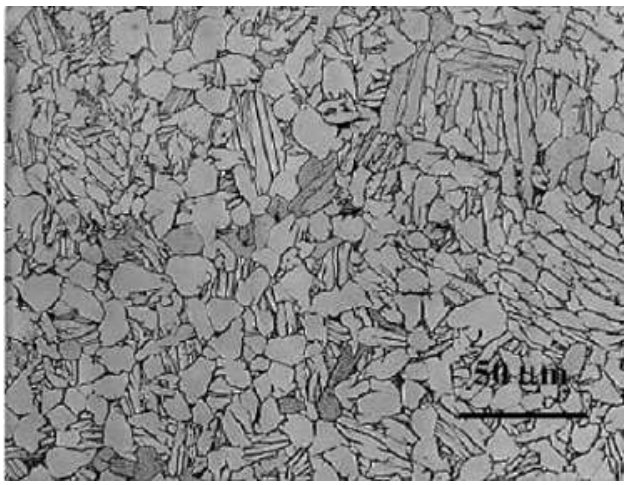

(d) grãos $\alpha$ alongados com $\beta$ intergranular

Figura 2.10: Microestruturas presentes nas ligas Ti-6Al-4V (a) e (b) lamelar, (c) e (d) bimodal.

Meyers \& Chawla (2009) define bandas de cisalhamento adiabático como regiões estreitas onde podem ocorrer redução da resistência e deformação plástica concentrada. A formação das banda de cisalhamento também decorre de operações com alta taxa de deformação, como forjamento e impacto balístico. A microestrutura nas bandas de cisalhamento é distinta da microestrutura do restante do material. No impacto balístico, essas bandas de cisalhamento desempenham um papel importante tanto para a perfuração da blindagem quanto para a quebra dos projetis (108).

Nesterenko et al. (2003) relatam que sob carregamento a alta taxa de deformação, a microestrutura da liga de titânio pode experimentar o surgimento e o crescimento de bandas de cisalhamento adiabático. No Ti-6Al-4V essas bandas podem surgir nas interfaces $\alpha / \beta$ ou na região entre a microestrutura de Widmanstatten e os grãos equiaxiais. Essa propensão ao cisalhamento é um dos principais mecanismos de fratura nas ligas de titânio (58).

Meyer et al. (2008) analisam as diferentes microestruturas da liga de Ti$6 \mathrm{Al}-4 \mathrm{~V}$ obtidas após variados tratamentos térmicos, correlacionando-as com 
propriedades mecânicas apresentadas em ensaios de alta taxa de deformação. Os resultados demonstram forte relação da microestrutura presente com o comportamento do material, destacando a importância do estudo metalográfico do material (59).

Siebert (2017) aborda a necessidade de realizar uma preparação da superfície das seções a serem analisadas por microscopia da liga de Ti-6Al$4 \mathrm{~V}$, a fim e tornar viável a observação da microestrutura presente. O autor destaca o emprego de reagente com a composição de $6 \%$ de ácido nítrico, $3 \%$ de ácido fluorídrico e $100 \mathrm{ml}$ de água, reagente de Kroll, como sendo eficiente para revelar a microestrutura da liga, destacando os contornos de grão (100).

Yogi (2008) mostrou a aplicação de uma variação do reagente de Kroll, com a composição $5 \mathrm{ml}$ de ácido nítrico, $3 \mathrm{ml}$ de ácido fluorídrico e $100 \mathrm{ml}$ de água destilada, e também obteve sucesso ao analisar a microestrutura da liga de titânio (107).

Fedrigo \& Wolfart (2017) realizaram a metalografia da liga Ti-6Al-4V com um variação do reagente de Kroll $\left(2 m l \mathrm{HF}, 6 m l \mathrm{HNO}_{3}, 92 m l \mathrm{H}_{2} \mathrm{O}\right.$ ) e estudaram a microestrutura decorrente de diferentes tratamentos térmicos, visando a caracterização e aumento da dureza do material. Os autores relatam que o tratamento térmico de solubilização (quando realizado abaixo de $995^{\circ} \mathrm{C}$ ), seguido de resfriamento em água, e envelhecimento, produz uma mistura fina das fases $\alpha$ e $\beta$, conhecida por estrutura bimodal, que é caracterizada por propriedades mecânicas elevadas (102).

\subsection{3}

\section{Bases para Análise Estatística}

Segundo Montgomery \& Runger (2003), os métodos estatísticos são ferramenta importante para a concepção e para o desenvolvimento de novos produtos e processos de fabricação, como também tem aplicação fundamental para possibilitar a melhoria de processos existentes.

O campo da estatística envolve também a coleta, a disposição, a análise e o emprego dos dados para embasar a tomada de decisões, facilitar a solução de problemas, e possibilitar a otimização do planejamento de processos (42).

\subsection{1}

\section{Análise de Regressão}

A Análise de Regressão trata-se de uma técnica estatística que permite a pesquisa e modelagem da relação entre duas ou mais variáveis, de forma a buscar a otimização de um processo. Como uma solução balística pode ser composta de diversos materiais, em proporções variadas, e submetida a um 
processo de fabricação com detalhadas configurações (temperatura, pressão, tempo), tem-se amplo campo para aplicação desta técnica visando otimizar a interação entre essas diversos fatores (109).

Montgomery \& Runger (2003) apresentam uma forma de elaborar um modelo e por meio de regressão, sugerir as estimativas dos parâmetros que melhor atendem à solução do problema. Fazem parte desse conjunto de ferramentas, dentre outras, o Método dos Mínimos Quadrados, Teste de Hipóteses, Análise de Variância (ANOVA), Análise Residual, Teste F e o Coeficiente de Determinação $\left(R^{2}\right)$ (109).

De acordo com Deniz (2010), os testes balísticos são parte vital para o desenvolvimento de novas blindagens, no entanto é inviável testar todas as condições, sendo necessário limitar o número de ensaios para reduzir os altos custos envolvidos. Com a maior disponibilidade de computadores de alto desempenho, tem crescido o interesse em estudos de simulação para cortar esses custos (53).

Conforme mencionado, o problema de fabricação de placas balísticas compósitas laminadas agrupa um conjunto de variáveis quantitativas e qualitativas (ou categóricas). Dessa forma se faz necessário abordar o problema empregando um modelo de Regressão Linear Múltipla, no qual tem-se mais de um termo regressor. As variáveis independentes são geralmente chamadas variáveis previsoras ou preditoras. De posse dos dados experimentais do processo, pode-se modelar o mesmo e realizar a análise de regressão com objetivo de chegar a um modelo otimizado.

Um exemplo de equação para modelo de regressão linear múltipla pode ser visto na Equação 2-15, onde $Y$ representa o valor de resposta, $x_{1}, x_{2}$ e demais componentes podem fazer referência às variáveis independentes ou previsoras que afetam o modelo, os parâmetros $\beta_{j}(j=0,1, \ldots, k)$ são chamados de coeficientes de regressão, e o $\epsilon$ é um termo de erro aleatório (109).

$$
Y=\beta_{0}+\beta_{1} x_{1}+\beta_{2} x_{2}+\ldots+\beta_{k} x_{k}+\epsilon
$$

Dal Bello (2010) menciona que o emprego dos fundamentos estatísticos possibilita identificar os fatores de produção denominados de variáveis independentes, fatores estes que podem interferir nas características de qualidade de um processo ou produto, que por sua vez é determinada de variável de resposta. Por meio do emprego de modelos matemáticos é viável mensurar a influência das variáveis independentes sobre a variável de resposta, podendo desses modelos predizer respostas e estimar a média das mesmas (110).

Em uma análise de regressão, o termo Resíduo é definido por estimativas do erro experimental obtido subtraindo as respostas observadas das respostas 
previstas (111).

Montgomery \& Runger (2003) afirmam que pode-se utilizar o método de eliminação Backward para a promover a eliminação de interações e de fatores irrelevantes, obtendo o modelo mais adequado. Esse método começa com o modelo completo que considera todas as variáveis, e gradativamente realiza a remoção dos fatores com $P>0,05$ (não significativas), um por vez, retrocedendo em direção a um número cada vez menor de termos, até restarem apenas os significativos (109).

Segundo Nimon \& Oswald (2013), as ferramentas gráficas complementam os cálculos da análise de regressão, permitindo verificar os pressupostos adotados para a construção do modelo. O gráfico de Dispersão Residual aponta se os resíduos são independentes, caso não haja concentração e/ou Outliers. O gráfico Q-Q (gráfico quantil-quantil) é uma ferramenta que orienta a análise para avaliar se um conjunto de dados de dois quantis provém de uma distribuição Normal, de forma que se os dois conjuntos de pontos se aproximarem da formação de uma linha reta, essa suposição se confirma. Já o gráfico de Histograma de Resíduos deve ser semelhante ao padrão em forma de sino caso os dados sejam normalmente distribuídos (111).

\subsection{2}

\section{Distribuição de Weibull}

A distribuição de Weibull é frequentemente empregada para modelar o comportamento de falha de diferentes sistemas físicos. Durante a análise de um gráfico de probabilidade Weibull, quanto mais os dados se dispuserem ao longo de uma linha reta, mais adequada será a utilização do modelo para os dados analisados (109).

De acordo com Meyers \& Chawla (2009), a variação na resistência de amostras durante ensaios mecânicos pode ser analisada por meio da distribuição de Weibull. O sucesso da distribuição se justifica não só pela sua eficácia, mas também pelo fato de existirem recursos gráficos que facilitam sua interpretação e por ser capaz de predizer com acurácia razoável mesmo quando a quantidade de dados disponível é reduzida (108).

Huang et al. (2004) demonstrou o emprego da distribuição de Weibull na análise das propriedades dinâmicas de tração de fibras UHMWPE em variadas taxas de deformação. Segundo a pesquisa, a função Weibull pode ser usada para representar a distribuição da resistência à tração das fibras UHMWPE, resultante de ensaios de tensão-deformação (14). 


\section{3}

\section{Materiais e Métodos Experimentais}

Neste capítulo serão abordados os materiais que foram empregados para o desenvolvimento desta tese, bem como as metodologias para preparação das amostras e para as análises realizadas.

\section{1}

\section{Aspectos gerais}

A fabricação das placas balísticas foi feita após análise de procedimentos relatados em diversos artigos, relatórios técnicos, e em consonância com as capacidades do equipamento ao qual se obteve acesso. Assim, foram levadas à prensagem a quente dois tipos de prepregs balísticos, chapas metálicas da liga Ti-6Al-4V, e um filme adesivo de poliolefina modificada para união dessas duas camadas.

Posteriormente à prensagem foi incorporado às placas mais uma camada, com a função de redução de trauma da face posterior, constituída de uma lâmina de material polimérico em forma de espuma (dois tipos diferentes). A composição final das placas foi formada por três ou cinco camadas: metal, filme adesivo (alguns CPs não tem essas duas primeiras camadas), compósito de UHMWPE, adesivo (aplicado em spray) e a espuma para redução do trauma.

A Figura 3.1 ilustra a sequência de procedimentos para a preparação, fabricação e teste das placas balísticas.

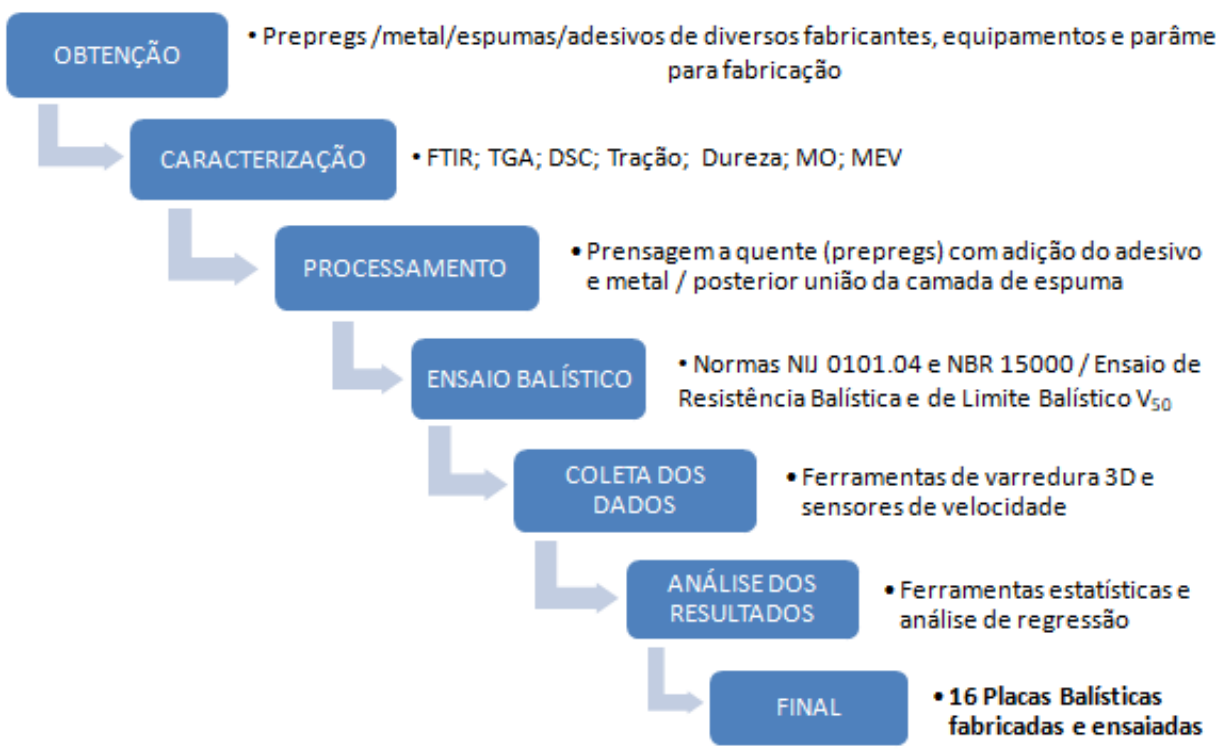

Figura 3.1: Fluxograma para fabricação das placas balísticas. 


\section{2}

\section{Materiais Utilizados}

Como compósito principal foram empregados dois tipos comerciais de prepregs balísticos bidirecionais de fibras de UHMWPE em matriz polimérica (ST-HB13 e HB212, respectivamente da Sarkar Tactical Company e DSM Company). Ocorreu a adição de um chapa metálica da liga Ti-6Al-4V, da empresa ACNIS do Brasil em parte das placas balísticas. Essa união com o UHMWPE ocorreu por meio do filme adesivo de poliolefina modificada (BP21.2008, Pontacol).

Como complemento para a face posterior, com a função de buscar a redução do trauma, houve o confronto entre a utilização de dois tipos de espumas comerciais, a de poliuretano de célula aberta (Poron XRDMA20236-65, Rogers Corporation - EUA), e a espuma flexível de célula fechada PEBD/EVA expandidos tipo A (PEE130AE, Stamp Spumas - Brasil). O Adesivo Spray $3 \mathrm{M}^{\mathrm{TM}} 76$ foi utilizado para a união da face posterior de UHMWPE com as espumas supracitadas.

Os esquemas gráficos expostos nas Figuras 3.2 e 3.3 ilustram os ensaios para os quais se destinaram e a composição dos corpos de prova, respectivamente, de HB212 e de ST-HB13.

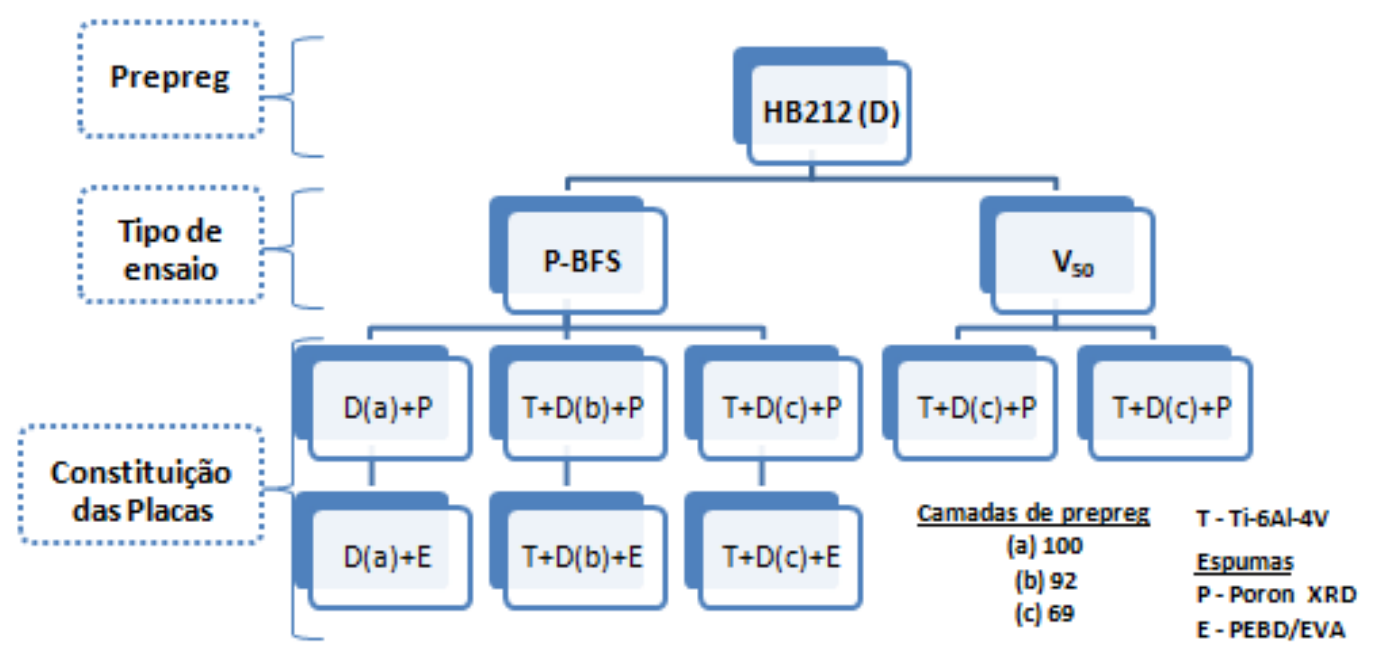

Figura 3.2: Esquema de constituição e ensaio das placas de HB212.

O prepreg ST-HB13, especificado na Tabela $3.1(112,113)$, foi adquirido pelo CTEx no ano de 2017, sendo que esse material já foi recebido cortado em lâminas quadradas com $22 \mathrm{~cm}$ de lado, conforme Figura 3.4a. O prepreg é composto de duas camadas unidirecionais de fibras de UHMWPE na configuração $0^{\circ} / 90^{\circ}$, com filmes poliméricos intercalados entre essas camadas. $\mathrm{O}$ material tem revestimentos diferentes em cada face externa, sendo necessário 


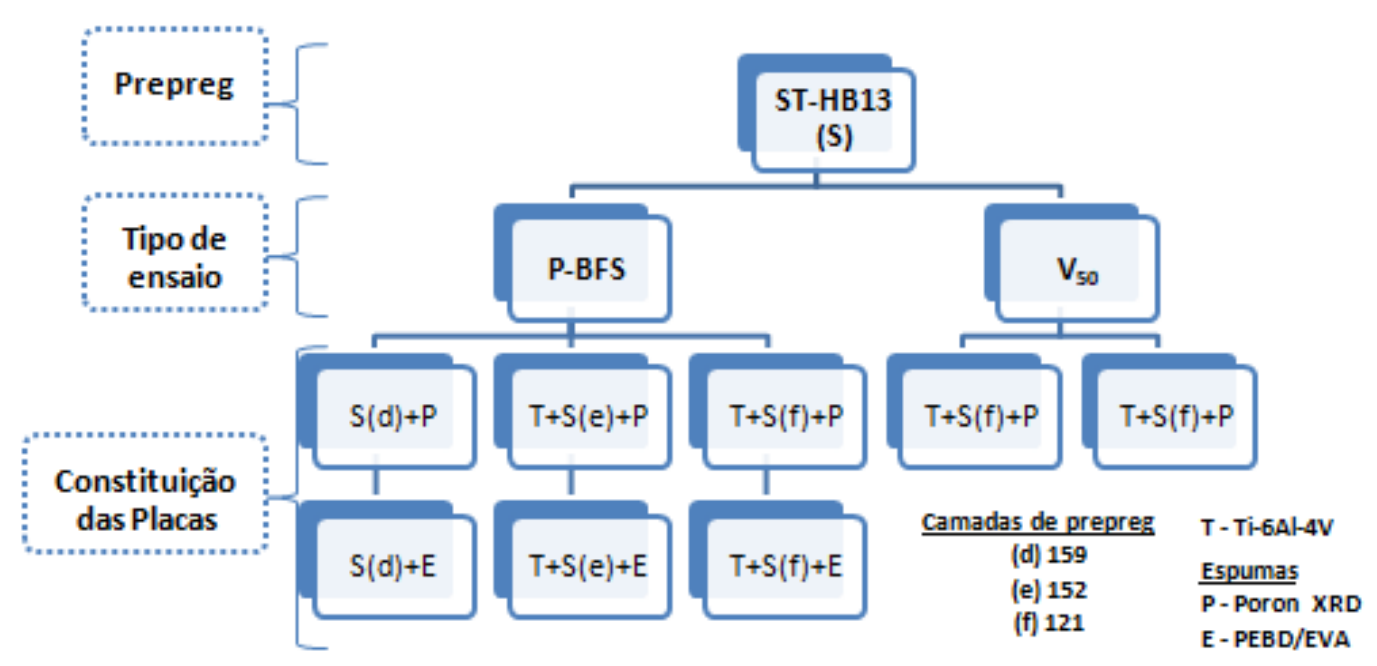

Figura 3.3: Esquema de constituição e ensaio das placas de ST-HB13.

posicionar o lado correto para que ocorra a aderência com as demais lâminas durante a prensagem a quente.

Tabela 3.1: Especificações do compósito ST-HB13.

\begin{tabular}{cccc}
\hline $\begin{array}{c}\text { Densidade de área } \\
\left(\mathrm{g} / \mathrm{m}^{2}\right)\end{array}$ & $\begin{array}{c}\text { Espessura } \\
(\mathrm{mm} / \text { lâmina })\end{array}$ & $\begin{array}{c}\text { Temperatura } \\
\text { de fusão }\left({ }^{\circ} \mathrm{C}\right)\end{array}$ & $\begin{array}{c}\text { Densidade } \\
\left(\mathrm{g} / \mathrm{cm}^{3}\right)\end{array}$ \\
\hline $120 \pm 8$ & $0,15 \pm 0,02$ & 150 a 200 & $0,95 \mathrm{a} 0,98$ \\
\hline Densidade de área indicada para Nível de Blindagem NIJ III $19\left(\mathrm{~kg} / \mathrm{m}^{2}\right)$ \\
\hline
\end{tabular}

Já o segundo prepreg, a DSM Company (EUA) doou em maio de 2018, na quantidade de 644 lâminas do compósito HB212, cujas propriedades estão expostas na Tabela 3.2 (21). O material foi entregue já cortado no tamanho retangular de $26,4 \mathrm{~cm}$ por $31,2 \mathrm{~cm}$, conforme Figura $3.4 \mathrm{~b}$.

Tabela 3.2: Especificações do compósito HB212, DSM Company.

\begin{tabular}{cccc}
\hline $\begin{array}{c}\text { Densidade de } \\
\text { área }\left(\mathrm{g} / \mathbf{m}^{2}\right)\end{array}$ & $\begin{array}{c}\text { Espessura } \\
(\mathbf{m m} / \text { lâmina })\end{array}$ & $\begin{array}{c}\text { Temperatura } \\
\text { de fusão }\left({ }^{\circ} \mathrm{C}\right)\end{array}$ & $\begin{array}{c}\text { Densidade } \\
\left(\mathrm{g} / \mathbf{c m}^{3}\right)\end{array}$ \\
\hline $136 \pm 5$ & $0,21 \pm 2$ & 150 a 200 & 0,95 a 0,98 \\
\hline Densidade de área para Nível de Blindagem NIJ III $13,6\left(\mathrm{~kg} / \mathrm{m}^{2}\right)$ \\
\hline
\end{tabular}




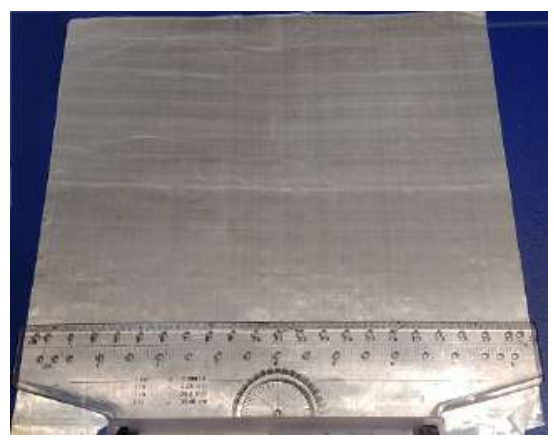

(a) ST-HB13

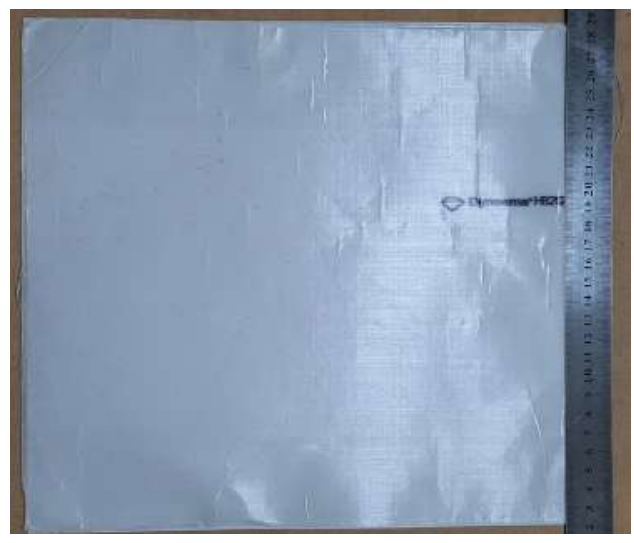

(b) HB212

Figura 3.4: Prepregs balisticos (a) e (b) como recebidos.

Este compósito trata-se de uma lâmina de quatro camadas de fibras de UHMWPE dispostas na configuração $0 \% / 90^{\circ} / 0^{\circ} / 90^{\circ}$, impregnadas por um polímero que compõe a matriz, de nome comercial Kraton, copolímero em tribloco de estireno-isopreno-estireno $(S I S T C)$, sendo que nesse prepreg não há distinção entre faces, podendo ser empilhado para prensagem de forma livre.

Foi adquirida pela PUC/Rio da empresa ACNIS do Brasil em abril de 2019 uma chapa metálica da Liga Ti-6Al-4V ELI, com a dimensão retangular de 100 por $82 \mathrm{~cm}$, e $1 \mathrm{~mm}$ de espessura. A chapa precisou passar por cortes para ficar com as medidas de área dos prepregs balísticos.

A Rogers Company (EUA) forneceu gratuitamente em fevereiro deste ano uma placa da espuma de poliuretano de célula aberta Poron XRDMA-20236, de especificações na Tabela 3.3 (48), com medidas de aproximadamente 137 por $91 \mathrm{~cm}$, e $6 \mathrm{~mm}$ de espessura, conforme Figura 3.5.

Já a espuma de PEBD/EVA de célula fechada, com propriedades da Tabela 3.3 (114) foi doada pela empresa Glágio do Brasil - MG, em maio de 2019, com as dimensões de 100 por $60 \mathrm{~cm}$, e $5 \mathrm{~mm}$ de espessura.

Tabela 3.3: Especificações das espumas Poron XRD e PEBD/EVA.

\begin{tabular}{cccc}
\hline Tipo de célula & $\begin{array}{c}\text { Espessura } \\
(\mathbf{m m})\end{array}$ & $\begin{array}{c}\text { Temperatura } \\
\text { de fusão }\left({ }^{\circ} \mathrm{C}\right)\end{array}$ & $\begin{array}{c}\text { Densidade } \\
\left(\mathbf{k g} / \mathbf{m}^{3}\right)\end{array}$ \\
\hline fechada & 5 & 95 a 110 & 100 a 140 \\
aberta & 6 & 150 a 200 & 320 \\
\hline
\end{tabular}

Foram adquiridos dois frascos do Adesivo Spray 3M $\mathrm{M}^{\mathrm{TM}} 76$ em maio deste ano, por meio da PUC/Rio, em estabelecimento comercial de venda de ferramentas e acessórios. Este adesivo foi escolhido após consulta técnica à empresa fornecedora do prepreg, e também à própria empresa 3M. 


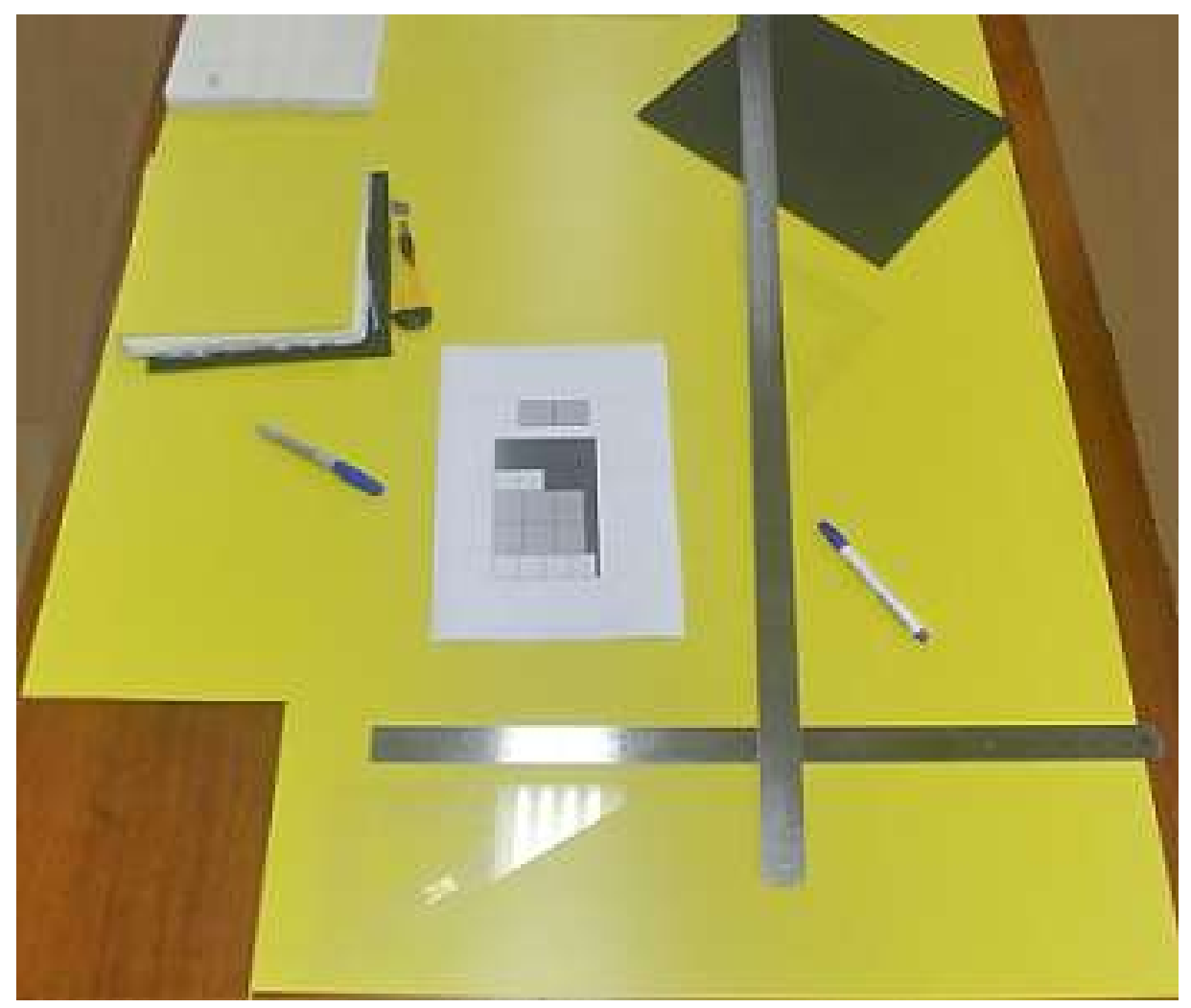

Figura 3.5: Espuma Poron $\mathrm{XRD}^{\circledR}$ para corte.

A empresa Pontacol AG (Suíça) remeteu em maio do corrente ano, a quantidade de 25 folhas do filme adesivo BP21.2008, com 25 por $30 \mathrm{~cm}$.

Os dados técnicos da chapa de titânio e dos adesivos $3 \mathrm{M}^{\mathrm{TM}} 76$ e BP21.2008 constam do Apêndice A, seção A.1, Tabelas A.1, A.2 e A.3, respectivamente.

\section{3}

\section{Fabricação das placas balísticas}

Foi empregada a moldagem por compressão (prensagem) a quente, por meio da prensa hidráulica (de matrizes planas) de capacidade de 400 toneladas (Figura 3.6). Essa operação foi realizada ao longo de dois dias, na empresa Glágio do Brasil - MG.

No primeiro dia foi realizada a separação, contagem, ordenamento e pesagem dos diversos corpos de prova a serem fabricados. Houve ainda um ciclo de prensagem de oito placas, do material HB212. No dia posterior, ocorreu a prensagem das placas de ST-HB13.

A separação e montagem dos materiais das placas balísticas foi realizada de forma que após a fabricação as mesmas obtivessem a configuração constante das Figuras 3.2 e 3.3 . 


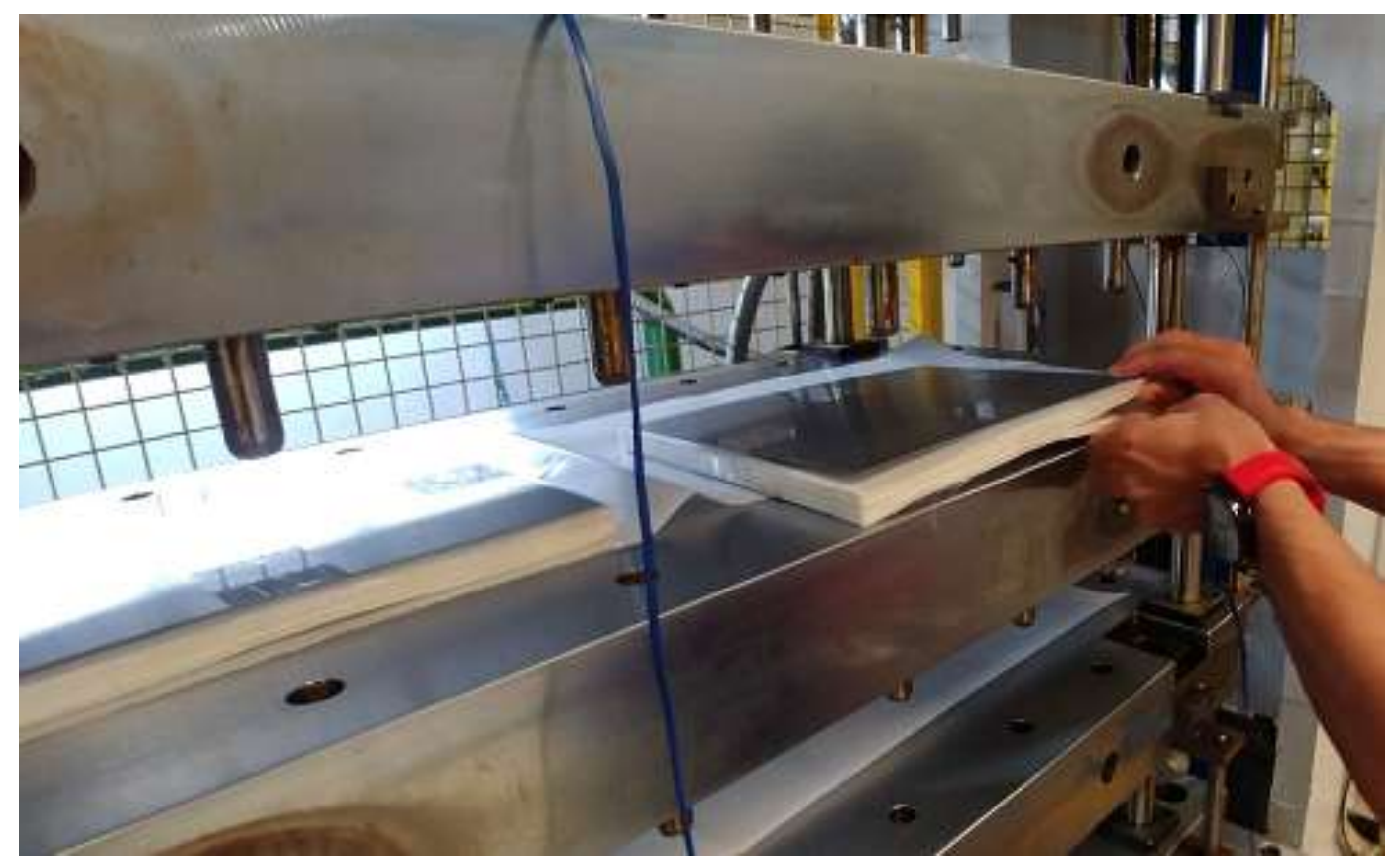

Figura 3.6: Prensa hidráulica utilizada (empresa Glágio do Brasil-BH).

\subsection{1}

\section{Técnica de fabricação}

Optou-se neste estudo por seis diferentes configurações dos conjuntos de prepregs de UHMWPE (com e sem lâmina metálica e adesivo) para formação das placas balísticas. A compactação e cura ocorreu com o controle de temperatura devido à presença de malha de termopares nas matrizes da prensa. Além disso, outros termopares foram posicionados dentro de parte dos compósitos empilhados, possibilitando a análise do perfil de temperatura em função do tempo e da espessura das amostras. Portanto, foram tomadas as medidas necessárias para assegurar o atendimento aos parâmetros da curva de pressão por temperatura desejada.

Os parâmetros iniciais para a prensagem foram obtidos com os fabricantes dos laminados, porém foi realizada uma adequação dos parâmetros em decorrência de particularidade do equipamento empregado. Os prepregs foram empilhados sempre seguindo a configuração $\left[0^{\circ} / 90^{\circ}\right]_{n}$, para que se atinja a resistência balística para Nível III de ameaça. Semelhante ao estudo (90), que apresenta as informações para consolidação de uma placa de Dyneema ${ }^{\circledR}$ HB26, pretende-se, após os ensaios de caracterização, obter dados para compreender as transformações que irão ocorrer durante este processamento.

O gráfico da Figura 3.7 (115) mostra um exemplo típico do ciclo de moldagem por compressão de painéis balísticos rígidos feitos com Dyneema ${ }^{\circledR}$ destinados a barrar munição de fuzil como 7.62x51mm OTAN e 7.62x39mm 
AK47 Kalashnikov com núcleo de aço macio. O gráfico mostra 3 linhas, sendo a primeira (vermelha pontilhada) indicando a temperatura máxima permitida do painel, a segunda (verde) com o perfil de pressão de moldagem que deve ser aplicado ao painel de prepregs HB UD em função do tempo, e por fim a linha que indica o perfil de temperatura (azul) adequado para o núcleo das placas prensadas em função do tempo.

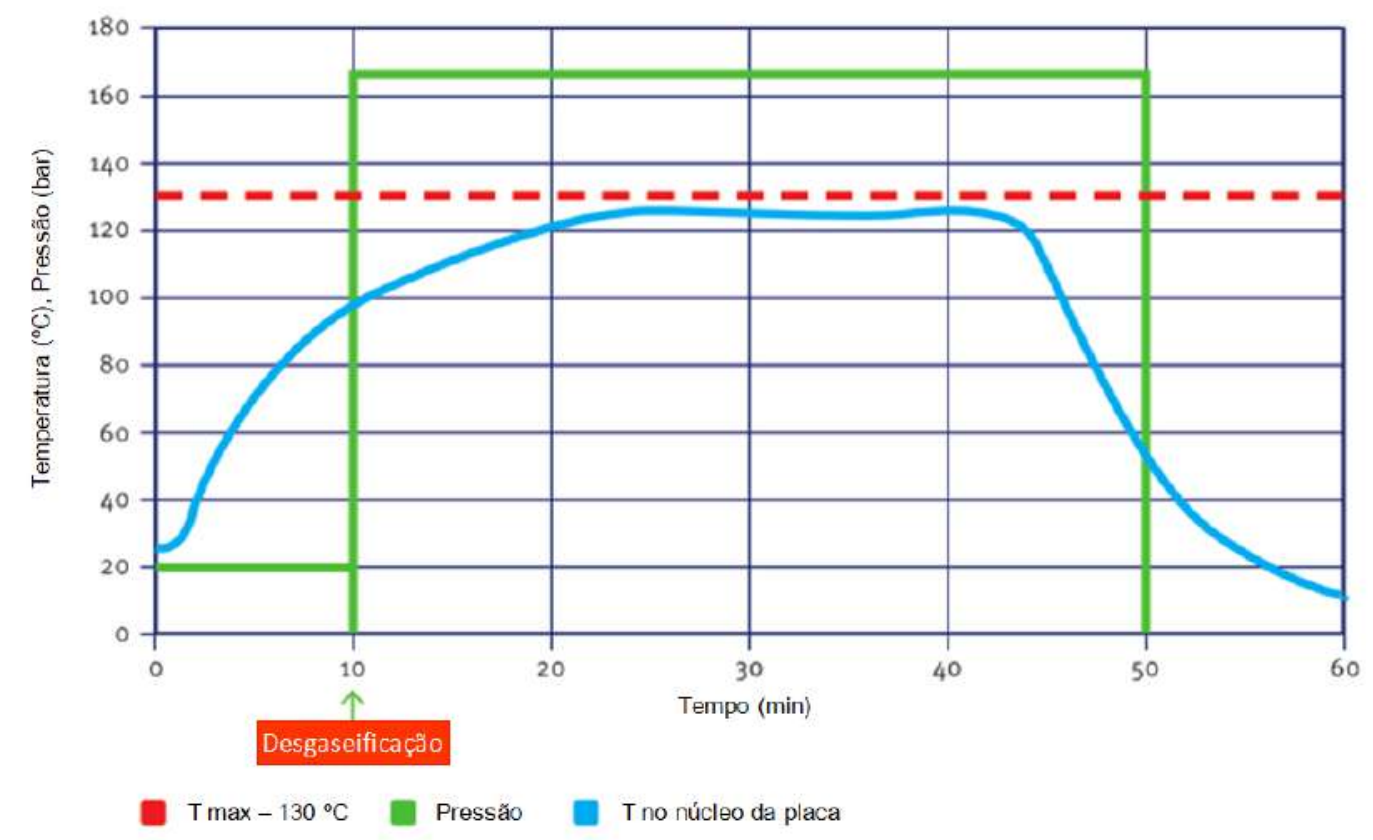

Figura 3.7: Ciclo de prensagem de placas balísticas Nível III.

Como consequência das informações e dos materiais reunidos, foram fabricadas com sucesso o total de 16 placas balísticas, por prensagem a quente, na Empresa Glágio do Brasil. A Tabela 3.4 contém listada a constituição das peças produzidas e o modo como foram avaliadas nesta tese. Está indicado se foi ou não empregada a chapa de liga de titânio na face frontal das placas, e qual a espessura total de cada placa (após a adição da espuma). 
Tabela 3.4: Constituição e finalidade dos Corpos de prova fabricados.

\begin{tabular}{ccccccc}
\hline CP & $\begin{array}{c}\text { Metal } \\
(\mathbf{a})\end{array}$ & $\begin{array}{c}\text { Adesivo } \\
(\mathbf{b})\end{array}$ & Prepreg & $\begin{array}{c}\text { Espessura } \\
\text { total }(\mathbf{m m})\end{array}$ & $\begin{array}{c}\text { Espuma } \\
(\mathbf{c})\end{array}$ & $\begin{array}{c}\text { Emprego } \\
\text { (ensaio) }\end{array}$ \\
\hline 01 & - & - & HB212 & 20,5 & $\mathrm{P}$ & Trauma \\
02 & - & - & HB212 & 19,5 & $\mathrm{E}$ & Trauma \\
03 & $\mathrm{Ti}$ & $\mathrm{BP}$ & HB212 & 20,6 & $\mathrm{P}$ & Trauma \\
04 & $\mathrm{Ti}$ & $\mathrm{BP}$ & HB212 & 19,8 & $\mathrm{E}$ & Trauma \\
05 & $\mathrm{Ti}$ & $\mathrm{BP}$ & HB212 & 17,4 & $\mathrm{P}$ & Trauma \\
06 & $\mathrm{Ti}$ & $\mathrm{BP}$ & HB212 & 17,3 & $\mathrm{P}$ & V50 \\
07 & $\mathrm{Ti}$ & $\mathrm{BP}$ & HB212 & 17,6 & $\mathrm{P}$ & V50 \\
08 & $\mathrm{Ti}$ & $\mathrm{BP}$ & HB212 & 16,9 & $\mathrm{E}$ & Trauma \\
09 & - & - & ST-HB13 & 26,1 & $\mathrm{P}$ & Trauma \\
10 & - & - & ST-HB13 & 25,1 & $\mathrm{E}$ & Trauma \\
11 & $\mathrm{Ti}$ & $\mathrm{BP}$ & ST-HB13 & 26,4 & $\mathrm{P}$ & Trauma \\
12 & $\mathrm{Ti}$ & $\mathrm{BP}$ & ST-HB13 & 25,4 & $\mathrm{E}$ & Trauma \\
13 & $\mathrm{Ti}$ & $\mathrm{BP}$ & ST-HB13 & 22,6 & $\mathrm{P}$ & Trauma \\
14 & $\mathrm{Ti}$ & $\mathrm{BP}$ & ST-HB13 & 22,7 & $\mathrm{P}$ & V50 \\
15 & $\mathrm{Ti}$ & $\mathrm{BP}$ & ST-HB13 & 22,8 & $\mathrm{P}$ & V50 \\
16 & $\mathrm{Ti}$ & $\mathrm{BP}$ & ST-HB13 & 21,8 & $\mathrm{E}$ & Trauma \\
\hline
\end{tabular}

(a) Liga de Ti-6Al-4V com $1 \mathrm{~mm}$ de espessura

(b) BP - Filme adesivo BP21.2008, Pontacol - três camadas

(c) $\mathrm{P}$ - Poron XRD com $6 \mathrm{~mm}$ de espessura

E - PEBD/EVA com $5 \mathrm{~mm}$ de espessura

Devido a restrições do equipamento, as placas deveriam ser prensadas em pares de mesma espessura. Visando melhor consolidação, a operação ocorreu com a configuração de máxima carga do equipamento para o tempo de cura, em ambos os dias.

Nessa pesquisa houve o controle de temperatura, fator crítico para evitar a degradação das propriedades mecânicas das fibras de UHMWPE que reforçam os prepregs, tanto nos moldes quanto em seis das placas fabricadas. A temperatura máxima em momento algum ultrapassou o valor de $130^{\circ} \mathrm{C}$, considerando o controle exposto nas informações das Figuras 3.8a e 3.8b.

Atenção também foi dada ao processo de resfriamento das placas e à temperatura mínima indicada para se aliviar a carga máxima de prensagem. Segundo documentação da empresa DSM (115), somente após a temperatura no interior das placas chegar à $60^{\circ} \mathrm{C}$ a prensa poderia ser aberta. No processamento adotado nesta tese, só houve a redução da carga máxima quando a temperatura do molde chegou à $40^{\circ} \mathrm{C}$. 


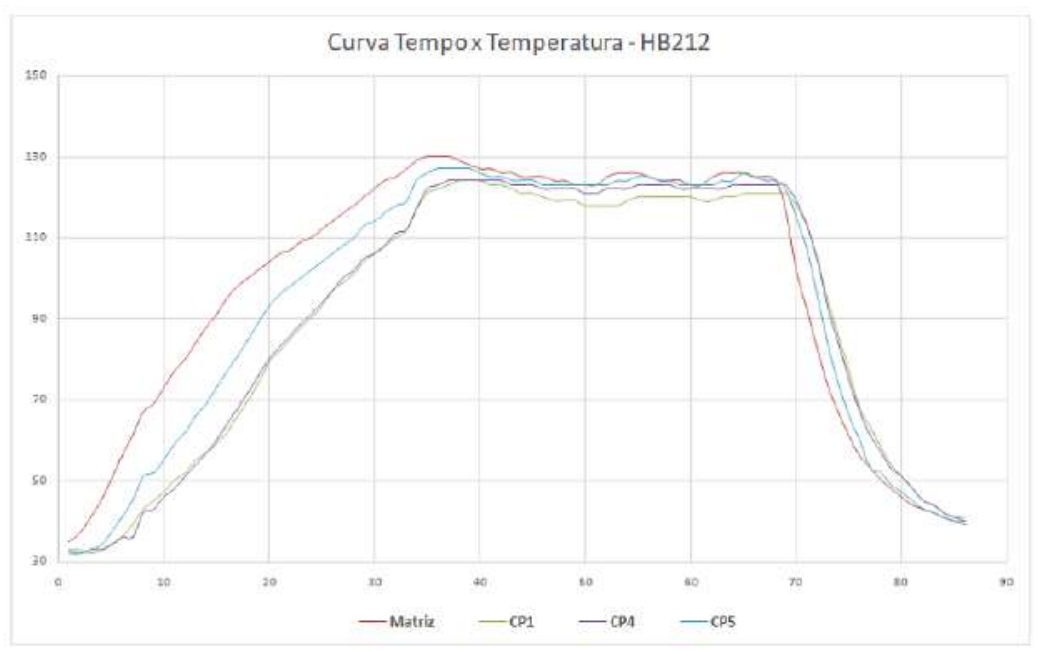

(a) Temperaturas na matriz e interna nas placas 1,4 e 5

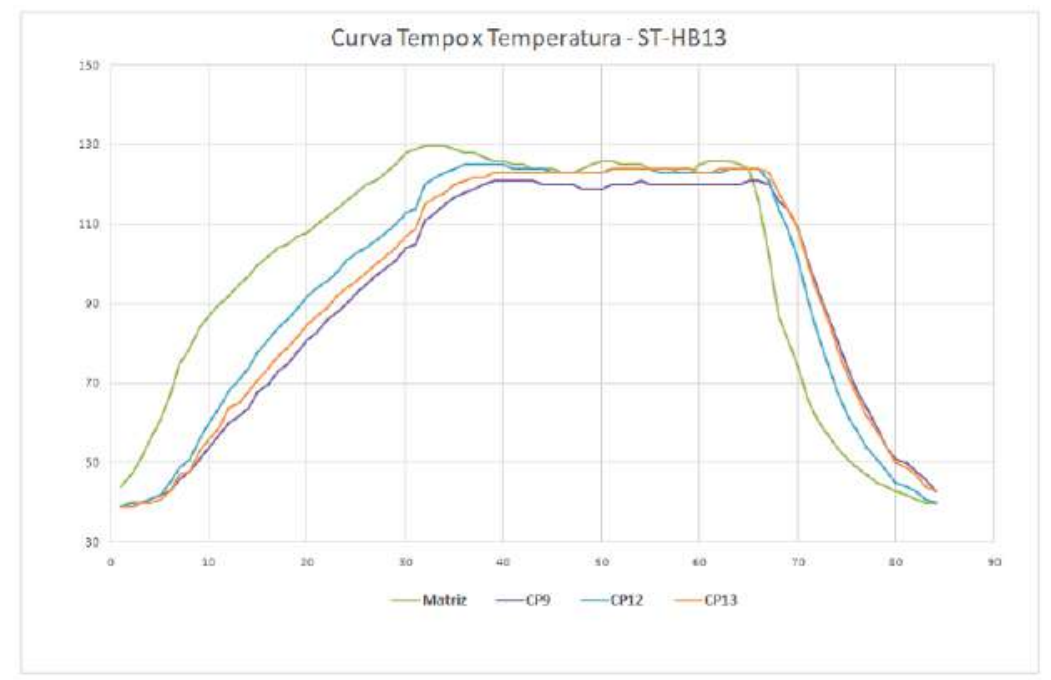

(b) Temperaturas na matriz e interna nas placas 9, 12 e 13

Figura 3.8: Variação de temperatura na matriz e interna das placas durante a prensagem (a) dos CPs de HB212; e (b) dos CPs de ST-HB13.

\subsection{2}

\section{Preparação dos corpos de prova}

As placas foram preparadas nas dimensões de placas balísticas utilizadas em coletes reais, ou seja, 25 por $30 \mathrm{~cm}$, para o material DSM HB212. Para o material da Sarkar, ST-HB13, devido às restrições nas dimensões da matéria prima importada, as placas foram fabricadas com medidas de 22 por $22 \mathrm{~cm}$. A chapa de Ti-6Al-4V foi cortada nas dimensões semelhantes aos dois tipos de placas com a Máquina de Corte com Jato de água (Figura 3.9) do fabricante Flow, série Mach2 (precisão de $\pm 0,127 \mathrm{~mm} / \mathrm{m}$ ), com velocidade de deslocamento de $1 \mathrm{~m} / \mathrm{min}$, pressão de $50.10^{3} \mathrm{psi}$, da Fábrica da IMBEL-RJ. 


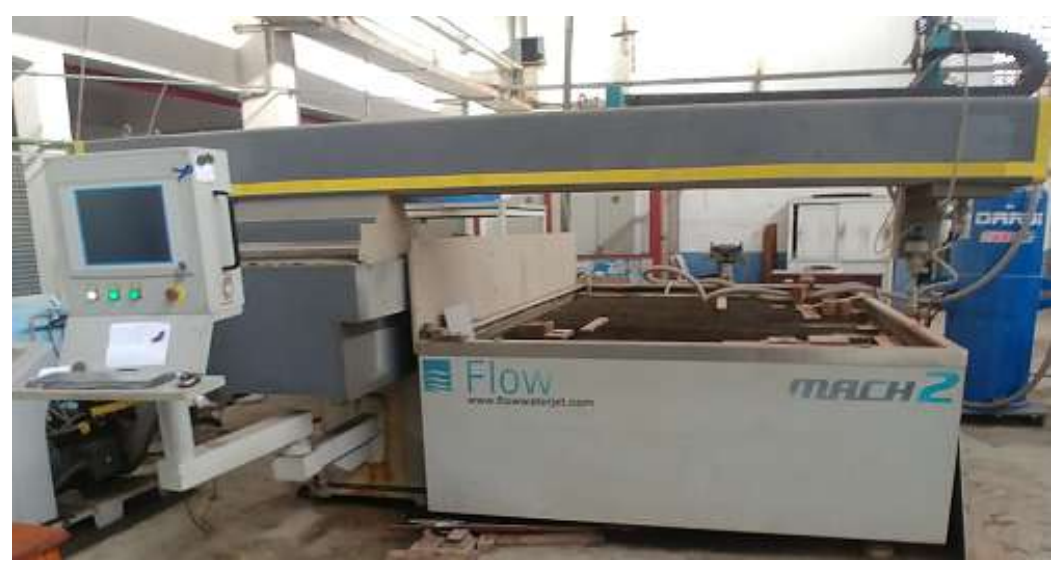

Figura 3.9: Máquina de Corte com Jato de água Flow Mach 2 (IMBEL).

As placas foram numeradas e identificadas de 1 à 16 de acordo com o exposto na Tabela 3.4. O conjunto de CPs de 3 a 8 e de 11 a 16 foram montados para a prensagem a quente com as respectivas chapas de titânio e mais três camadas sobrepostas de filme adesivo BP21.2008 (Pontacol), entre o metal e o prepreg.

\subsection{3}

\section{Metrologia das placas}

Foram utilizados diversos instrumentos de metrologia, inicialmente, para os insumos das placas balísticas e para a montagem dos componentes que seriam prensados, até a parte final da pesquisa, quando da verificação dos corpos de prova fabricados, e das deformações geradas na plastilina decorrentes da realização dos ensaios balísticos.

Na empresa Glágio do Brasil - MG, foi utilizada uma balança Filizola Modelo BP15 (capacidade máxima de $15 \mathrm{~kg}$ e mínima de $100 \mathrm{~g}$, com erro de $5 \mathrm{~g}$ ) para pesagem das lâminas de UHMWPE e da chapas de Ti-6Al-4V que seriam prensadas (Figuras 3.10a e 3.10b).

No CTEx o micrômetro Mitutoyo digital $(0,001 \mathrm{~mm} 0-25 \mathrm{~mm})$ e o paquímetro Vertical Mitutoyo Cod No. 940-101, serviram para a verificação da espessura das 16 placas fabricadas (Figura 3.10c). A regularidade da espessura foi verificada pela medição em nove pontos distribuídos uniformemente pela superfície destes CPs, conforme esquema da Figura 3.11. 


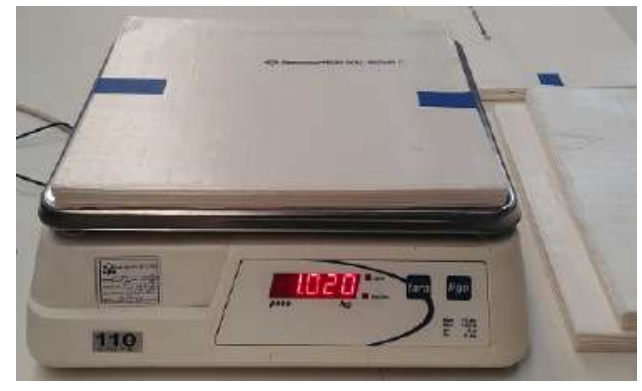

(a) massa de HB212 pré-prensagem

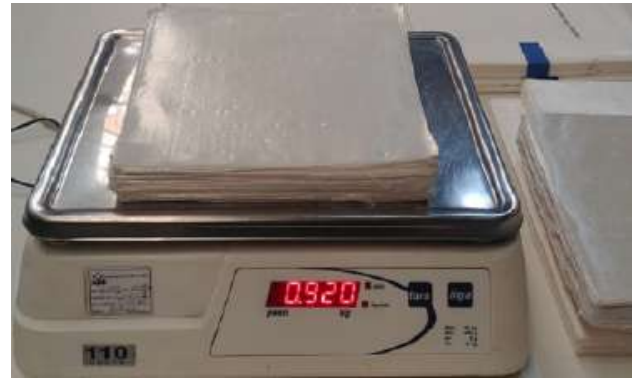

(b) massa de STHB13 pré-prensagem

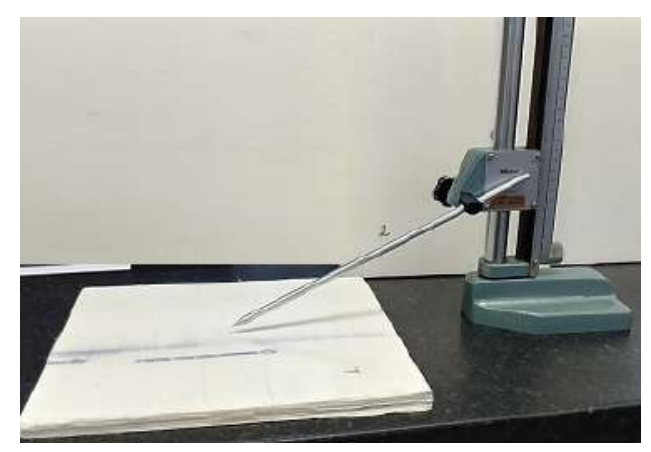

(c) placa prensada e paquímetro vertical

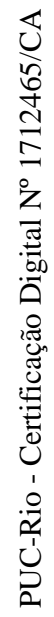

Figura 3.10: Metrologia das lâminas pré e pós prensagem.
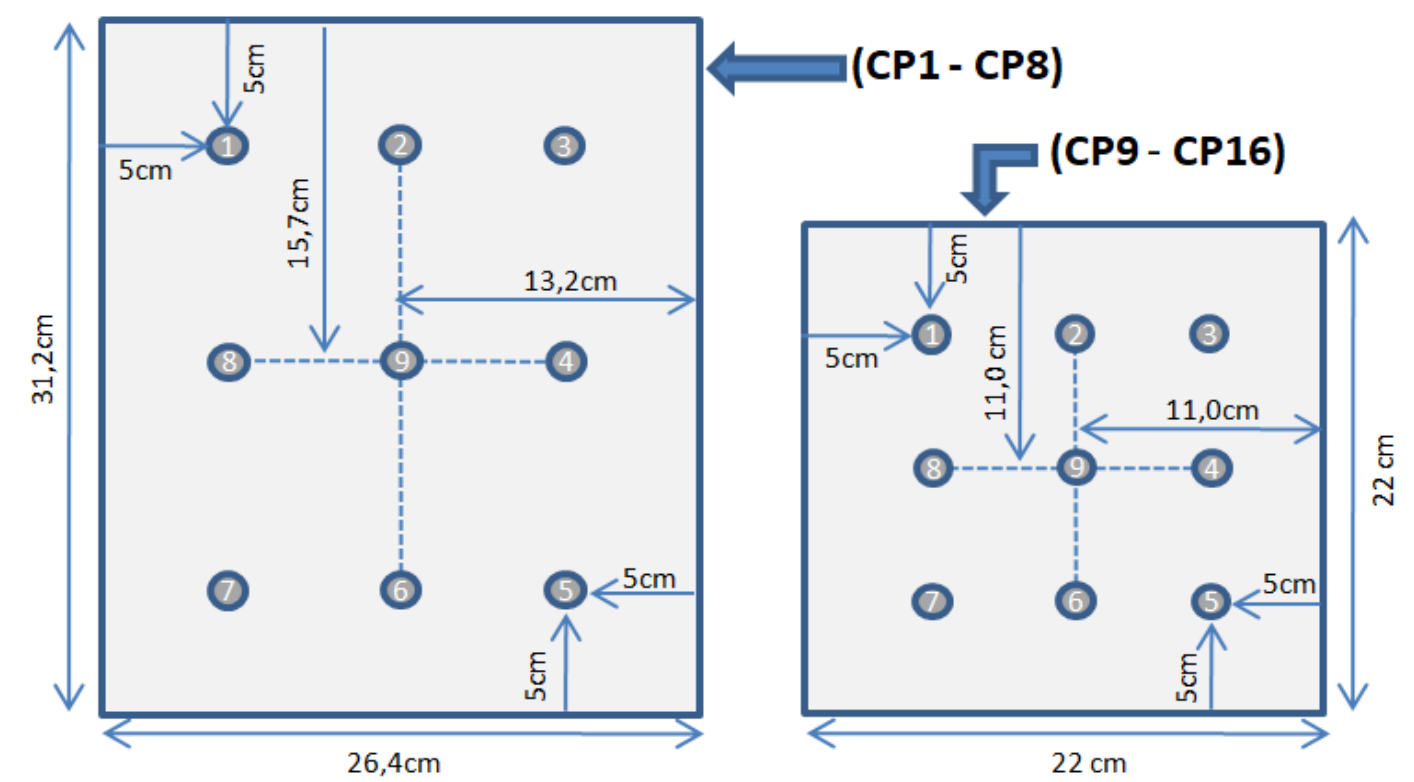

Figura 3.11: Esquema utilizado para medição da espessura das placas.

O trabalho de metrologia mais detalhado foi realizado na caixa de plastilina na qual as placas balísticas foram posicionadas para receber o impacto dos disparos. Essas medições contaram com equipamento portátil de varredura a laser para pequenos volumes FARO FreeStyle ${ }^{3 D}$ Objects. Este 
equipamento tem alcance útil de 0,3 a $0,8 \mathrm{~m}$, com precisão de $0,5 \mathrm{~mm}$, e uma tela acoplada que permite a visualização da nuvem de pontos adquirida. Foi realizada a gravação dos dados referentes ao volume deformado da plastilina após cada impacto que não perfurou as placas balísticas ensaiadas.

Para o pós-processamento das informações e para a reconstrução em três dimensões da deformação gerada em decorrência dos impactos balísticos, utilizou-se o programa PolyWorks Viewer 2017 IR3.1 (build 4075) 64-bit July 2017 - InnovMetric Software Inc.

\subsubsection{1}

\section{Densidade de área}

Para determinar a densidade de área foram empregadas a Balança Eletrônica Bioscale (capacidade de $10 \mathrm{~kg}$ e resolução de $1 \mathrm{~g}$ ) e a trena de aço Starret de $10 \mathrm{~m}$ graduada em $\mathrm{mm}$ (ambas do CAEx). Dessa forma, os cálculos da densidade superficial das placas foram realizados considerando a massa das placas e a dimensão plana ortogonal à direção submetida ao impacto balístico, conforme a Equação 3-1.

onde,

$$
D / A=\frac{M}{W L}
$$

$D / A=$ densidade de área em $\mathrm{kg} / \mathrm{m}^{2}$.

$M=$ massa da placa, em $\mathrm{kg}$.

$W=$ largura da placa, em $m$.

$L=$ comprimento da placa, em $m$.

Esse cálculo foi realizado para as 16 placas, antes da adição das espumas na face posterior, considerando assim a densidade de área dos materiais que realizam a função de reduzir a velocidade dos projetis: os prepregs e a chapa de titânio.

\section{4}

\section{Caracterização dos materiais}

Foi realizada a caracterização dos materiais que seriam empregados na fabricação das placas balísticas, para identificar as diferenças de constituição entre os dois compósitos balísticos de fibras de UHMWPE e também entre as espumas.

A caracterização físico-química dos compósitos de UHMWPE teve ainda como objetivo identificar possíveis alterações estruturais ocorridas nos materiais, comparando-os antes da etapa prensagem à quente, com amostras retiradas das placas após esse processamento. 
As fibras retiradas dos prepregs balísticos passaram por ensaios mecânicos de tração para verificar a relação entre a resistência das fibras e o desempenho balísticos dos compósitos. As placa de Ti-6Al-4V passou por ensaio de dureza.

Os compósitos de UHMWPE foram caracterizados por meio dos seguintes ensaios: espectroscopia no infravermelho (FTIR), análise termogravimétrica (TGA) e Calorimetria exploratória diferencial (DSC). Todos os materiais passaram por microscopia ótica ou eletrônica, dependendo das magnificações necessárias às estruturas de interesse.

\subsection{1}

\section{Caracterizações Espectroscópicas}

Os ensaios de FTIR foram realizados utilizando um IRPrestige-21 Fourier Transform Infrared Spectrophotometer, com o Microscópio acoplado AIM-8800 Automatic Infrared (Shimadzu), expostos nas Figuras 3.12a e 3.12b, do Centro Brasileiro de Pesquisas Físicas (CBPF).

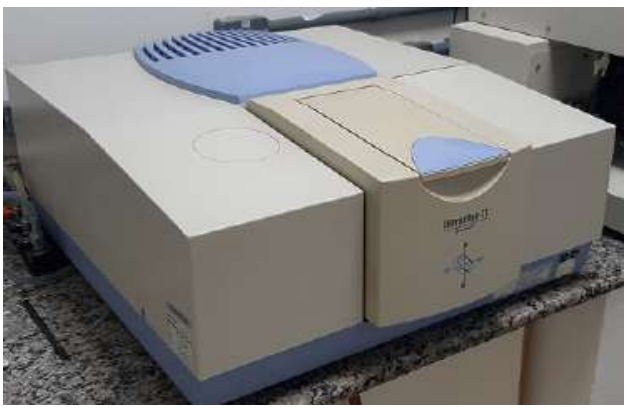

(a) Equipamento IRPrestige-21 FTI Spectrophotometer

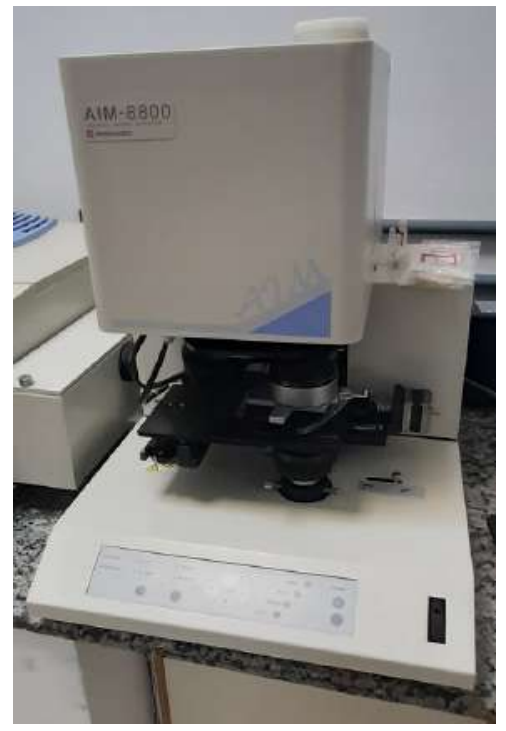

(b) Equipamento $A I M-8800 A u-$ tomatic Infrared

Figura 3.12: Equipamento de FTIR (a) e Microscópio (b) do CBPF.

Para todos os materiais analisados neste estudo, o método empregado foi o de Refletância Total Atenuada (ATR), na faixa de 450 a $4000 \mathrm{~cm}^{-1}$, com resolução de $4 \mathrm{~cm}^{-1}$ e 256 varreduras. O programa utilizado para gravação dos dados foi Shimadzu IResolution 1.60.

Dessa forma buscou-se realizar a caracterização estrutural, pela determinação de grupos e compostos funcionais presentes na superfície das amostras. 


\subsubsection{1 \\ Ensaio de FTIR}

Os dois prepregs, tanto o HB212, quanto o ST-HB13, antes de passar por prensagem, foram cortados em dimensões aproximadas de 5 por $5 \mathrm{~mm}$. Amostras em dimensões semelhantes também foram preparadas após esses materiais passarem pelo processo de prensagem a quente, quando foram consolidados como placas rígidas.

Uma amostra por vez foi disposta no microscópio e o cristal foi aplicado ao mesmo de maneira adequada, após a obtenção do foco. Tanto o espectro de fundo (o espectro do cristal) quanto o espectro da amostra foram gravados. A medição de fundo foi subtraída automaticamente da medição da amostra para a correta leitura do sinal.

Para processamento das informações adquiridas neste ensaio e comparação entre as diversas amostras e situações, foi utilizado o programa OriginPro 9.0.0 (64-bit) SR2, da OriginLab Corporation.

Com este ensaio procurou-se obter as bandas características de cada material analisado, visando as similaridades e diferença entre eles, de forma a poder relacionar esses resultados com as propriedades dos compósitos.

As duas espumas em estudo nessa tese, a de célula aberta Poron $\mathrm{XRD}^{\circledR}$ e a de célula fechada de PEBD/EVA, tiveram cinco CPs analisados. A preparação dessas amostras se deu cortando os materiais com $1 \mathrm{~mm}$ de espessura e aproximadamente 5 por $5 \mathrm{~mm}$ de lado, usando um estilete.

O filme adesivo de BP21.2008 foi recortado com uma tesoura, preparando três amostras com 5 por $5 \mathrm{~mm}$ de lado.

\subsection{2}

\section{Caracterizações Térmicas}

Os polímeros constituintes das placas balísticas foram submetidos à técnica de Análise Térmica Simultânea (STA), combinando Termogravimetria (TGA) e Calorimetria exploratória diferencial (DSC), realizada em um equipamento da Perkin-Elmer, Simultaneous Thermal Analyzer STA-6000 (Seer Green, U.K.), com taxa de aquecimento de $10^{\circ} \mathrm{C} \cdot \mathrm{min}^{-1}$ em atmosfera controlada com fluxo do gás nitrogênio $\left(\mathrm{N}_{2}\right)$ à vazão de $50 \mathrm{mLmin}^{-1}$, com o emprego de um cadinho de platina para acondicionar as amostras.

O ensaio conjunto de TGA e DSC foi realizado de $30{ }^{\circ} \mathrm{C}$ a $600{ }^{\circ} \mathrm{C}$, para estudar as transformações ocorridas ao longo do processo. A Figura 3.13 mostra o equipamento da PUC/Rio utilizado nessa caracterização.

As amostras de prepregs, fibras de UHMWPE, e de espumas, foram reduzidas a pequenos pedaços com auxílio de um estilete, para realização des- 


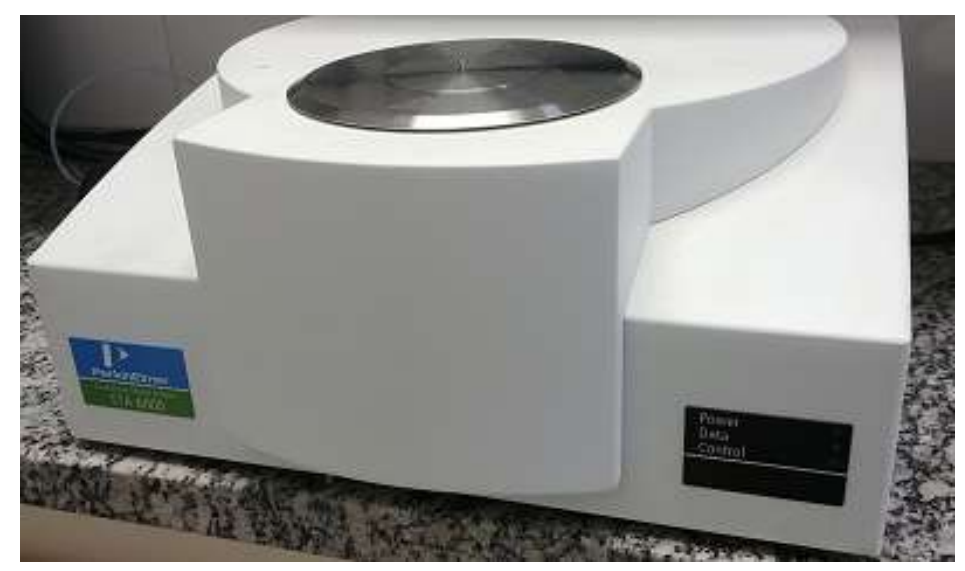

Figura 3.13: Equipamento de análises térmicas da PUC-Rio.

tes ensaios. Esses materiais foram colocados em uma ultramicrobalança, da PerkinElmer ${ }^{\circledR}$, modelo AD 6000 Autobalance, capaz de pesar amostras até $1000 \mathrm{mg}$, com a resolução de $0,1 \mu \mathrm{g}$ (CTEx). Foram preparadas aproximadamente $10 \mathrm{mg}$ de cada amostra, para que pudessem ser colocadas dentro do cadinho de platina do equipamento de STA.

A técnica de STA foi aplicada para os prepregs, para as fibras, e para o adesivo BP21.2008, tanto com amostras "pré-prensagem", quanto após os mesmos terem passado pelo processo termo-mecânico de fabricação das placas.

A análise dos dois tipos de espumas, Poron $\mathrm{XRD}^{\circledR}$ e de PEBD/EVA, foi realizada com idêntico protocolo ao empregado para os prepregs, mas como as espumas não passaram pelo ciclo térmico de prensagem, foram analisadas por STA somente na situação "como recebidas".

Estão presentes na Tabela 3.5 a massa (proveniente da balança interna do equipamento de STA) das amostras e a condição em que cada material foi analisado.

\subsubsection{1}

\section{Ensaio de DSC}

A técnica de DSC foi empregada para determinar os valores de entalpia associados aos eventos térmicos que ocorreram com os materiais, em decorrência do ciclo programado de temperatura.

Foram determinados, para cada tipo e condição de amostra, a quantidade de energia $(J / g)$ que uma amostra absorve durante a fusão $\left(\Delta H_{m}\right)$ e a percentagem de cristalinidade $\left(X_{c}\right)$.

Para calcular $\Delta H_{m}$, que corresponde numericamente à área sob o "pico" de fusão na curva DSC, utilizou-se o software OriginPro 9.0.0 ${ }^{\circledR}$ (64-bit) SR2, da OriginLab Corporation, na função "Peak Analyzer", onde foi criada uma 
Tabela 3.5: Amostras utilizadas para ensaio de STA (DSC/TGA).

\begin{tabular}{lcc}
\hline Material & Condição & Massa $(\mathbf{m g})$ \\
\hline HB212 & pré-prensagem & 11,62 \\
HB212 & pós-prensagem & 10,38 \\
Fibras de HB212 & retirada do prepreg & 9,22 \\
ST-HB13 & pré-prensagem & 9,16 \\
ST-HB13 & pós-prensagem & 10,82 \\
Fibras de ST-HB13 & retirada do prepreg & 11,47 \\
Espuma Poron XRD & como recebida & 10,72 \\
Espuma PEBD/EVA & como recebida & 4,92 \\
Adesivo BP21. 2008 & pré-prensagem & 11,28 \\
Adesivo BP21. 2008 & pós-prensagem & 11,36 \\
\hline
\end{tabular}

linha de base e realizada a integração do pico endotérmico em relação a esta linha. A área calculada foi dividida pela massa em gramas da amostra (Tabela 3.5), sendo o resultado considerado como a entalpia (calor de fusão).

A percentagem de cristalinidade $\left(X_{c}\right)$, para cada condição e material, foi calculada de acordo com a Equação 2-14.

\subsubsection{2}

\section{Ensaio de TGA}

A análise de TGA pode fornecer informações sobre a estabilidade térmica e alterações decorrentes do ciclo de fabricação das placas. Foram ensaiadas amostras retiradas a partir dos prepregs HB212 e ST-HB13, das fibras retiradas desses prepregs, das espumas Poron $\mathrm{XRD}^{\circledR}$ e de PEBD/EVA, e do adesivo BP21.2008.

O objetivo foi obter mais informações sobre a constituição dos materiais e verificar as temperaturas e parâmetros de prensagem a quente, analisando quais as transformações podem ocorrer, bem como limitações de temperaturas para o ciclo de processamento.

Foram determinadas a perda de massa, a temperatura de início da perda de massa $\left(T_{\text {onset }}\right)$ e a temperatura de máxima taxa de perda de massa $\left(T_{d}\right)$, levado em consideração para este valor a posição do ponto de máxima intensidade na primeira derivada da curva termogravimétrica (DTG).

\subsection{3}

\section{Análise Termodinâmica}

Foi realizada a análise matemática com o emprego do programa ThermoCalc ${ }^{\circledR}$ Versão 2015, utilizando o banco de dados SSUB3 (SGTE Substances 
Database v3.3). O objetivo desses cálculos foi determinar o que poderia ocorrer durante a transferência da energia cinética translacional do projetil quando este incidisse sobre a determinada massa metálica.

O diâmetro médio da perfuração resultante nas placas de titânio foi medido com paquímetro Mitutoyo de $200 \mathrm{~mm}$, com precisão de 0,05mm. Após 4 medidas de cada orifício estimou-se o volume médio da chapa de titânio removido durante o ensaio balístico.

O valor de diâmetro médio das perfurações, a exemplo da Figura 3.14, considerado para a realização dos cálculos no Thermo-Calc ${ }^{\circledR}$ foi de $7,68 \mathrm{~mm}$. A velocidade média e a massa do projetil considerados para cálculo da energia cinética no momento do impacto, são, respectivamente, $845 \mathrm{~m} / \mathrm{s}$ e $9,63 \mathrm{~g}$, o que acarreta uma energia de aproximadamente $3200 \mathrm{~J}$.

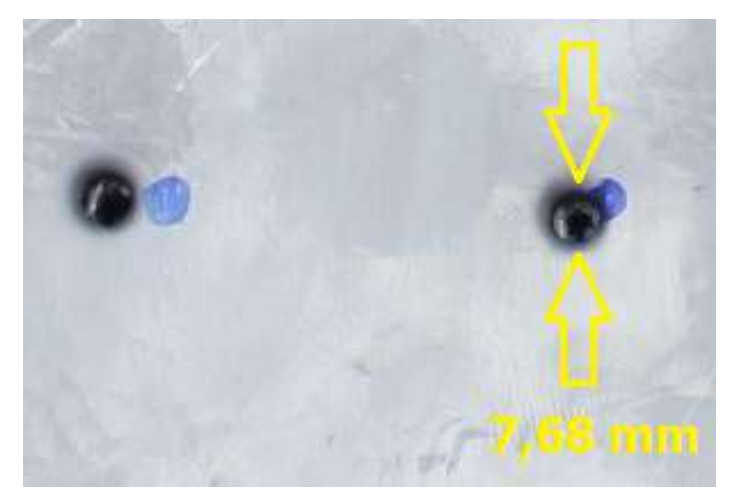

Figura 3.14: Medição do diâmetro da perfuração na chapa de titânio.

Para possibilitar os cálculos de forma aproximada, as seguintes hipóteses foram adotadas quando da utilização do Thermo-Calc ${ }^{\circledR}$ :

- toda a energia do projetil seria transferida ao titânio;

- o material foi considerado como titânio puro;

- transformação decorrente seria adiabática;

- pressão de uma atmosfera; e

- temperatura inicial de $25^{\circ} \mathrm{C}$.

Considerou-se que o volume da chapa de titânio correspondente ao diâmetro médio de 7,68 mm passou por fusão/evaporação adiabática, devido à elevada velocidade dos eventos em questão.

A indagação apontada foi de qual seria o caminho do sistema uma vez que a energia cinética incidente fosse dada como a entalpia da massa do volume estimado de titânio. 


\section{5}

\section{Ensaios Mecânicos}

\subsection{1}

\section{Ensaio de Dureza do Titânio}

Para obtenção dos valores na escala de Dureza Rockwell C em três amostras da chapa de Ti-6Al-4V as medidas foram executadas utilizando um durômetro Testor HT1 Rockwell C, da Sussen-Wolpert (CTEx), com pré-carga de $10 \mathrm{~kg} f$ e carga de $150 \mathrm{~kg} f$, empregando o cone de diamante $\left(120^{\circ}\right)$, por um minuto, sendo a leitura de dureza feita diretamente no equipamento.

A norma que balizou os ensaios foi a ASTM E 18 - American Standard Test Methods for Rockwell Hardness of Metallic Materials. A escala HRC tem faixa de utilização de 20 a 70, e pode ser realizada em aço, titânio, aços com camada profunda endurecida e materiais com dureza Brinell maior do que 100.

Como o ensaio foi realizado em uma chapa de $1 \mathrm{~mm}$ de espessura, foi necessário dedicar atenção ao cálculo da profundidade estimada do penetrador em relação à espessura da liga de titânio (cerca de dez vezes menor). As bordas da chapa também deveriam ser evitadas, para não incorrer em imprecisão, assim como a distância entre as diversas indentações, que se mantiveram a mais de três vezes o diâmetro do indentador uma da outra. Por fim, a superfície analisada deveria possuir boa planicidade.

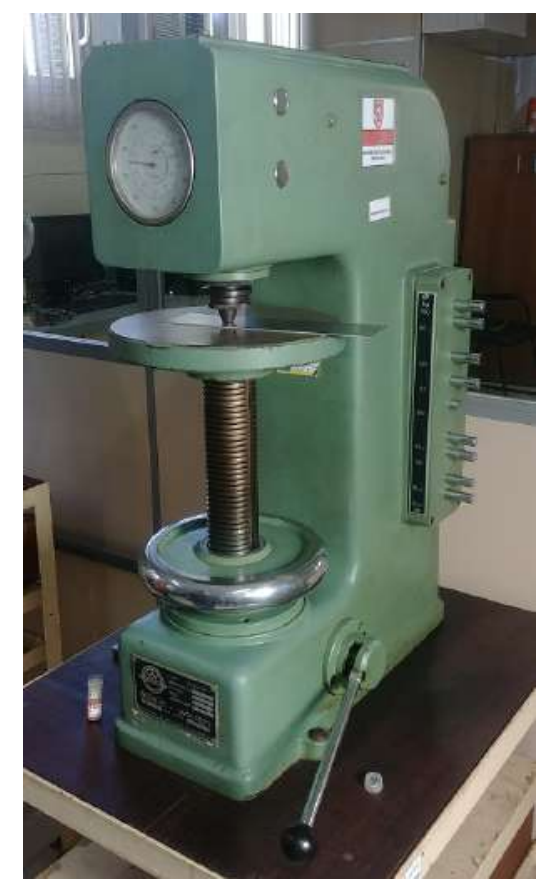

Figura 3.15: Máquina para ensaio de dureza. 


\subsection{2}

\section{Ensaio Mecânico de Tração (EMT) de fibras de UHMWPE}

Os ensaios mecânicos de tração nas fibras foram conduzidos no equipamento composto por um micrômetro de varredura a laser LDS0200, e o sistema de teste de tração LEX-820 (Dia-Stron, Reino Unido) do CTEx, expostos na Figura 3.16, utilizando-se um método adaptado da norma ASTM C1557.

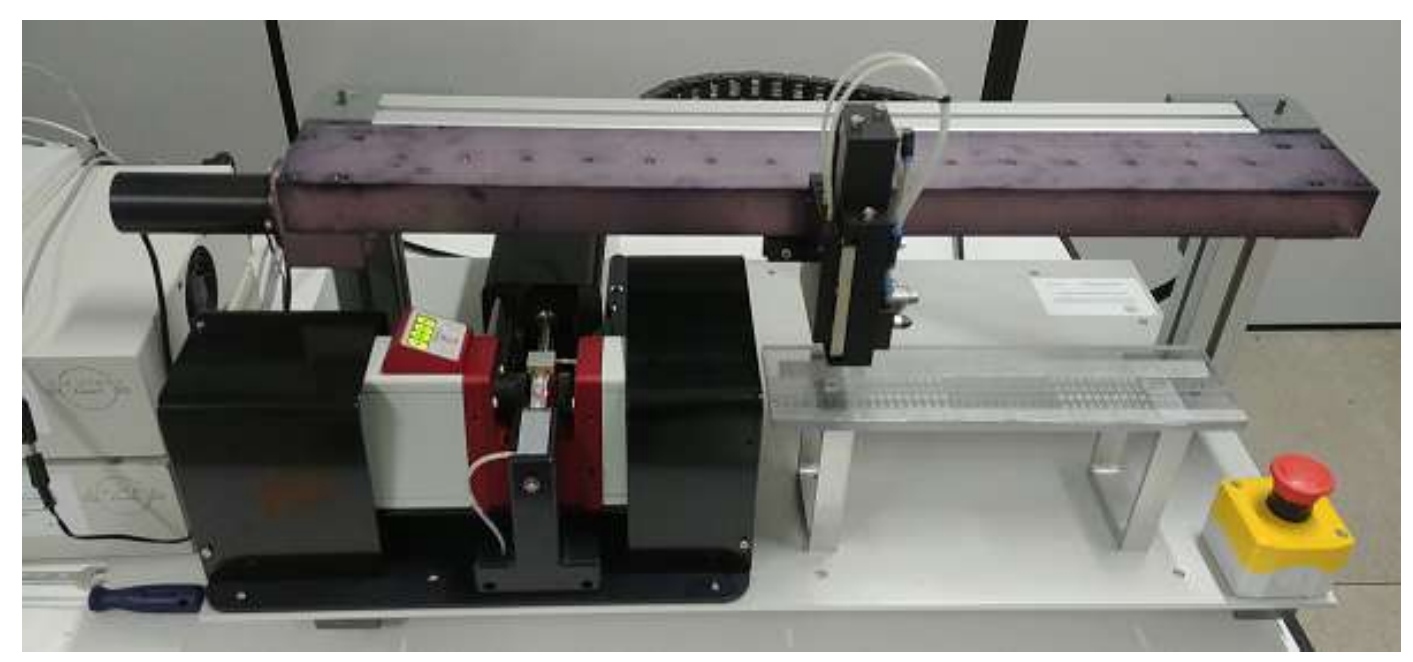

Figura 3.16: Equipamento LEX-820 Dia-Stron para EMT de fibra.

Conjuntos de fibras de UHMWPE foram retirados dos prepregs, em seguida cada fibra foi cuidadosamente separada destes filamentos, passando pelo processo de preparação, com a inserção em suportes específicos e colagem. Essa etapa crítica do processo se encerrou com a fixação das fibras de UHMWPE nos suportes (Figura 3.17a), quando a cura do adesivo utilizado foi acelerada utilizando fonte de luz ultravioleta (UV), com na Figura 3.17b. 


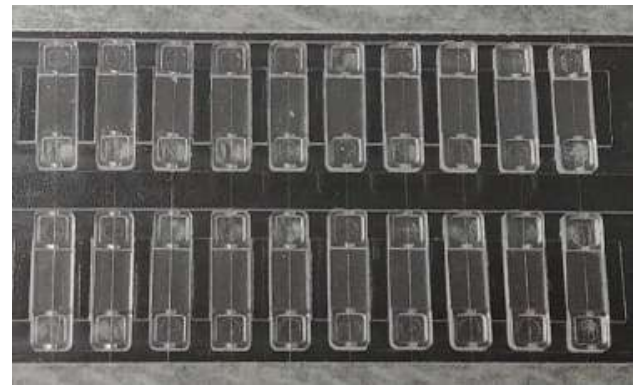

(a) disposição de fibras nos suportes

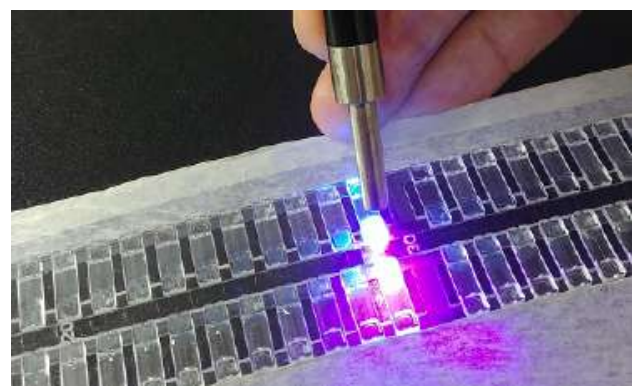

(b) cura do adesivo com luz UV

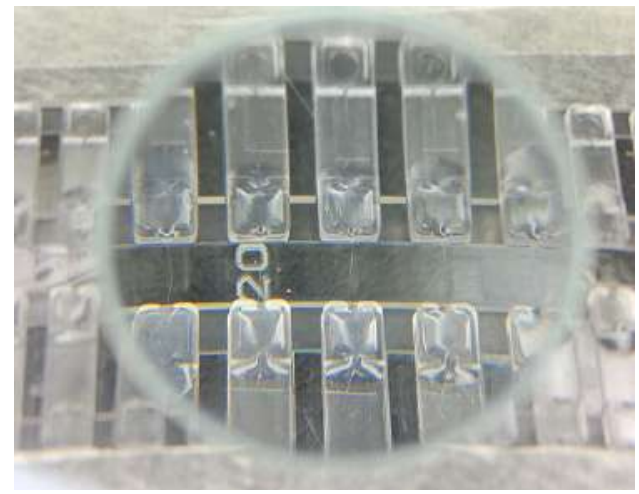

(c) fibras prontas para o EMT

Figura 3.17: Preparação para EMT nas etapas (a), (b) e (c).

Apesar das propriedades do material serem desfavoráveis à ancoragem, o emprego do adesivo Dymax 3193, Ultra Light-Weld ${ }^{\circledR}$ Adhesives 8 Coatings, se mostrou eficaz para tal procedimento.

A medição do diâmetro precisou ser feita no Microscópio Ótico Leica, com o programa Leica Application Suite (LAS), para em seguida executar o EMT propriamente dito, pois o equipamento LDS0200 não foi eficaz em levantar todas as medidas devido à translucidez das fibras.

O sistema para teste de tração LEX-820 realiza a alimentação automática das amostras. O ensaio ocorreu conforme a rotina de teste estabelecida, com os parâmetros expressos na Tabela 3.6. O testes eram interrompidos quando se atingia o limite configurado no equipamento.

O EMT foi executado na seguinte sequência: pré-tração da fibra a uma taxa de $0,15 \mathrm{~mm} / \mathrm{s}$, com uma carga inicial de $0,2 \mathrm{gmf}$ (grama-força) e ajustada a uma força máxima de $200 \mathrm{gmf}$. O comprimento útil das amostras era de $4 \mathrm{~mm}$. Para cada tipo de fibra foram preparadas 40 amostras, e os resultados foram analisados após os testes.

O método empregado possibilitou gerar curvas tensão-deformação, as quais foram utilizadas para determinar o limite de resistência à tração (LRT).

Buscou-se caracterizar o valor médio para esses parâmetros, obtido como resultado de ensaios de tração válidos realizados com 29 corpos de prova de 
Tabela 3.6: Parâmetros para Ensaio Mecânico de Tração de fibras.

\begin{tabular}{|c|c|}
\hline Extension (\%) & 5 \\
\hline Gauge Force & 2 \\
\hline Break Threshold & 0,5 \\
\hline Rate (mm.seg ${ }^{-1}$ ) & 0,15 \\
\hline Maximum Force & 200 \\
\hline Sample Size (mm) & 4 \\
\hline Relaxation Time & 0 \\
\hline LEX 820 - Extension Method \\
\hline
\end{tabular}

fibras do ST-HB13 e de 22 do HB212.

Para a análise do gráfico de Tensão x Deformação se fez necessário adotar procedimento para identificar o ponto de tensão máxima e testar se este ponto estaria de acordo. Tal estudo foi realizado empregando a Distribuição de Weibull para validação dos resultados. O cálculo do Módulo de Weibull para cada material ensaiado permite indicar a consistência na identificação dos pontos de LRT.

\section{6 \\ Microscopias}

\subsection{1}

\section{Microscopia Ótica}

Inicialmente, foi utilizado o Microscópio Ótico LEICA, modelo DMI 5000 (Figura 3.18), com auxílio do programa Leica Application Suite (LAS), do CTEx. Por meio da técnica de Microscopia ótica por campo escuro, associado ao emprego de polarizador para distinguir entre o anisotrópico e porções isotrópicas de cor, foram levantados os diâmetros médios das fibras dos compósitos em estudo.

Em fase posterior da pesquisa, o Microscópio Ótico ZEISS Axio Imager (Figura 3.19a) do Laboratório de Materiais do CTEx, foi empregado para realizar a análise metalográfica da liga de Ti-6Al-4V.

Para a preparação de amostra a chapa da liga de Ti-6Al-4V foi cortada e colada a um disco de baquelite para possibilitar o lixamento. A sequência de lixamentos empregou as granulometrias: 220, 320, 400, 600, chegando ao polimento com 1200, sempre com lixas de Carbeto de Silício. Na sequência da operação de polimento foram utilizadas pastas com partículas de diamante, de tamanhos $6 \mu \mathrm{m}, 3 \mu \mathrm{m}$ e por fim $1 \mu \mathrm{m}$.

Para ataque químico da superfície e revelação da microestrutura, foi utilizado o Reagente de Kroll, com a seguinte composição: 2\% de Ácido 


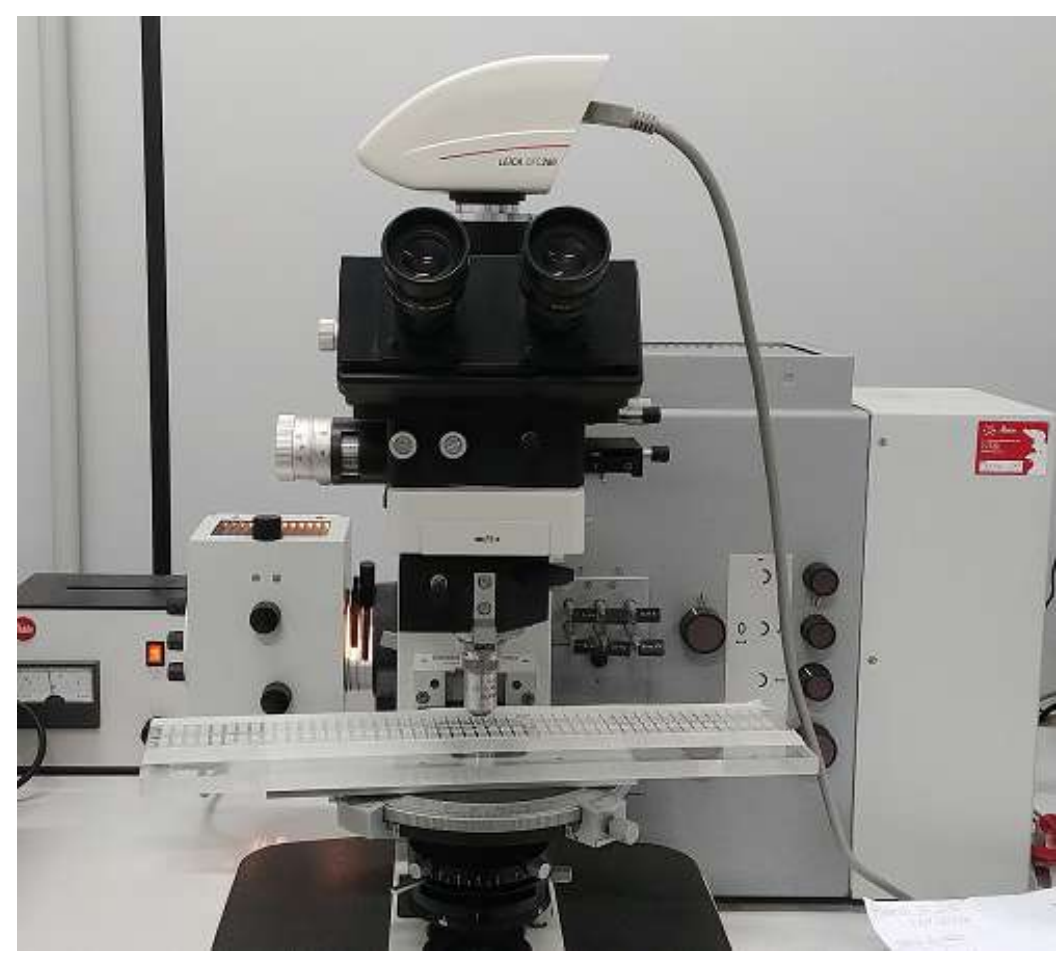

Figura 3.18: Equipamento de Microscopia Ótica do Laboratório de Materiais de Carbono do CTEx.

Fluorídrico $10 \%$ de Ácido Nítrico $88 \%$ de água destilada. O procedimento para ataque foi o de imersão direta no reagente, em banhos de 3 a 5 segundos, até que se revelasse a microestrutura da liga.

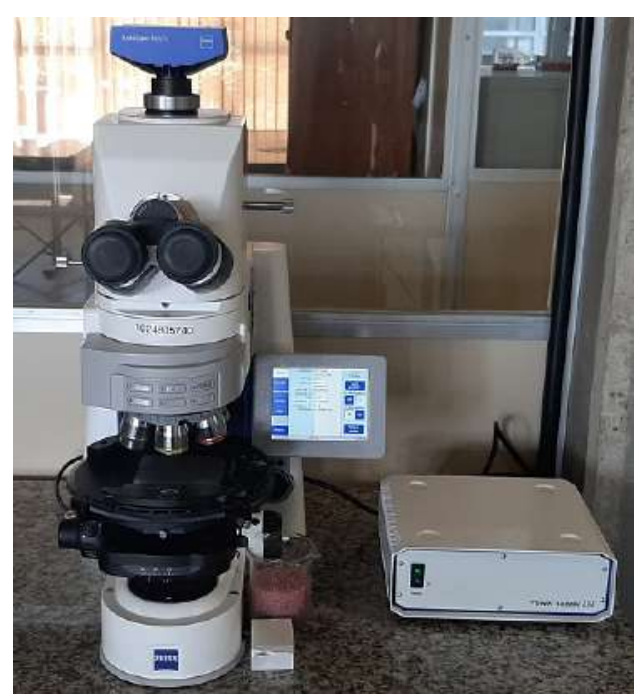

(a) Equipamento de Microscopia Zeiss

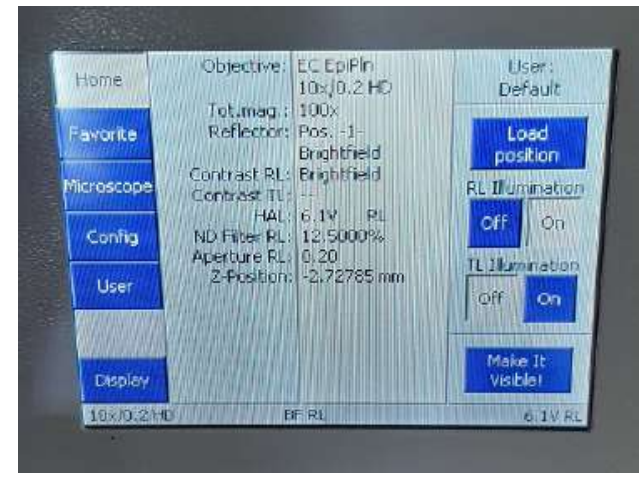

(b) Tela de configuração do microscópio

Figura 3.19: Equipamento (a) e configurações (b) da microscopia ótica do CTEx empregada para metalografia. 


\subsection{2}

\section{Microscopia eletrônica de varredura (MEV)}

Para realização da análise dos materiais dessa pesquisa foi utilizado o microscópio eletrônico de varredura Carl Zeiss EVO MA 10 do CTEx, exposto na Figura 3.20. As amostras foram avaliadas usando o método de elétrons secundários.

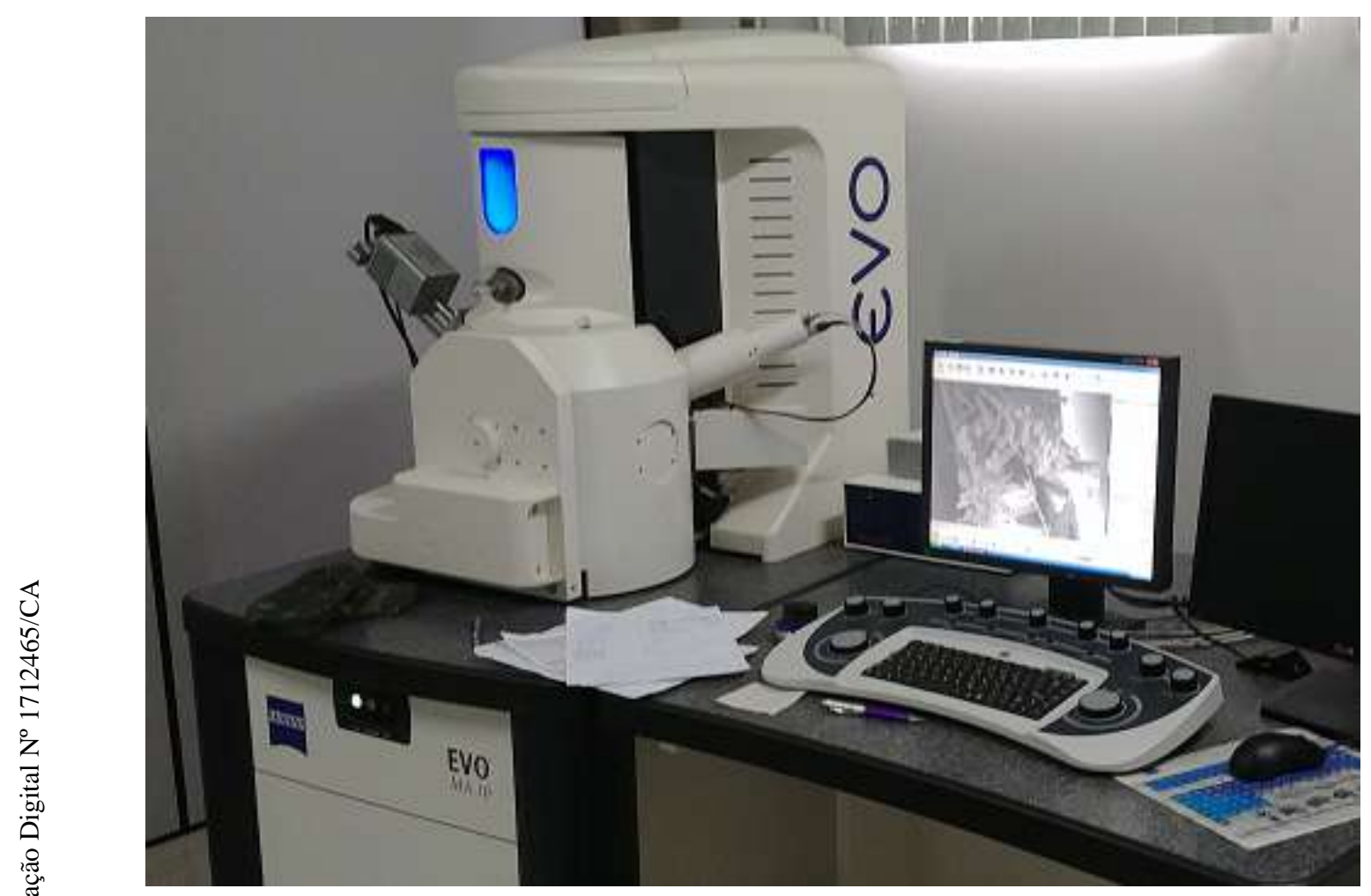

Figura 3.20: Equipamento de Microscopia Eletrônica de Varredura do CTEx.

O estudo com o MEV forneceu informações sobre as diferentes fibras de UHMWPE retiradas dos compósitos HB212 e ST-HB13, sobre as lâminas inteiras, e ainda a respeito das espumas utilizadas como redutoras de trauma. O objetivo pretendido foi de compreender o comportamento mecânico e balístico associado à microestrutura encontrada, buscando a relação entre as propriedades dos materiais e o desempenho do compósito final.

A obtenção de imagens no MEV ocorreu com tensão de aceleração entre 5 e $8 k V$, Work Distance (WD) entre 8 e $18 \mathrm{~mm}$, e diversas magnificações para os materiais analisados. As amostras foram recobertas com um filme de ouro para evitar o acúmulo de carga pela absorção de elétrons, que poderia resultar em má qualidade de imagem. Essa deposição foi feita com o equipamento EMITECH Peltier Cooled Coating com a configuração de 30 miliamperes e vácuo de $10^{-2}$ mbar em atmosfera de gás argônio, do Laboratório de Materiais de Carbono do CTEx, conforme Figura 3.21a. 


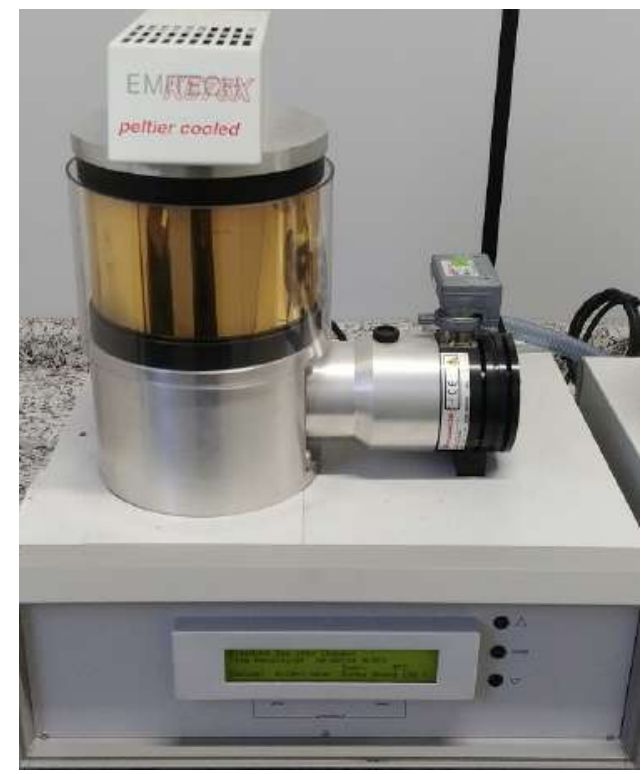

(a) deposição de camada de ouro

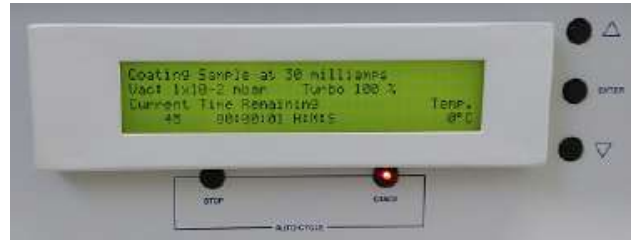

(b) configuração para a deposição

Figura 3.21: Equipamento (a) e configurações para recobrimento (b).

Na Figura 3.22 está exposta a vista de topo do arranjo de parte dos CPs de fibras, compósitos e espumas, para estudo no MEV após a deposição de ouro, fixadas nos suportes por fita condutora de carbono.

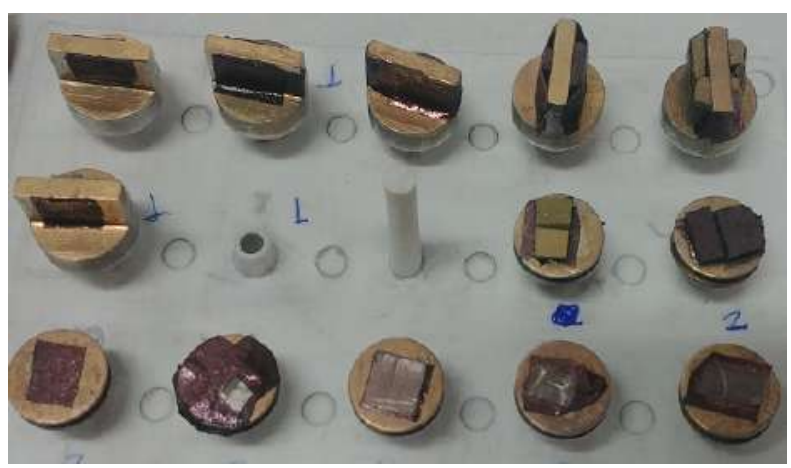

Figura 3.22: Amostras preparadas para estudo no MEV do CTEx.

A análise por MEV permitiu verificar a distribuição das fibras nas camadas do compósito, bem como a distribuição de matriz nas camadas préimpregnadas. Quanto ao estudo das espumas, foi possível verificar a morfologia do material e o diâmetro médio das células dos dois tipos em questão. 


\section{7 \\ Ensaio Balístico}

Para a realização dos ensaios balísticos as placas deveriam ser alvejadas seguindo as especificações da NIJ 0101.04 (74) e da NBR 15000 (70). No dia anterior ao ensaio, as mesmas foram acondicionadas em um ambiente com temperatura $\left(22^{\circ} \mathrm{C}\right)$ e umidade $(30 \%)$ controladas, visando garantir a homogeneidade das condições dos materiais durante o período de avaliações.

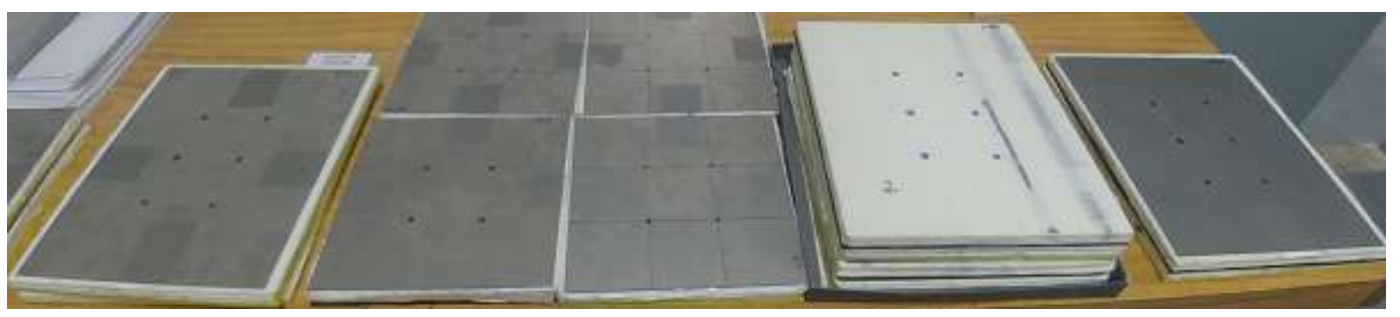

Figura 3.23: Placas fabricadas para teste.

As 16 placas completas fabricadas nesta pesquisa (Figura 3.23), com diferentes composições e massas, estão descritas na Tabela 3.4, e tiveram a eficiência testada quanto à resistência e ao limite balístico contra a munição 7,62 M80 (Figura 3.24).

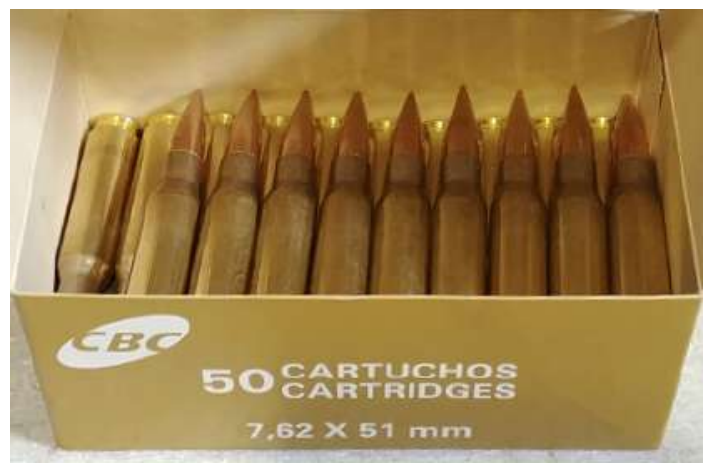

Figura 3.24: Munição 7,62 x 51 mm FMJ.

Para tanto, os testes contaram com a estrutura e os equipamentos da Linha IV do CAEx, conforme Figura 3.25, destinada aos testes que empregam armas e munições até o calibre .50 polegada $(12,7 \mathrm{~mm})$. A equipe que realizou os ensaios é responsável por este tipo de procedimento para análise de blindagens desenvolvidas no Brasil e no exterior, que dependam de homologação para serem comercializadas para as forças de segurança no país.

Para esses ensaios foram utilizados os seguintes equipamentos e materiais: Provetes de $51 \mathrm{~mm}$ e $63 \mathrm{~mm}$, fixados a um Receptor universal (todos da 


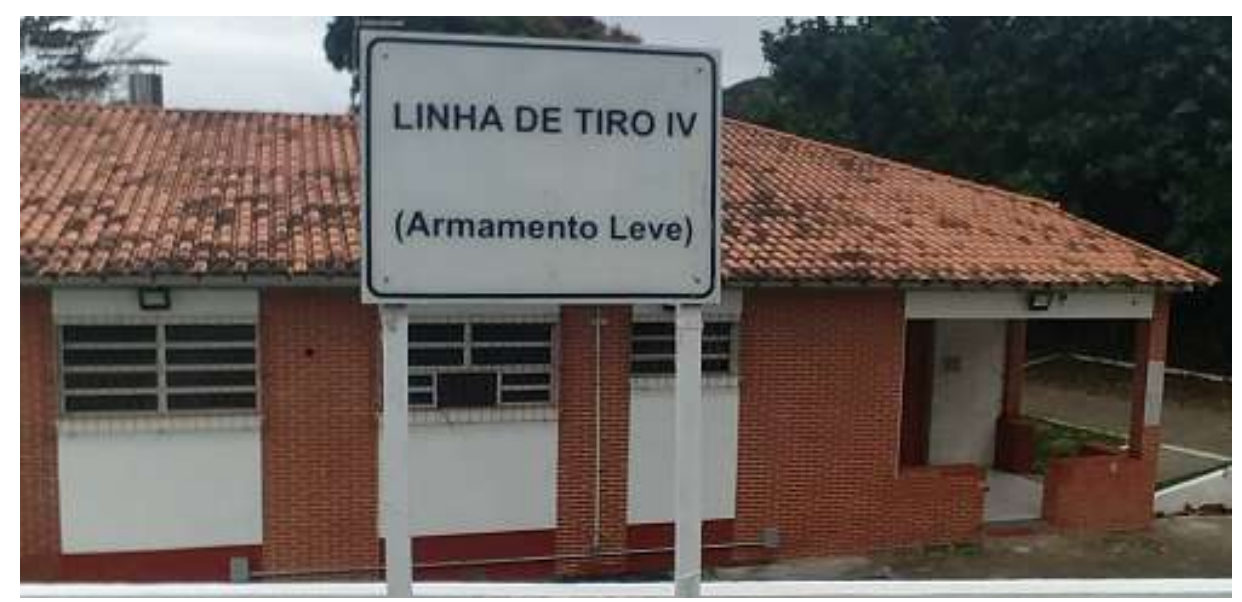

Figura 3.25: Linha de Tiro IV do CAEx.

AVL), exposto na Figura 3.26; Barreira Ótica B471 da HPI (Figura 3.27a), com o sensor inicial posicionado a dois metros da extremidade do provete, e o sensor final a três metros, para controle da velocidade dos disparos; Anteparo para as placas (preenchido por plastilina balística), conforme Figura 3.27b; computador com programa de aquisição de dados e controle da barreira ótica; Balança Analítica modelo AUW220, fabricante Marte/Shimadzu (Figura 3.28a) para pesagem da pólvora que seria usada no preenchimento dos estojos; Projetil modelo 147 M80 FMJ de munição 7,62mm (Figura 3.28b), com estojos $51 \mathrm{~mm}$ e $63 \mathrm{~mm}$; e Equipamento do varredura tridimensional FARO e o respectivo programa de pós-processamento de dados, nas Figuras 3.29a e 3.29b.

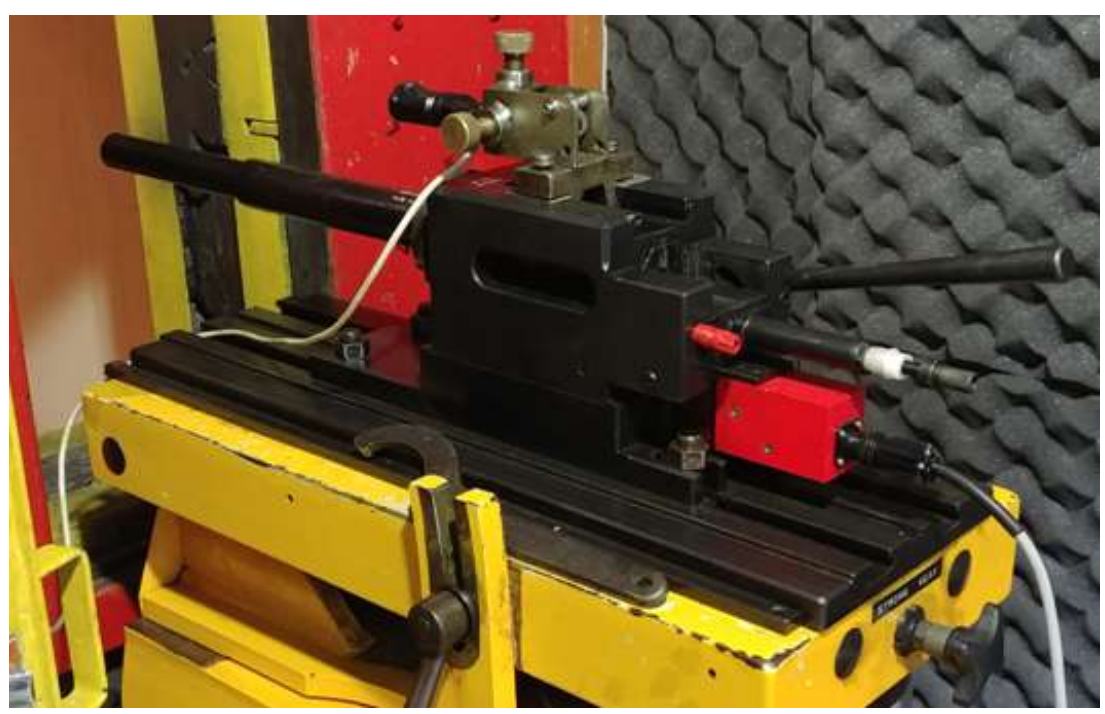

Figura 3.26: Provete 7,62x51 mm e Receptor universal AVL. 
0

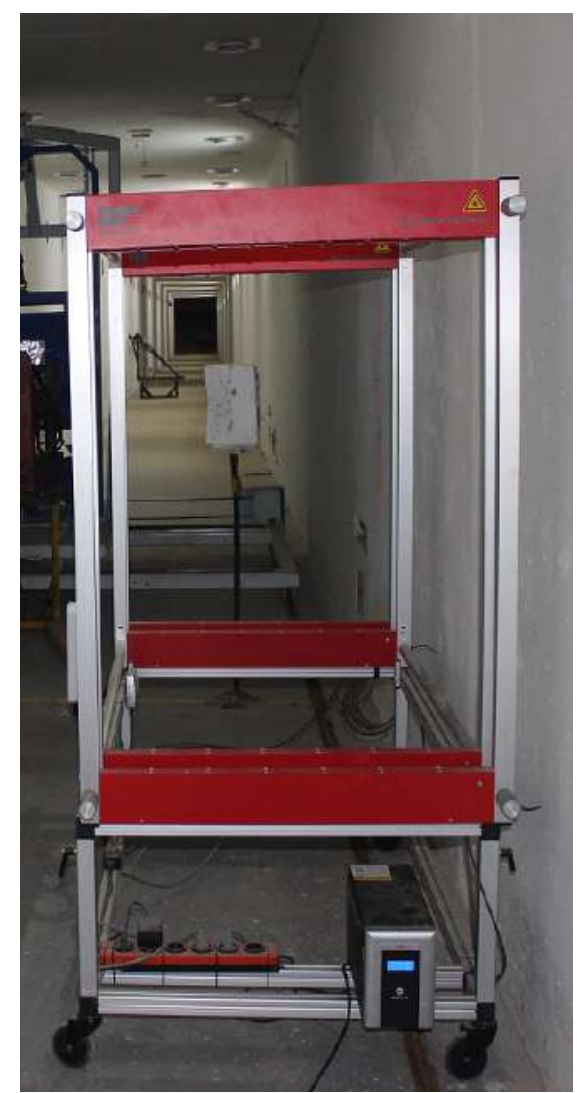

(a) Barreira Ótica B471 da HPI

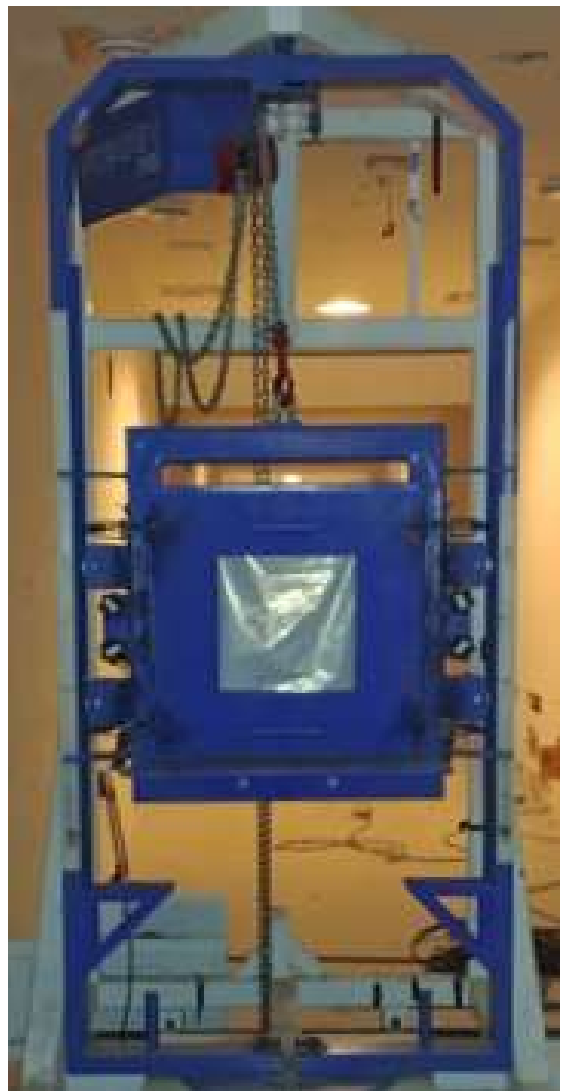

(b) Suporte para caixa de plastilina

Figura 3.27: Equipamento para medição da velocidade (a) e o suporte de alvo (b) para o ensaio balístico.

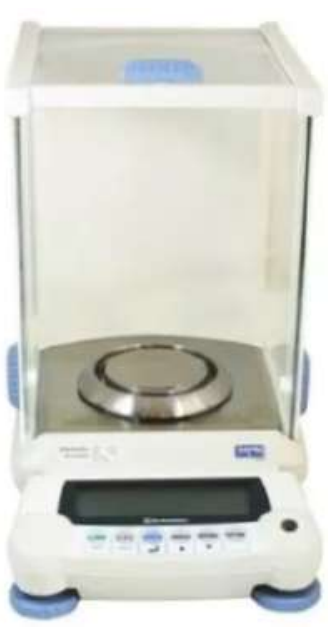

(a) Balança Analítica

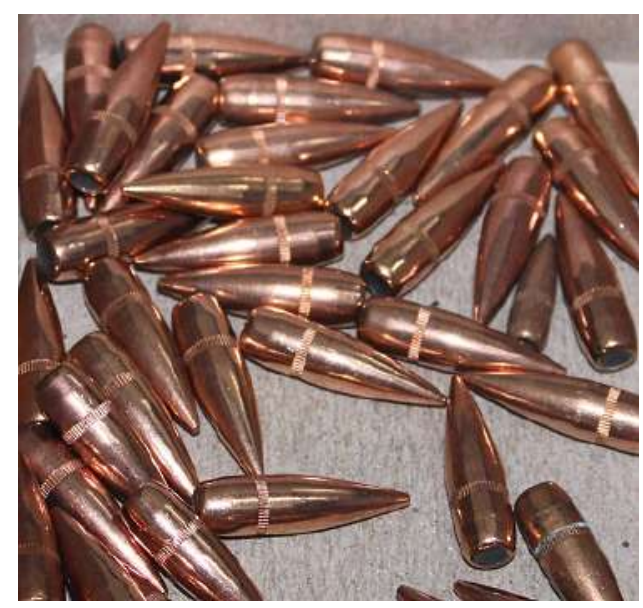

(b) Projetis de calibre $7,62 \mathrm{~mm}$

Figura 3.28: Balança (a) e projetis (b) empregados para os ensaios. 


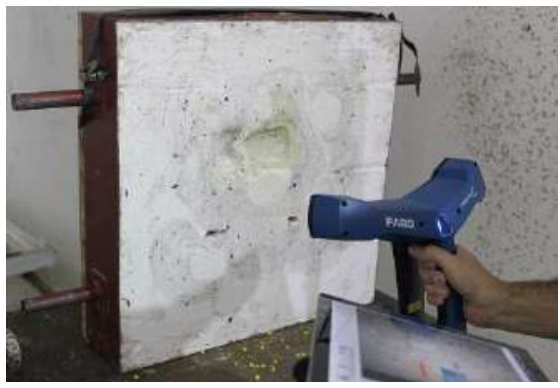

(a) Escâner FARO FreeStyle ${ }^{3 D}$

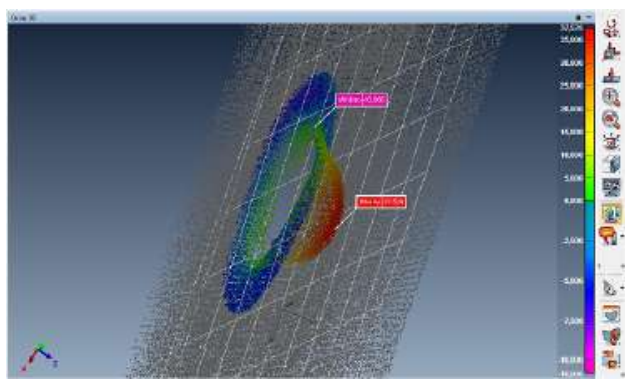

(b) Programa PolyWorks Viewer ${ }^{T M}$

Figura 3.29: Equipamento de varredura (a) e programa de suporte (b).

A caixa de plastilina balística ficou acondicionada por cerca de 48 horas à $22^{\circ} \mathrm{C}$ antes da realização dos ensaios. Foi realizado o Teste de queda padronizado com cinco esferas de aço, da altura de dois metros, com o objetivo de verificar se o material estava apto para ser empregado como suporte para o teste balístico. O valor de deformação máximo foi de $17,4 \mathrm{~mm}$, o que se mostrou dentro do aceitável.

A caixa de plastilina para apoio das placas foi posicionada para que a distância da boca do provete fosse de $15 \mathrm{~m}$. As placas foram fixadas por meio de suportes metálicos e bandas elásticas à caixa de plastilina.

Empregando os equipamentos e materiais descritos acima, dois tipos de ensaios foram realizados. O primeiro chamado de Limite Balístico, mais conhecido como $V_{50}$, e o segundo de Resistência Balística. A finalidade era, respectivamente, levantar velocidade em que a probabilidade de ocorrência de penetração seria de 50\% (V50), e quantificar a capacidade de absorção e dissipação de energia de todos os modelos de placas ao serem alvejadas por projetis 7,62 mm, mensurando o valor de trauma, como previsto no ensaio de resistência balística.

Fez-se necessário realizar o aquecimento do provete e testar a relação entre a quantidade de pólvora e as velocidades obtidas, com uma série de cerca de 15 disparos, sem os alvos posicionados. Na sequência teve início o ensaio dos $16 \mathrm{CPs}$, com as quatro placas (CPs 6, 7, 14 e 15) para calcular o $V_{50}$ e, em seguida, com as doze placas (CPs 1, 2, 3, 4, 5, 8, 9, 10, 11, 12, 13 e 16) para o teste de resistência.

\subsection{1}

\section{Teste de Limite Balístico (V50)}

Durante o ensaio de $\mathrm{V}_{50}$ houve a necessidade de alterar o provete e o estojo de $51 \mathrm{~mm}$ para o provete e estojo de $63 \mathrm{~mm}$, pois se atingiu o limite de 
segurança da quantidade de pólvora nos estojos de $51 \mathrm{~mm}$, com uma velocidade de $890 \mathrm{~m} / \mathrm{s}$, sem que houvesse perfuração das placas.

A utilização do estojo de $63 \mathrm{~mm}$ permitiu aumento da quantidade de pólvora de base dupla $(W C 844-C B C)$ empregada no Ensaio de $V_{50}$, e possibilitou disparos com velocidades de até $1000 \mathrm{~m} / \mathrm{s}$.

O critério de falha adotado nesta pesquisa (Critério do Exército) considera que a perfuração ocorreu se foi possível a passagem de luz visível através de um orifício produzido pelo impacto do projétil ou se a ponta do mesmo se tornou visível na parte posterior da blindagem. Caso houvesse perfuração, a deformação decorrente na plastilina era facilmente identificada.

\subsection{2}

\section{Teste de Resistência Balística}

As placas com medidas padrão receberam seis impactos, e as menores, com 22 por $22 \mathrm{~cm}$ só puderam ser impactadas com quatro disparos, conforme Figura 3.30. Não deveria haver perfuração e as deformações deveriam ser inferiores à $44 \mathrm{~mm}$. A massa de plastilina se mantém deformada após o impacto balístico, se mostrando como um importante meio para a aferição de energia transmitida pela placa alvejada. Para poder quantificar a energia absorvida e dissipada pelas placas, foi realizada a varredura da plastilina após cada disparo, empregando o equipamento portátil de varredura a laser para volumes FARO FreeStyle $^{3 D}$ Objects, do CAEx.

Desse modo, com o pós-processamento das informações, tornou-se possível reconstruir em três dimensões a deformação total gerada por cada impacto. Baseado nesses dados buscou-se calcular a profundidade máxima de deformação a partir do plano externo da plastilina, também chamado de valor de trauma. O programa utilizado para verificar estes dados do escaneamento foi o PolyWorks Viewer ${ }^{T M} 2017$ IR3.1 (build 4075) 64-bit July 2017 - InnovMetric Software Inc, também do CAEx.

\section{8}

\section{Câmera de vídeo de ultra alta velocidade}

Uma câmera de ultra alta velocidade Photron Limited modelo FASTCAM $S A-Z$ foi usada para capturar o instante do impacto do projétil nas placas, a deformação inicial e a propagação mecânica de danos durante o evento de impacto. Essa câmera tem capacidade de registrar até um milhão de quadros por segundo, sendo este vídeo processado por meio do programa Photron FASTCAM Viewer for High Speed Digital Imaging, do CAEx. 

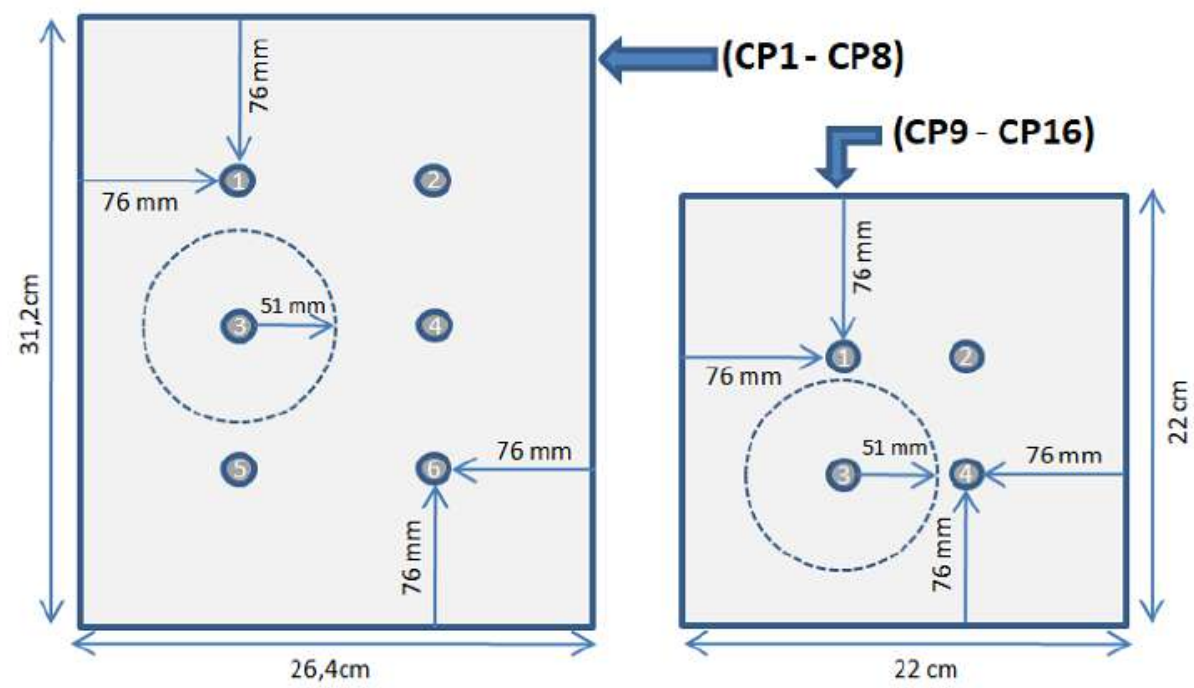

Figura 3.30: Disposição do local dos impactos nas placas.

Foi utilizado ainda um conjunto de refletores para propiciar iluminação adequada para gravação de imagens em alta velocidade, conforme exposto no conjunto de Figuras 3.31a, 3.31b e 3.31c. Dessa forma se torna possível reproduzir o fenômeno do impacto, que ocorre em cerca de $35 \mu \mathrm{s}$, em velocidade de vídeo adequada para a visualização da interação causada pelo evento balístico. Nessa pesquisa foi empregada a velocidade de gravação de cem mil quadros por segundo, devido à dificuldade de obtenção de foco e a demora no processamento das imagens ao se utilizar a capacidade máxima do equipamento.

Essa análise foi utilizada em testes balísticos complementares para estudar a diferença da propagação inicial do impacto em placas com e sem a chapa de titânio na face de impacto. 


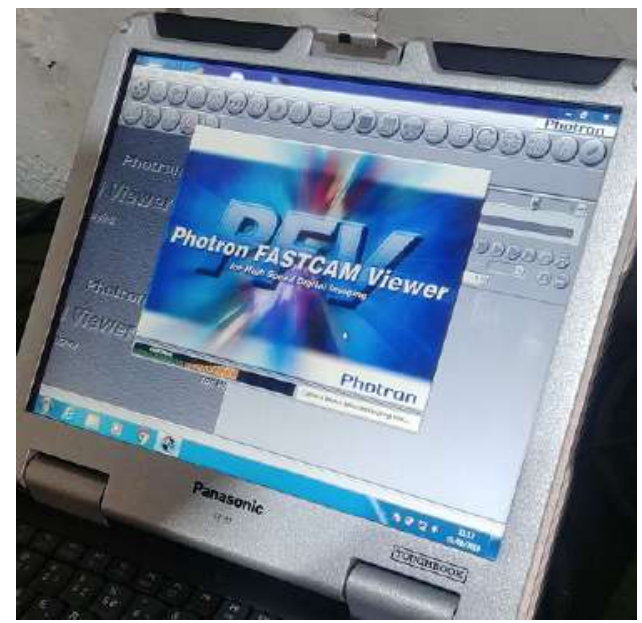

(a) programa Photron FastCam Viewer

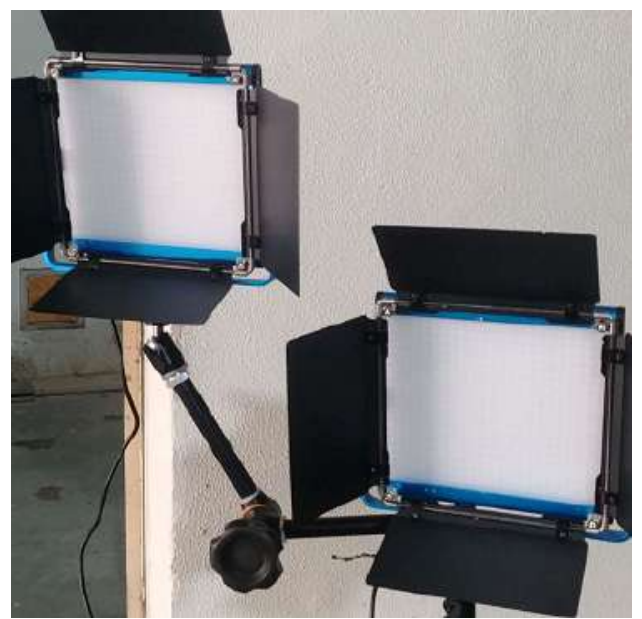

(b) conjunto de refletores de led

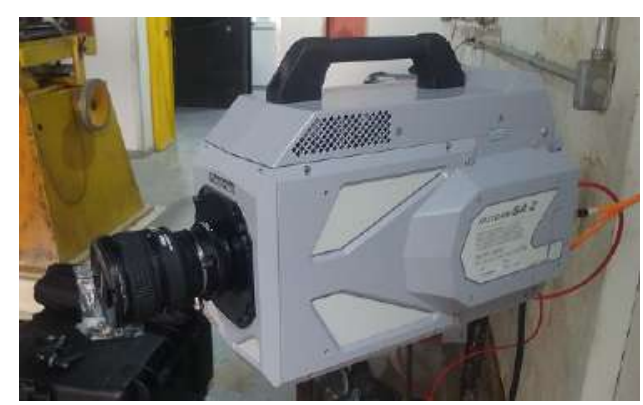

(c) Câmera Photron Limited modelo FastCam $S A-Z$

Figura 3.31: Equipamento para gravação de vídeo em ultra alta velocidade composto por: (a) programa de processamento de imagens; (b) conjunto de iluminação adequado; (c) câmera de ultra alta velocidade.

O foco foi feito em um ponto definido na face anterior da placa balística, onde houve o apontamento com o sistema de pontaria com feixe de laser do provete de tiro. Dessa forma se fez viável analisar o início da interação e dissipação da energia cinética do projetil quando atingiu a placa. Este procedimento foi repetido por seis vezes, sendo três na placa apenas de prepreg, e outras três em placas com a face anterior recoberta pela chapa de titânio.

\section{9}

\section{Análise Estatística}

A estatística como ferramenta de apoio foi empregada nos trabalhos e metrologia dos diversos materiais que fizeram parte da fabricação das placas. Após o processo de prensagem, houve novo controle dimensional das amostras. Logo, foram calculadas as dimensões, massa e densidade de área.

Os dados dos ensaios balísticos também foram verificados quanto à média das velocidades e das deformações. 
A Distribuição de Weibull foi utilizada no ensaio mecânico de tração de fibra para análise e validação dos resultados de tensão x deformação. Os cálculos foram realizados com o programa Microsoft Excel ${ }^{\circledR}$ (2007). Dessa forma, obteve-se o Módulo de Weibull relativo a cada conjunto de fibras ensaiadas.

Para possibilitar o emprego da análise de regressão linear múltipla foi elaborada uma planilha consolidada no programa Microsoft Excel ${ }^{\circledR}$ (2007) contendo os dados constitutivos das placas, as variáveis de processo e as respostas dos ensaios balísticos, conforme apresentado no Apêndice D, Seção D.1.

Para estudo de regressão os dados foram inseridos no programa de análise estatística $\mathrm{R}^{\odot}$. O modelo para experimento foi analisado usando o método de eliminação Backward e os resultados com $P<0$, 05 foram considerados significativos. O Software R, versão 3.6.1 (2019-07-05) - ("Action of the Toes"2019 The R Foundation for Statistical Computing Platform, Vienna, Austria - A language and environment for statistical computing - http://www.Rproject.org) trata-se de um programa gratuito em linguagem de programação voltado para manipulação, análise e visualização gráfica de dados.

Fizeram parte do modelo inicial as variáveis qualitativas (Ti, PE, Espuma), as quantitativas ( $n^{o}$ de camadas, D/A, Velocidade, Tiro), a interação duas a duas dessas variáveis, e os dados de resposta da deformação medida na plastilina para cada disparo que não perfurou a placa. As variáveis qualitativas assumiam o valor 1 ou -1, baseadas em: $T i$ - ter ou não a chapa de Ti-6Al-4V, PE - prepreg de ST-HB13 ou HB212, e Espuma - Poron XRD ou PEBD/EVA.

Foi considerada a possibilidade de interação entre os parâmetros, o que levou à combinação dois a dois, gerando um sistema de 28 variáveis de entrada, entre qualitativas e quantitativas.

Foram analisados por Backward dois modelos de regressão. O primeiro deles somente com os 7 fatores principais, sem considerar interação entre as variáveis (Mod1), e o segundo modelo começou com 28 fatores, advindos das interações dois a dois das variáveis principais (Mod2). 


\section{Resultados e Discussões}

Neste capítulo, serão abordados os resultados obtidos ao longo do desenvolvimento desta tese, no que tange à caracterização, fabricação, e ensaios balísticos, considerando nesses ensaios os dados sobre o trauma medido na plastilina como pontos principais. São relevantes também as diferenças na caracterização e no desempenho dessas placas, em decorrência das variadas composições dos corpos de prova e condições de análise, e o resultado do estudo de regressão linear múltipla.

\section{1}

\section{Fabricação de placas balísticas}

Após a prensagem, os dois grupos de placas passaram por inspeção visual colocadas sobre uma fonte de luz, para procurar falhas de consolidação, e não foi detectado problema em nenhum dos 16 CPs.

A Tabela 4.1 expressa o resultado do controle dos parâmetros de força e temperatura aos quais os materiais foram submetidos. O gráfico de temperatura por tempo pode ser revisto nas Figuras 3.8a e 3.8b.

Tabela 4.1: Principais valores dos ciclos de fabricação das placas.

\begin{tabular}{l|c|c|c}
\hline \multicolumn{1}{c|}{ Etapas } & $\mathbf{1}^{\mathbf{o}}$ dia & $\mathbf{2}^{\mathbf{o}}$ dia & \multirow{2}{*}{ variação } \\
\cline { 2 - 3 } & HB212 & ST-HB13 & \\
\hline Tempo de aquecimento $\left(30{ }^{\circ} \mathrm{C}\right.$ a $\left.130{ }^{\circ} \mathrm{C}\right)$ & 35 & 32 & $-8,6 \%$ \\
Força média de prensagem - aquecimento & 43 & 39 & $-9,3 \%$ \\
Pressão média no ciclo de aquecimento & 25,5 & 39,1 & $+53 \%$ \\
Força média de prensagem - compactação & 390 & 390 & - \\
Pressão média no ciclo de compactação & 232,1 & 394,7 & $+70 \%$ \\
Tempo no platô (entre $\left.130{ }^{\circ} \mathrm{C} \mathrm{e} 125^{\circ} \mathrm{C}\right)$ & 33 & 33 & - \\
Resfriamento I de $125^{\circ} \mathrm{C}$ a $60^{\circ} \mathrm{C}($ tempo) & 10 & 13 & $+30 \%$ \\
Resfriamento II de $60^{\circ} \mathrm{C}$ a $40^{\circ} \mathrm{C}$ (tempo) & 8 & 6 & $-25 \%$ \\
Tempo total do ciclo & 86 & 84 & $-2,3 \%$ \\
\hline Tempo (minutos) & & \\
Força (tonelada-força) & & \\
Pressão (bar) &
\end{tabular}

No Apêndice B estão dispostas as Tabelas B.1 e B.2, com os resultados detalhados de controle dos processos de fabricação.

Apesar das prensagens terem transcorrido sem alteração, verifica-se pela Tabela 4.1 que os tempos totais de cada processo ultrapassaram $80 \mathrm{~min}$. 
De acordo com orientação da empresa DSM (115) fabricante do prepreg HB212, com o perfil de aquecimento que foi imposto às amostras, seria possível consolidar a cura das placas de HB212 em aproximadamente 33 min a menos, reduzindo o tempo de desgaseificação, de cura à carga máxima e o tempo antes do alívio da carga durante o resfriamento.

Foi verificado que durante o processo de fabricação a temperatura máxima do molde não ultrapassou os $130^{\circ} \mathrm{C}$. Porém, a temperatura mais alta chegou à $127^{\circ} \mathrm{C}$ dentre as placas de HB212 (CP5), e atingiu a máxima de $125^{\circ} \mathrm{C}$ nas placas de ST-HB13 (CP12). As diferentes espessuras e composições das placas afetaram a transferência de calor, causando diferenças nas curvas de aquecimento.

A força média de prensagem aplicada durante a etapa de compactação foi similar para os dois ciclos de fabricação. Porém, a diferença de área superficial entre as placas dos dois prepregs acarretou em pressão média resultante da compactação distinta para os dois grupos.

Devido à maior área das placas de HB212 (cerca de $824 \mathrm{~cm}^{2}$ ), a pressão de consolidação a que estes CPs foram submetidos foi da ordem de 230 bar. Já no caso das placas feitas de ST-HB13, com área de $484 \mathrm{~cm}^{2}$, a pressão na etapa de consolidação foi de aproximadamente 395 bar.

Ambos os valores estão acima do indicado como mínimo pela empresa DSM (115), e pelos artigos científicos citados anteriormente nessa pesquisa $(34,61)$, o que sugere boa consolidação.

Sobre a diferença de 70\% no valor de pressão média entre as placas (Tabela 4.1), cabe retomar o estudo de Greenhaldh et al. (2013), que aponta alteração nos mecanismos de deformação atuantes nas placas quando a fabricação se dá em pressões distintas (64), pois a distribuição da matriz entre as fibras se modifica.

Dessa forma, acredita-se que a consolidação das placas de ST-HB13 com pressão consideravelmente superior, apesar de o material ter menor resistência balística específica, foi positiva para melhorar seu desempenho. Essa questão será apresentada nos resultados de ensaio de Limite Balístico de $V_{50}$.

\section{2}

\section{Caracterização de placas balísticas}

\subsection{1}

\section{Determinação da densidade de área}

Quando do delineamento para a fabricação dos corpos de prova, dentro das restrições dos materiais existentes e das condições de contorno limitantes 
para a prensagem, buscou-se seguir a premissa das especificações de cada fabricante quanto às densidades mínimas para resistência ao Nível de proteção NIJ III (Tabelas 3.1 e 3.2) para as placas feitas exclusivamente de prepreg, pois seria essa a condição de controle. Os dois outros protótipos (com adição da chapa de titânio) de cada tipo de prepreg foram especificados para buscar equivalência de espessura e de densidade de área com as placas controle, dentro de cada grupo. Segundo as especificações, o HB212 teria a mesma eficiência balística que o ST-HB13, com apenas $68 \%$ de massa da solução.

Os cálculos das D/A foram realizados e estão condensados na Tabela 4.2. Percebe-se que o objetivo do planejamento foi cumprido, e os resultados das dimensões das placas estão próximos da proposta inicial, conforme destacado nas colunas Espessura e Densidade de área, para cada conjunto de placas.

Tabela 4.2: Densidade de área das placas fabricadas.

\begin{tabular}{cccccc}
\hline Placa & $\begin{array}{c}\text { Liga } \\
\text { metálica }\end{array}$ & $\begin{array}{c}\text { Espessura }^{a} \\
(\mathbf{m m})\end{array}$ & Prepreg & $\begin{array}{c}\text { Massa } \\
(\mathrm{kg})\end{array}$ & $\begin{array}{c}\text { Densidade de } \\
\text { área }\left(\mathrm{kg} / \mathrm{m}^{2}\right)\end{array}$ \\
\hline 01 & - & 14,50 & HB212 & 1,08 & 13,01 \\
02 & - & 14,49 & HB212 & 1,07 & 13,02 \\
03 & Ti-6Al-4V & 14,64 & HB212 & 1,36 & 16,48 \\
04 & Ti-6Al-4V & 14,78 & HB212 & 1,37 & 16,68 \\
05 & Ti-6Al-4V & 11,40 & HB212 & 1,11 & 13,42 \\
06 & Ti-6Al-4V & 11,33 & HB212 & 1,10 & 13,32 \\
07 & Ti-6Al-4V & 11,64 & HB212 & 1,09 & 13,22 \\
08 & Ti-6Al-4V & 11,86 & HB212 & 1,11 & 13,45 \\
\hline 09 & - & 20,08 & ST-HB13 & 0,92 & 19,07 \\
10 & - & 20,12 & ST-HB13 & 0,92 & 19,13 \\
11 & Ti-6Al-4V & 20,39 & ST-HB13 & 1,12 & 23,16 \\
12 & Ti-6Al-4V & 20,41 & ST-HB13 & 1,11 & 23,09 \\
13 & Ti-6Al-4V & 16,58 & ST-HB13 & 0,94 & 19,46 \\
14 & Ti-6Al-4V & 16,67 & ST-HB13 & 0,94 & 19,53 \\
15 & Ti-6Al-4V & 16,76 & ST-HB13 & 0,94 & 19,51 \\
16 & Ti-6Al-4V & 16,79 & ST-HB13 & 0,93 & 19,35 \\
\hline$a$ & \multicolumn{5}{c}{ Espessura: refere-se às placas antes da união com a camada de espuma } \\
\hline \multicolumn{5}{c}{}
\end{tabular}

\subsection{2}

\section{Caracterização das placas de Ti-6Al-4V}

\subsubsection{1}

\section{Resultado dos Ensaios de Dureza}

A dureza da chapa da liga de Ti-6Al-4V foi determinada após ensaio de três amostras, retiradas de diferentes regiões do material adquirido. As indentações (Figura 4.1) demonstraram resultados semelhantes, ao longo da realização dos testes, sendo este valor igual a $40 \mathrm{HRC}$ (cerca de $390 \mathrm{HV}$ ). 


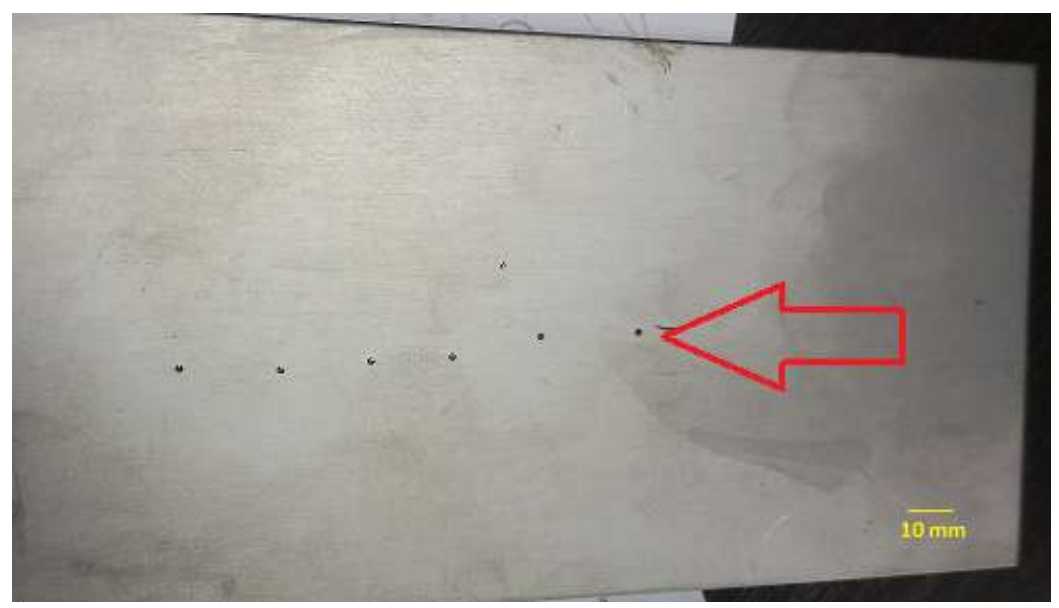

Figura 4.1: Indentações do ensaio de dureza HRC na placa de Ti-6Al-4V.

A dureza de $40 H R C$ é consistente com publicações sobre processos de fabricação, tratamentos térmicos e mecânicos dessa liga (100, 101, 59). Segundo Lee \& Lin (1998), é possível ainda elevar esse resultado de dureza até $450 H V(46 H R C)$, induzindo deformação plástica em temperaturas abaixo da temperatura de recristalização da liga (101).

Tal procedimento seria interessante para futuros trabalhos, pois como apresentado por Deniz (2010) em estudos de simulação de blindagens, quanto maior a dureza, maior a eficiência da proteção balística em placas modeladas (53).

Conforme apresentado por Kissell et al. (2004), cabe ainda destacar uma alternativa de liga a ser considerada para aplicações em blindagem, a Timetal 62S (Ti-6Al-2Fe-0,1Si), cuja base para produção é uma liga de Al-Fe, com menor custo do que o Ti-6Al-4V (57).

\subsubsection{2}

\section{Análise termodinâmica do impacto balístico na placa de Ti-6Al-4V}

O resultado da análise realizada no programa Thermo-Calc ${ }^{\circledR}$ para estimar o efeito da transmissão da energia cinética do projetil e conversão em entalpia, quando do impacto nas placas com a lâmina de Ti-6Al-4V, está exposta na Figura 4.2.

A simulação proposta pelo Programa Thermo Calc sugere que a massa aproximada de $2,06.10^{-1} \mathrm{~g}$ de titânio, se recebesse o montante de $3200 \mathrm{~J}$ de energia cinética do projetil, passaria do estado sólido à $25^{\circ} \mathrm{C}$ diretamente para vapor, atingindo ainda a temperatura hipotética de cerca de $7572,56^{\circ} \mathrm{C}$. Essa simulação não considerou a estrutura da placa consolidada de prepreg reforçado com fibras de UHMWPE a qual a chapa de titânio está unida. 


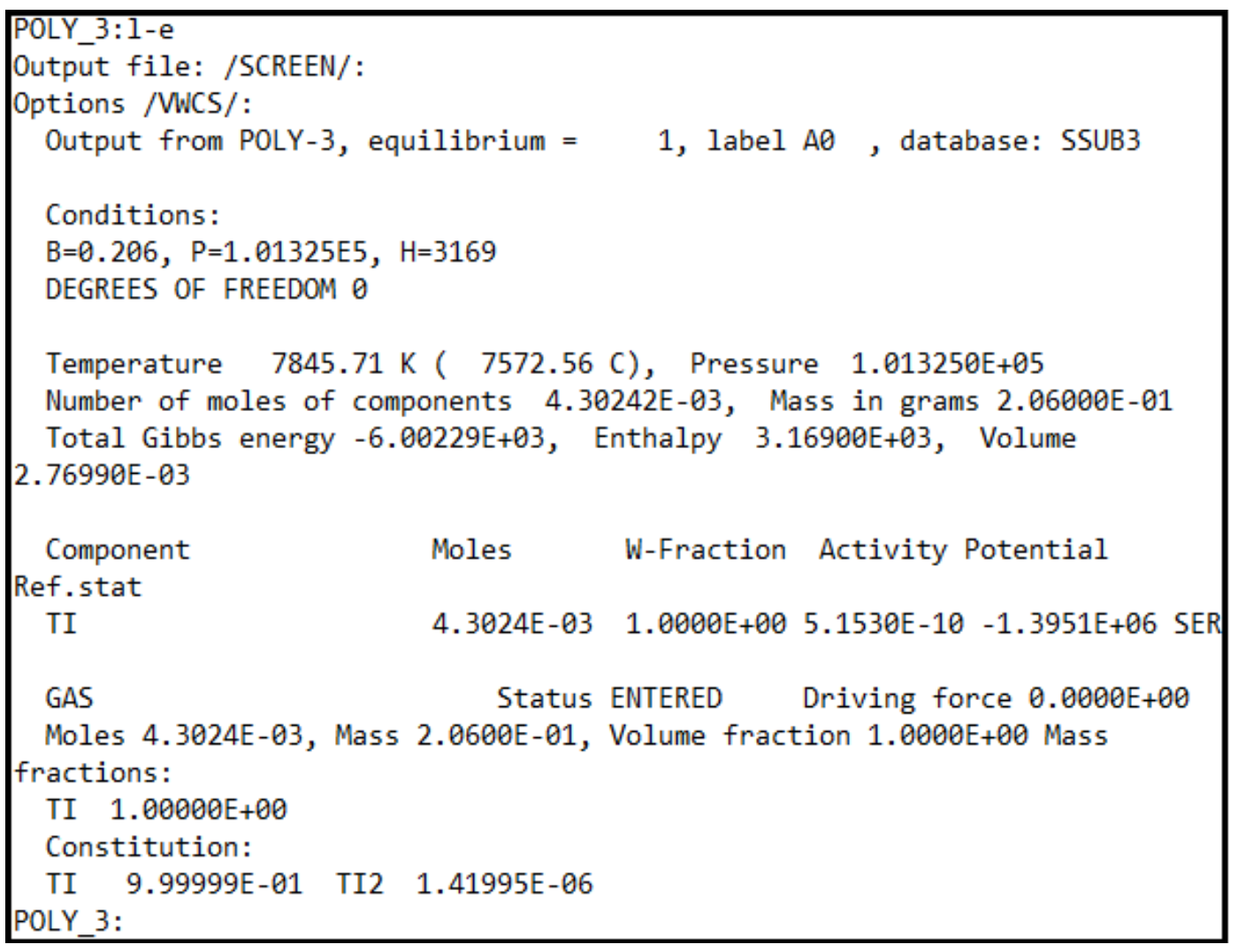

Figura 4.2: Tela de resposta do programa Thermo-Calc ${ }^{\circledR}$.

As imagens obtidas com a Câmera de ultra alta velocidade, conforme os quadros da Figura 4.3, sugerem que o impacto do projetil de $9,63 \mathrm{~g}$ à aproximadamente $845 \mathrm{~m} / \mathrm{s}$ transfere energia suficiente para evaporar a massa da liga de titânio à sua frente.

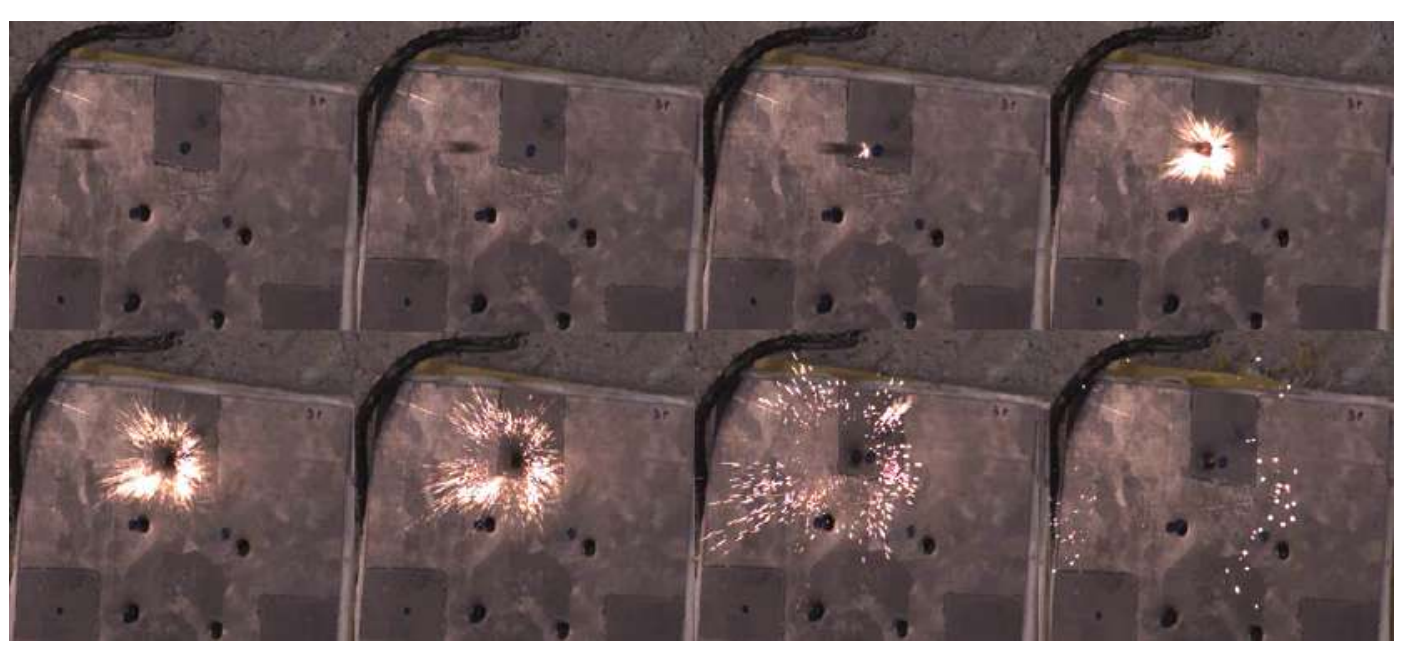

Figura 4.3: Imagens câmera alta velocidade. 


\subsubsection{3}

\section{Resultado da Metalografia com Microscopia Ótica}

Da análise metalográfica realizada com a liga de Ti-6Al-4V, com suporte nas publicações citadas anteriormente $(58,100,59,102,108)$, pode-se dizer que o material apresentou as fases $\alpha$ e $\beta$ em uma distribuição bimodal. Identificouse os grãos $\alpha$ primários (que tem estrutura hexagonal compacta) e regiões escuras que definem a presença da fase $\beta$ (cúbica de corpo centrado) ao longo dos contornos de grão de $\alpha$ (Figura 4.4).

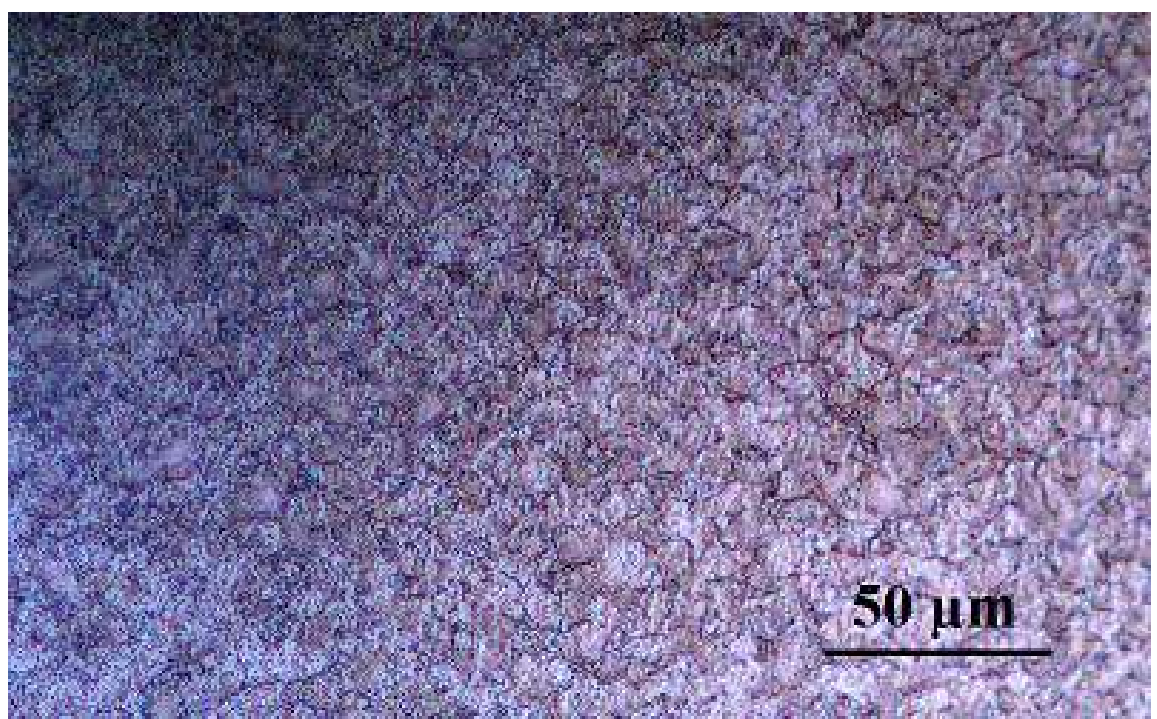

Figura 4.4: Imagem por MO da microestrutura da liga de Ti-6Al-4V (500x).

Essa microestrutura sugere que a placa passou por tratamento térmico após a fabricação, pois não se percebe grãos alongados característicos de materiais laminados, ou bandas de cisalhamento adiabático devido à deformação plástica localizada. Tão pouco se percebe microestrutura lamelar, de forma que a placa pode ter sido submetida à solubilização em temperatura abaixo de $955^{\circ} \mathrm{C}$, têmpera em água e envelhecimento, acarretando na microestrutura revelada e no valor de dureza aferido.

\subsection{3}

\section{Caracterização dos prepregs e das espumas}

\subsubsection{1}

\section{Resultado da Microscopia Ótica}

As fibras retiradas dos prepregs e preparadas para o ensaio de tração tiveram o diâmetro verificado por microscopia ótica. As amostras extraídas do HB212 apresentaram diâmetro de 13,55 $\mu m \pm 1,74(\mathrm{n}=32)$, já o valor para as fibras do ST-HB13 foi de 17,98 $\mu m \pm 1,98(\mathrm{n}=55)$. 
O resultado para a fibra do HB212 está próximo do valor das poucas publicações disponíveis $(17,33)$. Entretanto, esses artigos analisaram a fibra SK99 como material isolado, e não após ser retirada de um prepreg, além de não haver informação relacionada com amostragem utilizada para medição dos diâmetros. Era esperado encontrar diferenças nas dimensões e na resistência, devido ao tratamento superficial que as fibras sofreram para otimizar a adesão com a matriz no HB212 $(92,93)$.

O diâmetro médio da fibra destacada do ST-HB13 é similar às medidas de fibras de gerações anteriores a da fibra SK99, da DSM, como a SK66 e SK76 (17, 91, 98). Essa tendência pela redução do diâmetro e otimização da resistência específica está descrita na publicação de Park \& Rutledge (2018).

\subsubsection{2}

\section{Resultado da Microscopia Eletrônica de Varredura}

O ensaio de MEV foi realizado com: prepregs HB212 e ST-HB13, fibras destacadas de cada um destes compósitos, espumas Poron $\mathrm{XRD}^{\circledR}$ e PEBD/EVA.

Por meio da análise das fibras, verificou-se nas Figuras 4.5a, 4.6a e 4.6b, resquícios de matriz aderida e alterações superficiais, como rugosidades, provavelmente provocadas pelo processo de fabricação dos prepregs, com objetivo de aumentar a adesão com a matriz. Nessas imagens pode-se constatar ainda o diâmetro das fibras, registrando valores dentro da especificação relatada no ensaio de MO, na Seção 4.2.3.1.

Na Figura 4.5b pode-se constatar a espessura do prepreg HB212, em consonância com a publicação de O'Masta et al. (2016), considerando as quatro camadas de fibras alternadas $\left(0^{\circ} / 90^{\circ} / 0^{\circ} / 90^{\circ}\right)$ formando a unidade básica desse prepreg (33). O prepreg de ST-HB13 é composto por duas camadas $\left(0^{\circ} / 90^{\circ}\right)$, da acordo com a Figura 4.7 a.

Na Figura $4.5 \mathrm{c}$ foi verificada a orientação de $0^{\circ} / 90^{\circ}$ entre as camadas de fibras do HB212.

Foi comprovada diferença na estrutura dos prepregs. O HB212 apresentou a matriz dispersa sobre as fibras, como uma massa de particulados, por vezes com distribuição mais homogênea (Figura 4.5d). Já o ST-HB13 é constituído por camadas intercaladas de filmes (matriz) e fibras (Figura 4.7b). 


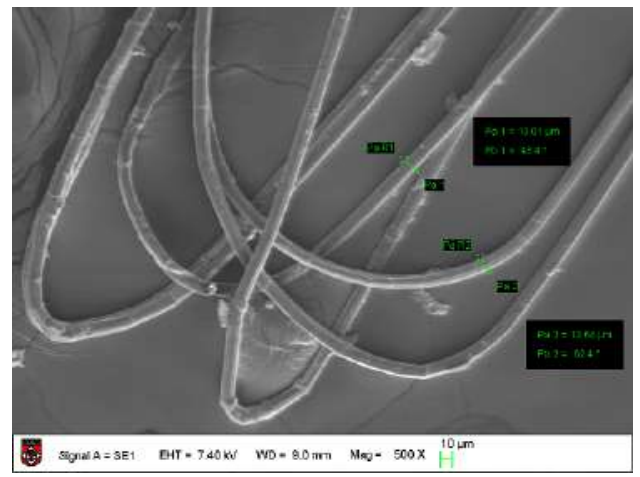

(a) Diâmetro de fibras de HB212 (500x)

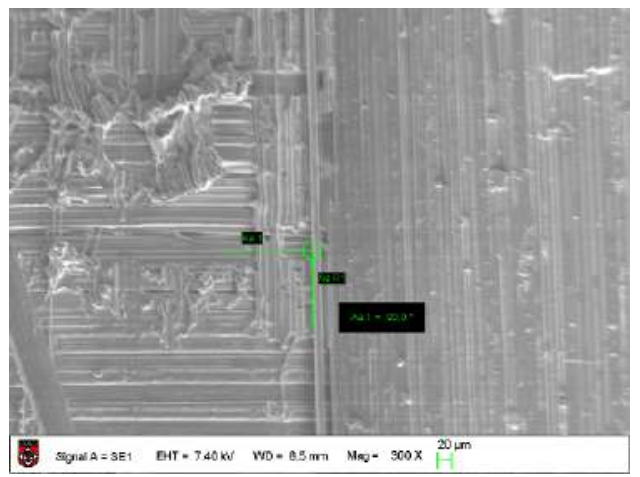

(c) Fibras dispostas a $0^{\circ} / 90^{\circ}$ no HB212 (300x)

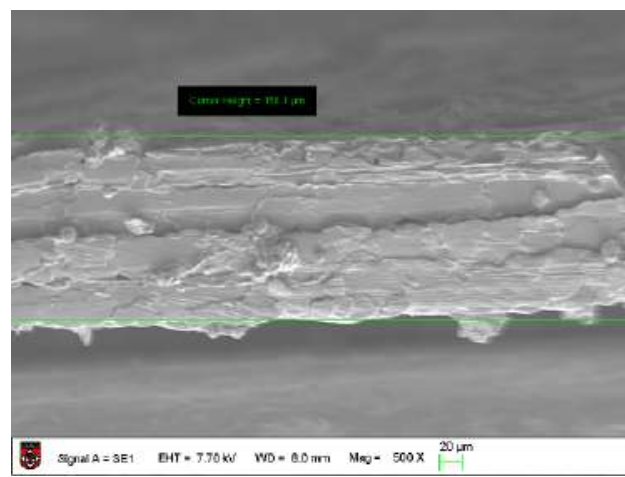

(b) Espessura do prepreg HB212 (500x)

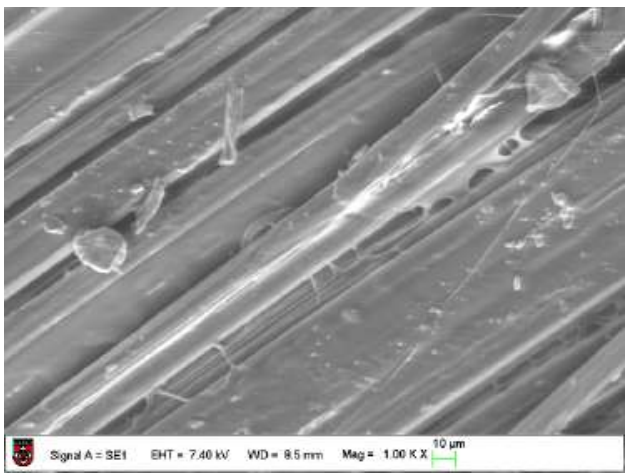

(d) Matriz dispersa sobre as fibras do HB212

Figura 4.5: Imagens de MEV do prepreg HB212 e fibras.

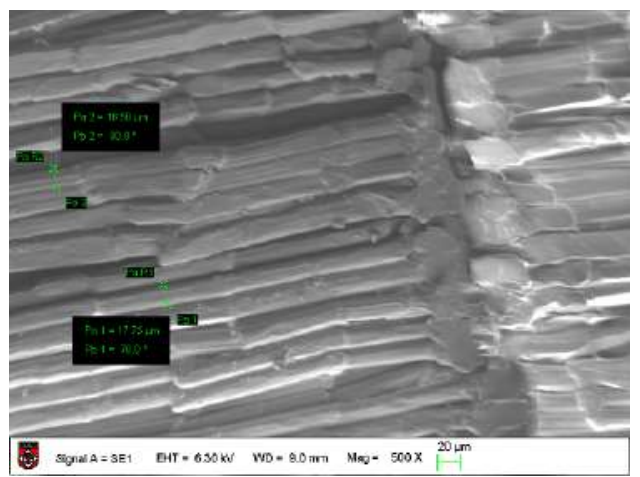

(a) Diâmetro de fibras de ST-HB13 (500x)

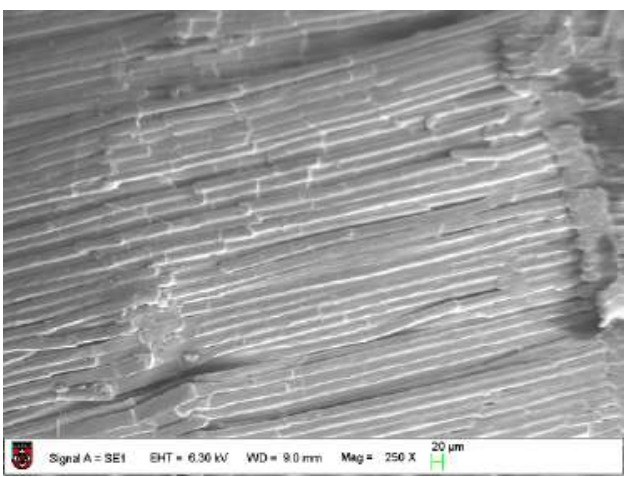

(b) Matriz aderida e alterações superficiais das fibras do ST-HB13 (250x)

Figura 4.6: Imagens de MEV da disposição de fibras do ST-HB13. 


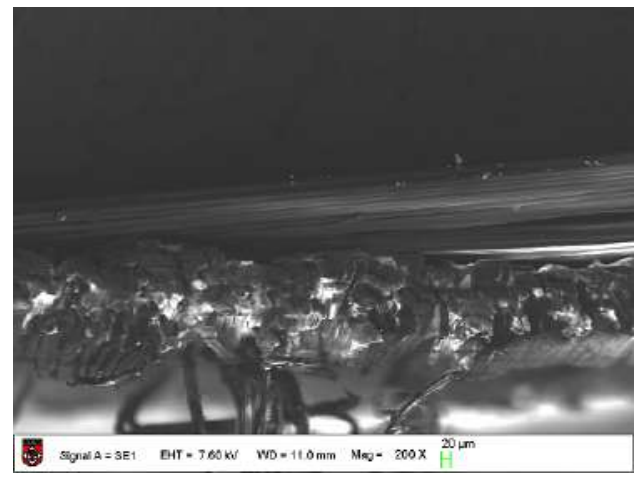

(a) Camadas do prepreg ST-HB13 (200x)

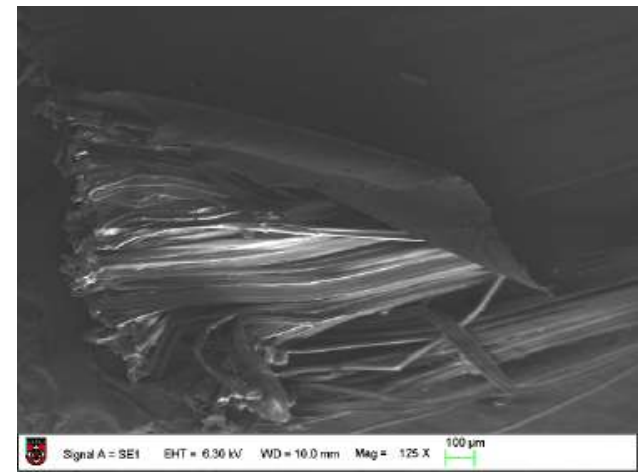

(b) Filme que compõe a matriz do STHB13 (125x)

Figura 4.7: Imagens de MEV do prepreg ST-HB13.

A análise por MEV das espumas ressaltou a diferença morfológica entre o Poron XRD e a de PEBD/EVA.

As Figuras 4.8a e 4.8b exibem a microstrutura do Poron XRD com destaque para uma amostra de medidas de dimensão dos diâmetros das células abertas, e para o tamanho dos poros que servem de comunicação entre essas células.

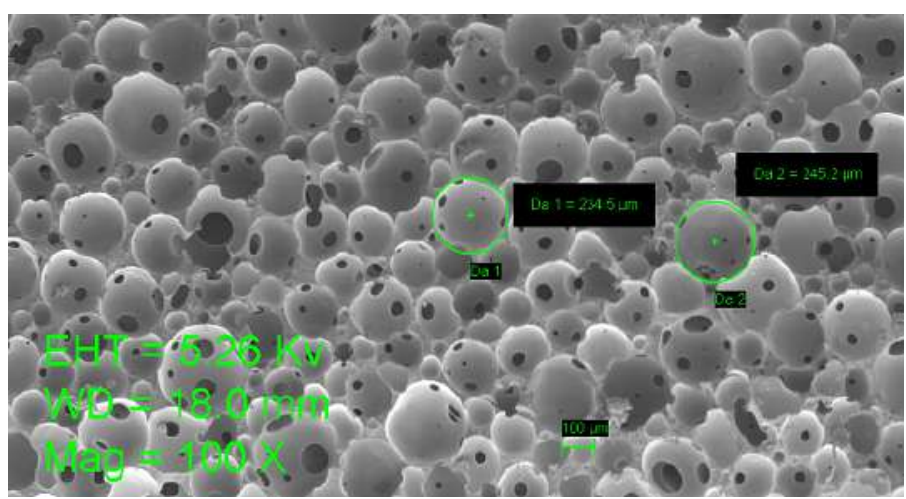

(a) Medição do diâmetro de células abertas (100x)

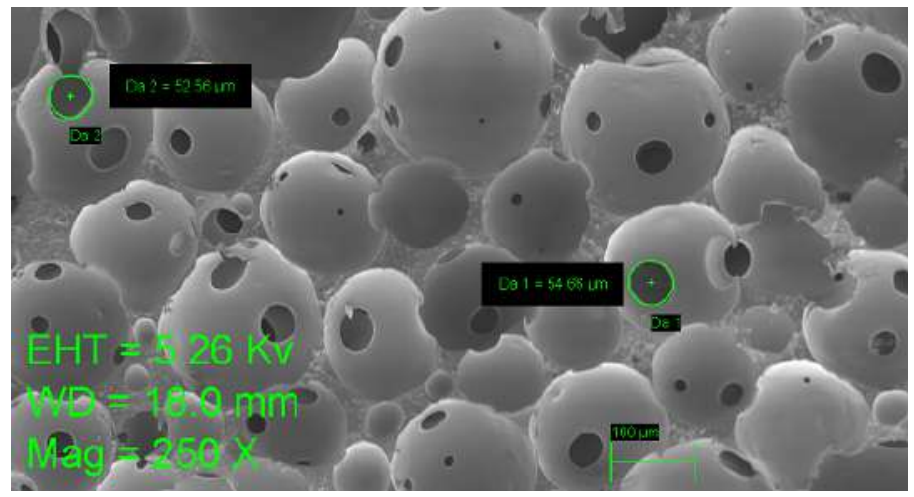

(b) Dimensão de poros das células abertas (250x)

Figura 4.8: Imagem de MEV da estrutura interna da espuma Poron XRD. 
Essa microestrutura possibilita o fluxo de ar dentro do Poron XRD quando o material sofre deformação, conforme descrito anteriormente (44), sendo que o material tem rápida recuperação após a retirada da carga (47). Imagens semelhantes a essa microestrutura foram apresentadas em estudo recente (51) por Ramirez et al. (2018).

A Figura 4.9 expõe imagem de MEV da estrutura interna da espuma Poron XRD (500x) mostrando em detalhe a morfologia das células abertas, e um corte na espuma feito durante a preparação da amostra.

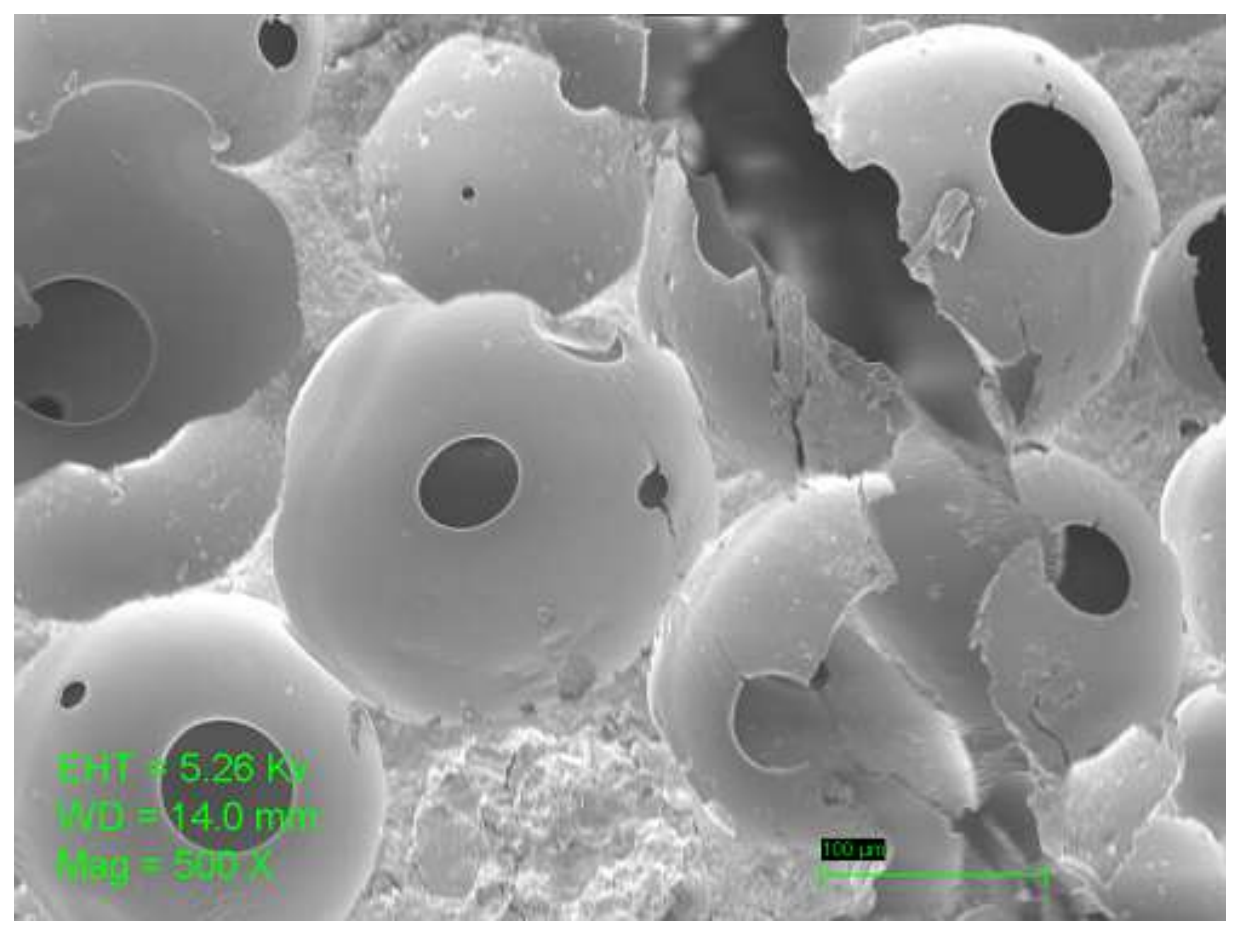

Figura 4.9: Imagem de MEV da estrutura interna da espuma Poron XRD $(500 \mathrm{x})$.

As Figuras 4.10a e 4.10b exibem a microstrutura da espuma de PEBD/EVA, sendo destacada uma amostra de diâmetros em região seccionada das células fechadas. Não foi realizado o processamento digital de imagens para calcular o diâmetro médio das células. 


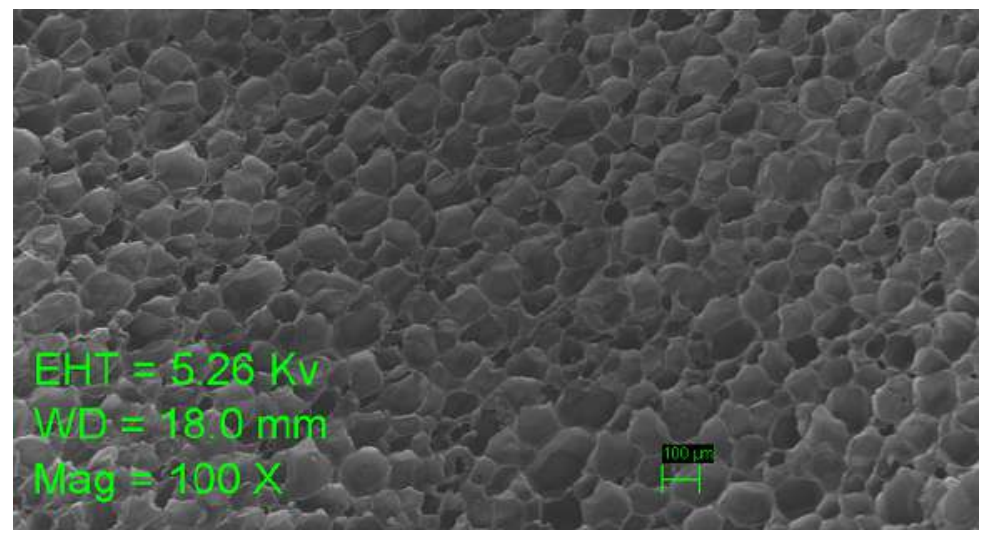

(a) Microestrutura de célula fechada seccionada (100x)

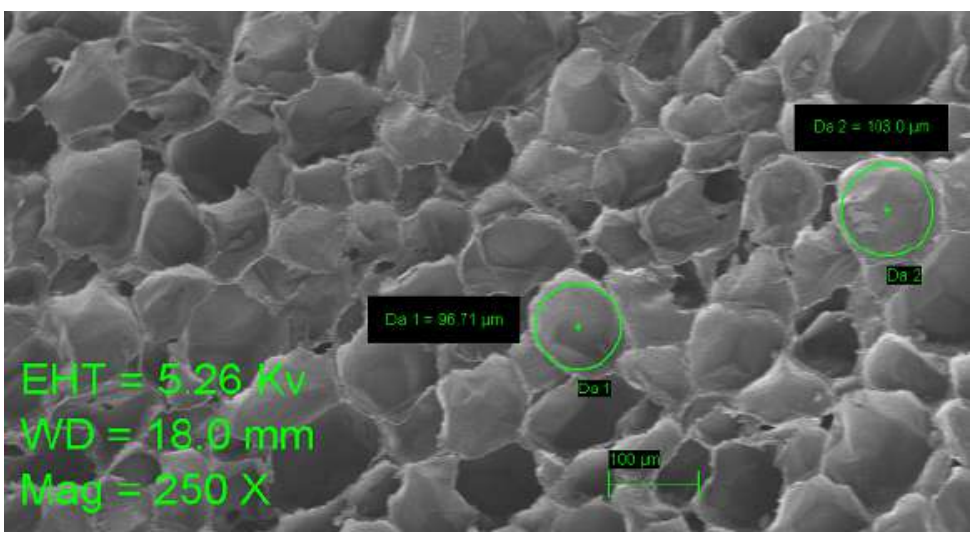

(b) Dimensão de células fechadas seccionadas (250x)

Figura 4.10: Imagem de MEV da estrutura interna da espuma PEBD/EVA.

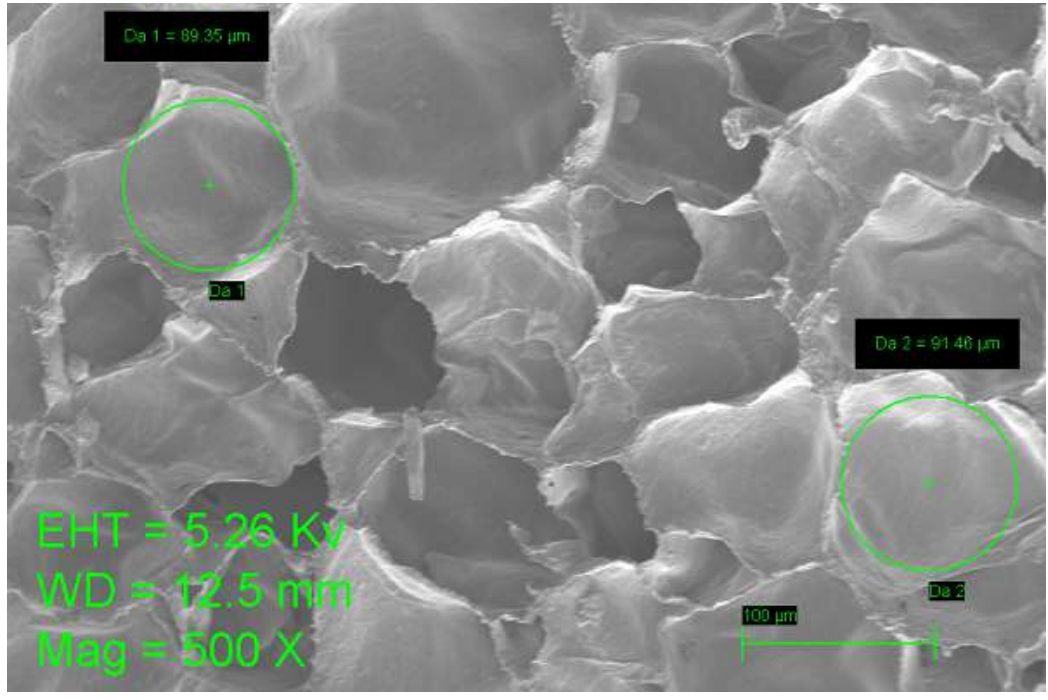

Figura 4.11: Imagem de MEV da estrutura interna do PEBD/EVA (500x). 


\subsubsection{3}

\section{Resultado do ensaio de FTIR}

A análise por FTIR foi utilizada para identificar grupos funcionais ativos presentes nos constituintes principais dos pré-impregnados, das espumas, e do adesivo. Dessa forma, os picos encontrados nos espectros de FTIR desses materiais serão apresentados a seguir.

As Figuras 4.12a e 4.12b exibem o espectro FTIR do material HB212 como recebido e após ter sido prensado a quente para consolidação da placa balística.

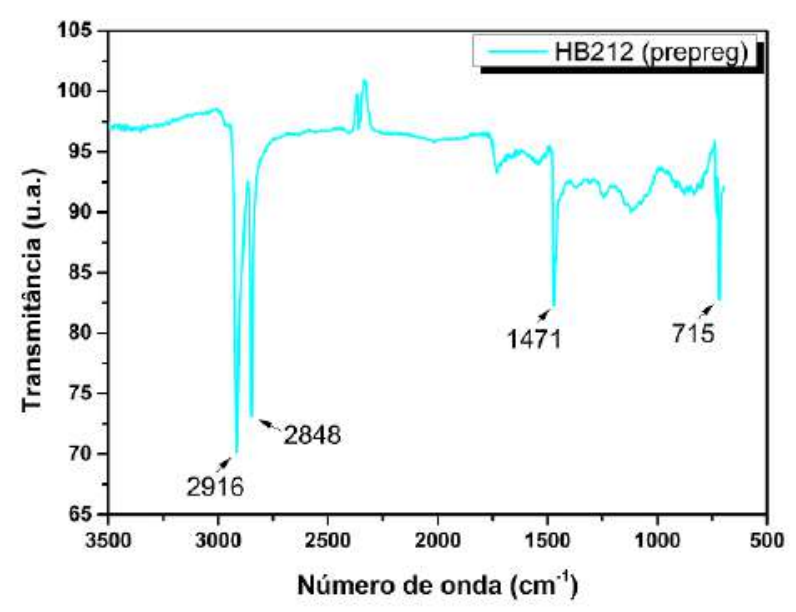

(a) Amostra obtida do HB212 prepreg

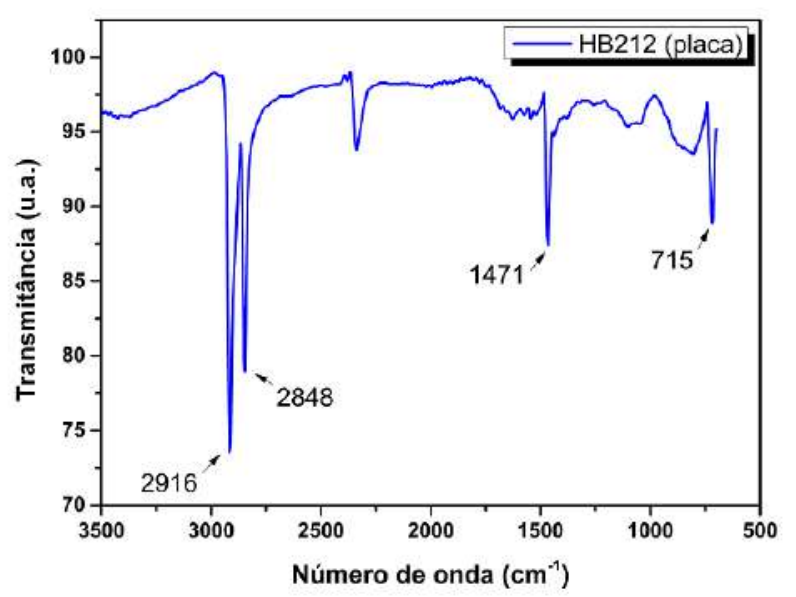

(b) Amostra obtida do HB212 placa

Figura 4.12: Espectro FTIR de amostras de HB212 (a) prepreg e (b) placa.

Verificou-se que praticamente não houve alteração no espectro da amostra de HB212 após passar pelo processo de prensagem a quente. As bandas de 
energia identificadas foram $2916 \mathrm{~cm}^{-1}, 2848 \mathrm{~cm}^{-1}, 1471 \mathrm{~cm}^{-1}, 715 \mathrm{~cm}^{-1}$, sendo os quatro valores bastante similares aos resultados publicados por Fejdyś et al. (2016). Esses autores apontam as bandas de energia de $2911 \mathrm{~cm}^{-1}, 2845 \mathrm{~cm}^{-1}$, $1470 \mathrm{~cm}^{-1}, 730 \mathrm{~cm}^{-1}$, como sendo referentes à vibração das ligações $C-H_{3}$ do material Dyneema ${ }^{\circledR}$ HB26, uma geração anterior de prepreg balístico em relação ao HB212 analisado (90).

A Figuras 4.13a exibe o espectro FTIR do material ST-HB13 como recebido, e o espectro FTIR para esse material após ter passado pela prensagem a quente para fabricar a placa balística está exposto na Figura 4.13b.

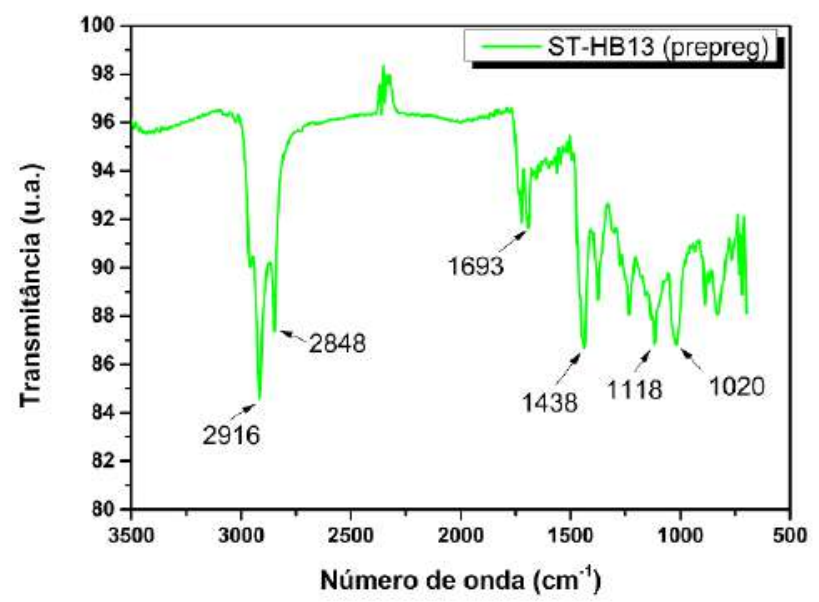

(a) Amostra obtida do ST-HB13 prepreg

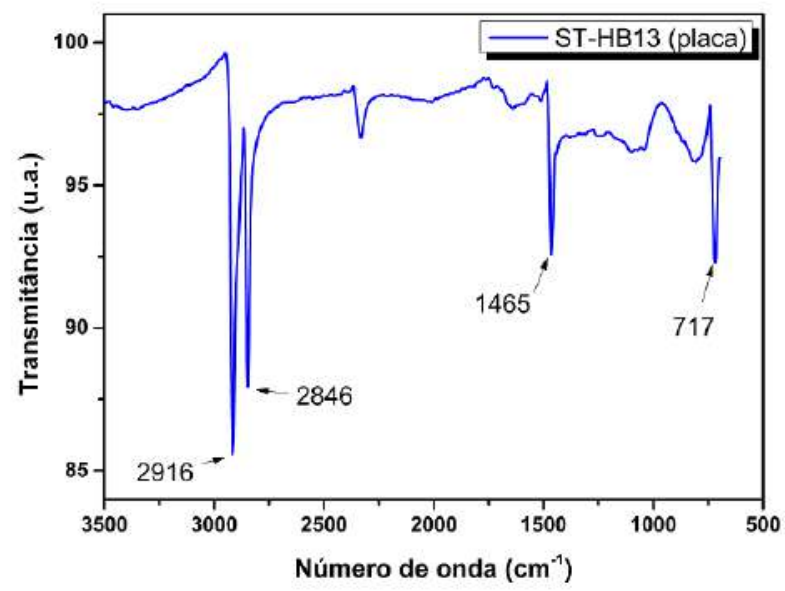

(b) Amostra obtida do ST-HB13 placa

Figura 4.13: Espectro FTIR de amostras de ST-HB13 (a) prepreg e (b) placa.

Para o prepreg ST-HB13, foi identificada diferença decorrente da operação de prensagem a quente. O espectro do material manteve a maior banda de 
absorção e energia igual $\left(2916 \mathrm{~cm}^{-1}\right)$, e os valores bem similares em $2848 \mathrm{~cm}^{-1}$ e $2846 \mathrm{~cm}^{-1}$. Essas bandas são referentes à vibração das ligações $C-H_{3}$, provavelmente do UHMWPE constituinte das fibras do prepreg (90).

Já na faixa de valores de número de onda entre $1693 \mathrm{~cm}^{-1}$ e $717 \mathrm{~cm}^{-1}$ os espectros foram consideravelmente distintos.

Visando o suporte à caracterização da espuma Poron XRD, foram localizados poucas publicações, todas nos últimos anos. Lothe (2013) especifica 16 modelos diferentes de espumas Poron XRD, e realiza somente a caracterização mecânica dos materiais, sem demostrar valores de FTIR (50).

No estudo apresentado por Tang et al. (2017), quatro bandas de energia por ensaio de FTIR são detalhadas para o Poron XRD, entretanto não se especifica qual o modelo de Poron XRD utilizado (47).

Na Figura 4.14 tem-se o espectro FTIR para a espuma Poron XRDMA20236, para o qual não foi identificado resultados semelhantes na literatura.

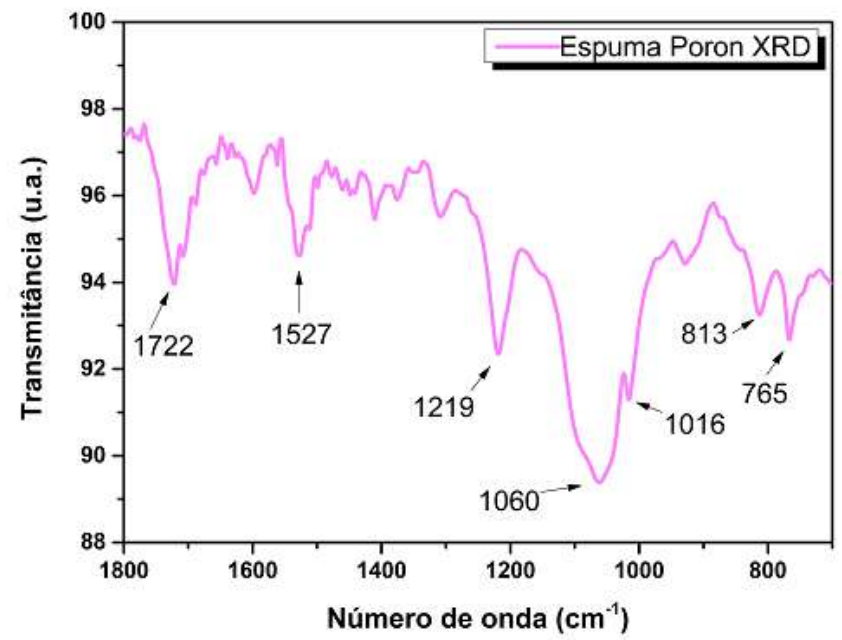

Figura 4.14: Espectro FTIR de amostra de espuma Poron XRD.

O espectro identificado nesta pesquisa não apresentou relação com outros estudos sobre a espuma Poron XRD.

Para o adesivo BP21.2008, utilizado na união da chapa de Ti-6Al-4V com os pré-impregnados durante a prensagem a quente, havia somente a descrição de constituição como "filme adesivo de polioleofina modificada"(Seção 3.2). A identificação espectrométrica desta amostra, presente na Figura 4.15, leva à conclusão de que o material pode ser considerado polietileno, por analogia com os valores de número de onda constantes da publicação de Zheng et al. (2004), que identifica por FTIR a fibra de polietileno SK66 (91). 


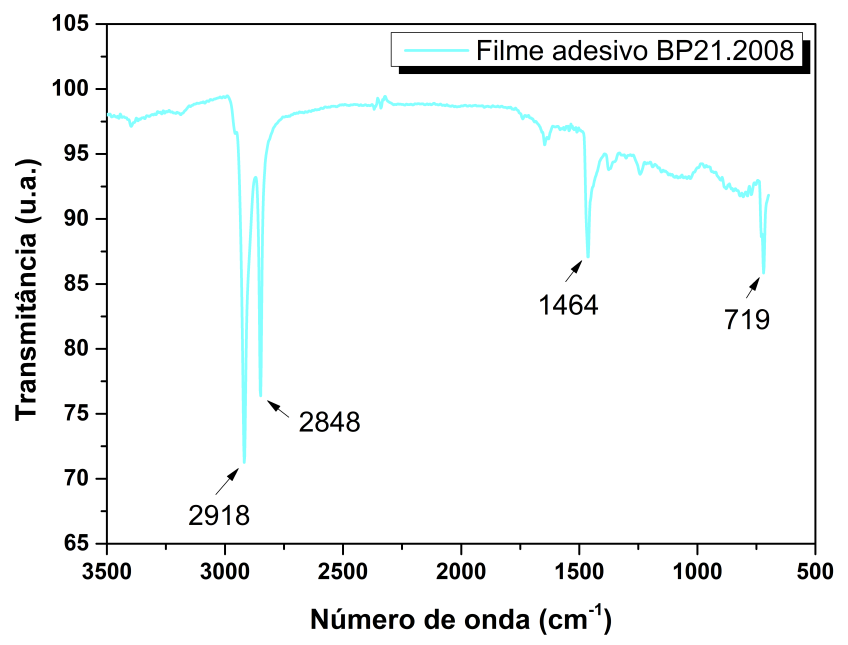

Figura 4.15: Espectro FTIR de amostra de adesivo BP21.2008.

\subsubsection{4}

\section{Resultado da Análise termogravimétrica}

Na TGA procurou-se avaliar a estabilidade térmica dos pré-impregnados HB212 e ST-HB13, bem como das fibras retiradas desses compósitos, em função do ciclo de fabricação das placas balísticas por prensagem a quente, comparando as propriedades dos materiais antes e após a ocorrência dessa atividade.

Estão dispostos no Apêndice A, Seção A.3, os gráficos dos ensaios de TGA das seguintes amostras, de forma comparativa:

- HB212 (pré-impregnado) e HB212 (placa);

- ST-HB13 (pré-impregnado) e ST-HB13 (placa);

- HB212 (pré-impregnado) e fibra do HB212;

- ST-HB13 (pré-impregnado) e fibra do ST-HB13;

- fibra do HB212 e fibra do ST-HB13; e

- HB212 (pré-impregnado) e ST-HB13 (pré-impregnado).

Pela análise das curvas desses materiais verificou-se uma discreta perda de massa se inicia a partir de aproximadamente $150^{\circ} \mathrm{C}$, e que há, basicamente, um único ponto de inflexão, entre $400^{\circ} \mathrm{C}$ e $450{ }^{\circ} \mathrm{C}$, indicando que o processo de decomposição térmica ocorre em apenas um estágio.

Não foi identificada dessa forma nenhuma diferença significativa entre as amostras pré-prensagem e após os processos, nem entre os dois tipos de materiais, sinalizando que a temperatura utilizada não acarretou danos e o processamento foi adequado para ambos. 


\subsubsection{5}

\section{Resultado da Calorimetria exploratória diferencial}

O ensaio de análise térmica por DSC possibilitou estudar o comportamento térmico dos pré-impregnados (HB212 e ST-HB13) e das fibras retiradas destes compósitos, antes e após a etapa de prensagem a quente.

Os gráficos gerados pelo ensaio de DSC, estão dispostos no Apêndice A, Seção A.3, e adotaram a mesma estrutura comparativa realizada para a TGA.

Constatou-se que os traçados das curvas de DSC dos pré-impregnados reforçados por fibras de UHMWPE, para todos os grupos de avaliação, não apresentam grandes divergências.

Inferiu-se que, considerando as condições de processamento da prensagem a quente, a temperatura de $130^{\circ} \mathrm{C}$ não foi suficiente para provocar alterações significativas nos pré-impregnados.

\subsection{4}

\section{Resultado do ensaio mecânico de tração de fibras}

Os gráficos de tensão-deformação gerados foram utilizadas para determinar o limite de resistência à tração (LRT). O valor médio para esse parâmetro foi calculado a partir dos resultados de 29 corpos de prova de fibras do ST-HB13 e de 22 do HB212, assim como o cálculo de desvio padrão dessas medidas.

Nas Figuras A.14 e A.15, constantes do Apêndice A, Seção A.4, podem ser vistos gráficos de fibras de HB212 e de ST-HB13, respectivamente, que foram submetidas ao ensaio mecânico de tração.

O valor encontrado de LRT para a fibra de UHMWPE da Dyneema é consistente com o valor apresentado por Callister (2006), que informa para o Spectra ${ }^{\circledR} 900$ LRT de 2,6 GPa e Módulo de Elasticidade de 117 GPa (42).

Segundo Kissel et al. (2004), o valor de LRT para a fibra de UHMWPE Spectra $^{\circledR}$ varia de 2,1 a $2,4 G P a(57)$, que se apresenta próximo dos valores encontrados para a fibra do prepreg HB212 nessa pesquisa.

O resultado consolidado do EMT das fibras de UHMWPE extraídas dos prepregs ST-HB13 e Dyneema ${ }^{\circledR}$ HB212 está exposto na Tabela 4.3, cujo valor indica que as fibras ensaiadas de ST-HB13 obtiveram cerca de $52 \%$ da resistência das fibras de HB212 analisadas.

O Teste de Weibull foi aplicado aos resultados de EMT, gerando as Equações 4-1 e 4-2 para as fibras extraídas dos prepregs ST-HB13 e HB212, respectivamente, das Figuras 4.16 e 4.17. Destaca-se o Módulo de Weibull $(m)$.

$$
y=5,57 x-38,80 \quad\left(m=5,57 \text { e } R^{2}=0,90\right)
$$


Tabela 4.3: Dados do EMT de fibras retiradas dos referidos prepregs.

\begin{tabular}{cccccc}
\hline $\begin{array}{c}\text { Prepreg } \\
(\text { fibra })\end{array}$ & $\begin{array}{c}\mathbf{n}^{\mathbf{o}} \text { de } \\
\text { amostras }\end{array}$ & $\begin{array}{c}\phi \text { médio } \\
(\mu \mathbf{m})\end{array}$ & $\begin{array}{c}\text { DP } \\
(\phi)\end{array}$ & $\begin{array}{c}\text { LRT } \\
(\mathbf{M P a})\end{array}$ & $\begin{array}{c}\text { DP } \\
(\mathbf{L R T})\end{array}$ \\
\hline ST-HB13 & 29 & 17,8 & 2,0 & 964 & 217 \\
HB212 & 22 & 13,6 & 1,7 & 1844 & 823 \\
\hline
\end{tabular}

$\phi$ - Diâmentro

LRT - Limite de Resistência à Tração

DP - Desvio Padrão

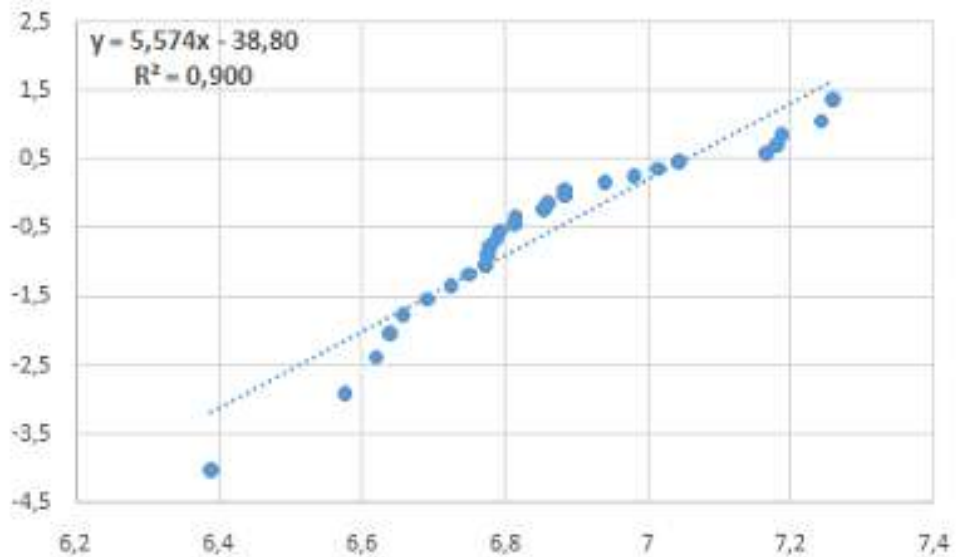

Figura 4.16: Distribuição de Weibull para EMT de fibra de ST-HB13.

$$
y=3,06 x-23,42 \quad\left(m=3,06 \text { e } R^{2}=0,84\right)
$$

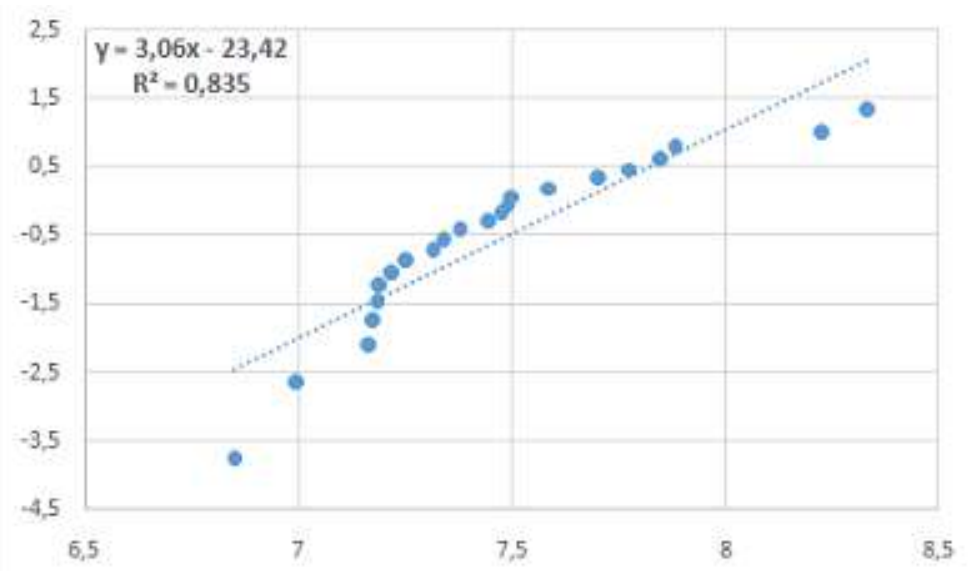

Figura 4.17: Distribuição de Weibull para EMT de fibra de HB212.

Os valores acima reforçam a validade do emprego desta metodologia de ensaio e seus consequentes resultados.

O método empregado mostrou-se consistente (equipamento e adesivos) e os resultados obtidos mostraram-se próximos aos dados disponíveis nos catálogos dos fabricantes de fibras similares e em outras publicações. 


\section{3 \\ Resultado dos Ensaios Balísticos}

Os ensaios balísticos, caracterização decisiva para o objetivo desta pesquisa, foram divididos em Teste de Limite Balístico $V_{50}$ e Teste de Resistência Balística.

A primeira fase contou com 4 placas apenas, e não foi possível alcançar o resultado definido por norma para o valor de $V_{50}$ devido à insuficiência de CPs, porém revelou informações inesperadas sobre os materiais. Já o segundo teste transcorreu dentro do esperado, com 12 placas balísticas, e os resultados serão apresentados em duas etapas, considerando somente o primeiro impacto de cada placa, e o conjunto dos impactos.

As velocidades de disparo estiveram no intervalo de $760 \mathrm{~m} / \mathrm{s}$ à $988 \mathrm{~m} / \mathrm{s}$. Essa amplitude foi necessária para os dois ensaios em decorrência da variação de densidade de área das placas.

Estudos recentes sobre o desempenho dos coletes indicaram a necessidade de melhorias nos métodos de ensaios balísticos. Atualmente, o teste de limite balístico $V_{50}$ e deformação da face posterior (BFS) é usado para estimar o desempenho dos coletes, mas ambos os métodos têm limitações (13).

\subsection{1 \\ Ensaio de V50}

As velocidades dos projetis durante o ensaio de $V_{50}$ variaram entre $794,8 \mathrm{~m} / \mathrm{s}$ e $987,9 \mathrm{~m} / \mathrm{s}$, aproximadamente $25 \%$. Essa grande amplitude foi intencional para se tentar obter duas perfurações e duas não perfurações para cada placa (no mínimo), e devido também às diferenças entre densidade de área, composição e espessura dos corpos de prova.

O resultado consolidado deste ensaio está disposto na Tabela 4.4, do qual destaca-se a alta energia absorvida média dos CPs, sendo esse valor para três deles superior à $3500 \mathrm{~J}$. Os valores detalhados estão dispostos no Apêndice C, na Tabela C.1.

Na Figura 4.18 pode-se verificar a evolução da variação de velocidade ao longo do ensaio das quatro placas, e os disparos que causaram a perfuração.

Observa-se que para o CP6 (Titânio+HB212+Poron XRD ${ }^{\circledR}$ ) as velocidades de impacto foram superestimadas, havendo cinco perfurações e somente um projetil parado completamente. Mesmo com a redução progressiva da velocidade, somente o último disparo foi retido. Cabe ressaltar que na ocasião desse último disparo a placa já contava com extenso dano na estrutura em decorrência das cinco perfurações anteriores, e que mesmo com uma velocidade de $856 \mathrm{~m} / \mathrm{s}$ (acima do limite máximo definido para o ensaio de resistência ba- 
Tabela 4.4: Resultado do Ensaio de Limite Balístico V50.

\begin{tabular}{lcccccccc}
\hline $\begin{array}{c}\text { Tipo } \\
\text { de CP }\end{array}$ & $\begin{array}{c}\text { Camadas } \\
\text { prepreg }\end{array}$ & $\begin{array}{c}\mathrm{D} / \mathrm{A} \\
\left(\mathrm{kg} / \mathrm{m}^{2}\right)\end{array}$ & $\begin{array}{c}\mathrm{n}^{o} \text { de } \\
\text { tiros }\end{array}$ & $\begin{array}{c}V_{i}^{a} \\
(\mathrm{~m} / \mathrm{s})\end{array}$ & $\begin{array}{c}V_{i}^{b} \\
(\mathrm{~m} / \mathrm{s})\end{array}$ & $\begin{array}{c}E_{a b s}^{c} \\
(\mathrm{~J})\end{array}$ & $E_{\text {esp }}^{d}$ & $\mathrm{P} / \mathrm{R}$ \\
\hline $\mathrm{TDP}_{(6)}$ & 69 & 13,3 & 6 & 948,3 & 856,0 & 3528 & 265 & $5 \mathrm{P} 1 \mathrm{R}$ \\
$\operatorname{TDP}_{(7)}$ & 69 & 13,2 & 6 & 872,6 & 794,8 & 3042 & 230 & $5 \mathrm{P} 1 \mathrm{R}$ \\
$\operatorname{TSP}_{(14)}$ & 121 & 19,5 & 4 & - & 863,0 & 3588 & 184 & $4 \mathrm{R}$ \\
$\mathrm{TSP}_{(15)}$ & 121 & 19,5 & 4 & 967,7 & 945,7 & 4309 & 221 & $1 \mathrm{P} 3 \mathrm{R}$ \\
\hline $\mathrm{T}-\mathrm{Ti}-6 \mathrm{Al}-4 \mathrm{~V} / \mathrm{D}-\mathrm{HB} 212 / \mathrm{S}-\mathrm{ST}-\mathrm{HB} 13 / \mathrm{P}$ - Poron XRD \\
${ }^{a}$ Velocidade média dos projetis que perfuraram a placa \\
${ }^{b}$ Velocidade média e ${ }^{c}$ Energia absorvida média dos projetis retidos \\
${ }^{d}$ Energia específica de impacto absorvida $\left[\mathrm{J} /\left(\mathrm{kg} / \mathrm{m}^{2}\right)\right]$ \\
$\mathrm{P}-\mathrm{n}^{o}$ de perfurações / R - no de projetis retidos pela placa \\
\hline
\end{tabular}

lística) a placa conseguir reter o projetil, absorvendo e dissipando sua energia cinética.

No ensaio com o CP7 também houve cinco perfurações e um projetil retido, não possibilitando o cálculo do parâmetro de $V_{50}$. Essa placa apresentava composição idêntica à do CP6, tendo sido o primeiro disparo com velocidade de $880 \mathrm{~m} / \mathrm{s}$, pouco superior à da não perfuração ocorrida na primeira placa. Da mesma forma as velocidades foram sendo reduzidas, e somente o último disparo ficou retido, dessa vez com a velocidade de $794,8 \mathrm{~m} / \mathrm{s}$. Não foi mensurada a deformação posterior da plastilina para essas duas placas, devido às perfurações ocorridas.

Para as placas CP14 e CP15 foi utilizado outro pré-impregnado $\left(\mathrm{Ti}+\mathrm{STHB} 13+\right.$ Poron $\left.\mathrm{XRD}^{\circledR}\right)$ e a área das placas era menor que das duas anteriores, só possibilitando 4 disparos em cada corpo de prova.

No ensaio do CP14, nenhum dos impactos penetrou a placa. No primeiro disparo a velocidade foi de $840 \mathrm{~m} / \mathrm{s}$ e nos subsequentes foi elevada até $890 \mathrm{~m} / \mathrm{s}$, quando mesmo com projetil dotado de energia cinética de cerca de $3800 \mathrm{~J}$ não houve perfuração. Nesse teste foi possível medir da deformação da face posterior transferida para a plastilina em cada um dos impactos. Para o primeiro, o BFS foi de 49,7 $\mathrm{mm}$, valor acima da permitido para o caso de um ensaio de resistência balística, no qual a placa seria alvejada com velocidade próxima de $838 \mathrm{~m} / \mathrm{s}$. Porém, para os três impactos seguintes, mesmo com velocidade média de $870 \mathrm{~m} / \mathrm{s}$ a média de BFS foi de apenas $32,7 \mathrm{~mm}$.

Já com o CP15 optou-se por iniciar com um velocidade consideravelmente superior, por não ter havido perfuração no CP14, porém, mesmo assim não foi possível determinar a $V_{50}$, pois só houve uma perfuração, e três disparos ficaram retidos pela placa. A perfuração ocorreu com a velocidade do projetil de cerca de $968 \mathrm{~m} / \mathrm{s}$, sendo o disparo seguinte $\operatorname{com} 916 \mathrm{~m} / \mathrm{s}$ retido pela placa. Para tentar obter a $V_{50}$ seria necessário mais uma perfuração e uma não perfuração. 


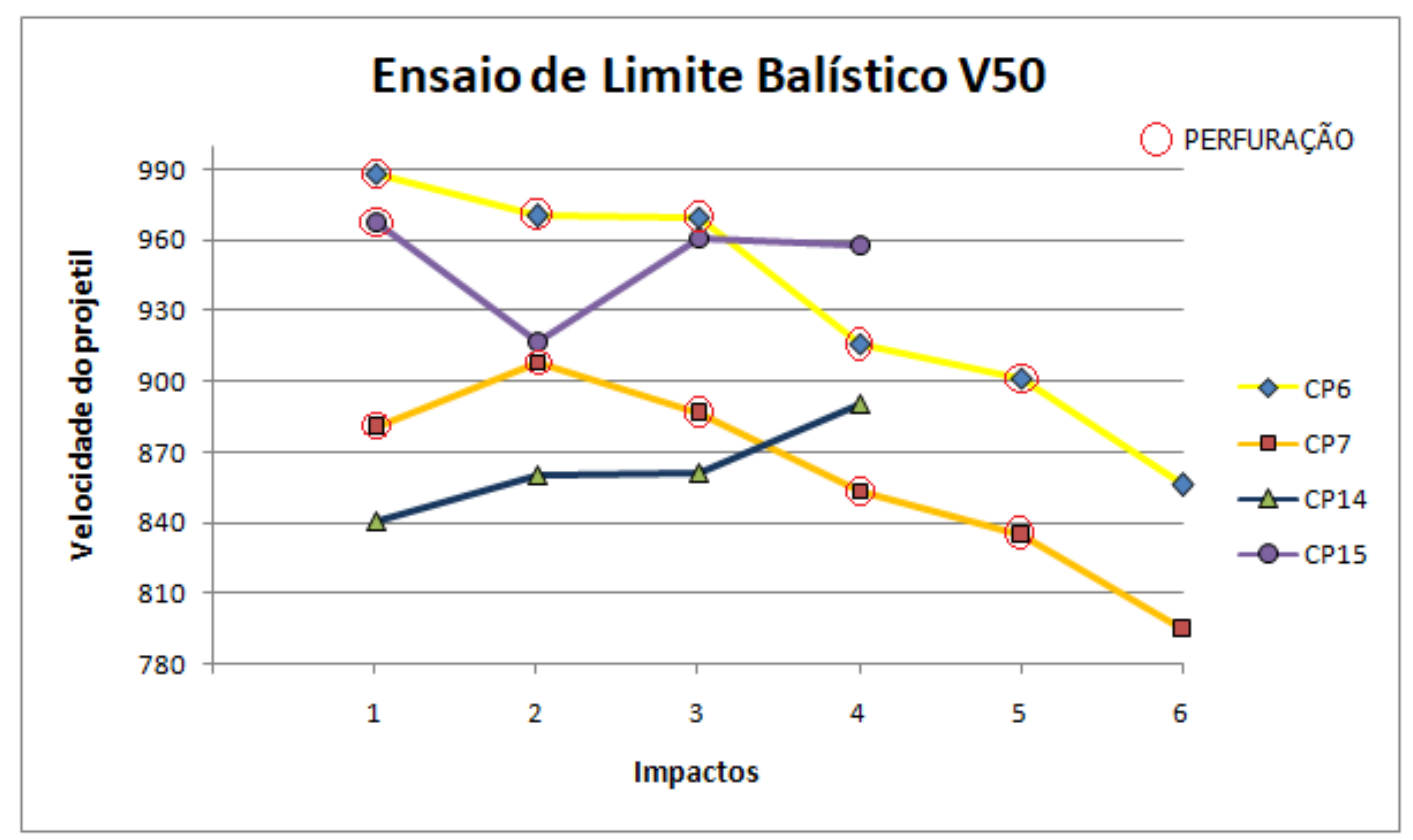

Figura 4.18: Resultado do Ensaio $V_{50}$ para CP6, CP7, CP14 e CP15.

Entretanto, mesmos elevando a velocidade para a faixa de $960 \mathrm{~m} / \mathrm{s}$ nos dois disparos subsequentes, não houve mais perfurações.

Apesar de não ter sido possível obter o valor de Limite Balístico $V_{50}$ para os corpos de prova, ficou evidenciada a alta resistência dos CPs de ST-HB13, com destaque para o CP15, que chegou a resistir ao disparo com $963 \mathrm{~m} / \mathrm{s}$ de velocidade, portando energia cinética de cerca de $4400 \mathrm{~J}$.

\subsection{2}

\section{Ensaio de resistência balística}

No Capítulo 3, a Tabela 3.4 apresenta detalhes da constituição das placas fabricadas, sendo que 12 delas foram utilizadas neste teste de resistência balística (P-BFS). O ensaio seguiu a norma NIJ 0101.04 quanto aos procedimentos para o Nível III de ameaça, no qual as placas devem resistir ao disparo da munição $7,62 \times 51$ FMJ à velocidade de $838 \pm 15 \mathrm{~m} / \mathrm{s}$ (corresponde ao valor de transferência de energia cinética de cerca $3400 \mathrm{~J}$ ), e reter seis impactos (não haver perfuração). O valor de trauma (BFS) deve ser inferior à $44 \mathrm{~mm}$ (78).

A Tabela 4.5 descreve a composição e estrutura das placas, e apresenta como resultados: o número de impactos com que foram alvejadas, a média de velocidade dos projetis retidos por cada uma delas, os valores de média da energia absorvida por cada CP, de média da energia específica absorvida, e média da deformação da face posterior (BFS).

Ressalta-se que as duas placas fabricadas com 69 camadas do préimpregnado HB212 e reforço de $1 \mathrm{~mm}$ da chapa de titânio, sofreram uma 
Tabela 4.5: Parâmetros da resistência balística das placas.

\begin{tabular}{|c|c|c|c|c|c|c|c|}
\hline $\begin{array}{c}\text { Tipo } \\
\text { de CP }\end{array}$ & $\begin{array}{c}\text { Camadas } \\
\text { prepreg }\end{array}$ & $\begin{array}{c}\mathrm{D} / \mathrm{A} \\
\left(\mathrm{kg} / \mathrm{m}^{2}\right)\end{array}$ & $\begin{array}{l}\mathrm{n}^{\mathrm{O}} \text { de } \\
\text { tiros }\end{array}$ & $\begin{array}{c}V_{i}^{a} \\
(m / s)\end{array}$ & $\begin{array}{l}E_{a b s}^{b} \\
(J)\end{array}$ & $E_{e s p}^{c}$ & $B F S^{d}$ \\
\hline $\mathrm{DP}_{(1)}$ & 100 & 13,0 & 6 & 854,6 & 3517 & 270,3 & 35,5 \\
\hline $\mathrm{DE}_{(2)}$ & 100 & 13,0 & 6 & 844,4 & 3433 & 263,7 & 36,4 \\
\hline $\mathrm{TDP}_{(3)}$ & 94 & 16,5 & 6 & 847,4 & 3458 & 209,8 & 39,6 \\
\hline $\mathrm{TDE}_{(4)}$ & 94 & 16,7 & 6 & 851,2 & 3489 & 209,1 & 36,5 \\
\hline $\operatorname{TDP}_{(5)}$ & 69 & 13,4 & $5^{*}$ & 768,6 & 2846 & 217,2 & 39,0 \\
\hline $\mathrm{TDE}_{(8)}$ & 69 & 13,5 & $5^{*}$ & 774,2 & 2887 & 214,2 & 43,6 \\
\hline $\mathrm{SP}_{(9)}$ & 159 & 19,1 & 4 & 847,9 & 3462 & 181,5 & 37,8 \\
\hline $\mathrm{SE}_{(10)}$ & 159 & 19,1 & 4 & 842,0 & 3414 & 178,5 & 36,9 \\
\hline $\operatorname{TSP}_{(11)}$ & 152 & 23,2 & 4 & 833,6 & 3347 & 144,5 & 33,4 \\
\hline $\operatorname{TSE}_{(12)}$ & 152 & 23,1 & 4 & 840,7 & 3404 & 147,4 & 35,3 \\
\hline $\operatorname{TSP}_{(13)}$ & 121 & 19,5 & 4 & 809,4 & 3155 & 162,1 & 33,9 \\
\hline $\operatorname{TSE}_{(16)}$ & 121 & 19,4 & 4 & 803,2 & 3106 & 160,5 & 37,9 \\
\hline $\begin{array}{l}\text { T.Ti-6A } \\
{ }^{a} \text { Veloci } \\
{ }^{b} \text { Energi } \\
{ }^{c} \text { Energi } \\
{ }^{d} \text { Deforn } \\
{ }^{*} \text { Foram }\end{array}$ & $\begin{array}{l}\text { absorvida } \\
\text { específica } \\
\text { ção posteı } \\
\text { disparos }\end{array}$ & $\begin{array}{l}\text { e impact } \\
\text { or média } \\
\text { etidos do }\end{array}$ & $\begin{array}{l}\text { abojeti } \\
\text { absor } \\
\text { otal de }\end{array}$ & $\begin{array}{l}\text { / P.Por } \\
\text { s pela } \\
\text { parado } \\
\text { da méc }\end{array}$ & $\begin{array}{l}\text { n XR } \\
\text { laca } \\
\text { pela } \\
\text { a }[\mathrm{J} /(\end{array}$ & $\begin{array}{l}\text { laca } \\
\left.\left.g / m^{2}\right)\right]\end{array}$ & 3D-EVA \\
\hline
\end{tabular}

perfuração cada, sendo a velocidade desses impactos desconsiderada para o cálculo das médias.

Na Figura 4.19 repara-se a média de deformação posterior das 12 placas ensaiadas. Pelo valor médio, o resultado de todas as placas se mostrou abaixo da linha vermelha que indica os $44 \mathrm{~mm}$. Os valores detalhados de todos os disparos realizados no ensaio balístico estão dispostos no Apêndice C, nas Tabelas C.2 e C.3. Destaca-se que, de forma inesperada, $20 \%$ dos impactos ocorreram com velocidade superior a norma, representando maior exigência para as placas avaliadas.

Depreende-se que oito das placas foram aprovadas no ensaio de resistência balística. As outras quatro foram testadas com velocidades abaixo da determinada pela norma, devido à composição $25 \%$ a $30 \%$ inferior de préimpregnado balístico na estrutura. Entretanto, mesmo com essa significativa redução, as velocidades de ensaio variaram entre $92 \%$ e $97 \%$ do valor previsto, e a deformação média foi de 41,3 $\mathrm{mm}$ para os CPs 5 e 8, e de apenas $35,9 \mathrm{~mm}$ para os CPs 13 e 16 .

Nas Figuras 4.20a, 4.20b, 4.20c e 4.20d pode-se verificar a face de impacto e a face posterior de duas placas após o ensaio balístico, evidenciando a deformação decorrente, como consequência da absorção do impacto.

Não houve resultado conclusivo que atestasse a diferença de desempenho 


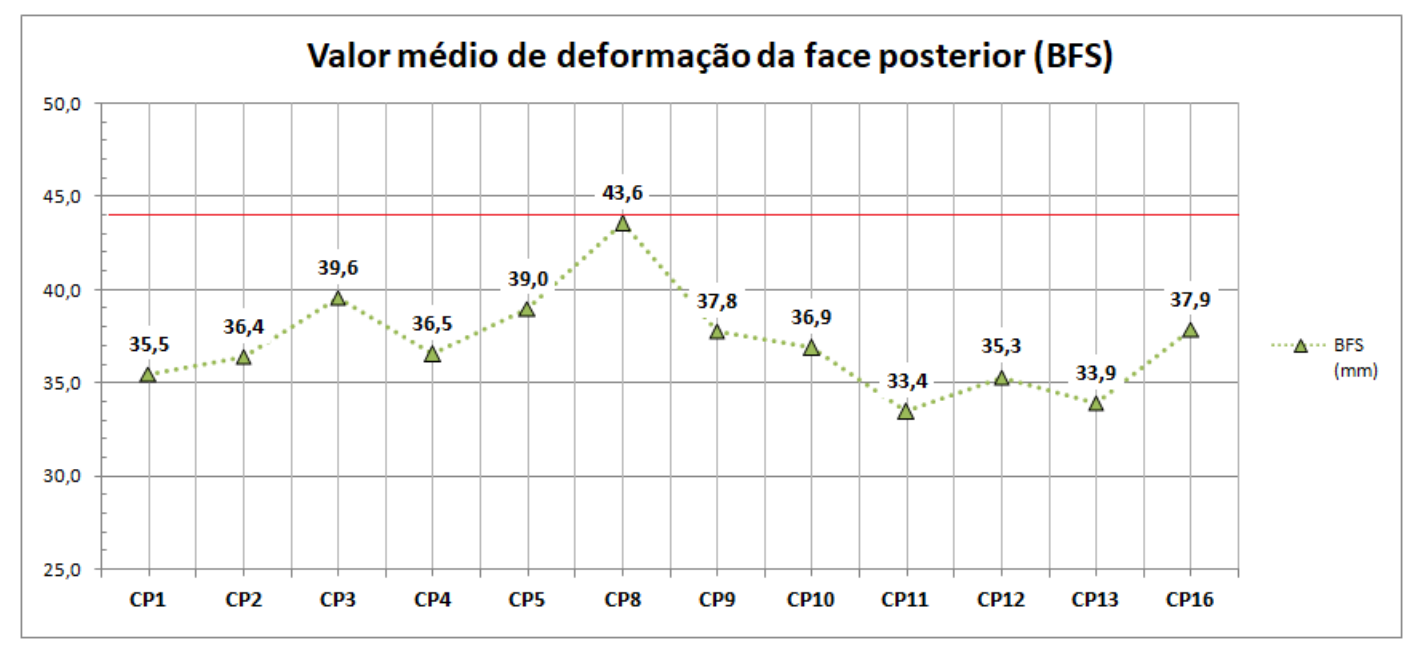

Figura 4.19: Resultados da média de BFS para o ensaio de P-BFS.

entre as duas espumas utilizadas, sendo necessário estudos complementares para tal.

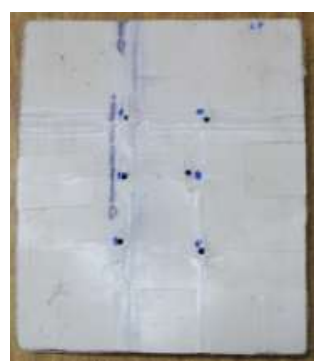

(a) Frontal CP1

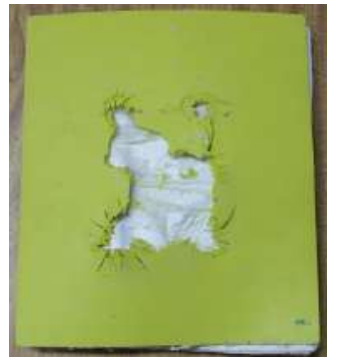

(b) Posterior CP1

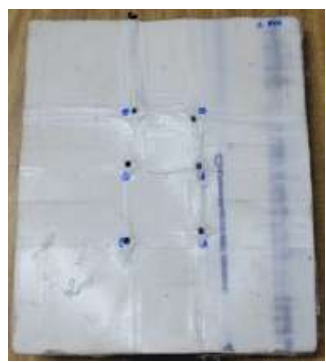

(c) Frontal CP2

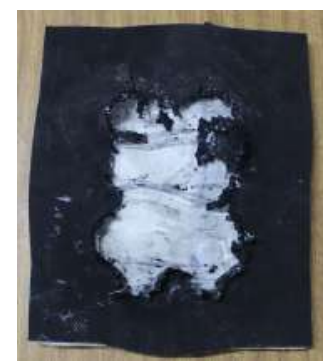

(d) Posterior CP2

Figura 4.20: Placas pós-teste de resistência balística, mostrando as faces anterior e posterior após ensaios.

Na Figura 4.21 pode-se verificar no gráfico de duplo eixo vertical, a variação da energia média absorvida, e os valores de energia específica absorvida, para as 12 placas avaliadas.

Conclui-se que o valor de energia específica absorvida para os CPs 1 e 2 foi de cerca de $270 \mathrm{~J} /\left(\mathrm{kg} / \mathrm{m}^{2}\right)$ e para os CPs 9 e 10, aproximadamente $180 \mathrm{~J} /\left(\mathrm{kg} / \mathrm{m}^{2}\right)$, apontando que a solução somente em ST-HB13 tem $67 \%$ da eficiência das placas feitas só de HB212.

Foi calculado o valor de somatório das energias cinéticas dos projetis absorvidas por cada uma das placas, considerando os impactos que ficaram retidos na estrutura das mesmas, sem causar perfuração. Ficou evidente a superioridade do material HB212, por sua maior eficiência específica e maiores valores de energia absorvidos. Cabe destacar a vantagem relativa da solução proposta pelos CPs 13 e 16, sobre os protótipos 5 e 8. A solução de ST-HB13 de 


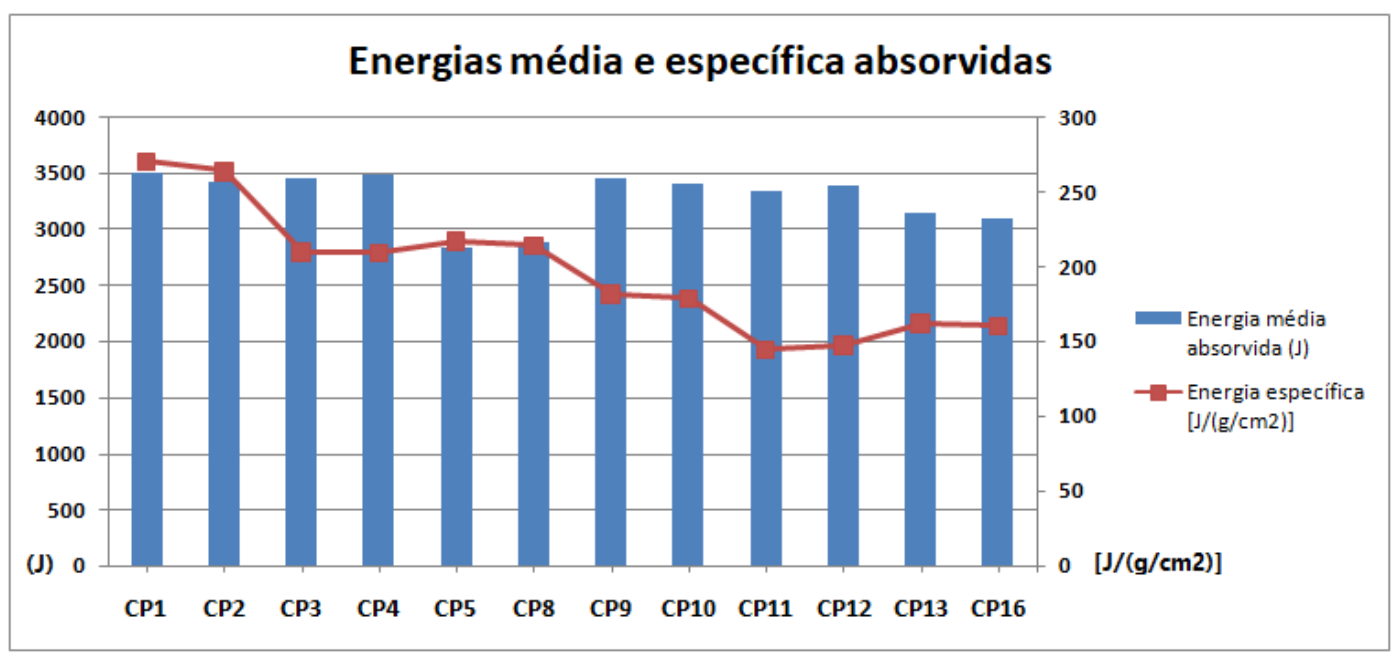

Figura 4.21: Resultado de energia média e específica absorvidas no Ensaio de P-BFS.

menor espessura avaliada, além de resistir ao impacto de projetis com energia cinética cerca de $10 \%$ acima do valor a que resistiu o CP equivalente de HB212, teve valor médio de BFS cerca de $13 \%$ inferior.

A Figura 4.22 apresenta em gráfico com dois eixos verticais a variação do somatório de energia absorvida $(J)$ e o valor somatório das deformações posteriores $(\mathrm{mm})$ geradas na plastilina nos ensaios de resistência balística, para cada uma das 12 placas avaliadas, sendo as informações sobre esse gráfico complementadas por dados da Tabela 4.6.

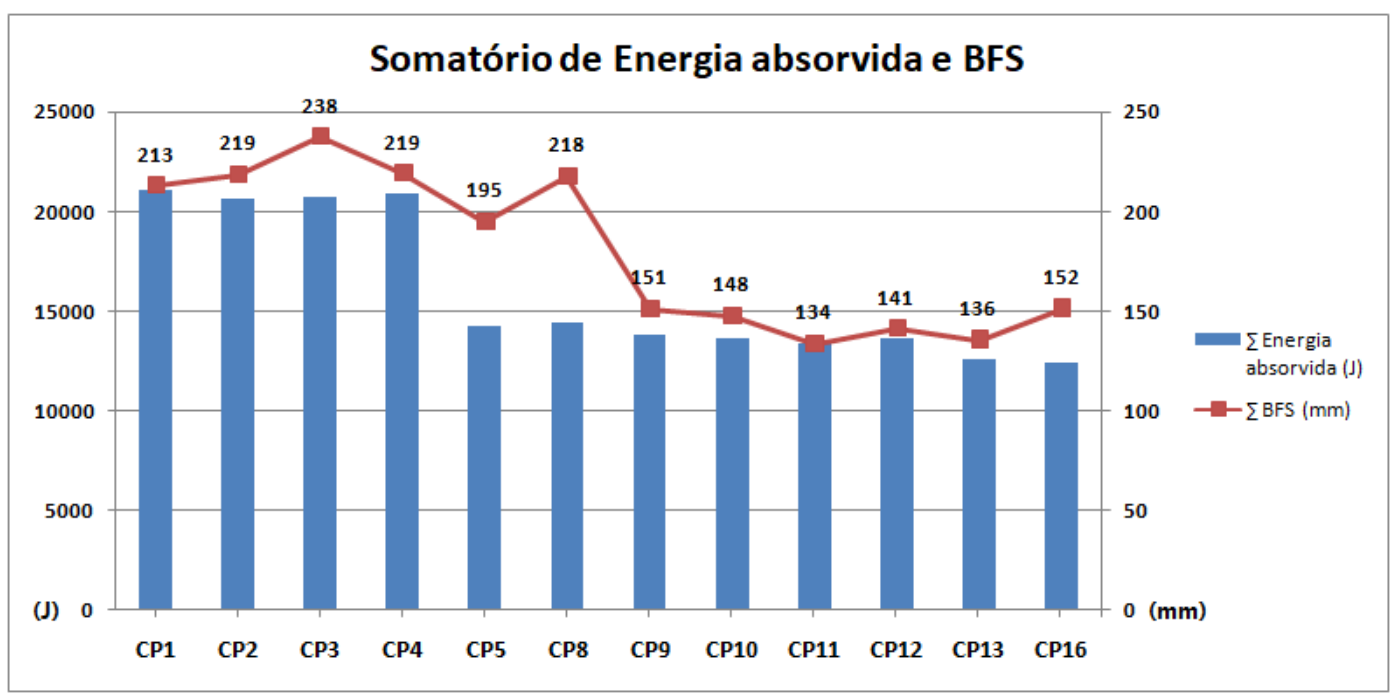

Figura 4.22: Resultado dos somatórios de energia absorvida e BFS no Ensaio de P-BFS.

Observa-se mais uma vez que o pré-impregnado HB212 apresenta o melhor desempenho, conforme resultado de somatório de energia absorvida 
Tabela 4.6: Energia absorvida e deformação da face posterior.

\begin{tabular}{|c|c|c|c|c|}
\hline Placa & ${ }^{a} \mathrm{P} / \mathrm{R}$ & ${ }^{b} \sum E_{a b s}(J)$ & ${ }^{c} E_{e s p}\left[J /\left(g / \mathrm{cm}^{2}\right)\right]$ & ${ }^{d} \sum B F S(m m)$ \\
\hline CP1 & $0 \mathrm{P} / 6 \mathrm{R}$ & 21102 & 270 & 213 \\
\hline $\mathrm{CP} 2$ & $0 \mathrm{P} / 6 \mathrm{R}$ & 20599 & 264 & 219 \\
\hline CP3 & $0 \mathrm{P} / 6 \mathrm{R}$ & 20748 & 210 & 238 \\
\hline $\mathrm{CP} 4$ & $0 \mathrm{P} / 6 \mathrm{R}$ & 20932 & 209 & 219 \\
\hline CP5 & $1 \mathrm{P} / 5 \mathrm{R}$ & 14232 & 217 & 195 \\
\hline CP8 & $1 \mathrm{P} / 5 \mathrm{R}$ & 14432 & 214 & 218 \\
\hline CP9 & $0 \mathrm{P} / 4 \mathrm{R}$ & 13847 & 182 & 151 \\
\hline CP10 & $\mathrm{OP} / 4 \mathrm{R}$ & 13655 & 178 & 148 \\
\hline CP11 & $\mathrm{OP} / 4 \mathrm{R}$ & 13387 & 145 & 134 \\
\hline CP12 & $0 \mathrm{P} / 4 \mathrm{R}$ & 13615 & 147 & 141 \\
\hline CP13 & $0 \mathrm{P} / 4 \mathrm{R}$ & 12619 & 162 & 136 \\
\hline CP16 & $0 \mathrm{P} / 4 \mathrm{R}$ & 12425 & 161 & 152 \\
\hline \multicolumn{5}{|c|}{$\begin{array}{l}\text { a P - } \mathrm{n}^{\mathrm{O}} \text { de perfurações / } \mathrm{R}-\mathrm{n}^{\mathrm{O}} \text { de projetis que ficaram retidos } \\
\text { b Somatório da Energia absorvida } \\
\text { c Média da Energia Específica } \\
\text { d Somatório da deformação da face posterior }\end{array}$} \\
\hline
\end{tabular}

dos disparos, a notável superioridade energia específica média absorvida, e o valor do somatório de deformação para os seis impactos mantido abaixo dos $240 \mathrm{~mm}$, que indica média menor do que $40 \mathrm{~mm}$.

\section{4}

\section{Resultados da Análise Estatística}

Retomando a equação modelo de regressão linear múltipla, Equação 215, os valores de $Y$ foram dados pelo conjunto de dados de deformação da face posterior, BFS, relativo a cada impacto, e as variáveis principais $\left(x_{1}\right.$ a $\left.x_{7}\right)$ foram designadas de acordo com a Tabela 4.7, para que fosse possível calcular os coeficientes $\beta$ dos modelos de regressão.

Tanto os dados de BFS, quanto os valores das 7 variáveis principais (termos de $x_{1}$ a $x_{7}$ ), estão relatados no Apêndice C, seção D.1, na Tabela D.1.

A Tabela 4.8 expõe a interação utilizada para formar as 21 variáveis $\left(x_{8}\right.$ a $x_{2} 8$ ) para o segundo modelo de regressão.

O primeiro modelo de regressão proposto $(\operatorname{Mod} 1)$ considerou somente as variáveis principais, e após 4 remoções de termos com p-valor não significativos, chegou ao modelo de regressão descrito na Equação 4-3. O valor de $R^{2}$ foi de 0,2919 com p-valor de 0,0003.

$$
B F S=16,49 \cdot x_{1}+0,80 \cdot x_{2}-7,57 \cdot x_{5}+3,496
$$


Tabela 4.7: Variáveis principais empregadas na Regressão Linear Múltipla.

\begin{tabular}{cccc}
\hline Variável & Referência & Tipo $^{a}$ & Valores \\
\hline$x_{1}$ & Chapa de Ti-6Al-4V & $\mathrm{C}$ & com / sem a chapa \\
$x_{2}$ & Tipo de prepreg balístico & $\mathrm{C}$ & HB212 / ST-HB13 \\
$x_{3}$ & Tipo de espuma & $\mathrm{C}$ & Poron XRD / PEBD-EVA \\
$x_{4}$ & $\mathrm{n}^{o}$ de camadas de prepreg & $\mathrm{Q}$ & $b$ \\
$x_{5}$ & D/A & $\mathrm{Q}$ & ${ }_{b}$ \\
$x_{6}$ & velocidade do impacto & $\mathrm{Q}$ & individualizados $^{c}$ \\
$x_{7}$ & ordem do disparo na placa & $\mathrm{Q}$ & 1 a $6{ }^{b}$ \\
${ }^{a}$ C - Categórica (assumem valores 1 ou -1$) /$ Q - Quantitativa \\
${ }^{b}$ Conforme Tabela 3.4 \\
${ }^{c}$ Conforme Tabela D.1 do Apêndice D & \\
\hline
\end{tabular}

Tabela 4.8: Descrição das variáveis de interação da Análise de Regressão.

\begin{tabular}{|c|c|}
\hline Variável & Interação \\
\hline$x_{8}$ & $x_{1} \cdot x_{2}$ \\
\hline$x_{9}$ & $x_{1} \cdot x_{3}$ \\
\hline$x_{10}$ & $x_{1} \cdot x_{4}$ \\
\hline$x_{11}$ & $x_{1} \cdot x_{5}$ \\
\hline$x_{12}$ & $x_{1} \cdot x_{6}$ \\
\hline$x_{13}$ & $x_{1} \cdot x_{7}$ \\
\hline$x_{14}$ & $x_{2} \cdot x_{3}$ \\
\hline$x_{15}$ & $x_{2} \cdot x_{4}$ \\
\hline$x_{16}$ & $x_{2} \cdot x_{5}$ \\
\hline$x_{17}$ & $x_{2} \cdot x_{6}$ \\
\hline
\end{tabular}

\begin{tabular}{|c|c|}
\hline Variável & Interação \\
\hline$x_{18}$ & $x_{2} \cdot x_{7}$ \\
\hline$x_{19}$ & $x_{3} \cdot x_{4}$ \\
\hline$x_{20}$ & $x_{3} \cdot x_{5}$ \\
\hline$x_{21}$ & $x_{3} \cdot x_{6}$ \\
\hline$x_{22}$ & $x_{3} \cdot x_{7}$ \\
\hline$x_{23}$ & $x_{4} \cdot x_{5}$ \\
\hline$x_{24}$ & $x_{4} \cdot x_{6}$ \\
\hline$x_{25}$ & $x_{4} \cdot x_{7}$ \\
\hline$x_{26}$ & $x_{5} \cdot x_{6}$ \\
\hline$x_{27}$ & $x_{5} \cdot x_{7}$ \\
\hline$x_{28}$ & $x_{6} \cdot x_{7}$ \\
\hline
\end{tabular}

A Equação 4-4 detalha o comando utilizado no Programa $\mathrm{R}^{\odot}$ para iniciar a segunda análise, iniciando pelo modelo completo com 28 variáveis (Mod2):

$$
\begin{array}{r}
r e g<-\operatorname{lm}(y x 1+x 2+x 3+x 4+x 5+x 6+x 7+x 8+x 9+x 10+x 11+x 12+ \\
x 13+x 14+x 15+x 16+x 17+x 18+x 19+x 20+x 21+x 22+x 23+ \\
x 24+x 25+x 26+x 27+x 28)
\end{array}
$$

A sequência de processamento da técnica Backward para a Análise de Regressão Linear Múltipla realizada está detalhada no Apêndice C, seção D.1.

A análise do segundo modelo proposto demandou 10 etapas e chegou à estrutura final formada por 17 termos significativos, com valor de $R^{2}$ igual a 0,608 e p-valor de 0,00076. O modelo de regressão está descrito na Equação 4-5. 


$$
\begin{array}{r}
B F S=-3,47 \cdot 10^{3} \cdot x_{1}-6,45 \cdot 10^{2} \cdot x_{2}-1,06 \cdot 10^{2} \cdot x_{3}-7,35 \cdot x_{4}-1,64 \cdot 10^{2} \cdot x_{5} \\
-4,68 \cdot 10^{-1} \cdot x_{6}-2,81 \cdot 10 \cdot x_{7}+6,45 \cdot 10^{2} \cdot x_{8}+2,01 \cdot 10^{2} \cdot x_{11}+2,51 \cdot x_{13} \\
-3,01 . x_{18}-3,09 \cdot 10^{-1} \cdot x_{19}+1,62 \cdot x_{20}+1,36 \cdot 10^{-1} \cdot x_{21}-5,36 \cdot 10^{-1} \cdot x_{22} \\
+2,70 \cdot 10^{-3} \cdot x_{24}-1,27 \cdot x_{27}+5,90 \cdot 10^{-2} \cdot x_{28}
\end{array}
$$

Os gráficos de análise residual (Figuras 4.23b e 4.23a, de Dispersão Q-Q (Figuras 4.24a e 4.24b, e de Histograma de Resíduos (Figuras 4.25a e 4.25b)podem ser vistos lado a lado, para as duas condições de regressão, considerando inicialmente o modelo sem interação, somente com as 7 variáveis principais e na segunda análise, adotando o modelo com os 28 fatores (com interação dois a dois).

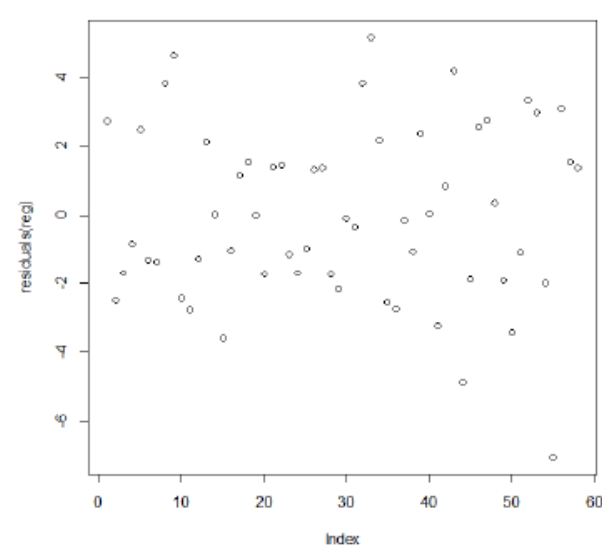

(a) Modelo com 7 variáveis

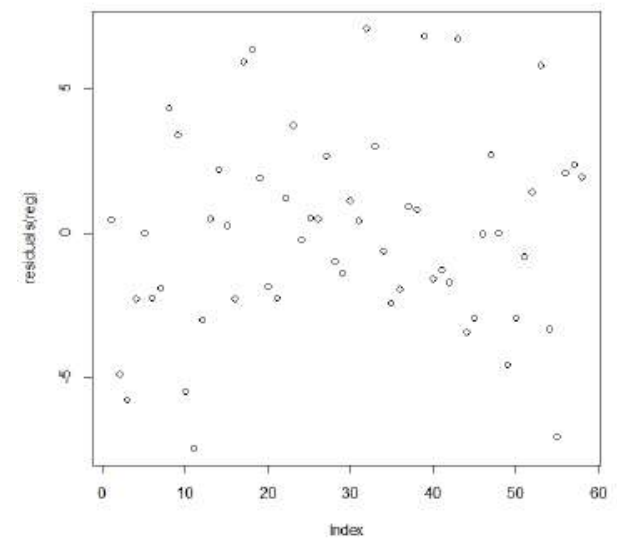

(b) Modelo com 28 variáveis

Figura 4.23: Gráficos de Análise Residual de Mod1 (a) e de Mod2 (b).

Uma vez que os gráficos de Dispersão Residual não apontam concentração dos dados e/ou Outliers pressupõe-se que os resíduos são independentes. 


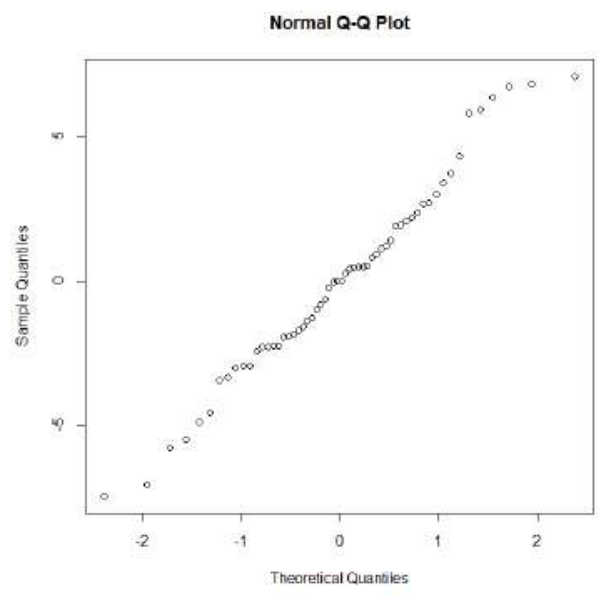

(a) Modelo com 7 variáveis

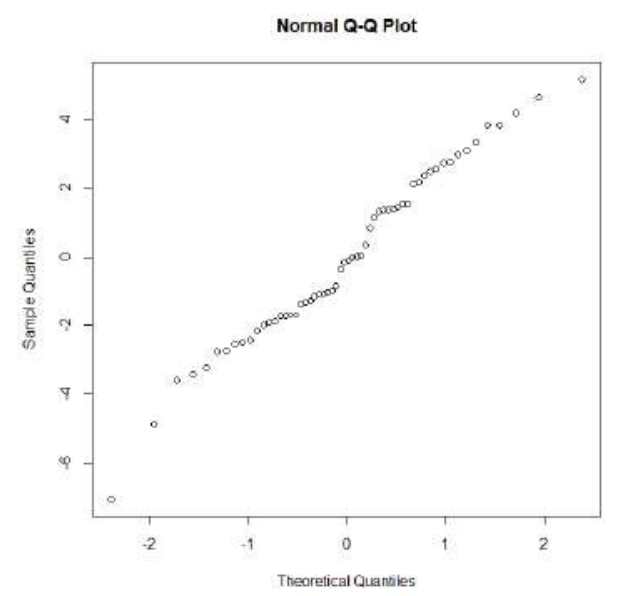

(b) Modelo com 28 variáveis

Figura 4.24: Gráficos Q-Q de Mod1 (a) e de Mod2 (b).

Como a distribuição de dados de ambos os gráficos se aproximam de uma reta, sem nenhum afastamento sistemático, concluí-se que os resíduos são normalmente distribuídos.

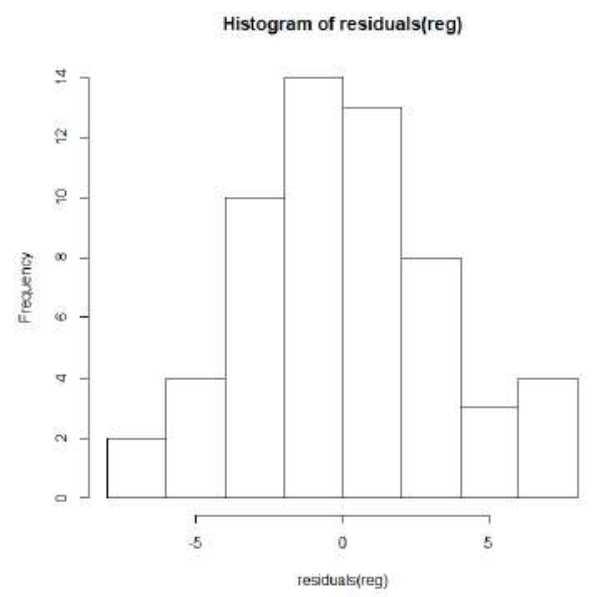

(a) Modelo com 7 variáveis

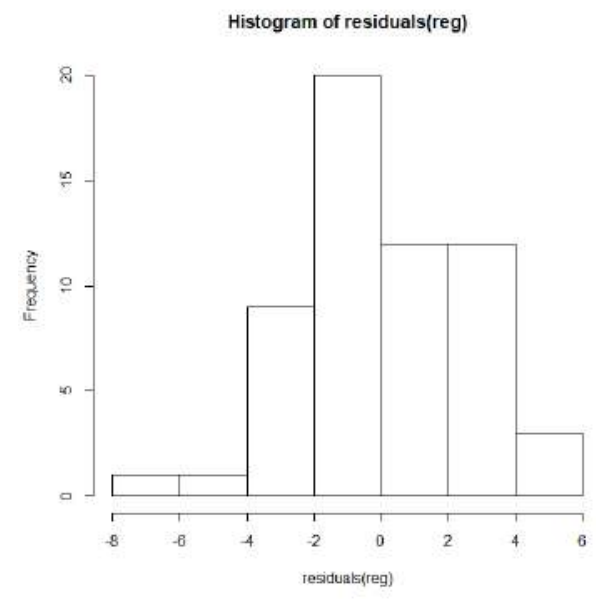

(b) Modelo com 28 variáveis

Figura 4.25: Histograma de Resíduos de Mod1 (a) e de Mod2 (b).

Os gráficos de Histograma de Resíduos tem o formato aproximado ao padrão em forma de sino, retratando que os dados são normalmente distribuídos, sendo a distribuição de dados do Modelo 1 mais fidedigna à descrição apontada. 


\section{5}

\section{Conclusões e Sugestões para Trabalhos Futuros}

No presente trabalho, o planejamento e a fabricação das placas balísticas ocorreram com sucesso, tendo a escolha dos materiais, as configurações das placas, e o método para a prensagem sido efetivos.

De 12 placas testadas para P-BFS, obteve-se oito placas que resistiram ao nível de ameaça NIJ III, tiro de munição 7,62 x 51 FMJ, com BFS abaixo de $44 \mathrm{~mm}$, sendo que seis delas apresentaram deformações posteriores abaixo do limite, mesmo quando submetidas à disparos com velocidades acima do definido pela norma. As demais placas avaliadas, com velocidades entre $92 \%$ e $97 \%$ do valor previsto, devido à composição $25 \%$ a $30 \%$ inferior de préimpregnado balístico, apresentaram a deformação média também abaixo do valor limite.

A placas com melhor capacidade de absorção de energia no ensaio de resistência balística foram as fabricadas com HB212.

Dos corpos de prova submetidos ao Ensaio de Limite Balístico $V_{50}$, os fabricados com ST-HB13 demonstraram desempenho superior.

Os resultados da fabricação e caracterizações dos materiais empregados na pesquisa apontaram para as seguintes conclusões:

- a fabricação das placas de ST-HB13 ocorreu com pressão de compactação $70 \%$ superior à imposta para as placas de HB212, o que favoreceu o desempenho balístico desses protótipos;

- o LMT das fibras que compõe os pré-impregnados tem relação direta com a capacidade de absorção de energia do impacto balístico, sendo que o LMT das fibras e a energia específica média absorvida das placas, foi de respectivamente $52 \%$ e $67 \%$, do ST-HB13 em relação ao HB212;

- o emprego da microscopia eletrônica de varredura foi essencial para avaliar a superfície das fibras, de pré-impregnados e das espumas, inferindo sobre as dimensões e diferenças microestruturais dos materiais;

- os resultados de termogravimetria evidenciaram que para a faixa de temperatura de prensagem a quente não há perda de massa significativa para os pré-impregnados utilizados; e

- o emprego da chapa da liga de Ti-6Al-4V com espessura de apenas $1 \mathrm{~mm}$ se deu em substituição de até 30\% do material pré-impregnado. Na situação limite, foi possível obter placas que resistiram aos impactos de 
munição de fuzil com cerca de $95 \%$ da velocidade especificada na norma, dentro da tolerância de deformação posterior.

A análise de Regressão Linear Múltipla:

- possibilitou a obtenção de duas equações para modelagem da constituição das placas e resultados de deformação posterior. Porém o baixo valor de $R^{2}$, mesmo adotando a técnica de interação dos fatores e gerando 28 variáveis, indica a complexidade para predição e modelagem dos fenômenos de altas taxas de deformação de materiais compósitos.

Sugestões para Trabalhos Futuros

- Estudar a fabricação das placas balísticas com novos ciclos de prensagem a quente, otimizando parâmetros como o tempo e a força de compressão.

- Analisar o emprego da liga Ti-6Al-4V (ou da liga Ti-6Al-2Fe-0,1Si) com variadas espessuras e propriedades mecânicas para aprimorar o desempenho balístico da solução.

- Trabalhar os dados do escaneamento da nuvem de pontos do volume deformado da plastilina para verificar a existência de mais informações sobre a dissipação/absorção de energia do que somente o valor de trauma.

- Analisar a dureza das placas balísticas por ensaio de dureza Shore e verificar a relação dessa propriedade com a variação da pressão de compressão na fabricação das placas. 


\section{6}

\section{Referências bibliográficas}

[1] GLÁGIO DO BRASIL. Catálogo de Produtos Glágio do Brasil, Disponível em:<http://www.glagio.com.br/\#produtos $>$. Acesso em: 30 jan. 2018. 1

[2] KUHN, H.; MEDLIN, D.. ASM Handbook. Volume 8: Mechanical Testing and Evaluation. ASM International, 2000. 2.1, 2.2

[3] U.S. DEPARTMENT OF DEFENSE. Composite Materials Handbook Volume 1: Polymer Matrix Composites - Guidelines for Characterization of Structural Materials, vol. 1. US Department of Defense, 2002. 2.1, 2.7.1, 2.8, 2.8.1, 2.8.2, 2.10, 2.11

[4] Thomazini, A. H. A.. Desenvolvimento de Estruturas Porosas de Polietileno de Ultra Alto Peso Molecular (PEUAPM) Recobertas com Apatitas para Substituição e Regeneração Óssea. Tese de doutorado, Universidade Estadual Paulista, 2009. 2.1

[5] LIU, X.; LI, M.; LI, X.; DENG, X.; ZHANG, X.; YAN, Y.; LIU, Y. ; CHEN, X.. Ballistic performance of UHMWPE fabrics/EAMS hybrid panel. Journal of Materials Science, 53(10):7357-7371, 2018. 2.1

[6] HORROCKS, A. RICHARD; ANAND, S. C.. Handbook of technical textiles. Elsevier, 2nd Ed., 2016. 2.1.1, 2.1.2

[7] RUSSELL, B. P.; KANDAN, K.; DESHPANDE, V. S. ; FLECK, N.. The high strain rate response of UHMWPE: from fibre to laminate. International Journal of Impact Engineering, 6:1-21, 2013. 2.1.1, 2.1.1, $2.1 .1,2.1 .2,2.3$

[8] VIVAS, V.. Influência da Degradação Ambiental no Comportamento Mecânico e Balístico de Compósitos Produzidos com Fibra de Polietileno de Ultra Alto Peso Molecular, 2013. Dissertação de Mestrado, Instituto Militar de Engenharia. 2.1.1, 2.8

[9] MIAO, M.; XIN, J. H.. Engineering of High-Performance Textiles. Woodhead Publishing, 2017. 2.1.1 
[10] U.S. DEPARTMENT OF DEFEnSE. Composite Materials Handbook. Polymer Matrix Composites Materials Usage, Design, and Analysis, vol. 3. Department of Defense, 2004. 2.1.1, 2.1.2

[11] CUNNIFF, P.. Decoupled response of textile body armor. In: PROC. 18TH INT. SYMP. ON BALLISTICS, número 01 em 3, p. 0-7, 1999. 2.1 .1

[12] LEIGH PHOENIX, S.; PORWAL, P. K.. A new membrane model for the ballistic impact response and V50 performance of multiply fibrous systems. International Journal of Solids and Structures, 40(24):6723-6765, 2003. 2.1.1

[13] U.S. DEPARTMENT OF COMMERCE, NATIONAL INSTITUTE OF STANDARDS AND TECHNOLOGY. Composite Materials Handbook Volume 3: Polymer Matrix Composites - Guidelines for Characterization of Structural Materials, 2010. 2.1.1, 4.3

[14] HUANG, W.; WANG, Y. ; XIA, Y.. Statistical dynamic tensile strength of UHMWPE-fibers. Polymer, 45(11):3729-3734, 2004. 2.2, $2.9 .1,2.13 .2$

[15] KOH, A. C. P.; SHIM, V. P. W. ; TAN, V. B. C.. Dynamic behaviour of UHMWPE yarns and addressing impedance mismatch effects of specimen clamps. International Journal of Impact Engineering, 37(3):324-332, 2010. 2.2

[16] DSM CORPORATION. DSM Factbook 2016. Technical report, DSM Company, 2017. 2.1.1

[17] PARK, J. H.; RUTLEDGE, G. C.. Ultrafine high performance polyethylene fibers. Journal of Materials Science, 53(4):3049-3063, 2018. 2.1.1, 2.1.2.1, 4.2.3.1

[18] CALlister, W. D. J.. Fundamentals of Materials Science and Engineering: An Interactive e-text, vol. 1. Wiley London, Utah, 5th Ed., 2000. 2.1.2, 2.1.3

[19] BHATNAGAR, A.. Lightweight ballistic composites. Military and lawenforcement application. Cambridge, London: Woodhead Publishing LTD, 2006. 2.1.2, 2.3.1

[20] DUPONT. DuPont TM Tensylon TM HSBD 30A. Technical report, DuPont, Wilmington, DE (USA), 2013. 2.4 
[21] DSM DYNEEMA. Product Specification: HB212 Ultra-High Molecular Weight Polyethylene fiber based composite laminate. Technical Report 602, DSM Company, 2014. 2.4, 3.2

[22] HONEYWELL INTERNATIONAL INC.. Advanced Fibers and Composites SPECTRA SHIELD ${ }^{\circledR}$ SR- 1226 ballistic material Customer Product Specification. Technical report, Honeywell Company, 2009. 2.4

[23] HONEYWELL INTERNATIONAL INC.. Advanced Fibers and Composites SPECTRA SHIELD ${ }^{\circledR} 5143$ ballistic material Customer Product Specification. Technical report, Honeywell Company, 2014. 2.4

[24] MARISSEN, R.. Design with Ultra Strong Polyethylene Fibers. Materials Sciences and Applications, 02(05):319-330, 2011. 2.1.2

[25] JACOBS, M. J. N.; VAN DINGENEN, J. L. J.. Ballistic protection mechanisms in personal armour. Journal of Materials Science, 36(13):3137-3142, 2001. 2.1.2.1

[26] HAZZARD, M. K.; HALlETT, S.; CURTIS, P. T.; IANNUCCI, L. ; TRASK, R. S.. Effect of fibre orientation on the low velocity impact response of thin Dyneema ${ }^{\circledR}$ composite laminates. International Journal of Impact Engineering, 100:35-45, 2017. 2.1.2.1

[27] LANGSTON, T.. An analytical model for the ballistic performance of ultra-high molecular weight polyethylene composites. Composite Structures, 179:245-257, 2017. 2.1.2.1, 2.3

[28] KARThikeyAn, K.; RUSSELL, B. P.. Polyethylene ballistic laminates: Failure mechanics and interface effect. Materials and Design, 63:115-125, 2014. 2.1.2.1, 2.3, 2.3.1

[29] KARTHIKEYAN, K.; RUSSELL, B. P.; FLECK, N. A.; WADLEY, H. ; DESHPANDE, V. S.. The effect of shear strength on the ballistic response of laminated composite plates. European Journal of Mechanics, A/Solids, 42:35-53, 2013. 2.1.2.1

[30] O'MASTA, M. R.; CRAYTON, D. H.; DESHPANDE, V. S. ; WADLEY, H. N. G.. Mechanisms of penetration in polyethylene reinforced cross-ply laminates. International Journal of Impact Engineering, 86:249-264, 2015. 2.1.2.1, 2.6 
[31] CHOCRON, S.; KING, N.; BIGGER, R.; WALKER, J. D.; HEISSERER, U. ; VAN DER WERFF, H.. Impacts and Waves in Dyneema ${ }^{\circledR}$ HB80 Strips and Laminates. Journal of Applied Mechanics, 80(3):031806, apr 2013. 2.1.2.1

[32] VAN DER WERFF, H.; HEISSERER, U.; LÄSSIG, T. ; RIEDEL, W.. New protection levels of UHMWPE armour: From a hydrocode model of HB26 to new generation Dyneema ${ }^{\circledR}$ for armour applications. Proceedings of the 28th International Symposium on Ballistics, p. 10, 2014. 2.1.2.1

[33] O'MASTA, M. R.; CRAYTON, D. H.; DESHPANDE, V. S. ; WADLEY, H. N.. Indentation of polyethylene laminates by a flat-bottomed cylindrical punch. Composites Part A: Applied Science and Manufacturing, 80:138-147, 2016. 2.1.2.1, 4.2.3.1, 4.2.3.2

[34] VAN DER WERFF, H.; HEISSERER, U.. High Performance Ballistic Fibres: Ultra-High Molecular Weight Polyethylene (UHMWPE). In: Chen, X., editor, ADVANCED FIBROUS COMPOSITE MATERIALS FOR BALLISTIC PROTECTION, número 01 em 03, p. 71-108. Woodhead, 2016. 2.1.2.1, 2.3.1, 2.4, 2.9.1, 4.1

[35] Alves, A. L. S.; NASCimento, L. F. C. ; MigueZ SUAREZ, J. C.. Comportamento balístico de compósito de polietileno de altíssimo peso molecular: efeito da radiação gama. Polímeros, 14(2):105-111, 2004. 2.1.2.1

[36] FIROUZI, D.; YOUSSEF, A.; AMER, M.; SROUJI, R.; AMLEH, A.; FOUCHER, D. A. ; BOUGHERARA, H.. A new technique to improve the mechanical and biological performance of ultra high molecular weight polyethylene using a nylon coating. Journal of the Mechanical Behavior of Biomedical Materials, 32:198-209, 2014. 2.1.2.1

[37] O'MASTA, M. R.. Mechanisms of Dynamic Deformation and Failure in Ultra-High Molecular Weight Polyethylene FiberPolymer Matrix Composites. Phd thesis, University of Virginia, Material Science and Engineering, 2014. 2.1.2.1, 2.3

[38] O'MASTA, M. R.; DESHPANDE, V. S. ; WADLEY, H. N.. Defect controlled transverse compressive strength of polyethylene fiber laminates. International Journal of Solids and Structures, 52:130-149, 2015. 2.1.2.1 
[39] KARTHIKEYAN, K.; KAZEMAHVAZI, S. ; RUSSELL, B. P.. Optimal fibre architecture of soft-matrix ballistic laminates. International Journal of Impact Engineering, 88:227-237, 2016. 2.1.2.1

[40] BOGETTI, T. A.; WALTER, M.; STANiszeWSKI, J. ; Cline, J.. Interlaminar shear characterization of ultra-high molecular weight polyethylene (UHMWPE) composite laminates. Composites Part A: Applied Science and Manufacturing, Vol. 98(03):105-115, 2017. 2.1.2.1, 2.4

[41] SINGH, B. B.; SUKUMAR, G.; SENTHIL, P. P.; JENA, P. K.; REDDY, P. R.; KUMAR, K. S.; MADHU, V. ; REDDY, G. M.. Future armour materials and technologies for combat platforms. Defence Science Journal, 67(4):412-419, 2017. 2.1.2.1, 2.2

[42] CAllister, W. D. J.. Fundamentos da Ciência e Engenharia de Materiais - Uma Abordagem Integrada, vol. 1. LTC Livros Técnicos e Científicos Editora, Rio de Janeiro, $2^{\text {a }}$ Ed., 2006. 2.1.3, 2.10, $2.13,4.2 .4$

[43] MA, Y.; SU, X.; PYRZ, R. ; RAUHE, J. C.. A novel theory of effective mechanical properties of closed-cell foam materials. Acta Mechanica Solida Sinica, 26(6):559-569, 2013. 2.1.3

[44] RAMIREZ, B. J.. Manufacturing and Characterization of Temperature-Stable, Novel, Viscoelastic Polyurea Based Foams for Impact Management. Tese de Doutorado, University of California, 2017. 2.1.3, 2.1.3, 4.2.3.2

[45] ElliotT, J. A.; WINDLE, A. H.; HOBDELL, J. R.; EECKHAUT, G.; OLDMAN, R. J.; LUDWIG, W.; BOLlER, E.; CLOETENS, P. ; BARUCHEL, J.. In-situ deformation of an open-cell flexible polyurethane foam characterised by $3 \mathrm{D}$ computed microtomography. Journal of Materials Science, 37(8):1547-1555, 2002. 2.1.3

[46] KOOHBOR, B.; KIDANE, A. ; LU, W. Y.. Characterizing the constitutive response and energy absorption of rigid polymeric foams subjected to intermediate-velocity impact. Polymer Testing, 54:48-58, 2016. 2.1.3

[47] TANG, M.; HUANG, G.; ZHANG, H.; LIU, Y.; CHANG, H.; SONG, H.; XU, D. ; WANG, Z.. Dependences of Rheological and Compression Mechanical Properties on Cellular Structures for Impact- 
Protective Materials. ACS Omega, 2(5):2214-2223, 2017. 2.1.3.1, 2.1.3.2, 2.7.1, 4.2.3.2, 4.2.3.3

[48] ROGERS CORPORATION. High Performance Foams Division PORON ${ }^{\circledR} \mathrm{XRD}^{\mathrm{TM}}$ Extreme Impact Protection - Physical Properties, 2018. Datasheet. 2.1.3.1, 3.2

[49] YANG, L. M.; SHIM, V. P.. A visco-hyperelastic constitutive description of elastomeric foam. International Journal of Impact Engineering, 30(8-9):1099-1110, 2004. 2.1.3.1

[50] LOTHE, I.. Development of Product for Prevention of Femur Fracture. Tese de Doutorado, Norwegian University of Science and Technology, 2013. 2.1.3.1, 4.2.3.3

[51] RAMIREZ, B.; MISRA, U. ; GUPTA, V.. Viscoelastic foamfilled lattice for high energy absorption. Mechanics of Materials, 127(1):39-47, dec 2018. 2.1.3.1, 4.2.3.2

[52] GRUJICIC, A.; LABERGE, M.; GRUJICIC, M.; PANDURANGAN, B.; RUNT, J.; TARTER, J. ; DILLON, G.. Potential improvements in shock-mitigation efficacy of a polyurea-augmented advanced combat helmet. Journal of Materials Engineering and Performance, 21(8):1562-1579, 2012. 2.1.3.2

[53] DENIZ, T.. Ballistic Penetration of Hardened Steel Plates. Tese de Doutorado, Middle East Technical University, 2010. 2.2, 2.2.1, 2.9.2, 2.13.1, 4.2.2.1

[54] CORTEZ, L. D.; REIS, D. A. P.; BRIGUEnTE, L. A. N. S. ; NETO, C. D. M.. Tratamentos Térmicos da Liga Ti-6Al-4V Para Realização de Ensaio de Fluência. Anais do $13^{\circ}$ Encontro de Iniciação Científica e Pós-Graduação do ITA - XIII ENCITA, p. 9, 2007. 2.2.1

[55] WESSEL, J. K.. The Handbook of Advanced Materials: Enabling New Designs, vol. 1. John Wiley \& Sons, Inc, New Jersey, 2004. 2.2.1

[56] ACNIS GROUP. Technical Datasheet Ti-6Al-4V ELI - Grade 23. Technical report, Acnis Company, 2016. 2.2.1, A.1

[57] KISSELL, J. R.; PANTELAKIS, S. G. ; HAIDEMENOPOUlOS, G. N.. Handbook of Advanced Materials. John Wiley \& Sons, 2004. 2.2.1, $2.2 .1,4.2 .2 .1,4.2 .4$ 
[58] NESTERENKO, V. F.; GOLDSMITH, W.; INDRAKANTI, S. S. ; GU, Y. B.. Response of hot isostatically pressed Ti-6Al-4V targets to normal impact by conical and blunt projectiles. International Journal of Impact Engineering, 28(2):137-160, 2003. 2.2.1, 2.2.1, 2.12, $2.12,4.2 .2 .3$

[59] MEYER, L. W.; KRÜGER, L.; SOMMER, K.; HALLE, T. ; HOCKAUF, M.. Dynamic strength and failure behavior of titanium alloy Ti-6Al-4V for a variation of heat treatments. Mechanics of TimeDependent Materials, 12(3):237-247, 2008. 2.2.1, 2.9.2, 2.12, 4.2.2.1, 4.2.2.3

[60] THOMAS, E. L.; MCGRATH, M. F.; BUCHANAN, R. C.; CHELLURI, B.; HABER, R. A.; HUTCHINSON, J. W.; JOHNSON, G. R.; KUMAR, S.; MCMEEKING, R. M.; ORLOVSKAYA, N. A.; ORTIZ, M.; RADOVITZKY, R. A.; RAMESH, K. T.; SHOCKEY, D. A.; SKAGGS, S. R. ; WAX, S. G.. Opportunities in Protection Materials Science and Technology for Future Army Applications. Technical report, National Academy of Sciences, Washington, DC, 2012. 2.2.1, 2.5

[61] LÄSSIG, T.; BAGUSAT, F.; PFÄNDLER, S.; GULDE, M.; HEUNOSKE, D.; OSTERHOLZ, J.; STEIN, W.; NAHME, H. ; MAY, M.. Investigations on the spall and delamination behavior of UHMWPE composites. Composite Structures, 182(May):590-597, 2017. $2.3,2.4,4.1$

[62] NAtional institute OF JUSTICE. Selection and Application Guide to Personal Body Armor, 2001. 2.3

[63] ANDERSON, T. L.; ANDERSON, T. L.. Fracture Mechanics: Fundamentals and Applications, vol. 1. CRC Press, Boca Raton - FL, 3th Ed., 2005. 2.3

[64] GREENHALGH, E. S.; BLOODWORTH, V. M.; IANNUCCI, L. ; POPE, D.. Fractographic observations on Dyneema ${ }^{\circledR}$ composites under ballistic impact. Composites Part A: Applied Science and Manufacturing, 44(1):51-62, 2013. 2.3, 2.4, 4.1

[65] MEYERS, M. A.. Dynamic Behavior of Materials. John Wiley \& Sons, Inc, San Diego, CA, 1st Ed., 1994. 2.3.1, 2.4, 2.6

[66] AVIllez, ROBERTO RIBEIRO; SilvA, A. L. V. D. C.. Termodinâmica dos Materiais e Processos. PUC-Rio, 2015. 2.3.1 
[67] HAMOUDA, A.; RISBY, M.. Lightweight Ballistic Composites. Woodhead Publishing in Materials, 2006. 2.4, 2.4, 2.5, 2.5, 2.9.2, 2.11

[68] YADAV, R.; NAEBE, M.; WANG, X. ; KANDASUBRAMANIAN, B.. Body armour materials: from steel to contemporary biomimetic systems. RSC Adv., 6(116):115145-115174, 2016. 2.4

[69] NATIONAL INSTITUTE OF JUSTICE. Ballistic Resistance of Personal Body Armor NIJ Standard-0101.06, 2008. 2.4, 2.4, 2.5

[70] ASSOCIAÇÃO BRASILEIRA DE NORMAS TÉCNICAS. Blindagens para impactos balísticos - Classificação e critérios de avaliação, 2005. 2.4, 2.5, 2.5, 3.7

[71] CARR, D. J.; MABBOTT, A. J.. Ballistic Damage. In: FORENSIC TEXTILE SCIENCE, p. 181-199. Elsevier Ltd., 2017. 2.4, 2.5

[72] BØRVIK, T.; DEY, S. ; CLAUSEN, A. H.. Perforation resistance of five different high-strength steel plates subjected to small-arms projectiles. International Journal of Impact Engineering, 36(7):948964, 2009. 2.4

[73] U.S. DEPARTMEnT OF DEFEnSE. Mil-Std-662F Test Method Standard V 50 Ballistic Test for Armor. Technical Report 01, Department of Defense, 1997. 2.5, 2.5.2

[74] NATIONAL INSTITUTE OF JUSTICE. Ballistic Resistance of Personal Body Armor NIJ Standard-0101.04, 2001. 2.5, 2.5.1, 3.7

[75] CHAGAS, C. F.. Minimização do efeito de aresta em blindagem cerâmica à base de alumina. Tese de doutorado, Instituto Militar de Engenharia, 2014. 2.5

[76] RODRÍGUEZ-MILlÁN, M.; ITO, T.; LOYA, J. A.; OLMEDO, A. ; MIGUÉLEZ, M. H.. Development of numerical model for ballistic resistance evaluation of combat helmet and experimental validation. Materials and Design, 110:391-403, 2016. 2.5

[77] MEDVEDOVSKI, E. Ballistic performance of armour ceramics: Influence of design and structure. Part 2. Ceramics International, $36(7): 2117-2127,2010.2 .5$

[78] NATIONAL InStitute OF JUSTICE. NIJ Standard-0101.04. Technical report, U.S. Department of Justice, 2000. 2.5, 4.3.2 
[79] BReEZe, J.; Penn-BarWell, J. G.; KeEne, D.; O'ReIlly, D.; JEYANATHAn, J. ; MAHONEY, P. F.. Ballistic Trauma. Springer International Publishing, Cham, 2017. 2.5

[80] WANG, P.; XU, S.; LI, Z.; YANG, J.; ZHANG, C.; ZHENG, H. ; HU, S.. Experimental investigation on the strain-rate effect and inertia effect of closed-cell aluminum foam subjected to dynamic loading. Materials Science and Engineering A, 620:253-261, 2014. 2.6

[81] LIU, L.; FAN, Y.; LI, W.. Viscoelastic shock wave in ballistic gelatin behind soft body armor. Journal of the Mechanical Behavior of Biomedical Materials, 34:199-207, 2014. 2.6

[82] LI, X.; ZHANG, X.; GUO, Y.; SHIM, V. P.; YANG, J. ; CHAI, G. B.. Influence of fiber type on the impact response of titanium-based fiber-metal laminates. International Journal of Impact Engineering, 114(May 2017):32-42, 2018. 2.6

[83] GROGAN, J.; TEKaluR, S. A.; SHUKla, A.; BOGDANOVICH, A. ; COFFELT, R. A.. Ballistic resistance of $2 \mathrm{D}$ and $3 \mathrm{D}$ woven sandwich composites. Journal of Sandwich Structures and Materials, 9(3):283-302, 2007. 2.6

[84] TAN, L. B.; TSE, K. M.; LEE, H. P.; TAN, V. B. C. ; LIM, S. P.. Performance of an advanced combat helmet with different interior cushioning systems in ballistic impact: Experiments and finite element simulations. International Journal of Impact Engineering, 50:99-112, 2012. 2.6

[85] NGUYEN, L. H.; LÄSSIG, T. R.; RYAN, S.; RIEDEL, W.; MOURITZ, A. P. ; ORIFICI, A. C.. A methodology for hydrocode analysis of ultra-high molecular weight polyethylene composite under ballistic impact. Composites Part A: Applied Science and Manufacturing, 84:224-235, 2016. 2.6

[86] SEDDON, R.; MAUDES, J.; MURILlO, N.; IZAGA, J. ; VENEGAS, P.. Material compuesto metálico para proteger contra proyectiles de alta velocidad e impactos de alta energía. Materiales Compuestos, 1:1-8, 2017. 2.6 
[87] HUdSPeth, M.; JEWELL, E.; HORNER, S.; ZHENG, J. ; CHEN, W.. Exploration of Wave Development during Yarn Transverse Impact. Fibers, 5(2):17, 2017. 2.6

[88] SPOSITO, G.; PROST, R.. Structure of Water Adsorbed on Smectites. Chemical Reviews, 82(6):553-573, 1982. 2.7.1

[89] AUERBACH, S. M.; CARRAdO, K. A. ; DUTTA, P. K.. Handbook of Layered Materials. Marcel Dekker, Inc., New York (USA), 2004. 2.7 .1

[90] FEJDYŚ, M.; KOŚLA， K.; KUCHARSKA-JASTRZA̧BEK， A. ; ŁANDWIJT, M.. Hybride composite armour systems with advanced ceramics and ultra-high molecular weight polyethylene (UHMWPE) fibres. Fibres and Textiles in Eastern Europe, 24(3):7989, 2016. 2.7.1, 3.3.1, 4.2.3.3, 4.2.3.3

[91] ZHENG, Z.; TANG, X.; SHI, M. ; ZHOU, G.. Surface Modification of Uitrahigh-Molecular-Weight Polyethylene Fibers. Journal of Polymer Science, Part B: Polymer Physics, 42(3):463-472, 2004. 2.7.1, 2.9.1, 2.11, 4.2.3.1, 4.2.3.3

[92] SILVERSTEIN, M. S.; BREUER, O. ; DODIUK, H.. Surface modification of UHMWPE fibers. Journal of Applied Polymer Science, 52(12):1785-1795, 1994. 2.7.1, 4.2.3.1

[93] OU, R.; ZHAO, H.; SUI, S.; SONG, Y. ; WANG, Q.. Reinforcing effects of Kevlar fiber on the mechanical properties of woodflour/high-density-polyethylene composites. Composites Part A: Applied Science and Manufacturing, 41(9):1272-1278, 2010. 2.7.1, 4.2.3.1

[94] SETHI, S.; RAY, B. C.. Environmental effects on fibre reinforced polymeric composites: Evolving reasons and remarks on interfacial strength and stability. Advances in Colloid and Interface Science, 217:43-67, 2015. 2.7.1

[95] ASTM. Standard Test Method for Transition Temperatures and Enthalpies of Fusion and Crystallization of Polymers by Differential Scanning Calorimetry, 2015. Datasheet. 2.8.1

[96] SOKUllu URKaC, E.; OZTARHAN, A.; TIHMinlioglu, F.; KAYA, N.; ILA, D.; MUNTELE, C.; BUDAK, S.; OKS, E.; NIKOLAEV, A.; EZDESIR, A. ; TEK, Z.. Thermal characterization of Ag and 
$\mathrm{Ag}+\mathrm{N}$ ion implanted ultra-high molecular weight polyethylene (UHMWPE). Nuclear Instruments and Methods in Physics Research, Section B: Beam Interactions with Materials and Atoms, 261(1-2 SPEC. ISS.):699-703, 2007. 2.8.1

[97] DENG, M.; UHRICH, K. E.. Analysis of Thermal Properties of Polymeric Biomaterials . I . Ultrahigh-Molecular-Weight Polyethylene. Polymer, p. 1353-1361, 1997. 2.8.1

[98] SAnBORN, B.; DILEOnARDI, A. M. ; WEERASOORIYA, T.. Tensile Properties of Dyneema SK76 Single Fibers at Multiple Loading Rates Using a Direct Gripping Method. Journal of Dynamic Behavior of Materials, 1(1):4-14, 2015. 2.9.1, 4.2.3.1

[99] HERRMANN, K.. Hardness Testing - Principles and Applications, vol. 25. ASM International, Ohio, 1st Ed., 2011. 2.9.2

[100] SIEBERT, A. R. J.. Caracterização Morfológica, Estrutural, Mecânica e Tribológica da Liga Ti-6Al-4V produzida por LENS e comercial. Dissertação de mestrado, Universidade Federal de Santa Catarina, 2017. 2.9.2, 2.12, 4.2.2.1, 4.2.2.3, A.1

[101] LEE, W.-S.; LIN, C.-F.. Plastic deformation and fracture behaviour of $\mathrm{Ti}-6 \mathrm{Al}-4 \mathrm{~V}$ alloy loaded with high strain rate under various temperatures. States News Service, 241:48-59, 1998. 2.9.2, 4.2.2.1

[102] FEDRIGO, G.; WOLFART, M. J.. Avaliação da microestrutura da liga de Titânio Ti-6Al-4V após tratamento térmico de envelhecimento. In: VI SECITEC, p. 21-29, Luzerna - SC, 2017. 2.9.2, 2.12, 4.2.2.3

[103] DANGSHENG, X.. Friction and wear properties of UHMWPE composites reinforced with carbon fiber. Materials Letters, 59(23):175-179, 2005. 2.11

[104] SUI, G.; ZHONG, W. H.; REN, X.; WANG, X. Q. ; YANG, X. P.. Structure, mechanical properties and friction behavior of UHMWPE/HDPE/carbon nanofibers. Materials Chemistry and Physics, 115(1):404-412, 2009. 2.11

[105] REN, Y.; DING, Z.; WANG, C.; ZANG, C.; ZHANG, Y. ; XU, L.. Influence of DBD plasma pretreatment on the deposition of 
chitosan onto UHMWPE fiber surfaces for improvement of adhesion and dyeing properties. Applied Surface Science, 396:15711579, 2017. 2.11

[106] ECHLIN, P.. Handbook of Sample Preparation for Scanning Electron Microscopy and X-Ray Microanalysis, vol. 1. Springer, Boston, MA, 2009. 2.11

[107] YOGI, L.; PIORINO NETO, F.; REIS, D. ; MOURA NETO, C.. Avaliação do Tratamento Térmico na Fluência da Liga Ti-6Al4V por Caracterização Microestrutural. XIV ENCITA, 2008. 2.12, 2.12

[108] MEYERS, M. A.; CHAWLA, K. K.. Mechanical Behavior of Materials. Cambridge University Press, 2009. 2.12, 2.13.2, 4.2.2.3

[109] MONTGOMERY, D. C.; RUNGER, G. C.. Applied Statistics and Probability for Engineers, vol. 1. John Wiley \& Sons, Inc, New York, 3rd Ed., jan 2003. 2.13.1, 2.13.1, 2.13.2

[110] LUIZ HENRIQUE ABREU DAL BELLO. Modelagem em Experimentos Mistura-Processo para Otimização de Processos Industriais. Tese de Doutorado, Pontifícia Universidade Católica do Rio de Janeiro, 2010. 2.13.1

[111] NIMON, K. F.; OSWALD, F. L.. Understanding the Results of Multiple Linear Regression: Beyond Standardized Regression Coefficients. Organizational Research Methods, 16(4):650-674, 2013. 2.13 .1

[112] SARKAR TACTICAL COMPANY. PE UD Sheet ST-HB13, 2016. Datasheet. 3.2

[113] SARKAR TACTICAL COMPANY. Safety Data sheet - ST-HB13 UD, 2017. Datasheet. 3.2

[114] STAMP SPUMAS. Datasheet: PEE130AE, 2015. 3.2

[115] DSM DYNEEMA. Recommended pressure cycle for Dyneema ${ }^{\circledR}$ HB UD grades (metric). Technical report, DSM Company, 2016. $3.3 .1,3.3 .1,4.1$

[116] NIINOMI, M.; KUO, C. K. ; MA, P. X.. Mechanical properties of biomedical titanium alloys. Biomaterials, 22(6):511-521, 1998. A.1 
[117] METALS, A.. Tabela de comparação de dureza. Technical report, AMS Metais, 2018. A.1

[118] 3M DO BRASIL. Adesivo 76 Spray, 2004. Datasheet. A.1

[119] AG, P.. Pontacol BP21.2008. Technical Report May, Pontacol AG, Schmitten, 2019. A.1 


\section{A \\ Caracterização dos materiais das placas balísticas}

Esta Apêndice apresenta as informações técnicas de materiais empregados na pesquisa, os resultados de metrologia realizados, os dados de caracterizações espectroscópicas e mecânicas.

\section{A.1}

\section{Especificação detalhada dos materiais empregados na pesquisa}

As informações técnicas da chapa de Ti-6Al-4V ELI, comprada da empresa Acnis do Brasil -SP estão apresentadas na Tabela A.1 (100, 116, 56).

Tabela A.1: Especificações da chapa de Ti-6Al-4V ELI.

\begin{tabular}{cc}
\hline Espessura da lâmina $(\mathbf{m m})$ & 1,03 \\
Temperatura de fusão $\left({ }^{\circ} \mathrm{C}\right)$ & 1650 \\
Densidade $\left(\mathrm{g} / \mathbf{c m}^{3}\right)$ & 4,43 \\
Módulo de elasticidade $(\mathbf{G P a})$ & 112,4 \\
Tensão de escoamento $(\mathbf{M P a})$ & 795 \\
Resistência à tração $(\mathbf{M P a})$ & 860 \\
Dureza Vickers $(\mathbf{H V}) *$ & 310 \\
\hline * Correspondência em Escala de Dureza $(117):$ & $310 \mathrm{HV} \approx 31 \mathrm{HRC}$ \\
\hline
\end{tabular}

As informações técnicas do Adesivo Spray $3 \mathrm{M}^{\mathrm{TM}} 76$ estão dispostos na Tabela A.2 (118).

Tabela A.2: Especificações do Adesivo Spray 3M $3 \mathrm{M}^{\mathrm{TM}} 76$.

\begin{tabular}{cc}
\hline Base & resinas e elastômeros sintéticos \\
Consistência & xarope fino (líquido viscoso) em aerosol \\
Sólidos & $9,6 \%$ mínimo \\
Solvente & cloreto de metileno e nafta \\
Peso específico & $1,25 \mathrm{~g} / \mathrm{cm}^{3}$ \\
Taxa de liberação & 55 a 85 gramas $/$ minuto \\
Propelente & Propano e Butano \\
\hline Aplicações: produto indicado para colagens de tecidos, borracha, \\
compensados e plásticos (inclusive polietileno e polipropileno). \\
\hline
\end{tabular}

As informações técnicas do Adesivo BP21.2008 (Pontacol AG - Suíça) seguem dispostos na Tabela A.3 (119). 
Tabela A.3: Especificações do Filme Adesivo BP21.2008, Pontacol.

\begin{tabular}{cc}
\hline Base & poliolefina modificada \\
Transparência & opaca \\
Densidade & $0,9 \mathrm{~g} / \mathrm{m}^{3}$ \\
Temperatura de fusão & $115-130\left({ }^{\circ} \mathrm{C}\right)$ \\
Temperatura de processamento & $130-180\left({ }^{\circ} \mathrm{C}\right)$ \\
\hline
\end{tabular}

\section{A. 2}

Metrologia das placas balísticas

A Tabela A.4 contem as medidas de espessura realizadas ao longo da superfície das 16 placas, para verificar a regularidade das dimensões decorrente das etapas de montagem, prensagem e resfriamento. As medidas determinadas de P1 a P9 foram realizadas nos pontos designados no esquema da Figura 3.11. Na última coluna está expresso o valor da média, sendo que este foi utilizado para especificar a espessura de material balístico das placas, que posteriormente receberam a camada de espuma.

Consta ainda da Tabela A.4 a aferição da espessura da chapa de Ti-6Al$4 \mathrm{~V}$ que foi usada em complemento à proteção dos pré-impregnados para as soluções de blindagem. Essa medição também foi realizada em nove pontos da superfície do material.

Tabela A.4: Metrologia da espessura das placas.

\begin{tabular}{ccccccccccc} 
CP & P1 & P2 & P3 & P4 & P5 & P6 & P7 & P8 & P9 & Média \\
\hline $\mathbf{1}$ & 14,7 & 14,6 & 14,5 & 14,4 & 14,3 & 14,5 & 14,7 & 14,4 & 14,4 & $\mathbf{1 4 , 5}$ \\
$\mathbf{2}$ & 14,3 & 14,5 & 14,7 & 14,7 & 14,3 & 14,4 & 14,5 & 14,5 & 14,5 & $\mathbf{1 4 , 5}$ \\
$\mathbf{3}$ & 14,5 & 14,4 & 14,5 & 14,7 & 14,9 & 14,9 & 14,7 & 14,7 & 14,5 & $\mathbf{1 4 , 6}$ \\
$\mathbf{4}$ & 14,9 & 15,0 & 14,9 & 14,8 & 14,6 & 14,7 & 14,5 & 14,7 & 14,9 & $\mathbf{1 4 , 8}$ \\
$\mathbf{5}$ & 11,5 & 11,2 & 11,4 & 11,5 & 11,3 & 11,5 & 11,2 & 11,4 & 11,6 & $\mathbf{1 1 , 4}$ \\
$\mathbf{6}$ & 11,1 & 11,1 & 11,1 & 11,4 & 11,5 & 11,4 & 11,5 & 11,5 & 11,4 & $\mathbf{1 1 , 3}$ \\
$\mathbf{7}$ & 11,5 & 11,5 & 11,6 & 11,7 & 11,8 & 11,6 & 11,9 & 11,7 & 11,5 & $\mathbf{1 1 , 6}$ \\
$\mathbf{8}$ & 11,9 & 11,9 & 11,5 & 11,9 & 11,9 & 11,9 & 11,9 & 11,9 & 11,9 & $\mathbf{1 1 , 9}$ \\
\hline $\mathbf{9}$ & 20,0 & 20,0 & 20,0 & 20,1 & 20,0 & 20,0 & 20,2 & 20,3 & 20,1 & $\mathbf{2 0 , 1}$ \\
$\mathbf{1 0}$ & 20,2 & 20,0 & 20,0 & 20,3 & 20,2 & 20,0 & 20,2 & 20,2 & 20,0 & $\mathbf{2 0 , 1}$ \\
$\mathbf{1 1}$ & 20,1 & 20,3 & 20,4 & 20,5 & 20,6 & 20,4 & 20,6 & 20,2 & 20,4 & $\mathbf{2 0 , 4}$ \\
$\mathbf{1 2}$ & 20,3 & 20,3 & 20,4 & 20,5 & 20,6 & 20,4 & 20,6 & 20,2 & 20,4 & $\mathbf{2 0 , 4}$ \\
$\mathbf{1 3}$ & 16,5 & 16,5 & 16,6 & 16,5 & 16,6 & 16,7 & 16,7 & 16,5 & 16,6 & $\mathbf{1 6 , 6}$ \\
$\mathbf{1 4}$ & 16,8 & 16,7 & 16,7 & 16,5 & 16,6 & 16,7 & 16,7 & 16,7 & 16,6 & $\mathbf{1 6 , 7}$ \\
$\mathbf{1 5}$ & 16,8 & 16,7 & 16,7 & 16,7 & 16,7 & 16,7 & 16,8 & 16,8 & 16,9 & $\mathbf{1 6 , 8}$ \\
$\mathbf{1 6}$ & 16,9 & 16,8 & 16,7 & 16,7 & 16,9 & 16,8 & 16,7 & 16,8 & 16,8 & $\mathbf{1 6 , 8}$ \\
\hline Ti & 1,032 & 1,035 & 1,031 & 1,035 & 1,037 & 1,033 & 1,031 & 1,034 & 1,035 & $\mathbf{1 , 0 3 4}$ \\
\hline CP1 & CP8 - prepreg HB212 & & & & & & \\
CP9 a CP16 - prepreg ST-HB13 & & & & & & \\
Ti - Chapa da Liga Ti-6Al-4V & & & & & & \\
\hline
\end{tabular}




\section{A.3}

\section{Análises de TGA e DSC das fibras e dos pré-impregnados}

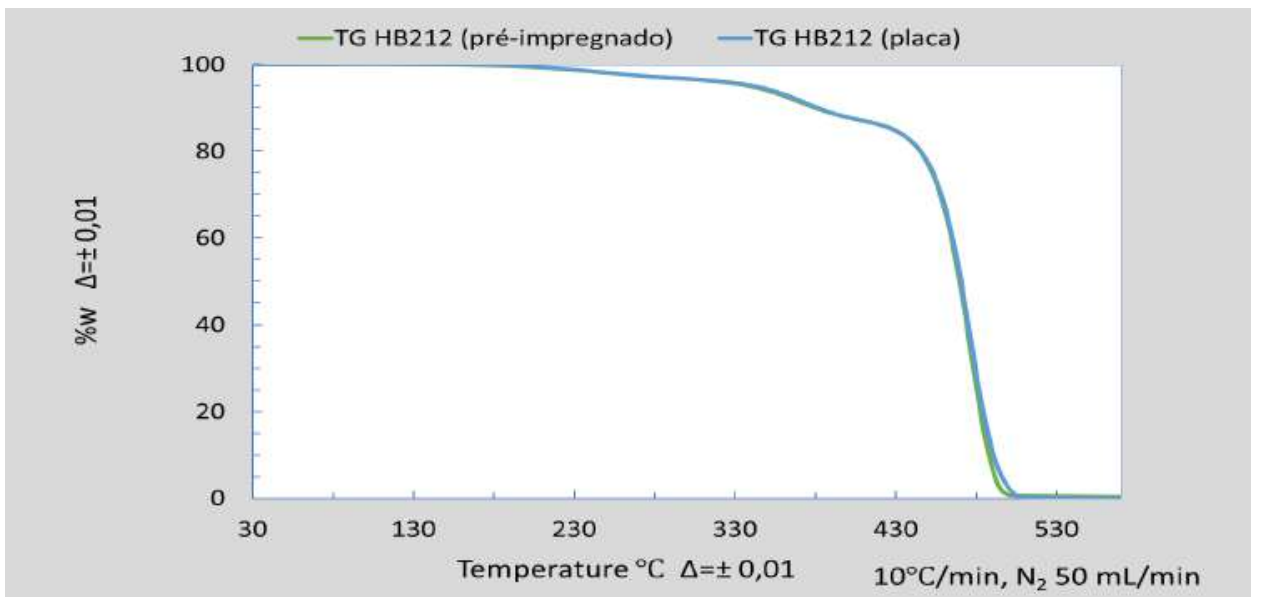

Figura A.1: Ensaio de TGA com amostras de HB212 pré-impregnado e placa.

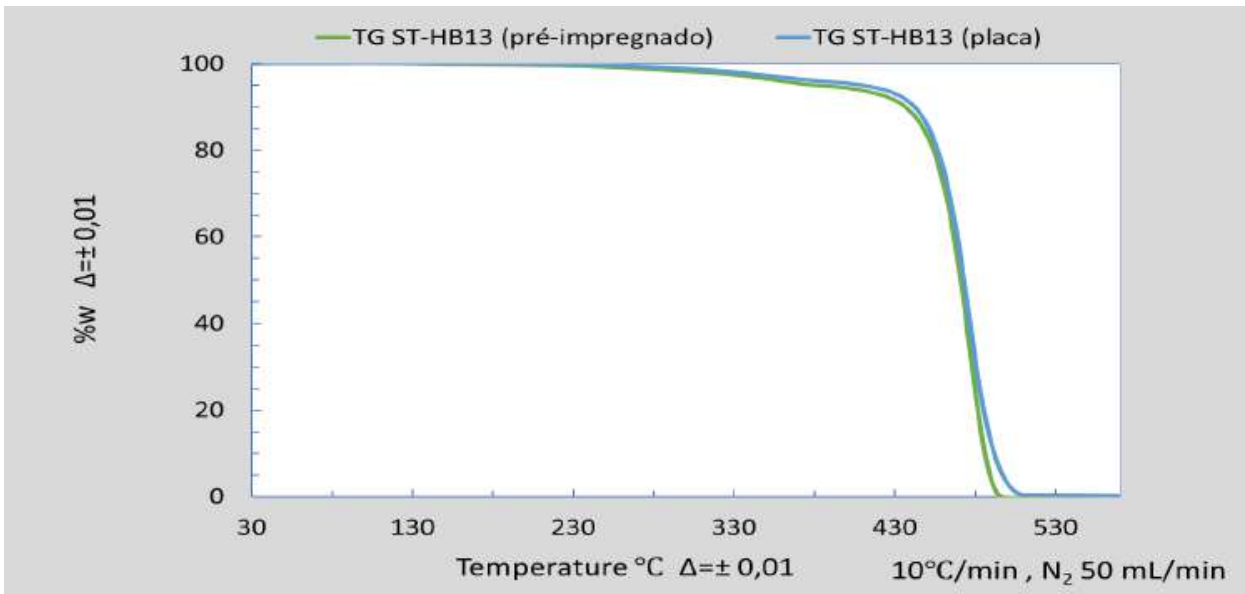

Figura A.2: Ensaio de TGA - ST-HB13 pré-impregnado e placa. 


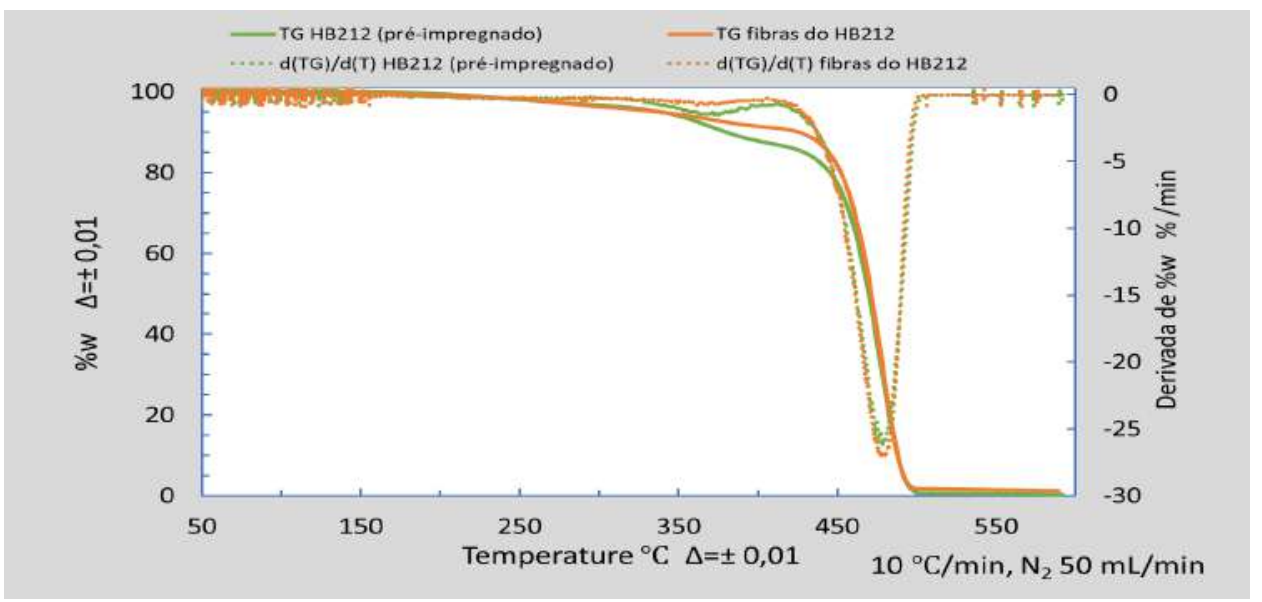

Figura A.3: Ensaio de TGA - HB212 pré-impregnado e fibra do HB212.

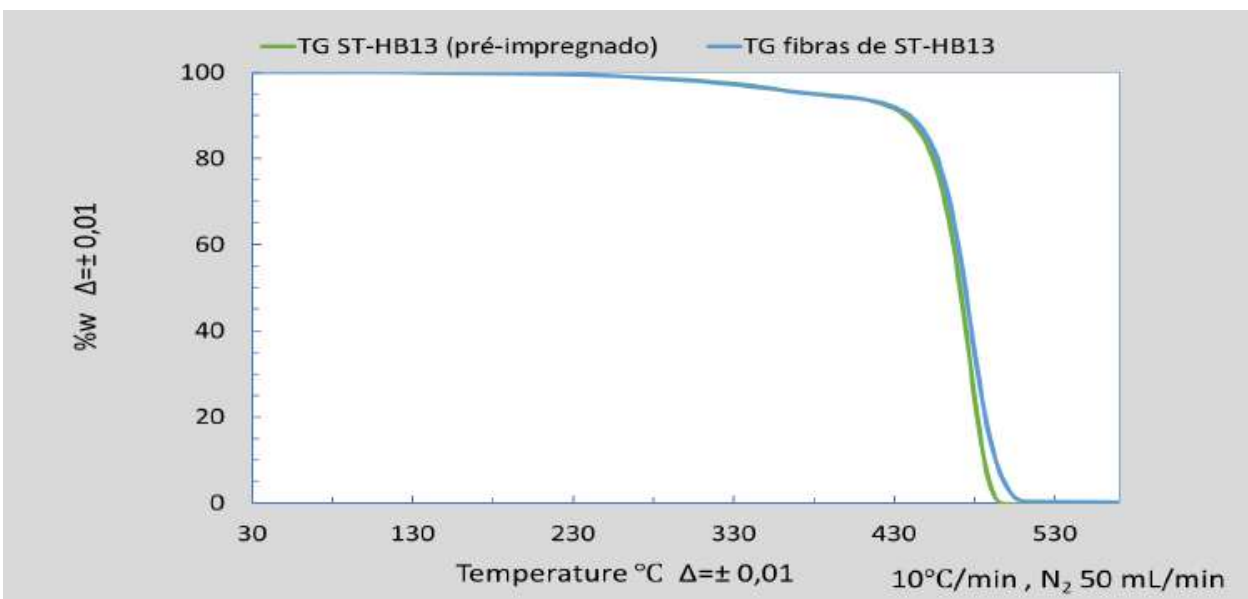

Figura A.4: Ensaio de TGA - ST-HB13 pré-impregnado e fibra do ST-HB13.

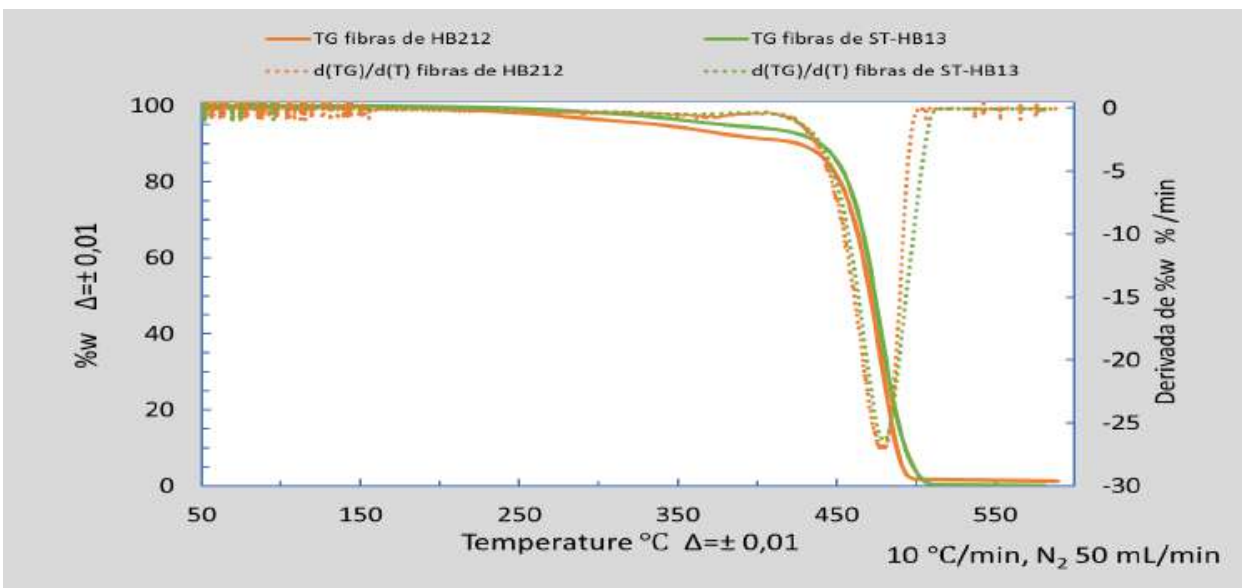

Figura A.5: Ensaio de TGA - fibra de HB212 e fibra do ST-HB13. 


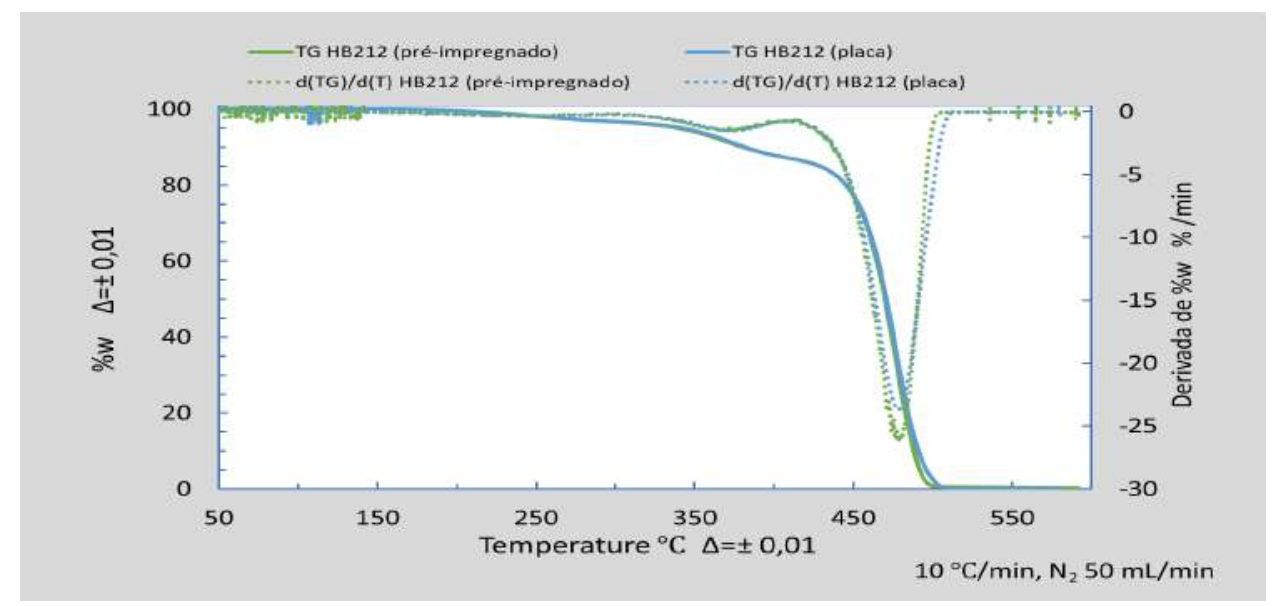

Figura A.6: Ensaio de TGA e curva DTG - HB212 pré-impregnado e de placa.

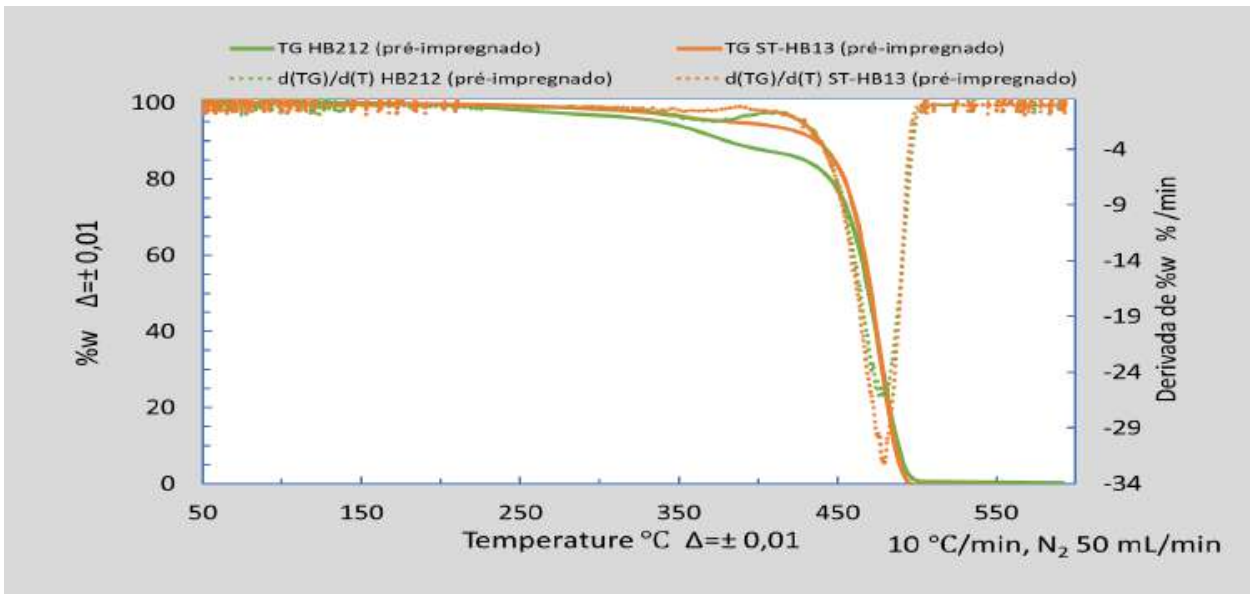

Figura A.7: Ensaio de TGA e curva DTG - pré-impregnados HB212 e STHB13.

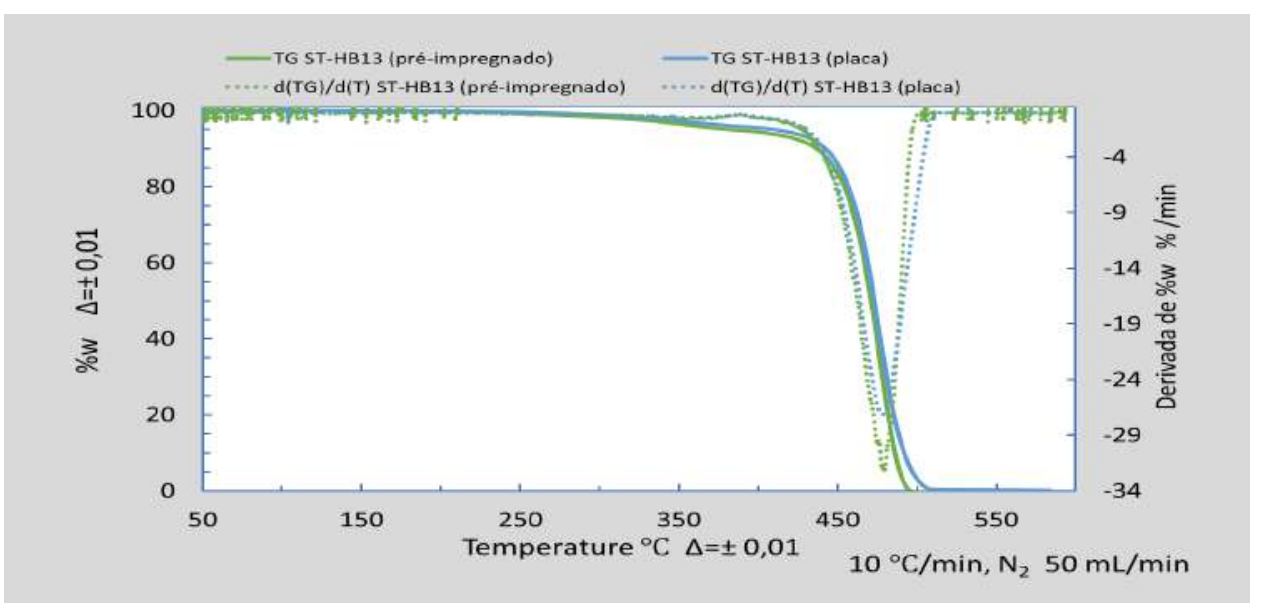

Figura A.8: Ensaio de TGA e curva DTG - ST-HB13 pré-impregnado e de placa. 


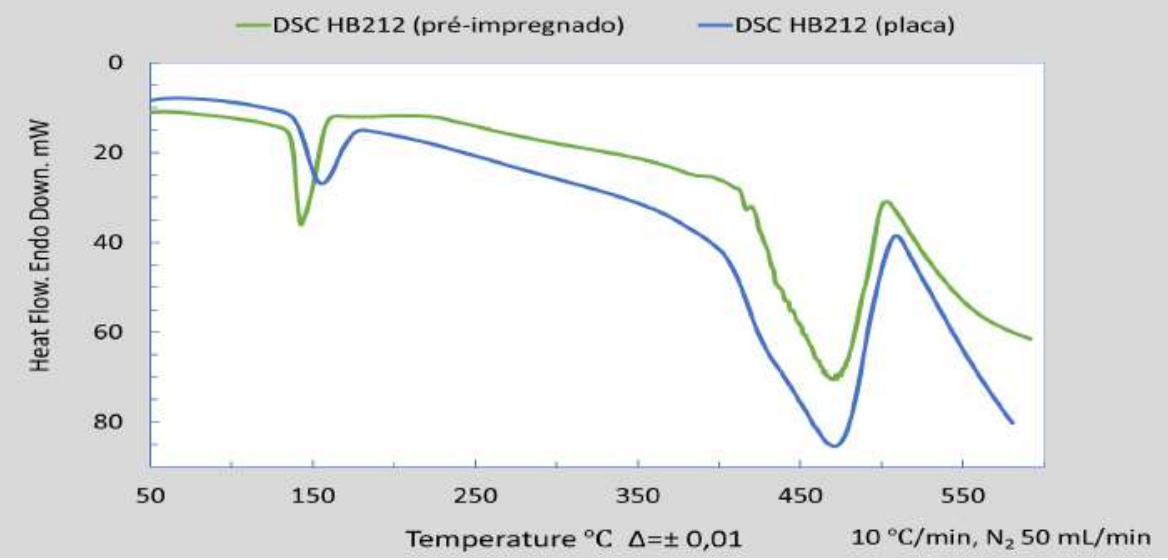

Figura A.9: Ensaio de DSC - HB212 pré-impregnado e placa.

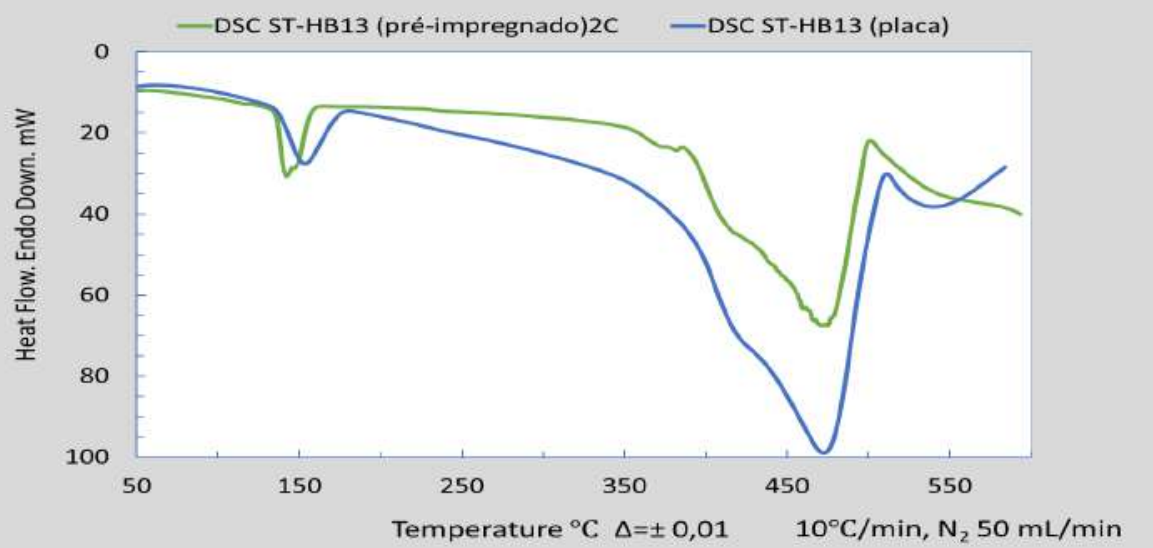

Figura A.10: Ensaio de DSC - ST-HB13 pré-impregnado e placa.

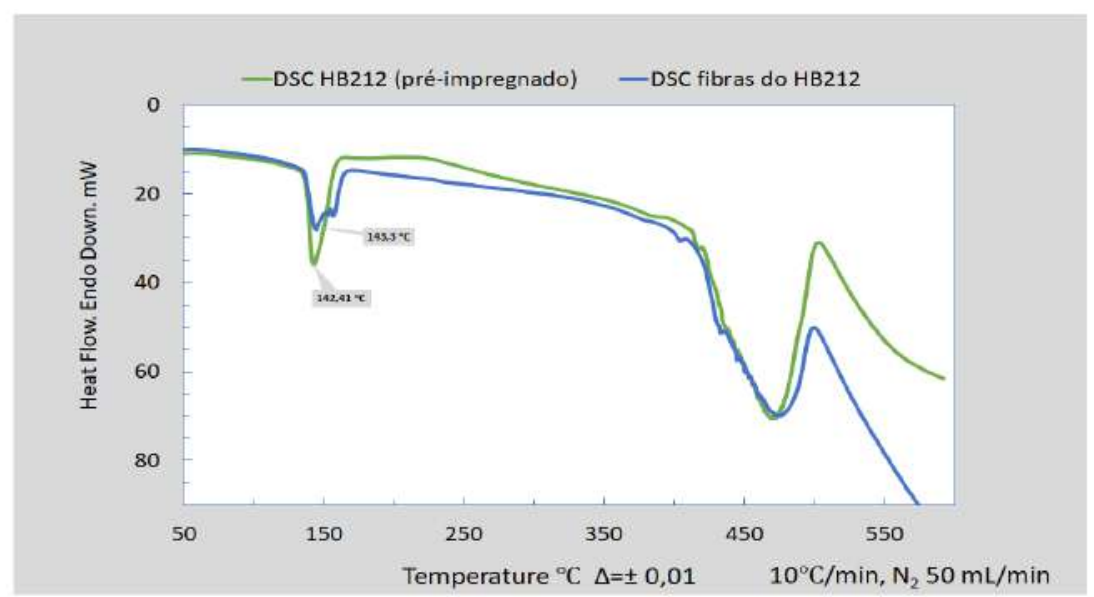

Figura A.11: Ensaio de DSC - HB212 pré-impregnado e fibra do HB212. 


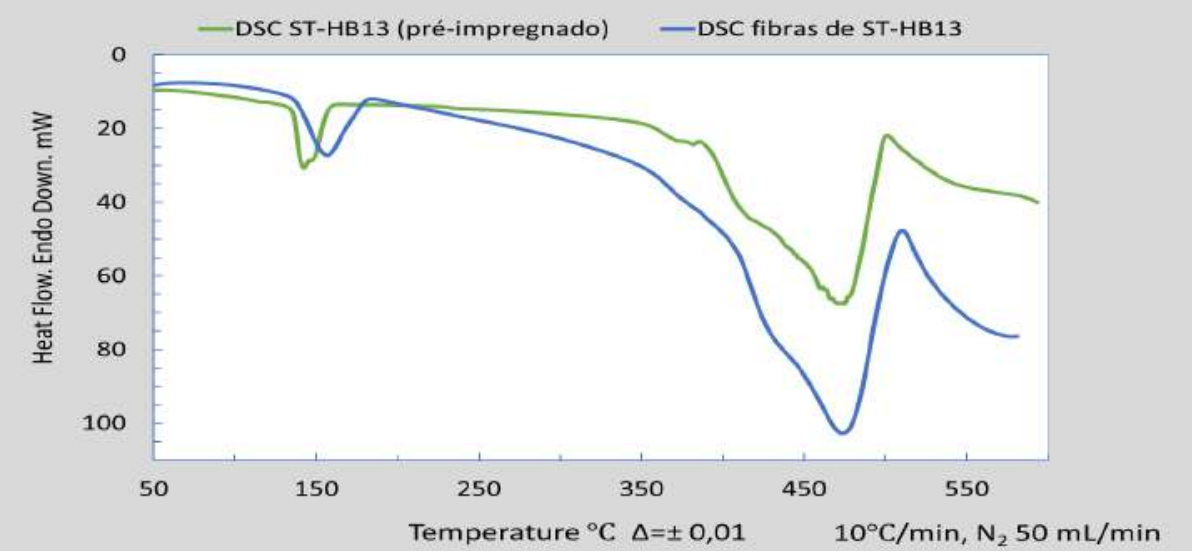

Figura A.12: Ensaio de DSC - ST-HB13 pré-impregnado e fibra do ST-HB13.

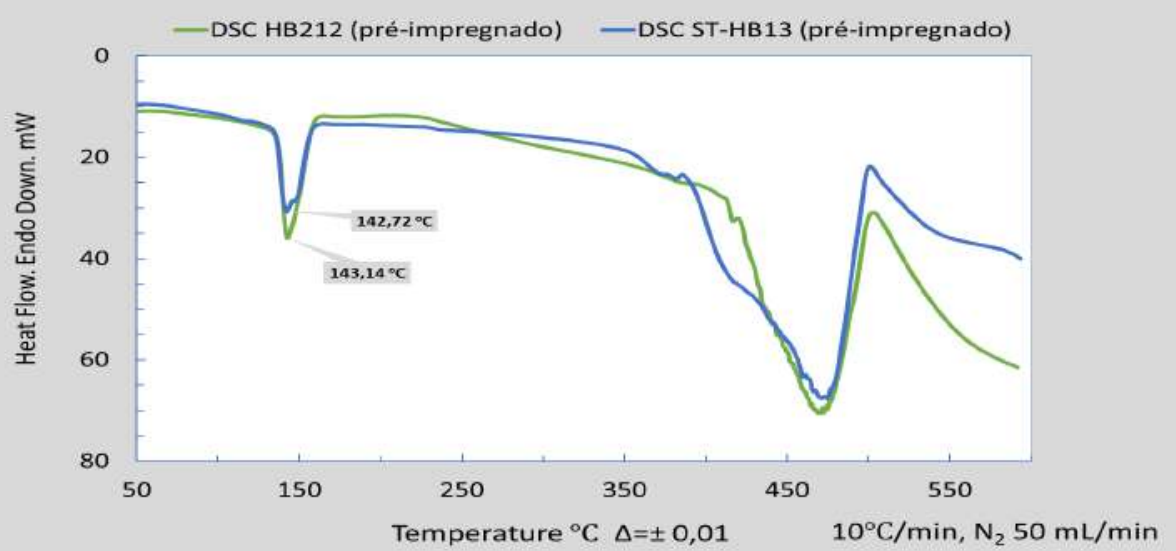

Figura A.13: Ensaio de DSC - pré-impregnados de HB212 e de ST-HB13.

\section{A.4}

\section{Ensaio Mecânico de Tração de fibra}

Foram realizados 103 ensaios de tração de fibras, somando os corpos de prova extraídos dos pré-impregnados HB212 e ST-HB13, dos quais estão representados quatro gráficos de cada material, respectivamente nas Figuras A.14 e A.15. 

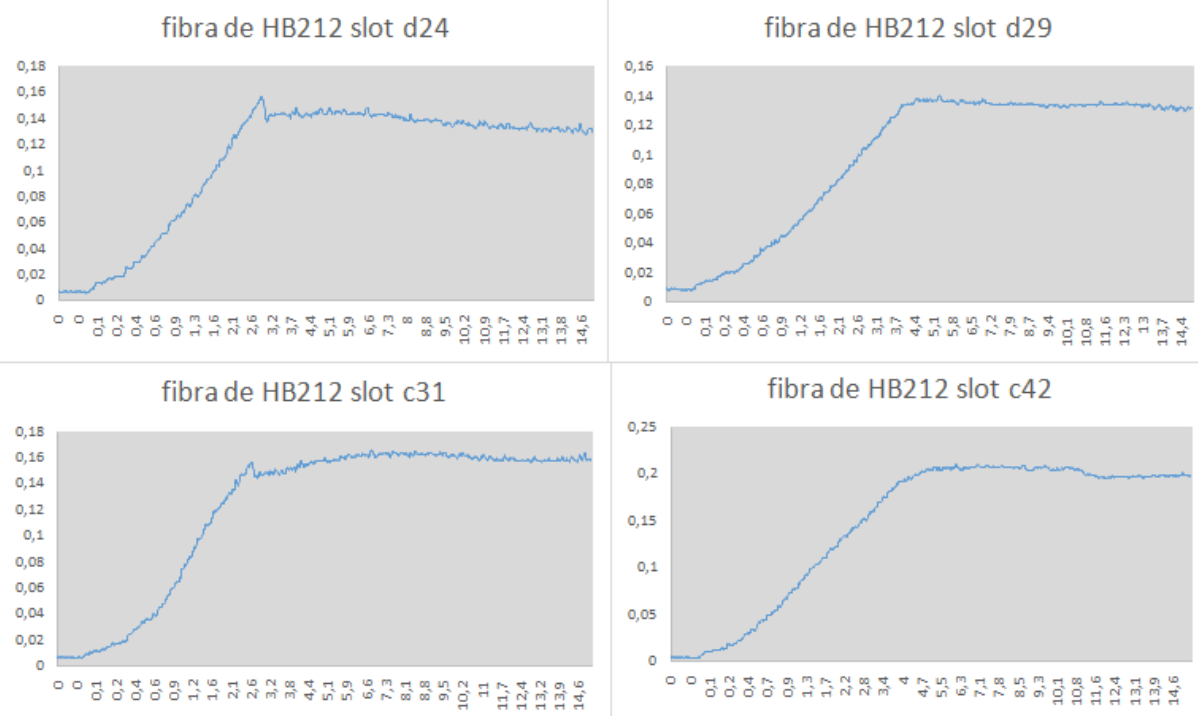

Figura A.14: Gráficos de EMT de fibra de HB212.

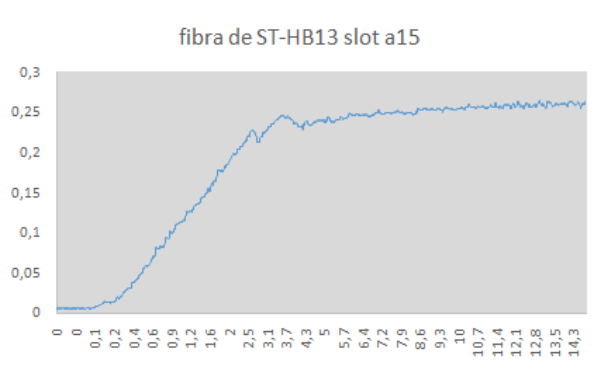

fibra de ST-HB13 slot b21

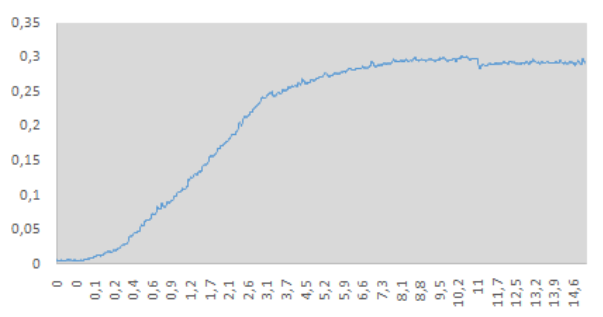

fibra de ST-HB13 slot a16

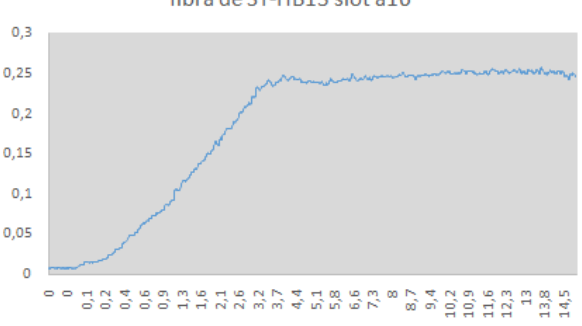

fibra de ST-HB13 slotb26

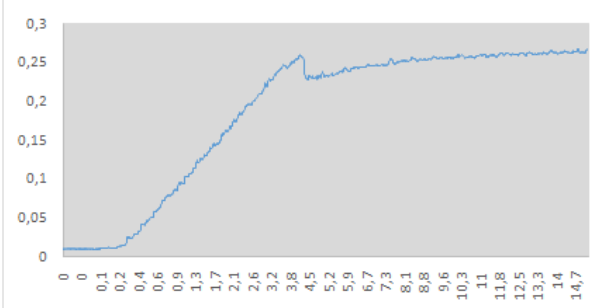

Figura A.15: Gráficos de EMT de fibra de ST-HB13. 
B

\section{Procedimento de fabricação por prensagem a quente}

A seguir as tabelas de controle de força e temperatura dos dois ciclos de prensagem a quente realizados para a fabricação dos protótipos de placas balísticas desta pesquisa.

A Tabela B.1 refere-se ao primeiro ciclo, que contou com 8 placas de HB212. A Tabela B.2 apresenta os parâmetros de controle da fabricação das placas com o prepreg ST-HB13.

As informações estão detalhadas em intervalos de 3 em 3 minutos do ciclo, e contam com destaques extras de intervalos de tempo onde cabe destacar temperaturas específicas das amostras. O processamento deveria seguir uma etapa de aquecimento e desgaseificação, com carga inicial aplicada de 60 ton.f, até que o molde atingisse $130^{\circ} \mathrm{C}$. Em seguida começaria o ciclo de carga máxima e cura dos prepregs, com a aplicação de 400 ton.f por 30 min. Passase então para o resfriamento, sem a retirada da carga máxima até que a temperatura do molde chegasse à $40^{\circ} \mathrm{C}$, quando então se daria o alívio da carga. 
Tabela B.1: Controle dos parâmetros de fabricação dos CPs de HB212.

\begin{tabular}{|c|c|c|c|c|c|}
\hline $\mathrm{t}(\mathrm{min})$ & ${ }^{a} \mathrm{~F}$ (ton.f) & ${ }^{b} T_{A}$ & ${ }^{c} T_{C P 1}$ & ${ }^{c} T_{C P 4}$ & ${ }^{c} T_{C P 5}$ \\
\hline 1 & 67 & 35 & 33 & 33 & 32 \\
\hline 4 & 59 & 45 & 33 & 33 & 34 \\
\hline 7 & 54 & 61 & 39 & 36 & 45 \\
\hline 10 & 48 & 73 & 47 & 46 & 55 \\
\hline 13 & 45 & 84 & 55 & 54 & 66 \\
\hline 16 & 42 & 95 & 62 & 64 & 77 \\
\hline 19 & 38 & 102 & 74 & 76 & 89 \\
\hline 22 & 35 & 107 & 85 & 86 & 98 \\
\hline 23 & 34 & 109 & 88 & 89 & 100 \\
\hline 25 & 33 & 112 & 93 & 94 & 104 \\
\hline 27 & 31 & 116 & 99 & 100 & 108 \\
\hline 28 & 31 & 118 & 101 & 102 & 110 \\
\hline 29 & 30 & 120 & 104 & 105 & 113 \\
\hline 32 & 29 & 125 & 110 & 111 & 118 \\
\hline 35 & 401 & 130 & 121 & 122 & 126 \\
\hline 38 & 382 & 129 & 124 & 124 & 127 \\
\hline 41 & 385 & 127 & 123 & 124 & 125 \\
\hline 44 & 394 & 125 & 121 & 123 & 124 \\
\hline 47 & 388 & 124 & 119 & 122 & 123 \\
\hline 50 & 381 & 123 & 118 & 121 & 123 \\
\hline 53 & 394 & 126 & 118 & 122 & 124 \\
\hline 56 & 391 & 125 & 120 & 123 & 125 \\
\hline 59 & 384 & 124 & 120 & 122 & 123 \\
\hline 62 & 397 & 125 & 119 & 122 & 123 \\
\hline 65 & 394 & 126 & 121 & 123 & 126 \\
\hline 68 & 388 & 124 & 121 & 123 & 124 \\
\hline 71 & 390 & 92 & 113 & 113 & 107 \\
\hline 74 & 409 & 67 & 86 & 84 & 74 \\
\hline 77 & 382 & 53 & 63 & 61 & 53 \\
\hline 78 & 392 & 50 & 58 & 57 & 52 \\
\hline 81 & 383 & 44 & 48 & 48 & 45 \\
\hline 84 & 390 & 41 & 42 & 42 & 41 \\
\hline 86 & 387 & 40 & 41 & 40 & 39 \\
\hline$a$ F - Força aplicada pela prensa & & \\
$b\left(T_{A}\right)$ Temperatura $\left({ }^{\circ} \mathrm{C}\right)$ de controle no molde da prensa \\
\hline Temperatura ( $\left.{ }^{\circ} \mathrm{C}\right)$ no termopar no centro das placas \\
\hline & & & & & \\
\hline
\end{tabular}


Tabela B.2: Controle dos parâmetros de fabricação dos CPs de ST-HB13.

\begin{tabular}{|c|c|c|c|c|c|}
\hline Min & ${ }^{a} \mathrm{~F}($ ton.f) & ${ }^{b} T_{A}$ & ${ }^{c} T_{C P 9}$ & ${ }^{c} T_{C P 12}$ & ${ }^{c} T_{C P 13}$ \\
\hline 1 & 62 & 44 & 39 & 39 & 39 \\
\hline 4 & 53 & 56 & 41 & 41 & 40 \\
\hline 7 & 48 & 75 & 46 & 49 & 47 \\
\hline 10 & 44 & 87 & 54 & 60 & 56 \\
\hline 13 & 40 & 95 & 62 & 71 & 65 \\
\hline 16 & 37 & 102 & 70 & 81 & 74 \\
\hline 19 & 33 & 107 & 78 & 89 & 82 \\
\hline 22 & 31 & 112 & 86 & 96 & 89 \\
\hline 24 & 29 & 116 & 90 & 101 & 94 \\
\hline 25 & 28 & 118 & 93 & 103 & 96 \\
\hline 27 & 27 & 121 & 97 & 106 & 100 \\
\hline 29 & 26 & 125 & 101 & 110 & 104 \\
\hline 31 & 25 & 129 & 105 & 114 & 109 \\
\hline 32 & 401 & 130 & 111 & 120 & 115 \\
\hline 34 & 384 & 130 & 115 & 123 & 118 \\
\hline 37 & 388 & 128 & 119 & 125 & 122 \\
\hline 40 & 391 & 126 & 121 & 125 & 123 \\
\hline 43 & 397 & 124 & 121 & 124 & 123 \\
\hline 46 & 388 & 123 & 120 & 123 & 123 \\
\hline 47 & 386 & 123 & 120 & 123 & 123 \\
\hline 49 & 384 & 125 & 119 & 123 & 123 \\
\hline 52 & 393 & 125 & 120 & 124 & 124 \\
\hline 55 & 387 & 124 & 120 & 124 & 124 \\
\hline 58 & 396 & 123 & 120 & 123 & 124 \\
\hline 61 & 393 & 126 & 120 & 123 & 123 \\
\hline 64 & 388 & 125 & 120 & 124 & 124 \\
\hline 65 & 383 & 124 & 121 & 124 & 124 \\
\hline 68 & 391 & 87 & 116 & 114 & 118 \\
\hline 71 & 393 & 66 & 101 & 91 & 100 \\
\hline 74 & 392 & 54 & 81 & 68 & 79 \\
\hline 76 & 390 & 49 & 68 & 58 & 67 \\
\hline 77 & 384 & 47 & 64 & 54 & 62 \\
\hline 78 & 392 & 45 & 59 & 51 & 58 \\
\hline 81 & 397 & 42 & 50 & 44 & 49 \\
\hline 84 & 399 & 40 & 43 & 40 & 43 \\
\hline
\end{tabular}


C

\section{Resultados detalhados dos Ensaios Balísticos}

A seguir serão apresentados os dados detalhados que demonstram os resultados dos ensaios balísticos, os cálculos realizados e valores obtidos, assim como a parte estatística de análise regressão linear múltipla para desenvolvimento e teste do modelo de descrição do experimento com as 16 placas balísticas.

Tabela C.1: Resultado detalhado do Ensaio de Limite Balístico $V_{50}$.

\begin{tabular}{|c|c|c|c|c|c|c|c|c|c|}
\hline $\mathrm{CP}$ & $\mathrm{Mat}^{\mathrm{a}}$ & Camadas & $\mathrm{Esp}^{\mathrm{b}}$ & Áreac & $D / A$ & Tiros & $V_{i}^{d}$ & $E^{e}$ & BFS \\
\hline \multirow{6}{*}{6} & \multirow{6}{*}{$\mathrm{Ti}+\mathrm{p} 1+\mathrm{p}$} & \multirow{6}{*}{69} & \multirow{6}{*}{11,33} & \multirow{6}{*}{0,0824} & \multirow{6}{*}{13,32} & 1 & 987,9 & 4699,0 & perfurou \\
\hline & & & & & & 2 & 970,0 & 4530,1 & perfurou \\
\hline & & & & & & 3 & 966,6 & 4498,6 & perfurou \\
\hline & & & & & & 4 & 915,6 & 4036,5 & perfurou \\
\hline & & & & & & 5 & 901,5 & 3912,8 & perfurou \\
\hline & & & & & & 6 & 856,0 & 3528,0 & \\
\hline \multirow{6}{*}{7} & \multirow{6}{*}{$\mathrm{Ti}+\mathrm{p} 1+\mathrm{p}$} & \multirow{6}{*}{69} & \multirow{6}{*}{11,64} & \multirow{6}{*}{0,0824} & \multirow{6}{*}{13,22} & 1 & 880,6 & 3733,5 & perfurou \\
\hline & & & & & & 2 & 908,1 & 3970,7 & perfurou \\
\hline & & & & & & 3 & 886,4 & 3783,5 & perfurou \\
\hline & & & & & & 4 & 853,6 & 3508,2 & perfurou \\
\hline & & & & & & 5 & 834,5 & 3353,3 & perfurou \\
\hline & & & & & & 6 & 794,8 & 3041,8 & \\
\hline \multirow{4}{*}{14} & \multirow{4}{*}{$\mathrm{Ti}+\mathrm{p} 2+\mathrm{p}$} & \multirow{4}{*}{121} & \multirow{4}{*}{16,67} & \multirow{4}{*}{0,0484} & \multirow{4}{*}{19,53} & 1 & 840,2 & 3399,2 & 49,74 \\
\hline & & & & & & 2 & 860,6 & 3565,7 & 32,17 \\
\hline & & & & & & 3 & 861,1 & 3570,4 & 31,28 \\
\hline & & & & & & 4 & 890,3 & 3816,1 & 34,78 \\
\hline \multirow{4}{*}{15} & \multirow{4}{*}{$\mathrm{Ti}+\mathrm{p} 2+\mathrm{p}$} & \multirow{4}{*}{121} & \multirow{4}{*}{16,76} & \multirow{4}{*}{0,0484} & \multirow{4}{*}{19,51} & 1 & 967,7 & 4509,4 & perfurou \\
\hline & & & & & & 2 & 916,4 & 4043,9 & \\
\hline & & & & & & 3 & 962,7 & 4462,3 & \\
\hline & & & & & & 4 & 958,0 & 4419,4 & \\
\hline $\begin{array}{l}{ }^{\mathrm{a}} \text { Comp } \\
{ }^{\mathrm{b}} \text { Espess } \\
{ }^{\mathrm{C}} \text { Área d } \\
{ }^{\mathrm{d}} \text { Veloci } \\
{ }^{\mathrm{e}} \text { Energi }\end{array}$ & $\begin{array}{l}\text { o: } \mathrm{Ti}(\mathrm{Ti}-6 \\
(\mathrm{mm}) \\
\text { aca }\left(\mathrm{m}^{2}\right) \\
\text { de impa } \\
\text { impacto }\end{array}$ & $(-4 V) \cdot p 1($ & -B212) & p2 (ST-H & $\mathrm{HB} 13)$. & Pspu & uma Po & ron XRD) & \\
\hline
\end{tabular}


Tabela C.2: Resultado detalhado do Ensaio de Resistência Balística (HB212).

\begin{tabular}{|c|c|c|c|c|c|c|c|c|c|}
\hline $\mathrm{CP}$ & Mat $^{\mathrm{a}}$ & Camadas & $\mathrm{Esp}^{\mathrm{b}}$ & Área $^{c}$ & $D / A$ & Tiros & $v_{i}^{d}$ & $E^{e}$ & BFS \\
\hline \multirow{6}{*}{1} & \multirow{6}{*}{$\mathrm{p} 1+\mathrm{P}$} & \multirow{6}{*}{100} & \multirow{6}{*}{14,50} & \multirow{6}{*}{0,0824} & \multirow{6}{*}{13,01} & 1 & 855,4 & 3522,8 & 38,88 \\
\hline & & & & & & 2 & 855,3 & 3522,2 & 36,19 \\
\hline & & & & & & 3 & 838,0 & 3380,9 & 31,64 \\
\hline & & & & & & 4 & 863,4 & 3589,6 & 33,25 \\
\hline & & & & & & 5 & 861,7 & 3575,1 & 35,38 \\
\hline & & & & & & 6 & 853,9 & 3510,9 & 37,62 \\
\hline \multirow{6}{*}{2} & \multirow{6}{*}{$\mathrm{p} 1+\mathrm{E}$} & \multirow{6}{*}{100} & \multirow{6}{*}{14,49} & \multirow{6}{*}{0,0824} & \multirow{6}{*}{13,02} & 1 & 833,2 & 3343,0 & 41,90 \\
\hline & & & & & & 2 & 850,0 & 3478,8 & 32,77 \\
\hline & & & & & & 3 & 844,3 & 3432,5 & 29,07 \\
\hline & & & & & & 4 & 856,1 & 3528,9 & 38,19 \\
\hline & & & & & & 5 & 829,8 & 3315,7 & 38,50 \\
\hline & & & & & & 6 & 852,6 & 3500,5 & 38,07 \\
\hline \multirow{6}{*}{3} & \multirow{6}{*}{$\mathrm{Ti}+\mathrm{p} 1+\mathrm{P}$} & \multirow{6}{*}{94} & \multirow{6}{*}{14,64} & \multirow{6}{*}{0,0824} & \multirow{6}{*}{16,48} & 1 & 837,4 & 3376,2 & 40,78 \\
\hline & & & & & & 2 & 842,4 & 3416,9 & 37,14 \\
\hline & & & & & & 3 & 847,1 & 3454,7 & 36,71 \\
\hline & & & & & & 4 & 851,0 & 3487,0 & 39,23 \\
\hline & & & & & & 5 & 848,7 & 3468,1 & 38,54 \\
\hline & & & & & & 6 & 858,0 & 3544,5 & 45,20 \\
\hline \multirow{6}{*}{4} & \multirow{6}{*}{$\mathrm{Ti}+\mathrm{p} 1+\mathrm{E}$} & \multirow{6}{*}{94} & \multirow{6}{*}{14,78} & \multirow{6}{*}{0,0824} & & 1 & 849,9 & 3477,7 & 39,58 \\
\hline & & & & & & 2 & 856,1 & 3528,8 & 35,95 \\
\hline & & & & & 1668 & 3 & 846,2 & 3447,7 & 34,11 \\
\hline & & & & & 10,68 & 4 & 845,1 & 3438,8 & 34,63 \\
\hline & & & & & & 5 & 849,5 & 3474,5 & 37,51 \\
\hline & & & & & & 6 & 860,4 & 3564,7 & 37,40 \\
\hline & & & & & & 1 & 821,7 & 3251,1 & perfurou \\
\hline & & & & & & 2 & 738,4 & 2625,5 & 44,80 \\
\hline 5 & Titon 1 & 60 & 1100 & lon & 124 & 3 & 767,5 & 2836,4 & 35,95 \\
\hline 5 & $11+p 1+p$ & 69 & 11,40 & 0,0824 & 13,42 & 4 & 759,9 & 2780,1 & 33,97 \\
\hline & & & & & & 5 & 789,1 & 2998,4 & 38,41 \\
\hline & & & & & & 6 & 788,2 & 2991,3 & 41,92 \\
\hline & & & & & & 1 & 774,2 & 2885,7 & 43,30 \\
\hline & & & & & & 2 & 770,1 & 2855,6 & 41,35 \\
\hline & & & & & & 3 & 792,3 & 3022,8 & 38,78 \\
\hline 8 & $T 1+p 1+E$ & 69 & 11,86 & 0,0824 & 13,46 & 4 & 767,2 & 2834,0 & 47,02 \\
\hline & & & & & & 5 & 767,2 & 2834,3 & 47,44 \\
\hline & & & & & & 6 & 771,1 & 2862,9 & perfurou \\
\hline $\mathrm{Ti}(\mathrm{Ti}-$ & ). $\mathrm{p} 1$ ( $\mathrm{H}$ & 12). p2 (s & $\mathrm{HB} 13$ & ). P (Porc & on XRD & $\mathrm{E}(\mathrm{PE}$ & $\mathrm{BD} / \mathrm{EVA}$ & & \\
\hline Espes & mm) & & & & & & & & \\
\hline Área c & $\mathrm{ca}\left(\mathrm{m}^{2}\right)$ & & & & & & & & \\
\hline Veloci & de impa & & & & & & & & \\
\hline Energ & impacto & & & & & & & & \\
\hline
\end{tabular}


Tabela C.3: Resultado detalhado do Ensaio de Resistência Balística (STHB13).

\begin{tabular}{|c|c|c|c|c|c|c|c|c|c|}
\hline $\mathrm{CP}$ & Mat $^{\mathrm{a}}$ & Camadas & $\mathrm{Esp}^{\mathrm{b}}$ & Área $^{c}$ & D/A & Tiros & $v_{i}^{d}$ & $E^{e}$ & BFS \\
\hline & \multirow{4}{*}{$\mathrm{p} 2+\mathrm{P}$} & \multirow{4}{*}{159} & \multirow{4}{*}{20,08} & \multirow{4}{*}{0,0484} & \multirow{4}{*}{19,07} & 1 & 850,7 & 3484,8 & $\overline{44,06}$ \\
\hline \multirow{3}{*}{ 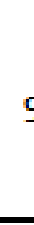 } & & & & & & 2 & 832,8 & 3339,7 & 35,63 \\
\hline & & & & & & 3 & 858,0 & 3544,8 & 35,95 \\
\hline & & & & & & 4 & 849,9 & 3477,7 & 35,50 \\
\hline \multirow{4}{*}{10} & \multirow{4}{*}{$\mathrm{p} 2+\mathrm{E}$} & \multirow{4}{*}{159} & \multirow{4}{*}{20,12} & \multirow{4}{*}{0,0484} & \multirow{4}{*}{19,13} & 1 & 841,3 & 3408,1 & 43,54 \\
\hline & & & & & & 2 & 829,2 & 3310,9 & 33,37 \\
\hline & & & & & & 3 & 851,1 & 3488,1 & 33,87 \\
\hline & & & & & & 4 & 846,2 & 3447,6 & 36,79 \\
\hline \multirow{4}{*}{11} & \multirow{4}{*}{$\mathrm{Ti}+\mathrm{p} 2+\mathrm{P}$} & \multirow{4}{*}{152} & \multirow{4}{*}{20,39} & \multirow{4}{*}{0,0484} & \multirow{4}{*}{23,16} & 1 & 819,4 & 3232,5 & 35,61 \\
\hline & & & & & & 2 & 830,6 & 3322,2 & 31,82 \\
\hline & & & & & & 3 & 831,0 & 3325,0 & 31,42 \\
\hline & & & & & & 4 & 853,5 & 3507,4 & 34,93 \\
\hline \multirow{4}{*}{12} & \multirow{4}{*}{$\mathrm{Ti}+\mathrm{p} 2+\mathrm{E}$} & \multirow{4}{*}{152} & \multirow{4}{*}{20,41} & \multirow{4}{*}{0,0484} & \multirow{4}{*}{23,09} & 1 & 841,4 & 3409,0 & 37,93 \\
\hline & & & & & & 2 & 862,2 & 3579,6 & 33,96 \\
\hline & & & & & & 3 & 821,4 & 3249,0 & 34,73 \\
\hline & & & & & & 4 & 837,5 & 3377,6 & 34,69 \\
\hline \multirow{4}{*}{13} & \multirow{4}{*}{$\mathrm{Ti}+\mathrm{p} 2+\mathrm{P}$} & \multirow{4}{*}{121} & \multirow{4}{*}{16,58} & \multirow{4}{*}{0,0484} & & 1 & 810,6 & 3164,1 & 37,52 \\
\hline & & & & & 19.46 & 2 & 810,3 & 3161,8 & 32,17 \\
\hline & & & & & 10,40 & 3 & 801,2 & 3090,6 & 31,28 \\
\hline & & & & & & 4 & 815,6 & 3202,6 & 34,78 \\
\hline & & & & & & 1 & 806,6 & 3132,7 & 37,85 \\
\hline 16 & $\mathrm{Ti}+\mathrm{n}^{2+\mathrm{F}}$ & 121 & 1679 & 00484 & 1935 & 2 & 802,7 & 3102,4 & 35,58 \\
\hline 10 & 11 & 121 & 10,17 & 0,0484 & 17,30 & 3 & 805,1 & 3120,7 & 35,93 \\
\hline & & & & & & 4 & 798,4 & 3069,3 & 42,18 \\
\hline & Ti-6Al-4 & ). $\mathrm{p} 1$ (HB2 & 12). p2 & (ST-HB1) & 3). $P(P$ & ron $\mathrm{XF}$ & ). E (P & D/EVA) & \\
\hline & pessura ( & $\mathrm{nm})$ & & & & & & & \\
\hline " Ár & ea da plac & $a\left(m^{2}\right)$ & & & & & & & \\
\hline${ }^{d} \mathrm{~V}$ & locidade & de impacto & & & & & & & \\
\hline${ }^{e} \mathrm{Er}$ & ergia de i & mpacto $(J)$ & & & & & & & \\
\hline
\end{tabular}


D

\section{Análise de Regressão Linear Múltipla}

D.1

Análise de Regressão Linear Múltipla com o emprego do programa $\mathbf{R}$

Os valores das variáveis principais $\left(x_{1}\right.$ a $\left.x_{7}\right)$ estão descritos na Tabela D.1.

A Figura D.1 apresenta a área de trabalho do programa $R$ após a primeira regressão entre os 28 fatores.

Foram removidos os fatores (seguindo a técnica Backward) de maior valor de $p$, um de cada vez. As variáveis retiradas da análise foram: $x_{25}, x_{26}, x_{23}$, $x_{9}, x_{10}, x_{12}, x_{17}, x_{16}, x_{15}$ e $x_{14}$. $\mathrm{O}$ modelo foi reduzido à 18 fatores previsores (Figura D.2). 
Tabela D.1: Valor das variáveis $x_{1}$ a $x_{7}$ do modelo de Regressão.

\begin{tabular}{|c|c|c|c|c|c|c|}
\hline Ti-6Al-4V & Prepreg & Espuma & Camadas & $\mathrm{D} / \mathrm{A}$ & Velocidade Impacto & Tiro \\
\hline $\mathrm{x} 1$ & $\mathrm{x} 2$ & $\mathbf{x} 3$ & $\mathrm{x} 4$ & $\mathrm{x} 5$ & $x 6$ & $x 7$ \\
\hline 1 & -1 & 1 & 121 & 19,5 & 810,64 & 1 \\
\hline 1 & -1 & 1 & 121 & 19,5 & 810,34 & 2 \\
\hline 1 & -1 & 1 & 121 & 19,5 & 801,17 & 3 \\
\hline 1 & -1 & 1 & 121 & 19,5 & 815,55 & 4 \\
\hline 1 & -1 & -1 & 121 & 19,4 & 806,61 & 1 \\
\hline 1 & -1 & -1 & 121 & 19,4 & 802,69 & 2 \\
\hline 1 & -1 & -1 & 121 & 19,4 & 805,06 & 3 \\
\hline 1 & -1 & -1 & 121 & 19,4 & 798,41 & 4 \\
\hline 1 & 1 & 1 & 69 & 13,4 & 738,43 & 2 \\
\hline 1 & 1 & 1 & 69 & 13,4 & 767,51 & 3 \\
\hline 1 & 1 & 1 & 69 & 13,4 & 759,86 & 4 \\
\hline 1 & 1 & 1 & 69 & 13,4 & 789,12 & 5 \\
\hline 1 & 1 & 1 & 69 & 13,4 & 788,19 & 6 \\
\hline 1 & 1 & -1 & 69 & 13,5 & 774,16 & 1 \\
\hline 1 & 1 & -1 & 69 & 13,5 & 770,10 & 2 \\
\hline 1 & 1 & -1 & 69 & 13,5 & 792,33 & 3 \\
\hline 1 & 1 & -1 & 69 & 13,5 & 767,19 & 4 \\
\hline 1 & 1 & -1 & 69 & 13,5 & 767,24 & 5 \\
\hline 1 & -1 & 1 & 152 & 23,2 & 819,36 & 1 \\
\hline 1 & -1 & 1 & 152 & \begin{tabular}{|l|}
23,2 \\
\end{tabular} & 830,65 & 2 \\
\hline 1 & -1 & 1 & 152 & \begin{tabular}{|l|}
23,2 \\
\end{tabular} & 830,99 & 3 \\
\hline 1 & -1 & 1 & 152 & \begin{tabular}{|l|}
23,2 \\
\end{tabular} & 853,49 & 4 \\
\hline 1 & -1 & -1 & 152 & 23,1 & 841,43 & 1 \\
\hline 1 & -1 & -1 & 152 & 23,1 & 862,22 & 2 \\
\hline 1 & -1 & -1 & 152 & 23,1 & 821,45 & 3 \\
\hline 1 & -1 & -1 & 152 & 23,1 & 837,55 & 4 \\
\hline 1 & 1 & 1 & 94 & 16,5 & 837,37 & 1 \\
\hline 1 & 1 & 1 & 94 & 16,5 & 842,40 & 2 \\
\hline 1 & 1 & 1 & 94 & 16,5 & 847,05 & 3 \\
\hline 1 & 1 & 1 & 94 & 16,5 & 851,00 & 4 \\
\hline 1 & 1 & 1 & 94 & 16,5 & 848,69 & 5 \\
\hline 1 & 1 & 1 & 94 & 16,5 & 857,99 & 6 \\
\hline 1 & 1 & -1 & 94 & \begin{tabular}{|l|}
16,7 \\
\end{tabular} & 849,86 & 1 \\
\hline 1 & 1 & -1 & 94 & 16,7 & 856,08 & 2 \\
\hline 1 & 1 & -1 & 94 & 16,7 & 846,19 & 3 \\
\hline 1 & 1 & -1 & 94 & \begin{tabular}{|l|}
16,7 \\
\end{tabular} & 845,10 & 4 \\
\hline 1 & 1 & -1 & 94 & 16,7 & 849,48 & 5 \\
\hline 1 & 1 & -1 & 94 & \begin{tabular}{|l|}
16,7 \\
\end{tabular} & 860,43 & 6 \\
\hline-1 & -1 & 1 & 159 & \begin{tabular}{|l|}
19,1 \\
\end{tabular} & 850,73 & 1 \\
\hline-1 & -1 & 1 & 159 & \begin{tabular}{|l|}
19,1 \\
\end{tabular} & 832,83 & 2 \\
\hline-1 & -1 & 1 & 159 & 19,1 & 858,03 & 3 \\
\hline-1 & -1 & 1 & 159 & \begin{tabular}{|l|}
19,1 \\
\end{tabular} & 849,86 & 4 \\
\hline-1 & -1 & -1 & 159 & \begin{tabular}{|l|}
19,1 \\
\end{tabular} & 841,32 & 1 \\
\hline-1 & -1 & -1 & 159 & \begin{tabular}{|l|}
19,1 \\
\end{tabular} & 829,23 & 2 \\
\hline-1 & -1 & -1 & 159 & 19,1 & 851,14 & 3 \\
\hline-1 & -1 & -1 & 159 & \begin{tabular}{|l|}
19,1 \\
\end{tabular} & 846,18 & 4 \\
\hline-1 & 1 & 1 & 100 & 13,0 & 855,35 & 1 \\
\hline-1 & 1 & 1 & 100 & 13,0 & 855,29 & 2 \\
\hline-1 & 1 & 1 & 100 & 13,0 & 837,96 & 3 \\
\hline-1 & 1 & 1 & 100 & 13,0 & 863,43 & 4 \\
\hline-1 & 1 & 1 & 100 & 13,0 & 861,69 & 5 \\
\hline-1 & 1 & 1 & 100 & 13,0 & 853,91 & 6 \\
\hline-1 & 1 & -1 & 100 & 13,0 & 833,24 & 1 \\
\hline-1 & 1 & -1 & 100 & 13,0 & 850,00 & 2 \\
\hline-1 & 1 & -1 & 100 & 13,0 & 844,32 & 3 \\
\hline-1 & 1 & -1 & 100 & 13,0 & 856,09 & 4 \\
\hline-1 & 1 & -1 & 100 & 13,0 & 829,83 & 5 \\
\hline-1 & 1 & -1 & 100 & 13,0 & 852,65 & 6 \\
\hline
\end{tabular}




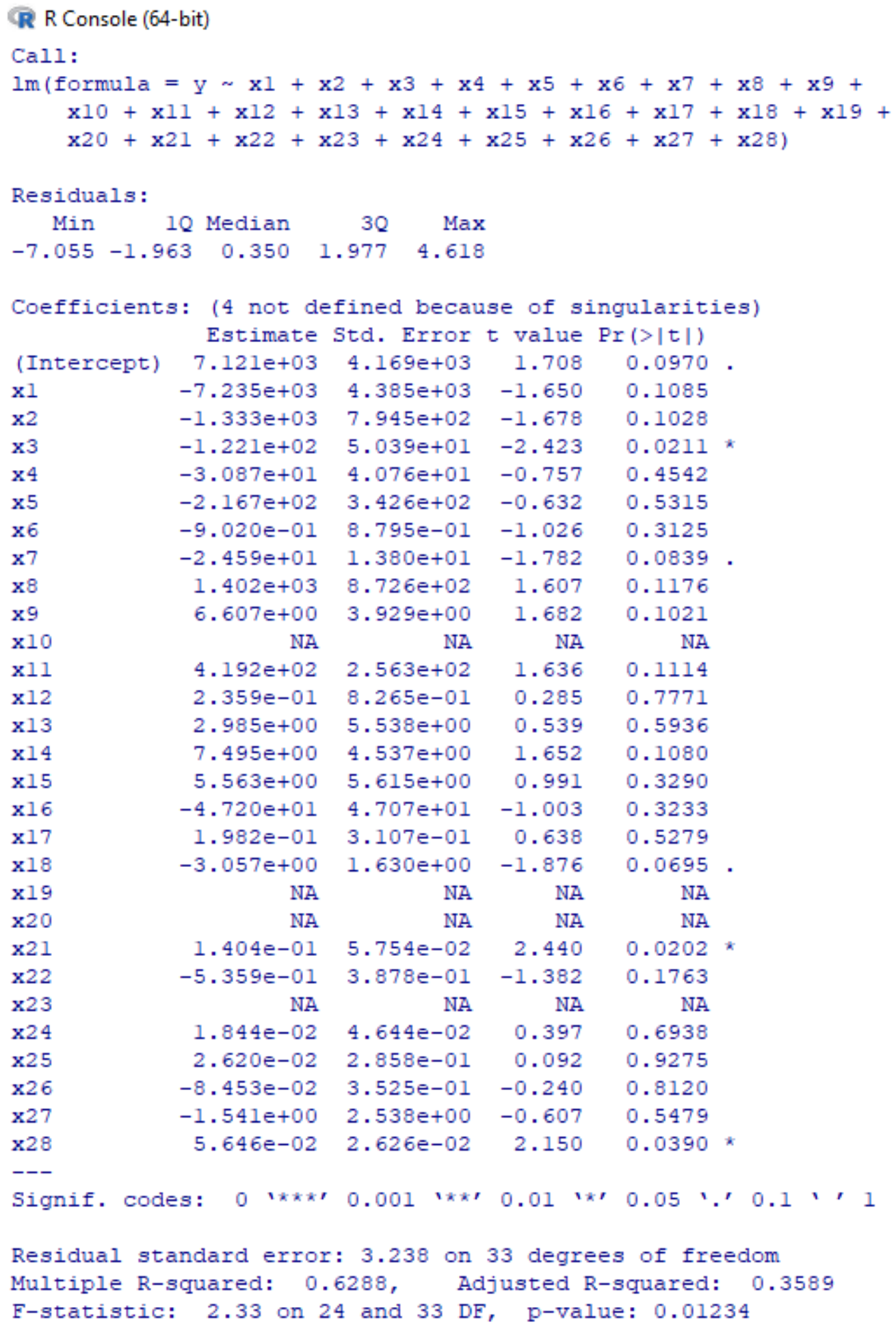

Figura D.1: Área de trabalho do Programa R - 28 fatores, primeira análise 
Call:

$\operatorname{lm}($ formula $=\mathrm{y} \sim \mathrm{x} 1+\mathrm{x} 2+\mathrm{x} 3+\mathrm{x} 4+\mathrm{x} 5+\mathrm{x} 6+\mathrm{x} 7+\mathrm{x} 8+\mathrm{x} 11+$ $\mathrm{x} 13+\mathrm{x} 18+\mathrm{x} 19+\mathrm{x} 20+\mathrm{x} 21+\mathrm{x} 22+\mathrm{x} 24+\mathrm{x} 27+\mathrm{x} 28)$

Residuals:

Min $1 Q$ Median $30 \quad$ Max

$\begin{array}{lllll}-7.0525 & -1.7313 & -0.1181 & 1.9707 & 5.1630\end{array}$

Coefficients:

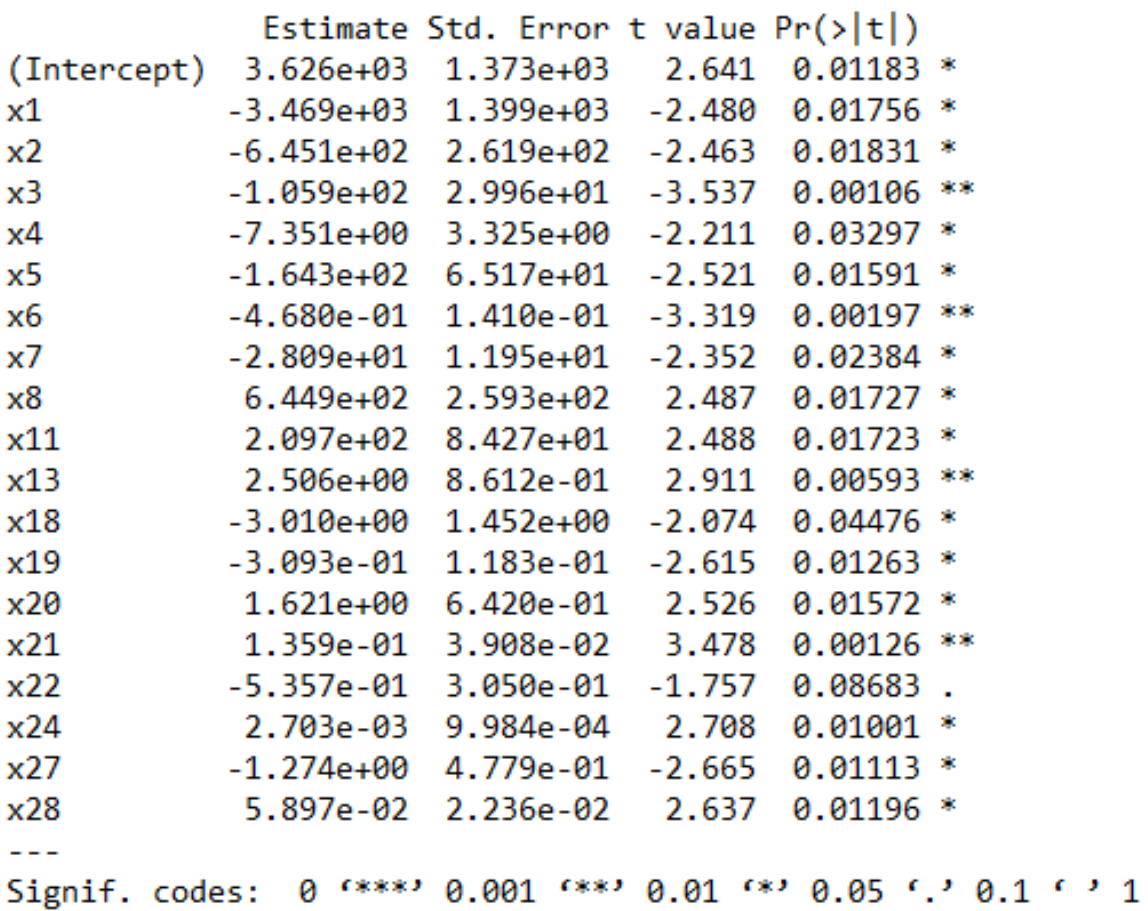

Residual standard error: 3.061 on 39 degrees of freedom Multiple R-squared: 0.608 , Adjusted R-squared: 0.427 F-statistic: 3.36 on 18 and $39 \mathrm{DF}, \mathrm{p}$-value: 0.0007586

Figura D.2: Área de trabalho do Programa R - 18 fatores, segunda análise 